\section{orin}

OAK RIDGE

NATIONAL

LABORATORY
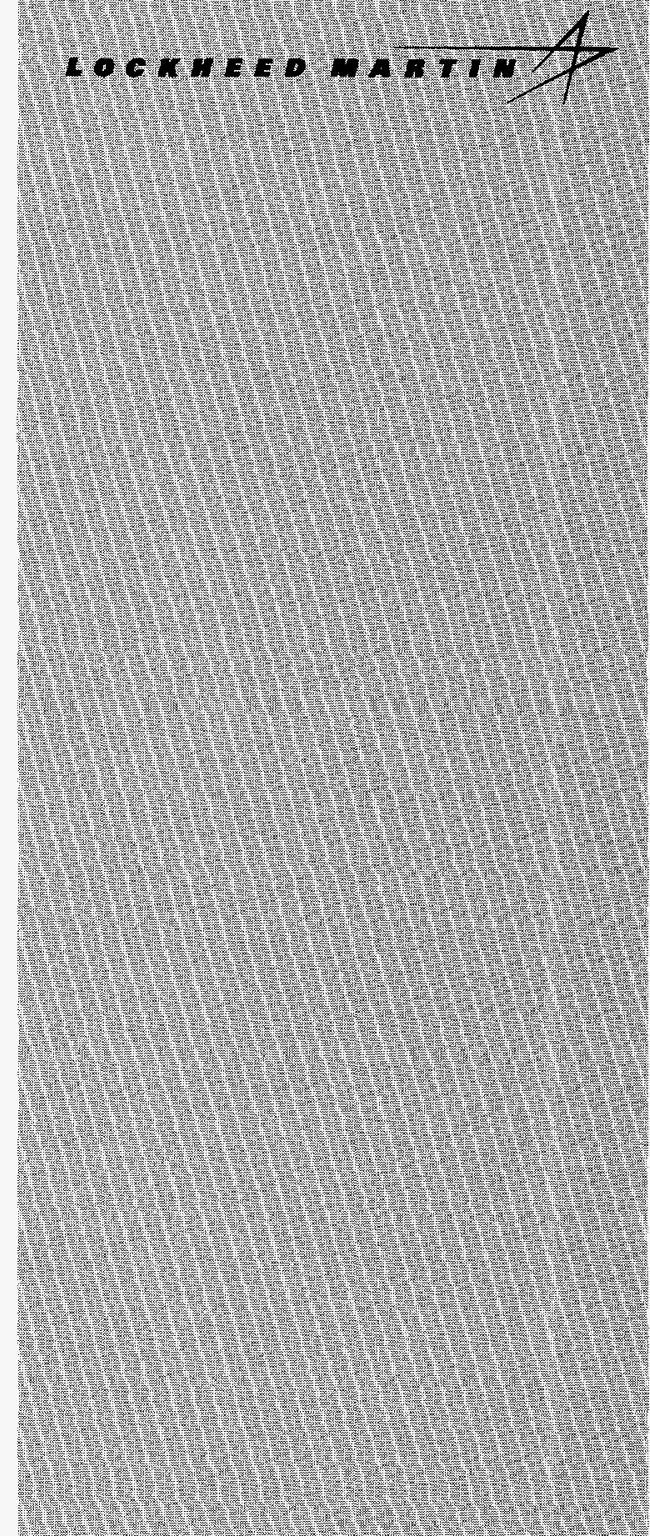

WMWGEO WWO OPERTIEO DY

LOCKHEED MARTH ENERCY HESEARCH CORPORATION FOR THE UUTEO STATES

DEPARTIENT OF ENERGY

\title{
The Evaluation of a 4000-Home Geothermal Heat Pump Retrofit at Fort Polk, Louisiana: Final Report
}

\author{
P. J. Hughes \\ J. A. Shonder
}

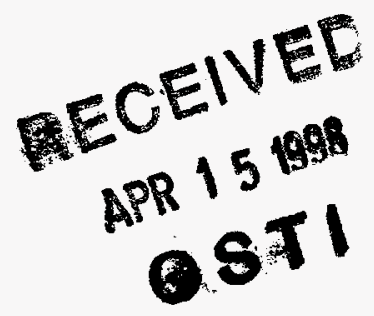

MASTER 
This report is available to DOE and DOE contractors from the Office of Scientific and Technical Information, P.O. Box 62, Oak Ridge, TN 37831; prices available from (423) 576-8401. Available to the public from the National Technical Information Service, U.S. Department of Commerce, 5285 Port Royal Rd., Springfield, VA 22161.

This report was prepared as an account of work sponsored by an agency of the United States Government. Neither the United States nor any agency thereof, nor any of their employees, makes any warranty, express or implied, or assumes any legal liability or responsibility for the accuracy, completeness, or usefulness of any information, apparatus, product, or process disclosed, or represents that its use would not infringe privately owned rights. Reference herein to any specific commercial product, process, or service by trade name, trademark, manufacturer, or otherwise, does not necessarily constitute or imply its endorsement, recommendation, or favoring by the United States Government or any agency thereof. The views and opinions of authors expressed herein do not necessarily state or reflect those of the United States Government or any agency thereof. 


\section{DISCLAIMER}

Portions of this document may be illegible electronic image products. Images are produced from the best available original document. 
The Evaluation of a 4000-Home Geothermal Heat Pump Retrofit at Fort Polk, Louisiana: Final Report

\author{
P. J. Hughes \\ J. A. Shonder
}

Date Published-March 1998

\author{
Prepared by \\ Oak Ridge National Laboratory \\ Oak Ridge, Tennessee 37831-6285 \\ managed by \\ LOCKHEED MARTIN ENERGY RESEARCH CORP. \\ for the \\ U.S. DEPARTMENT OF ENERGY \\ under contract DE-AC05-96OR22464
}




\section{CONTENTS}

1. INTRODUCTION

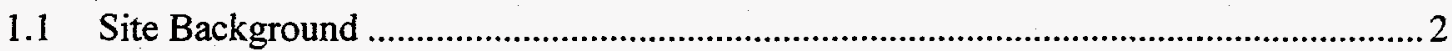

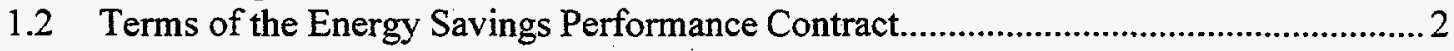

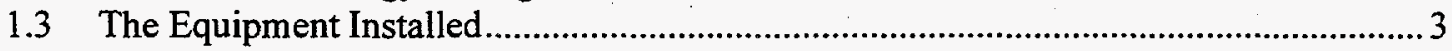

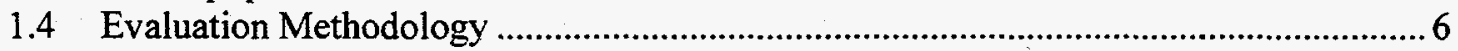

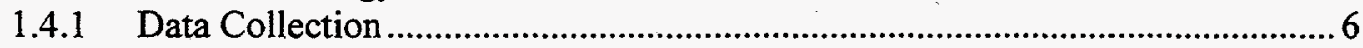

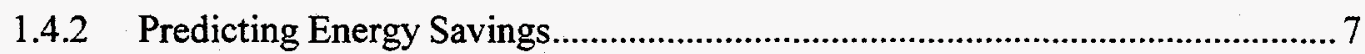

1.4.3 Geothermal Heat Pump System Model .......................................................... 7

1.4.4 Comparison of BHEx Sizing Methods ….......................................................... 7

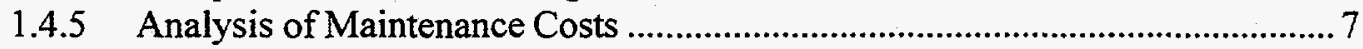

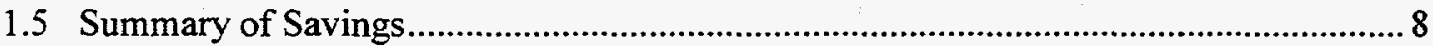

2. METHODOLOGY AND CALCULATION OF ENERGY SAVINGS _.........................9

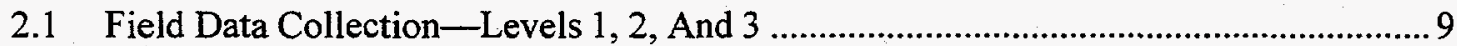

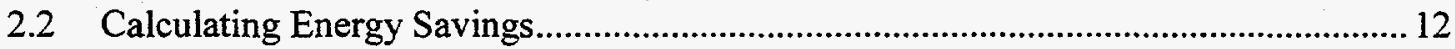

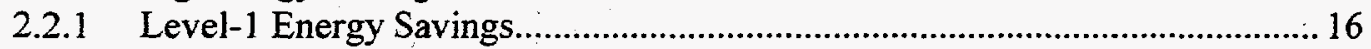

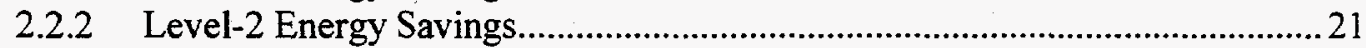

2.2.3 Energy Savings by Energy Conservation Measure ...........................................2 25

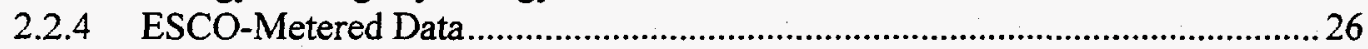

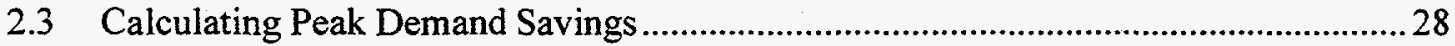

2.4 Effect of Vacancy Rate on Apparent Energy Savings ............................................... 30

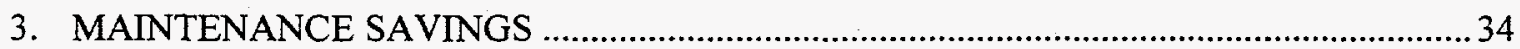

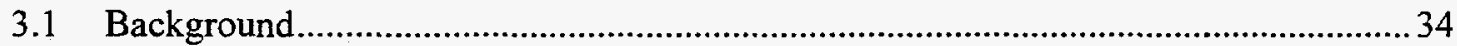

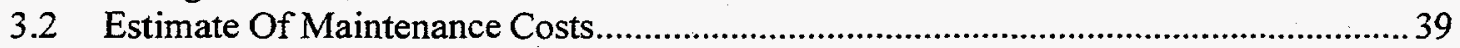

4. USING CALIBRATED ENGINEERING MODELS TO PREDICT ENERGY SAVINGS .. 45

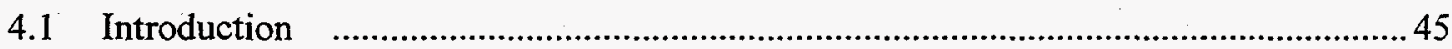

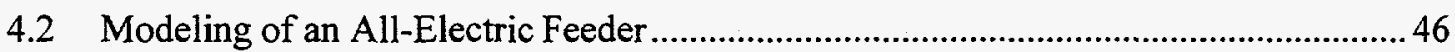

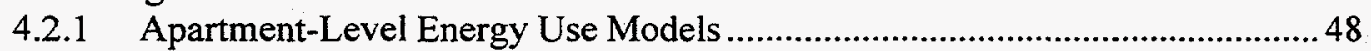

4.2.2 Streetlights and Other Nonhousing Loads ..................................................51

4.2.3 Model Calibration to Pre-Retrofit Data ........................................................ 51

4.2.4 Implementation of Energy Conservation Measures ......................................... 53

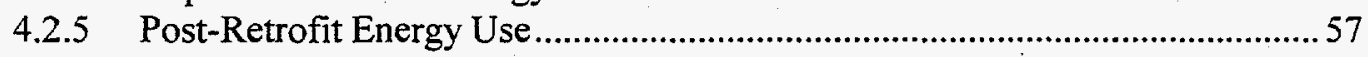

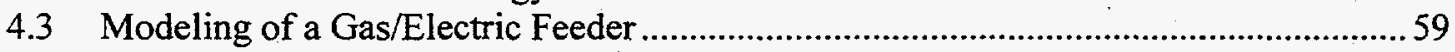

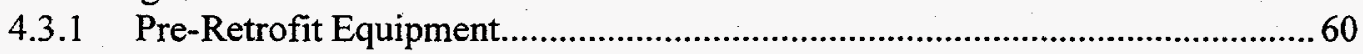

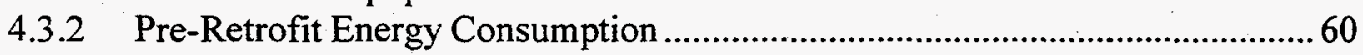

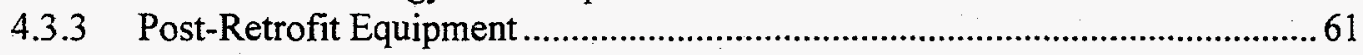

4.3.4 Post-Retrofit Energy Consumption ...........................................................61

4.4 Implications for Future Use of Calibrated Models .....................................................6 63

5. GEOTHERMAL HEAT PUMP SYSTEM MODELS, CALIBRATED TO DATA .............65

5.1 Configuration of the Geothermal Heat Pump ...........................................................65

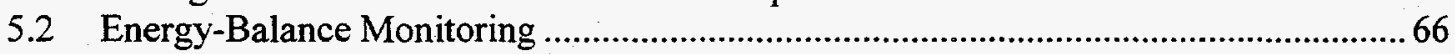

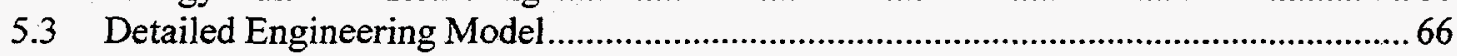

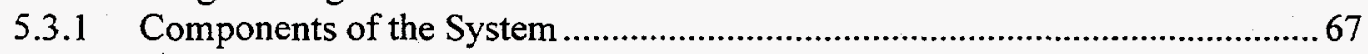


5.4 Calibrating The Engineering Model .................................................................... 71

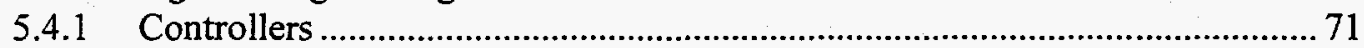

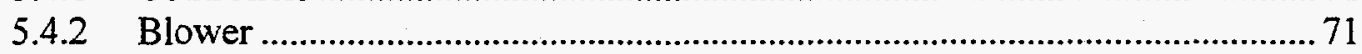

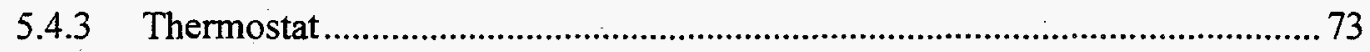

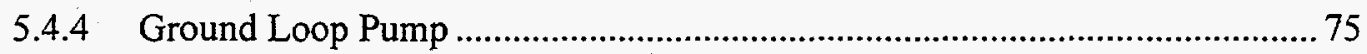

5.4.5 Vertical Borehole Ground Heat Exchanger ........................................................ 75

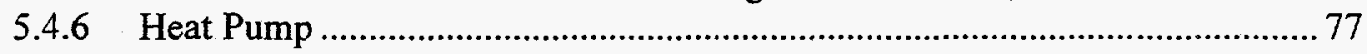

5.4.7 Building Model.............................................................................................. 78

5.4.8 System Calibration ……………………………………………………...... 79

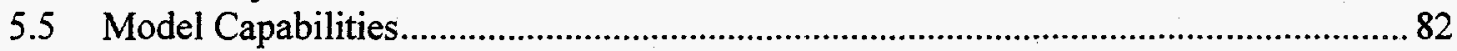

5.5.1 Effects of Soil Thermal Properties Assumptions............................................... 82

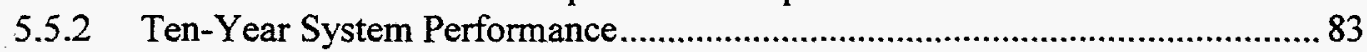

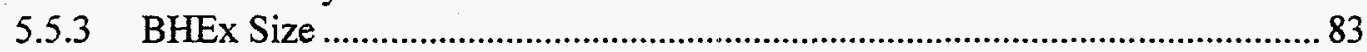

6. COMPARISON OF PRACTICAL BHEX DESIGN METHODS TO A

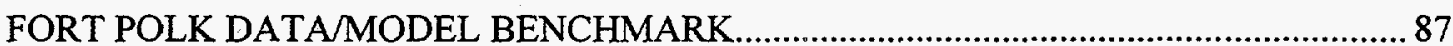

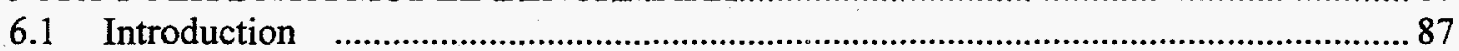

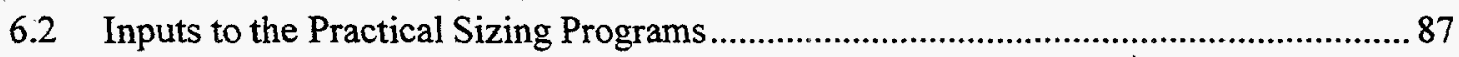

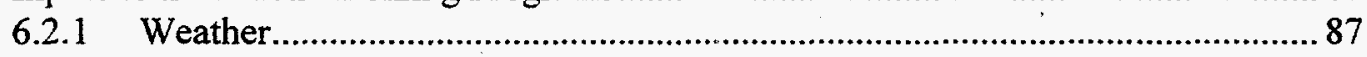

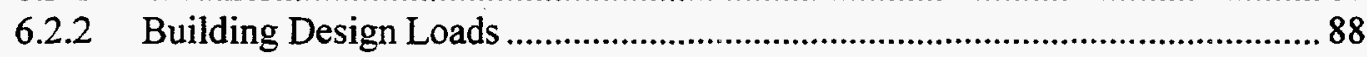

6.2.3 Building Monthly Loads................................................................................ 90

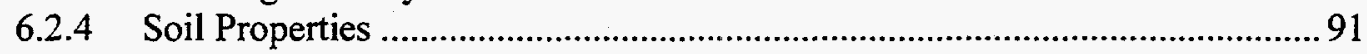

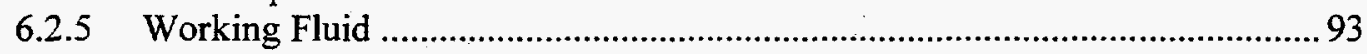

6.2.6 BHEx Configuration ................................................................................99

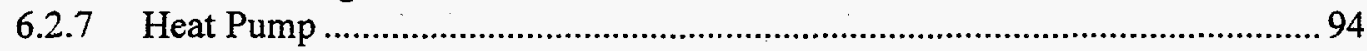

6.3 Comparison Of Results............................................................................................95

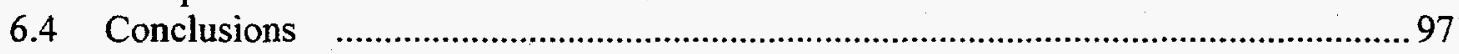

7. MEASUREMENT AND VERIFICATION OF ENERGY SAVINGS..................................99

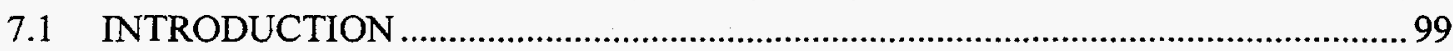

7.2 Option A .

7.2.1 Option A for Low-Flow Shower Heads …………………………………........ 101

7.2.2 Engineering Calculations.............................................................................. 102

7.2.3 Advantages and Disadvantages of Option A ................................................. 102

7.2.4 Summary of Option-A M\&V for Low-Flow Shower Heads........................... 102

7.3 Option B ........................................................................................................ 103

7.3.1 Option B for Lighting Retrofits ................................................................. 103

7.3.2 Isolating the Lighting Load ……………….............................................. 103

7.3.3 Engineering Calculations of Energy Savings .................................................... 104

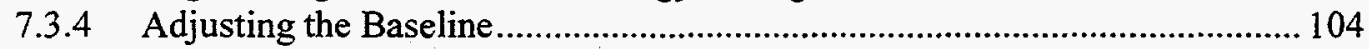

7.3.5 Summary of Option-B M\&V for Lighting Retrofits ...................................... 105

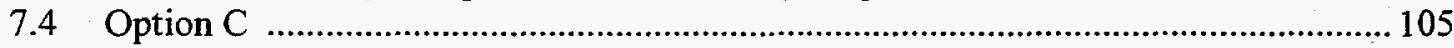

7.4.1 Determining Baseline Consumption................................................................ 106

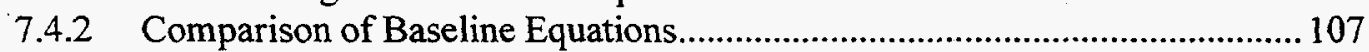

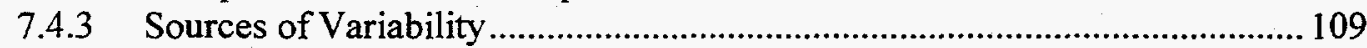

7.4.4 Baseline Adjustments for "Plug-Load Creep".............................................110

7.4.5 Summary of an Option-C Plan for an ECM Package ...................................... 111

7.5 Option D 


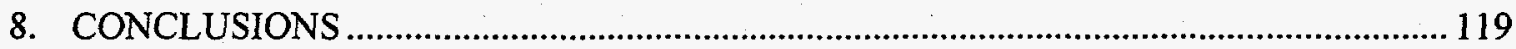

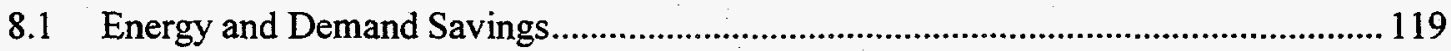

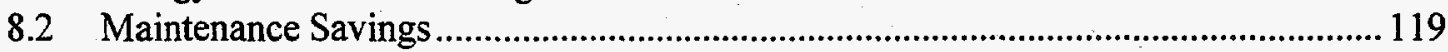

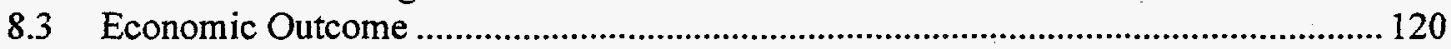

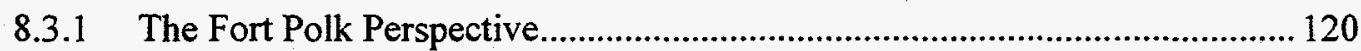

8.3.2 The ESCO Perspective ............................................................................ 121

8.4 Use of Calibrated Engineering Models to Predict Energy Savings ............................. 122

8.5 Geothermal Heat Pump System Models Calibrated to Data........................................ 123

8.6 Comparison of Practical BHEx Design Methods to a Fort Polk Data/Model

Benchmark

8.7 Measurement and Verification of Energy Savings .................................................... 124

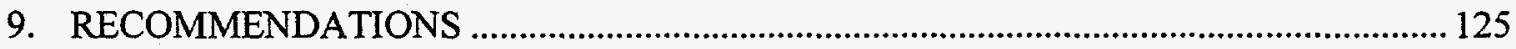

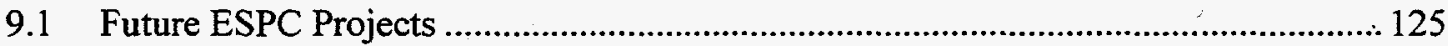

9.1.1 Opportunities Through Super-ESPC Procurements for GHPs ...................... 125

9.1.2 Improving ESPC Statutory Authority ......................................................... 126

9.2 Measurement and Verification of Energy Savings ....................................................... 129

9.3 Vertical Borehole Ground Heat Exchanger Design............................................... 129

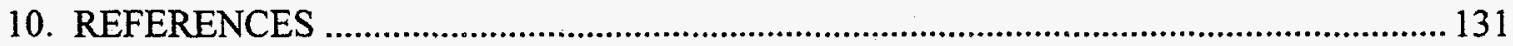

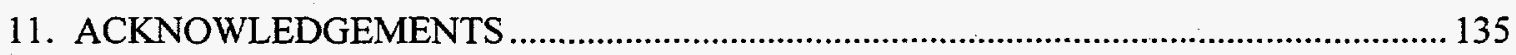




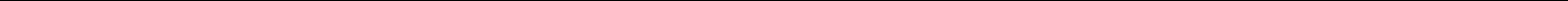




\section{LIST OF FIGURES}

Fig. 1.1 Entrance to Fort Polk Joint Readiness Training Center near Leesville, Louisiana.

Fig. 1.2 Family housing apartment buildings at Fort Polk. Attic insulation was installed in some apartments as part of the energy retrofit.

Fig. 1.3 Structure of Fort Polk ESPC.

Fig. 1.4 A rig drilling vertical boreholes for the gound heat exchangers. A total of $1,834,652 \mathrm{ft}$ of $41 / 8$-in. vertical bore was drilled for the vertical borehole heat exchangers.

Fig. 1.5 This pile of polyethylene piping-measured, cut, and ready to install-gives an idea of the scale of the retrofit project. The pipe installed in the vertical borehole heat exchangers at Fort Polk would reach 686 miles.

Fig. 1.6 Above-ground loops of pipe show where ground heat exchangers have been installed and are ready to be connected to heat pumps.

Fig. 1.7 The evaluation of the Fort Polk project was based on a three-level data collection approach.

Fig. 1.8 Monthly electrical energy savings in a typical meteorological year.

Fig. 2.1 Level-1 pre- and post-retrofit data collection technique.

Fig. 2.2 Level-2 pre-retrofit data collection technique.

Fig. 2.3 Level-2 post-retrofit data collection technique.

Fig. 2.4 Daily electrical energy use for a typical feeder (Feeder 1) serving housing that was all-electric before the retrofits.

Fig. 2.5 Daily electrical use for a typical feeder serving housing which was gas/electric before the retrofits.

Fig. 2.6 Pre- and post-retrofit daily electrical energy use for the 14 monitored feeders.

Fig. 2.7 Annual electrical use on feeders serving all-electric housing, pre- and postretrofit.

Fig. 2.8 Natural gas consumption at Fort Polk based on historical data.

Fig. 2.9 TMY energy savings vs building floor area for the 13 Level-2 buildings.

Fig. 2.10 Impact of retrofits on space conditioning, water heating, and lighting/appliance loads.

Fig. $2.11 \quad$ Breakdown of energy savings by conservation measure.

Fig. 2.12 Electricity use per square foot per day from ESCO monthly meter readings, preand post-retrofit.

Fig. 2.13 Pre- and post-retrofit demand profiles for three-day average "peak day," Feeder 2. 
Fig. 2.14 Demand during utility peak hour vs daily average temperature, pre- and postretrofit.

Fig. 2.15 Vacancy rate by month.

Fig. 3.1 Age of pre-retrofit outdoor units in family housing.

Fig. $3.2 \quad$ Age of outdoor units at failure.

Fig. 3.3 Fraction of outdoor units remaining in service as a function of their age.

Fig. 3.4 Weibull plot of outdoor unit reliability vs time.

Fig. 3.5 Expected number of outdoor units replaced per year.

Fig. 3.6 Average number of service calls per day, pre-retrofit, in family housing.

Fig. 3.7 Baseline maintenance cost estimate for year 1.

Fig. 4.1 Site plan for the area served by Feeder 1.

Fig. 4.2 Average electrical energy use per square foot per hour for lighting and other appliances.

Fig. 4.3 Average daily electrical energy use for lights and other appliances by apartment floorspace.

Fig. 4.4 Weekend and weekday hourly hot water draw for the average Fort Polk residence.

Fig. $4.5 \quad$ Feeder 1 pre-retrofit daily electrical energy use vs daily average temperature. Monitored data and calibrated simulation model.

Fig. 4.6 Side view of the ground heat exchanger configuration.

Fig. 4.7 Top view of a U-tube vertical ground heat exchanger.

Fig. 4.8 Feeder 1 post-retrofit daily electrical energy use vs daily average temperature. Monitored data and calibrated simulation model.

Fig. 4.9 Feeder 12 pre-retrofit daily electrical energy use vs daily average temperature. Monitored data and calibrated simulation model.

Fig. $4.10 \quad$ Feeder 12 post-retrofit daily electrical energy use vs daily average temperature. Monitored data and calibrated simulation model.

Fig. 5.1 Schematic of modeled geothermal heat pump system.

Fig. 5.2 Controller power draw in watts for each 15-minute interval in the month of April.

Fig. 5.3 Room temperatures for cooling turn-on and turn-off for the month of May.

Fig. 5.4 Room temperatures for cooling turn-on and turn-off for the month of August.

Fig. 5.5 Predicted vs measured heat pump entering water temperatures for three days in the month-long soil-calibration test. 
Fig. 5.6 Energy consumption of the heat pump compressor as a function of heat pump entering water temperature in cooling mode.

Fig. 5.7 Average heating and cooling load line comparisons.

Fig. 5.8 Predicted and measured maximum heat pump entering water temperatures.

Fig. 5.9. Predicted and measured heat pump power consumption.

Fig. 5.10 Maximum heat pump entering water temperatures for three different soil types.

Fig. 5.11 Predicted maximum EWT for various BHEx lengths (one-year analysis).

Fig. 5.12 Measured duration curves for EWT over all GHP run hours.

Fig. 6.1 Average heating load line comparison.

Fig. 6.2 Average total cooling load (sensible and latent) line comparison.

Fig. 6.3 Hourly heating and cooling loads during the heating and cooling design days.

Fig. 6.4 Design borehole lengths for various maximum EWTs at an undisturbed deepearth temperature of $69^{\circ} \mathrm{F}$.

Fig. 6.5 Design borehole lengths for various maximum EWTs at an undisturbed deepearth temperature of $62^{\circ} \mathrm{F}$.

Fig. 7.1 Elements of determining energy savings.

Fig. 7.2 Historical electricity consumption in Fort Polk family housing (normalized to a 30-day month).

Fig. 7.3 Annual electricity consumption in family housing as billed by the utility provider and as predicted by three methods.

Fig. 7.4 Comparison of the calibrated model's monthly predictions of monthly energy usage for a TMY with two years of historical energy use data from the modeled feeder.

Fig. 7.5 The calibrated model's predictions of pre-retrofit energy use, post-retrofit energy use, and energy savings for a TMY.

Fig. $7.6 \quad$ Reduced data set for Feeder 1.

Fig. 8.1 The Army's annual cash flow for energy and energy-related maintenance for Fort Polk family housing before, during, and after the ESPC contract period. 



\section{LIST OF TABLES}

Table 2.1 Characteristics of Fort Polk family housing stock

Table 2.2 Constants for five-parameter, dual-changepoint model for each feeder, pre- and post-retrofit

Table 2.3 Pre- and post-retrofit FMY energy use by feeder for Level-1 data

Table 2.4 Historical natural gas use in Fort Polk family housing

Table 2.5 Characteristics of the 12 Level-2 buildings analyzed

Table 2.6 Constants for five-parameter dual-changepoint models for the 12 Level-2 buildings

Table 2.7 Pre- and post-retrofit TMY energy use for the 13 Level-2 buildings

Table $2.8 \quad$ Average daily energy use per apartment per day (in $\mathrm{kWh}$ ) for the modeled feeder

Table 2.9 Summary of ESCO meter readings, pre- and post-retrofit

Table 2.10 Peak demand, annual consumption, and load factor by feeder, pre- and postretrofit

Table 2.11 Comparison of historical metered electrical energy use with predicted use

Table 2.12 Vacant housing units per month

Table 2.13 Annual energy use by feeder for 1997 adjusted for occupancy rate

Table 3.1 Fraction of maintenance savings to be paid to ESCO in each month of the ESPC

Table 3.2 Maintenance activities, duration, and associated costs

Table 3.3 Maintenance cost estimates by year

Table 4.1 Construction type and compass orientation of the buildings on Feeder 1

Table 4.2 Orientations simulated for each building type

Table 4.3 Lighting retrofits installed in apartments on Feeder 1

Table 4.4 Daily average energy use per apartment $(\mathrm{kWh})$ as retrofits are added successively.

Table 4.5 Comparison of monitored apartment average daily energy use (kWh) and simulation results

Table 4.6 Building types on Feeder 12

Table 4.7 Orientation of Feeder 12 buildings and retrofits installed

Table 5.1 Monthly thermostat setpoints in heating and cooling modes ( $\left.{ }^{\circ} \mathrm{F}\right)$

Table 6.1 Design heating and cooling loads for Program C 
Table 6.2 Monthly heating and cooling loads

Table 6.3 Monthly heat absorbed by and rejected to ground

Table 6.4 Design borehole lengths in feet per bore for various maximum EWTs at an undisturbed deep-earth temperature of $69^{\circ} \mathrm{F}$

Table 6.5 Design borehole lengths in feet per bore for various maximum EWTs at an undisturbed deep-earth temperature of $62^{\circ} \mathrm{F}$

Table 7.1 Comparison of payments to the ESCO: ORNL baseline vs contract baseline 


\section{LIST OF ACRONYMS AND ABBREVIATIONS}

ARI Air Conditioning and Refrigeration Institute

ASHP air-source heat pump

ASHRAE American Society of Heating, Refrigeration, and Air Conditioning Engineers

BHEx vertical borehole heat exchanger

CAC central air conditioner

CFL compact fluorescent lighting

COP coefficient of performance

CPI Consumer Price Index

DOE U.S. Department of Energy

DST duct ground heat storage (model)

ECM energy conservation measure

ECSM energy cost saving measure

EER energy efficiency rating

EIA Energy Information Administration

ESCO energy services company

ESPC energy savings performance contract

EWT entering water temperature

FEMP Federal Energy Management Programs

GHP geothermal heat pump

HVAC heating, ventilating, and air conditioning

IDIQ indefinite-delivery, indefinite-quantity (contract)

$\mathrm{M} \& \mathrm{~V} \quad$ measurement and verification

ORNL Oak Ridge National Laboratory

RFP request for proposals

RMSE root mean square error

TMY typical meteorological year 


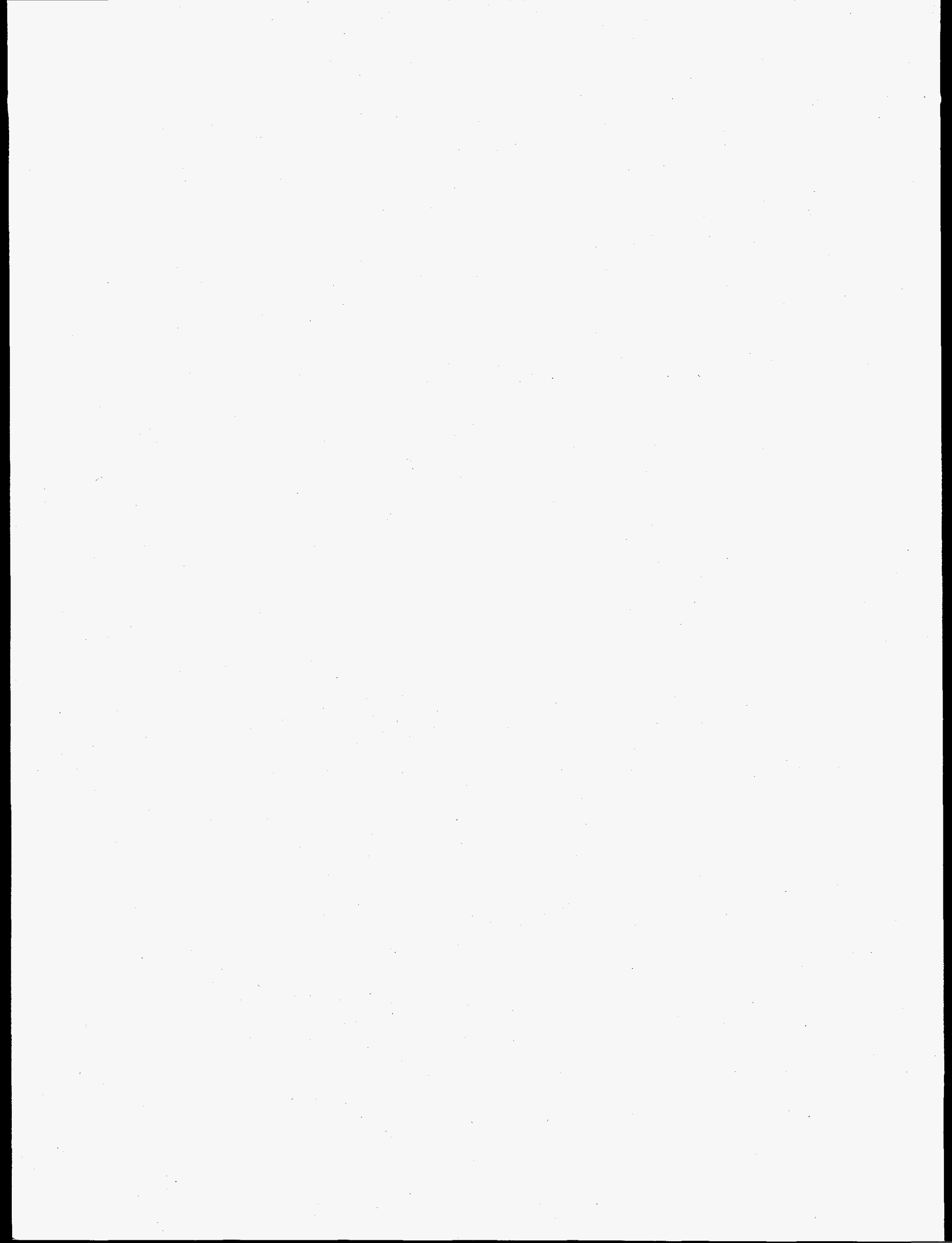




\begin{abstract}
This report documents an independent evaluation of an energy retrofit of 4003 family housing units at Fort Polk, Louisiana, under an energy savings performance contract (ESPC). Replacement of the heating, cooling, and water heating systems in these housing units with geothermal heat pumps (GHPs) anchored the retrofit; low-flow shower heads and compact fluorescent lighting were also installed, as well as attic insulation where needed. Statistically valid findings indicate that the project will save 25.8 million $\mathrm{kWh}$, or $32.5 \%$ of the pre-retrofit whole-community electrical consumption, and $100 \%$ of the whole-community natural gas previously used for space conditioning and water heating (260,000 therms) in a typical meteorological year. These savings result in an estimated reduction in $\mathrm{CO}_{2}$ emissions of 22,400 tons per year. Peak electrical demand has been reduced by $7.55 \mathrm{MW}$, which is $43.5 \%$ of the pre-retrofit peak demand. These energy and demand savings correspond to an improvement in the whole-community annual electric load factor, which went from about 0.52 to 0.62 . At the end-use level, the GHPs were found to save about $42 \%$ of the pre-retrofit electrical consumption for heating, cooling, and water heating in housing units that were all-electric in the pre-retrofit period. The ESPC also allows the Army to effectively cap its expenditures for maintenance of heating and cooling equipment in family housing at about $77 \%$ of previous costs.

It should be noted that the "apparent" energy savings presented above do not necessarily correspond to the "contracted" energy savings under the shared-savings ESPC. For example, operational deviations that are beyond the control and responsibility of the energy services company under the contract could result in savings appearing smaller than they would appear if the operational deviations did not occur, and may require baseline adjustments so that "contract" savings can be determined. Changes in comfort setpoints and occupancy rate and increases in appliance and/or plug-load growth are among the deviations that may result in "contract" savings being 30 million $\mathrm{kWh}$ or more even though "apparent" savings are 25.8 million $\mathrm{kWh}$. Baseline adjustments are negotiated, and may be supported by engineering estimates such as those described in Sect. 7.

This report also demonstrates an improved method of predicting energy savings. Using an engineering model calibrated to pre-retrofit energy use data collected in the field, the method predicted actual energy savings on one of the electric feeders at Fort Polk with a very high degree of accuracy. The accuracy of this model was in turn dependent on data-calibrated models of the geothermal heat pump and ground heat exchanger that are described in this report. In addition this report documents the status of vertical borehole ground heat exchanger (BHEx) design methods at the time this project was designed, and demonstrates methods of using data collected from operating GHP systems to benchmark BHEx design methods against a detailed engineering model calibrated to data. We also discuss the ESPC's structure and implementation and how the experience gained here can contribute to the success of future ESPCs.
\end{abstract}




\section{INTRODUCTION}

Under an energy savings performance contract (ESPC) awarded to an energy services company (ESCO) by the U.S. Army, a number of measures were implemented to reduce energy and maintenance costs in family housing at Fort Polk Joint Readiness Training Center near Leesville, Louisiana. The most important of these measures was installing geothermal heat pumps (GHPs) to replace existing space conditioning systems in all 4003 of the family housing units at the base. This report describes our independent evaluation of the implementation and effectiveness of the ESPC. The work was sponsored by the U.S. Department of Defense and the U.S. Department of Energy.

Energy savings performance contracting is gaining recognition as a viable means of implementing large-scale energy conservation projects, such as those that will be required to comply with Executive Order 12902, "Energy Efficiency and Water Conservation at Federal Facilities," which was signed by President Clinton in 1994. The order directs federal agencies to develop and implement plans for reducing energy use in all their facilities by $30 \%$, relative to 1985 consumption, by the year 2005 . ESPCs are expected to be used in many federal housing installations such as military housing and lowincome housing, as well as in privately owned planned communities such as condominium and townhome developments and senior-citizen housing. The information in this report should be useful to energy service companies, the facility owners contracting their services, and investors as future energy savings performance contracts are implemented.

The objectives of this evaluation were (1) to determine statistically valid impacts of retrofitting with GHPs in military family housing at Fort Polk in terms of energy use, electrical demand, and operation and maintenance; and (2) to improve capabilities to evaluate, design, install, operate, and maintain GHPs in military family housing.

Our evaluation was based on pre- and post-retrofit monitoring of energy flows through the electrical distribution feeders that serve the family housing areas of the post, with data taken at 15-minute intervals from August 1994 through February 1997. For reference, the retrofit construction period extended from March 1995 through August 1996. Data were also collected from a subsample of 13 buildings containing 42 apartments. Calibrated engineering models were used both to demonstrate a method to predict energy savings and to benchmark existing methods for determining average effective soil properties and designing vertical borehole ground heat exchangers (BHEx's) - the aspects of GHP system design that are least familiar to the design profession. Using these models we were able to predict the energy savings attributable to the retrofit on one of the 16 electrical feeders with a high degree of accuracy (within $1 \%$ of monitored values) and to determine the proportion of energy savings due to each of the various energy conservation measures (ECMs) installed in housing on that feeder.

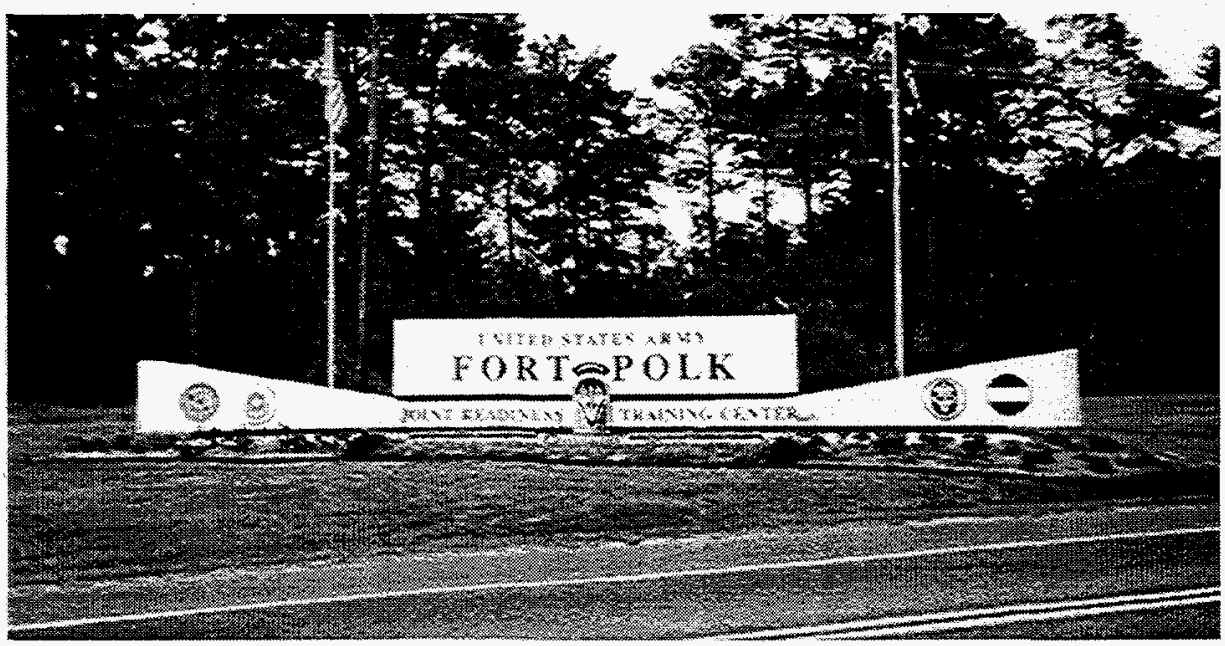

Fig. 1.1. Entrance to Fort Polk Joint Readiness Training Center near Leesville, Louisiana. 


\subsection{SITE BACKGROUND}

The Fort Polk Joint Readiness Training Center is located in west-central Louisiana just outside of Leesville. The 200,000-acre facility contains military offices, training centers, equipment and storage warehouses, a hospital, and housing for some 15,000 service members and their families. Figure 1.1 shows the main entrance to Fort Polk. Approximately 12,000 people live in Fort Polk family housing, which is the focus of the ESPC. Located in two distinct areas called North Fort and South Fort, the family housing stock consists of 4003 living units in 1290 buildings that were constructed in nine phases between 1972 and 1988 . Units range in size from 1073 to $2746 \mathrm{ft}^{2}$, with an average area of $1393 \mathrm{ft}^{2}$. Prior to the implementation of the ESPC, 3243 of the apartments (about $81 \%$ ) were served by air-source heat pumps and electric water heaters, while the remaining 760 had central air conditioners, natural-gas forced-air furnaces, and natural-gas-fired water heaters. Some of these apartments are shown in Fig. 1.2.

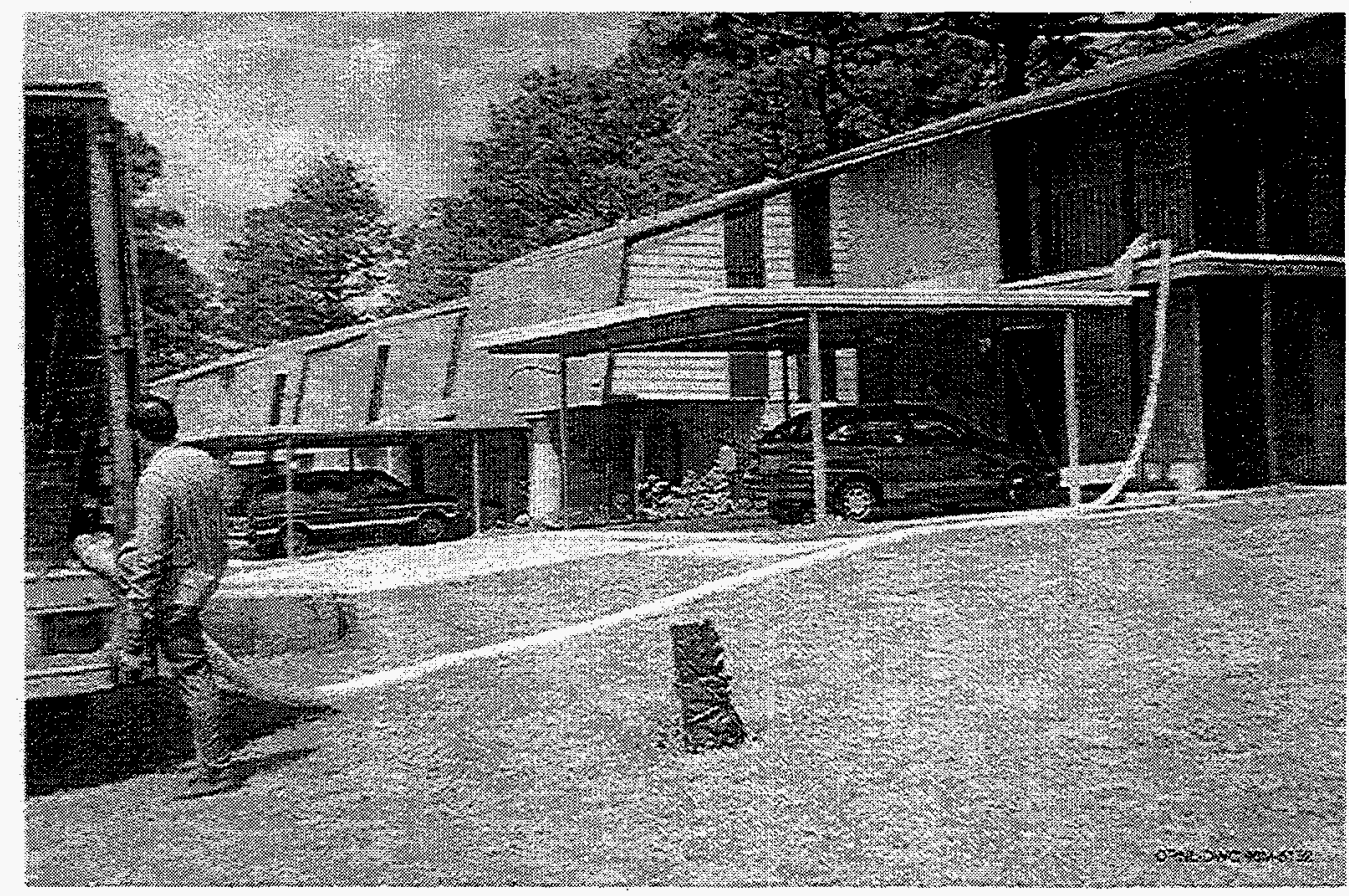

Fig. 1.2. Family housing apartment buildings at Fort Polk. Attic insulation was installed in some apartments as part of the energy retrofit.

\subsection{TERMS OF THE ENERGY SAVINGS PERFORMANCE CONTRACT}

The Fort Polk ESPC was awarded in January 1994. As a "shared-savings" contract, it provides for the U.S. Army and the ESCO to share the cost savings realized through the energy retrofit over the 20-year life of the contract. The entire up-front cost of all of the retrofits -approximately $\$ 18.9$ million ( $\$ 2867$ per installed ton of cooling capacity)-was borne by the ESCO, which also assumed responsibility for maintaining the installed equipment for the duration of the contract. In return, the Army has contracted to pay the ESCO a percentage of the energy and maintenance savings realized each month. The structure of the ESPC is shown in Fig. 1.3. 


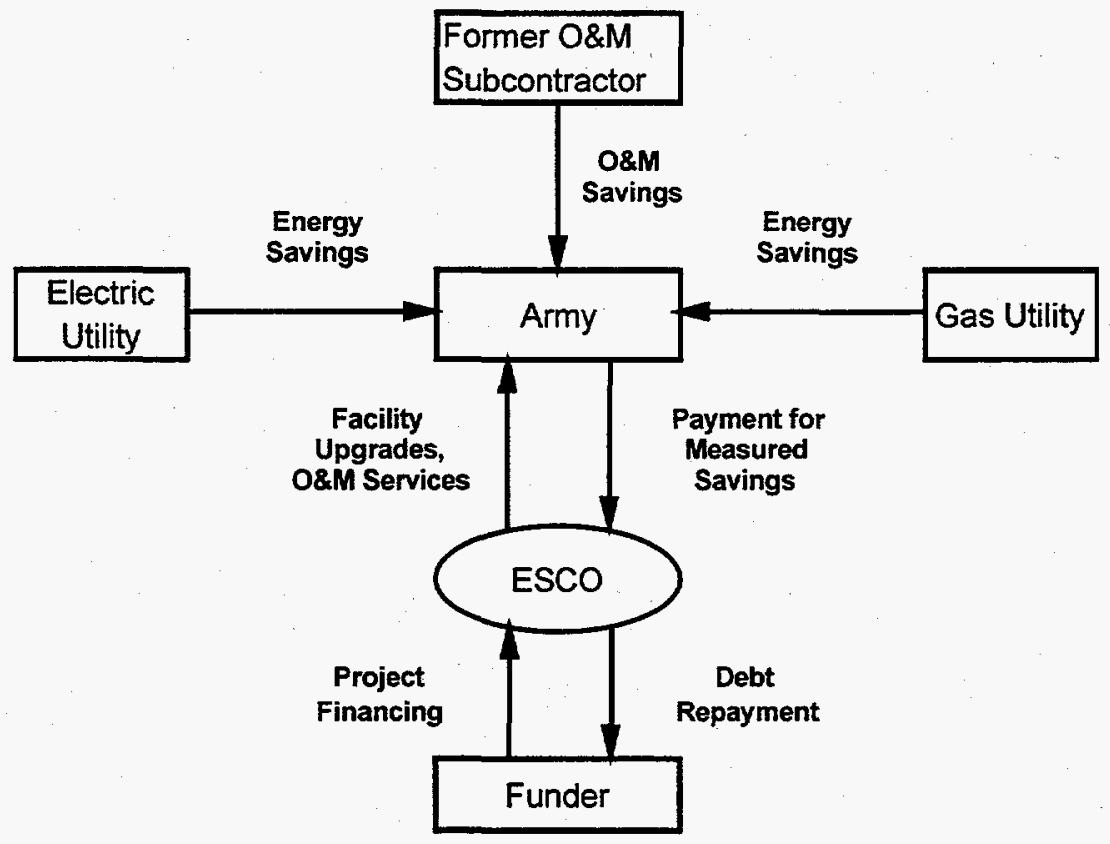

Fig. 1.3. Structure of Fort Polk ESPC.

Monthly electrical energy savings are determined by subtracting actual kilowatt-hour consumption from the agreed-upon baseline consumption, which is a function of the number of heating and cooling degree days that occur during the month. The baseline is derived from a quadratic regression of historical data on monthly electrical consumption in family housing vs total degree days (i.e., the sum of heating and cooling degree days, base $65^{\circ} \mathrm{F}$ ) in each period. Similarly, natural gas savings are determined by subtracting actual gas consumption in therms from a weather-corrected baseline consumption derived from a regression of Fort Polk's previous monthly natural gas consumption as a function of heating degree days. Dollar savings are then determined by multiplying the electrical and gas savings by that month's base-wide average energy prices per kilowatt-hour and per therm, as determined from utility bills. Over the life of the contract, the ESCO will receive about $77 \%$ of the savings achieved.

Since the ESCO assumes full responsibility for maintaining the equipment installed, the Army saves the entire amount previously paid annually for maintaining heating, ventilating, and airconditioning (HVAC) equipment in family housing. This is specified in the contract as $\$ 335.83$ per residence per year (with minor cash flow adjustment stipulations and a consumer price index escalator). For the 4003 residences, this comes to approximately 24 cents $/ \mathrm{ft}^{2}$ per year. As with the energy savings, the ESCO will receive about $77 \%$ of the maintenance savings over the life of the contract.

\subsection{THE EQUIPMENT INSTALLED}

Under the terms of the contract, the ESCO replaced the space conditioning systems in all of Fort Polk's family housing with GHPs. The total capacity of GHPs is 6593 tons, installed in heat pump nominal capacities of $1.5,2.0$, and 2.5 tons, with one heat pump per living unit. The mean size of heat pumps installed across the entire project is 1.65 tons. Each heat pump has its own 
ground heat exchanger of the vertical U-tube type, with one circuit (two pipes) per bore and two circuits in parallel. (Two single-family housing units for high-ranking officers had 2.5-ton heat pumps and three circuits in parallel.) A total of 1,834,652 ft of $41 / 8$-in. vertical bore was drilled. (The upper $3 \mathrm{ft}$ of each bore is not part of the heat exchanger, so the total installed vertical heat exchanger bore length is $1,810,628 \mathrm{ft}$, with an average of $275 \mathrm{ft}$ of bore per ton. A total of $3,621,256 \mathrm{ft}$ [about $686 \mathrm{miles}$ ] of 1-in.-diameter SDR-11 high-density polyethylene pipe was installed in the bores.) The bores were backfilled bottom to top with standard bentonite-based grout; no extraordinary measures were taken to thermally enhance the grout or to maintain space between the up and down pipes in the bore. Figures 1.4, 1.5, and 1.6 show several stages of the retrofit construction project.

Gas-fired water heaters were also replaced with electric water heaters in the 760 apartments that originally used natural gas. The new GHPs include desuperheaters to supplement domestic water heating with energy recovered from the GHP when it is operating for heating or cooling. (Because of the distance between the heat pump and water heater, it was practical to connect only some of the desuperheaters, about $65 \%$, to the hot water tanks during construction.) Low-flow shower heads and compact fluorescent lighting (in all indoor and outdoor fixtures attached to housing) were installed in all units, some fixtures were delamped, and attic insulation was installed as needed. Other energy conservation measures such as water-heater blankets were also identified but had not been implemented as of this writing.

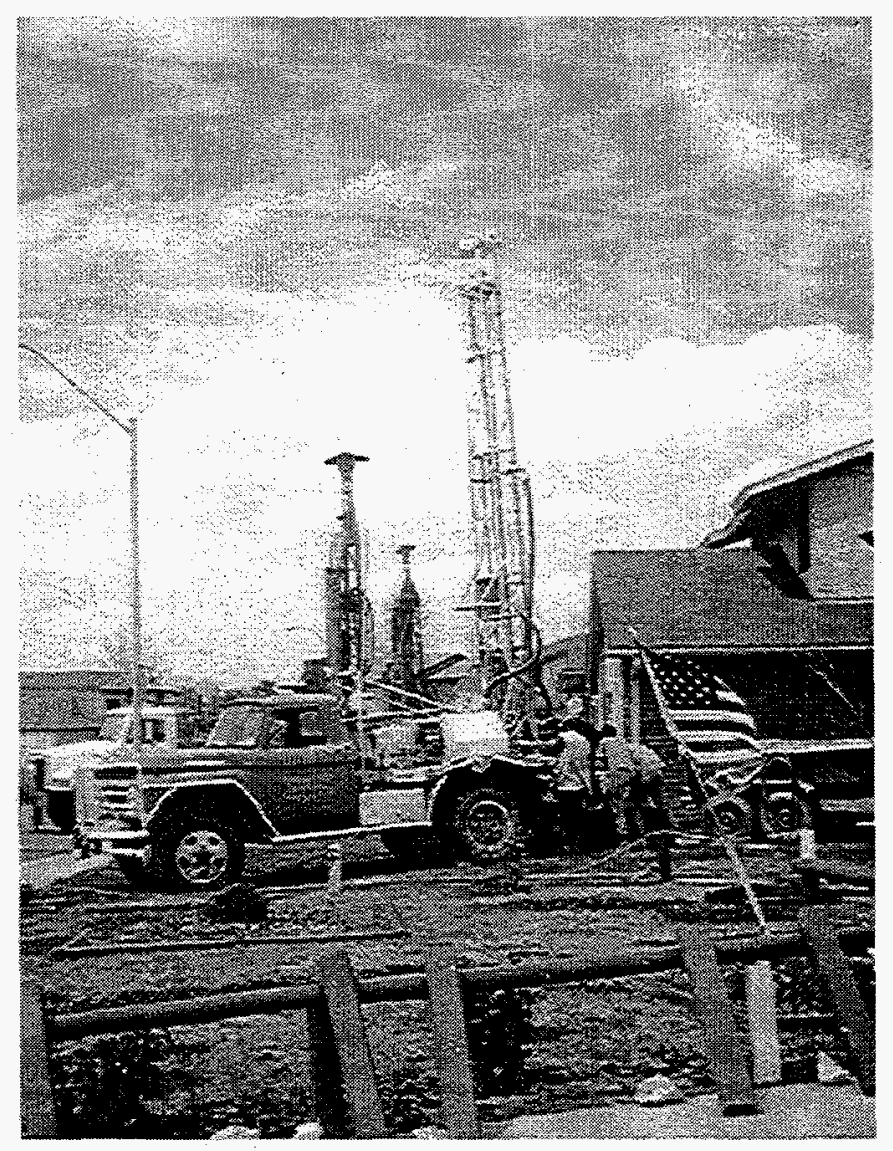

Fig. 1.4. A rig drilling vertical boreholes for the gound heat exchangers. A total of $1,834,652 \mathrm{ft}$ of 4 1/8-in. vertical bore was drilled for the vertical borehole heat exchangers. 


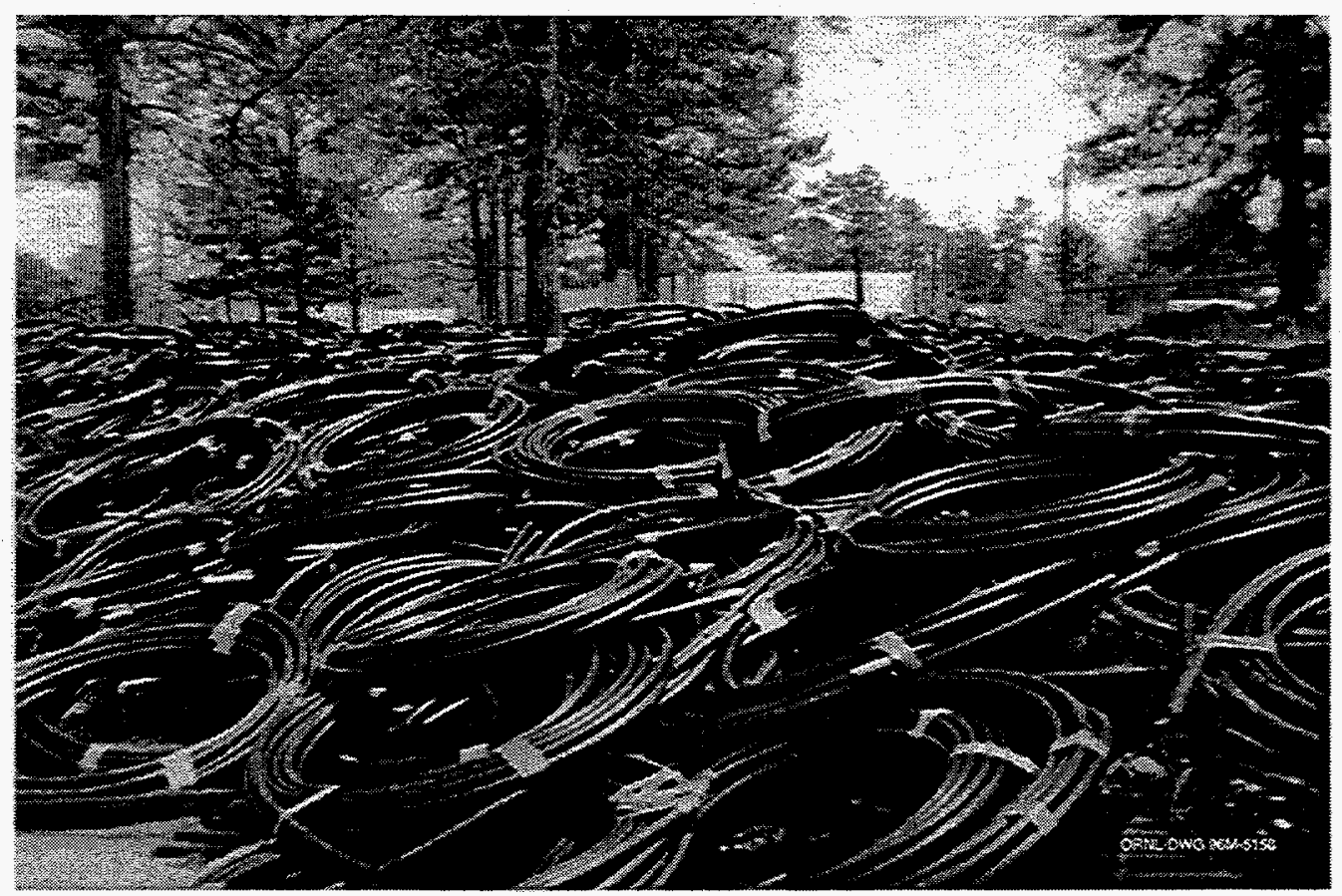

Fig. 1.5. This pile of polyethylene piping-measured, cut, and ready to install-gives an idea of the scale of the retrofit project. The pipe installed in the vertical borehole heat exchangers at Fort Polk would reach 686 miles.

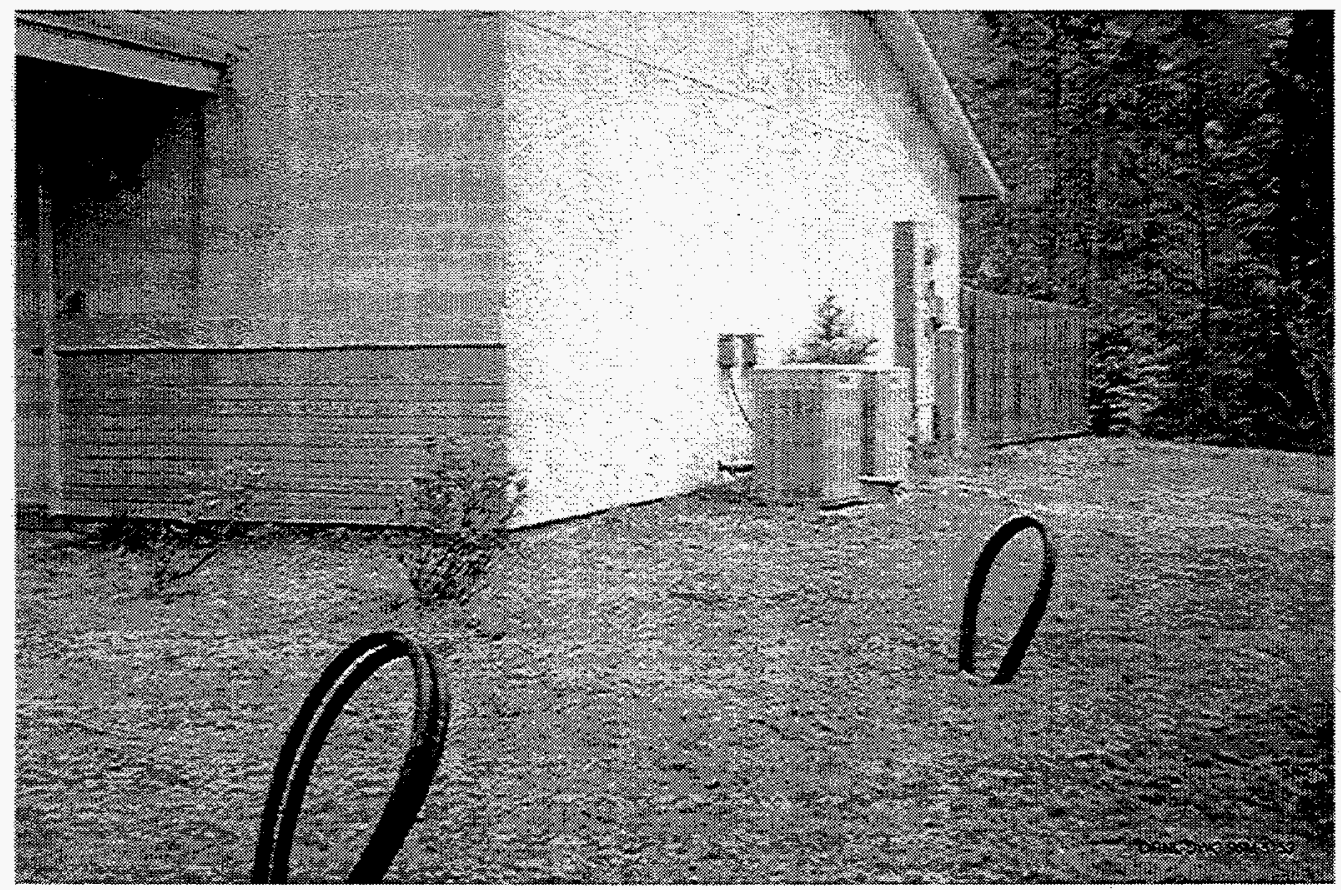

Fig. 1.6. Above-ground loops of pipe show where ground heat exchangers have been installed and are ready to be connected to heat pumps. 


\subsection{EVALUATION METHODOLOGY}

Our evaluation included a range of studies designed to take advantage of the opportunity to analyze a large-scale energy retrofit anchored by GHPs. Our methods of evaluating overall energy savings, predicting energy savings, and modeling the performance of the GHPs are described briefly in the following paragraphs and in more detail in other sections of this report. We also performed analyses of the overall structure of the contract, its implementation, and the economic implications for the parties to the contract, the Army and the ESCO. Our conclusions from these analyses are discussed in Sects. 3, 7, and 8.

\subsubsection{Data Collection}

Our analysis of energy savings and our improved method of predicting energy savings were based on a three-level data collection strategy. Level-1 represents monitoring of energy supplied by 14 of the 16 electrical feeders serving Fort Polk's family housing areas. On Level-2, we monitored total energy consumption and energy consumption by the HVAC outdoor units (heat pump or central air conditioner) in a set of 42 housing units selected at random from the population of 4003 units. Level 3 added monitoring of energy use by the water heaters and airhandling systems in a subset of 18 of the 42 Level-2 sites. Data at all three levels were collected at 15-minute intervals for about one year before and one year after the retrofits. (The overall data collection period was from August 1994 through February 1997.) At one of the Level-3 sites (a five-plex), "energy balance" data were also collected on the operation of the vertical BHEx and on domestic supply water temperature and indoor temperature and humidity. This data allowed us to use inverse heat transfer techniques to determine average effective soil heat transfer properties, and thus calibrate the BHEx model. Figure 1.7 schematically illustrates the evaluation approach. Evaluation professionals may recognize this as a multi-tier, nested evaluation design.

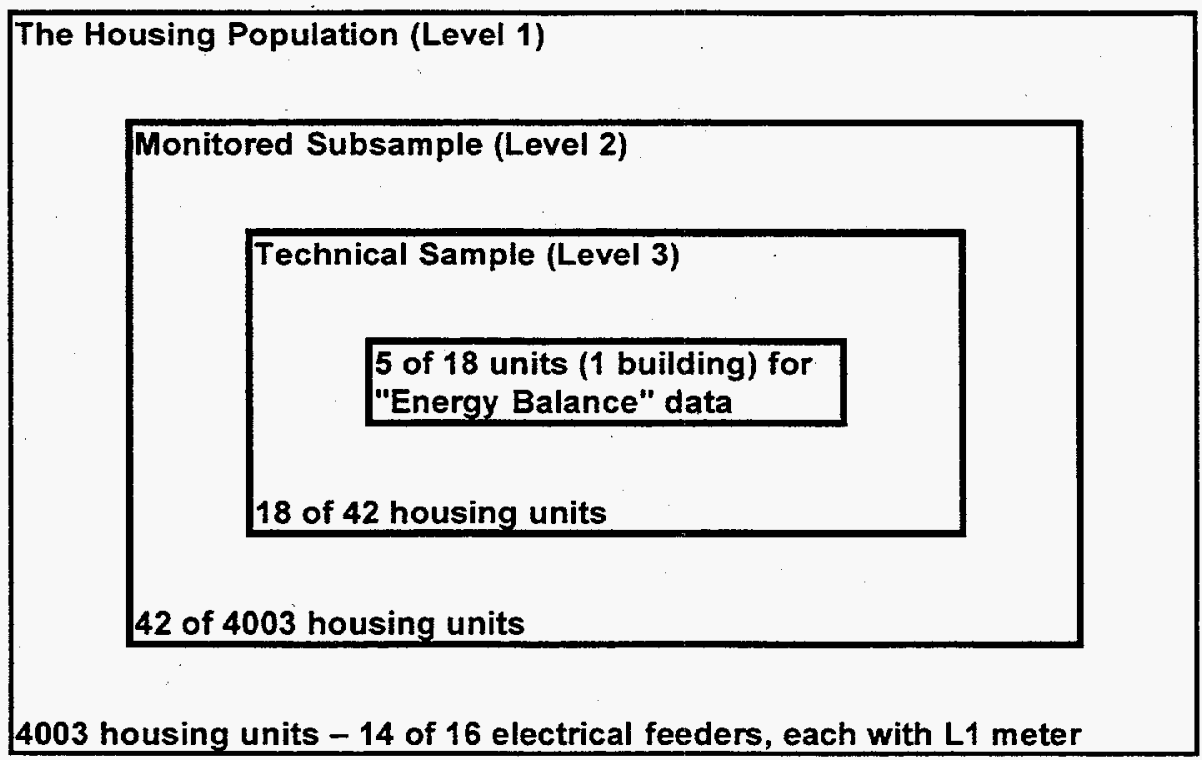

Fig. 1.7. The evaluation of the Fort Polk project was based on a three-level data collection approach. 


\subsubsection{Predicting Energy Savings}

The improved approach to predicting energy savings is based on an engineering model calibrated to the field-collected Level-1 data from the pre-retrofit period. A dynamic model of pre-retrofit energy use was developed for all the housing and nonhousing loads on one electrical feeder at Fort Polk. The feeder serves 46 buildings containing a total of 200 individual apartments. Analysis of pre- and post-retrofit data indicates that the retrofits have saved $30.3 \%$ of pre-retrofit electrical energy consumption on the feeder modeled for the prediction study. The method (described in Sect. 4) predicted this savings within 1\% of its measured value, using only pre-construction energy consumption data and post-retrofit data from one pilot test site.

\subsubsection{Geothermal Heat Pump System Model}

A calibrated GHP system model at the apartment level was perhaps the most important factor in the accuracy of the overall feeder model used to predict energy savings. An apartment's GHP system consists of a number of components, including the BHEx, the heat pump with desuperheater, the water tank, and the heating, cooling, and water heating loads served by the GHP system. A detailed component-based simulation of a GHP system was calibrated to monitored data from one family housing unit at Fort Polk. The system model was then exercised to demonstrate its capabilities to address soil property impacts, multibore interactions, long-term consequences of annual heat imbalance, bore spacing, bore diameter, pipe spacing, pipe diameter, grout properties, and most other elements of BHEx design. Calibration of the BHEx component model involves use of inverse heat transfer techniques to determine the average effective soil properties from the time interval heat transfer history in the data. This modeling effort is described in Sect. 5 of this report.

\subsubsection{Comparison of BHEx Sizing Methods}

The output from the detailed models calibrated to Fort Polk data were then used to test five practical BHEx design methods. Even with inputs kept as consistent as possible, these five practical methods calculate very different required borehole lengths necessary to keep the temperature of water entering the heat pump below a user-specified maximum. When the Fort Polk project was engineered, BHEx design was largely experience-based. A small cadre of experienced designers could develop effective BHEx designs by adjusting the outputs of the BHEx design methods they used based on experience. This study, detailed in Sect. 6, led to the conclusion that further calibration and comparison exercises should be done to give the developers of BHEx design methods an opportunity to calibrate and improve their methods, and to resolve the differences between the programs. This would help to expand the pool of designers that can develop effective BHEx designs.

\subsubsection{Analysis of Maintenance Costs}

To evaluate the ESPC in terms of maintenance costs and savings to the Army, we developed a rigorous baseline cost estimate based on a census of existing equipment age and a survey of maintenance records for the pre-retrofit HVAC equipment. The baseline cost estimate includes consideration of the reliability of the old existing equipment. An actuarial method was used to determine the number of units requiring replacement each year and the effect of these replacements on annual maintenance costs. This work is discussed in Sect. 3 of this report. 


\subsection{SUMMARY OF SAVINGS}

Analysis of our statistically valid monitored data shows that the energy retrofit at Fort Polk will save 25.8 million $\mathrm{kWh}$ in electrical energy use, or $32.5 \%$ of pre-retrofit whole-community electrical consumption, in a typical year in family housing. Figure 1.8 shows post-retrofit monthly energy use and savings. The total peak demand reduction for the family housing area is estimated at $7.55 \mathrm{MW}$, or $43.5 \%$ of pre-retrofit whole-community peak demand. These energy and demand savings correspond to an improvement in the whole-community annual electric load factor from about 0.52 to 0.62 . These reductions are achieved even though the average electricity savings in the housing units that had natural gas appliances prior to the retrofit is only $16.7 \%$, compared with $35.3 \%$ for units that were all-electric before the retrofit. Converting to all-electric space conditioning and water heating in all units also saves an estimated 260,000 therms of natural gas consumption per year. At the end-use level, the GHPs were found to save about $42 \%$ of the preretrofit electrical consumption for heating, cooling, and water heating in housing units that were all-electric before the retrofit.

A rigorous analysis of the costs of maintenance of HVAC equipment under the ESPC shows that the contract enables the Army to effectively cap its future expenditures for family housing HVAC maintenance at about $77 \%$ of its estimated 20 -year average baseline maintenance costs of $\$ 335.83$ per housing unit per year. This corresponds to a cap of about 18.1 cents $/ \mathrm{ft}^{2}$ per year. The net present-value maintenance cost savings to the Army over the life of the contract is estimated to be about $\$ 4.5$ million.

(Note that the energy savings reported in this document are "apparent" energy savings observed in the monitored data and should not be confused with the "contract" energy savings, which are used as the basis for payments under the shared-savings ESPC. Determining contract energy savings may require adjustments to the baseline for factors such as comfort setpoints, occupancy rate, and appliance and/or plug-load growth that are beyond the control and responsibility of the ESCO under the contract.)

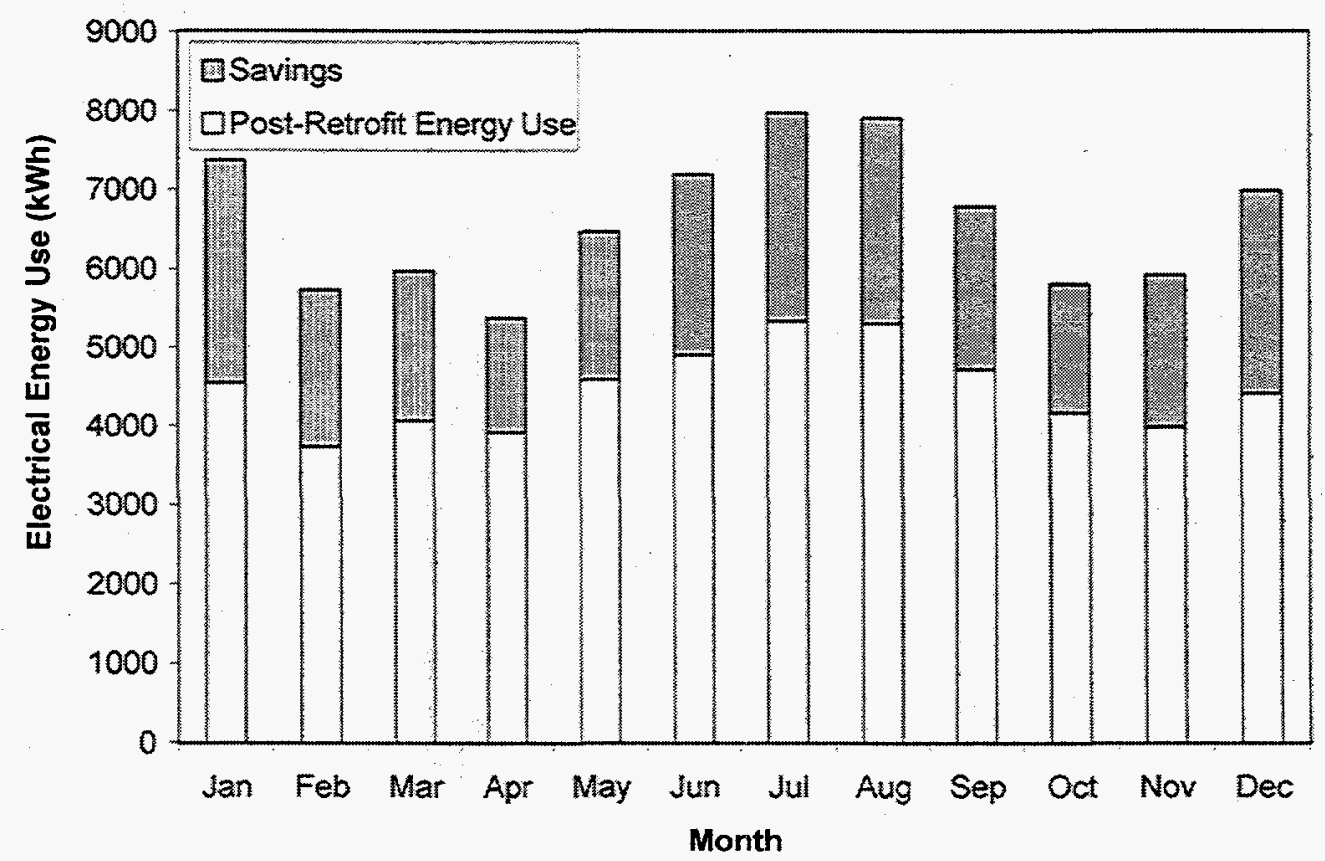

Fig. 1.8. Monthly expected whole-community electrical energy savings in a typical meteorological year. 


\section{METHODOLOGY AND CALCULATION OF ENERGY SAVINGS}

\subsection{FIELD DATA COLLECTION-LEVELS 1, 2, AND 3}

A three-level data collection plan was developed for our evaluation of the ESPC. The approach is illustrated schematically in Fig. 1.7. Levels 1, 2, and 3 are described in this section of the report. Energy-balance data were also collected to support the advancement of GHP system design and energy estimating methods and are discussed in Sects. 4, 5 , and 6.

Level 1 addresses the total population of housing units. Data on electrical demand and consumption were collected at 15-minute intervals from submeters on 14 of the 16 electrical feeders that supply electricity to the family housing areas at Fort Polk. (We intended to monitor all feeders, but the project's recording equipment could not be interfaced with existing metering on two feeders.) Temperature and humidity data were also collected at 15-minute intervals at four different locations within the family housing area. Level-1 data allows comparison of pre- and post-retrofit energy usage patterns in the aggregate of all loads served by each feeder. A schematic representation of the Level-1 data collection technique, pre- and post-retrofit, is presented in Fig. 2.1.

Most feeders serve housing of just one construction vintage, but some serve a mixture of vintages. In addition, all feeders serve street lighting, and some serve other loads as well, including sewage lift stations and a small maintenance facility. Table 2.1 lists the feeders and shows characteristics of the housing served by each feeder.

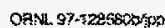

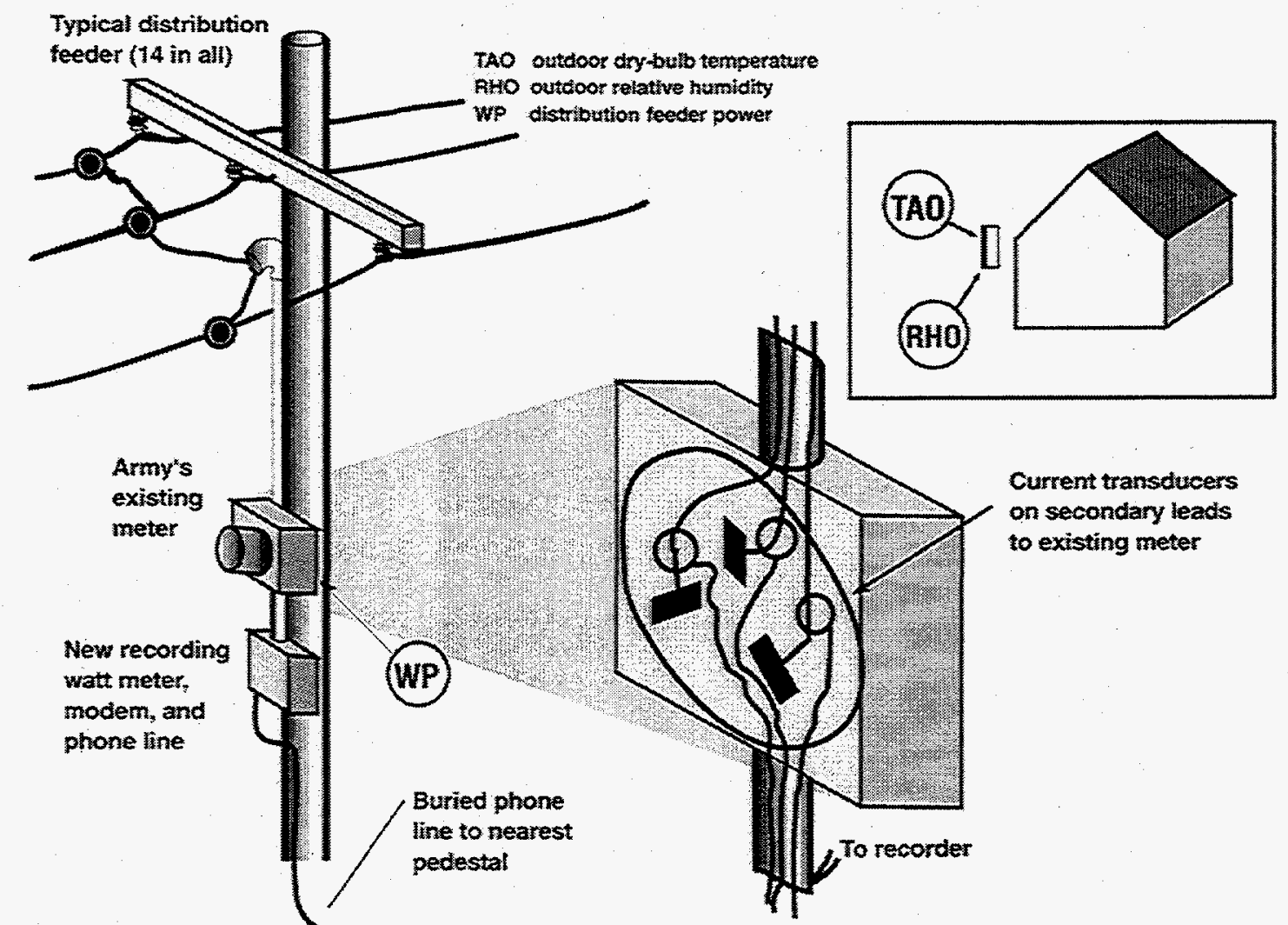

Fig. 2.1. Level-1 pre- and post-retrofit data collection technique. 
Table 2.1 Characteristics of Fort Polk family housing stock

\begin{tabular}{rlrrlrrrrr}
\hline Feeder & $\begin{array}{c}\text { Pre-retro } \\
\text { HVAC }\end{array}$ & $\begin{array}{c}\text { Number } \\
\text { of bldgs }\end{array}$ & $\begin{array}{c}\text { Number } \\
\text { of units }\end{array}$ & $\begin{array}{c}\text { Construction } \\
\text { vintage }\end{array}$ & $\begin{array}{r}\text { Total } \\
\mathrm{ft}^{2}\end{array}$ & $\begin{array}{r}\text { Average } \\
\mathrm{ft}^{2} / \text { unit }\end{array}$ & $\begin{array}{c}\text { Installed } \\
\text { tons }\end{array}$ & $\begin{array}{c}\text { Retrofit } \\
\text { start }\end{array}$ & $\begin{array}{c}\text { Construction } \\
\text { end }\end{array}$ \\
\hline 1 & all-electric & \multicolumn{1}{c}{46} & 200 & 1981 & 231248 & 1156 & 300.0 & $\mathbf{8} / 10 / 95$ & $9 / 1 / 95$ \\
2 & all-electric & 416 & 1220 & $1976 / 1980$ & 1741496 & 1427 & 2034.5 & $10 / 20 / 95$ & $3 / 25 / 96$ \\
3 & all-electric & 40 & 40 & 1976 & 74966 & 1874 & 80.5 & $3 / 11 / 96$ & $3 / 18 / 96$ \\
4 & mixture & 6 & 6 & $1975-1984$ & 12004 & 2001 & 12.0 & $6 / 12 / 95$ & $8 / 8 / 96$ \\
5 & gas/elect. & 45 & 100 & $1972 / 1975$ & 149480 & 1495 & 190.0 & $5 / 30 / 95$ & $8 / 10 / 95$ \\
6 & all-electric & 22 & 80 & 1977 & 108768 & 1360 & 130.0 & $7 / 13 / 95$ & $8 / 10 / 95$ \\
7 & all-electric & 193 & 571 & 1977 & 906917 & 1588 & 987.5 & $3 / 12 / 95$ & $4 / 30 / 96$ \\
11 & gas/elect. & 57 & 152 & 1975 & 212170 & 1396 & 269.0 & $4 / 11 / 95$ & $4 / 17 / 96$ \\
12 & gas/elect. & 48 & 142 & 1975 & 184992 & 1303 & 243.0 & $4 / 23 / 95$ & $5 / 15 / 96$ \\
13 & gas/elect. & 47 & 162 & 1975 & 202168 & 1248 & 265.0 & $4 / 29 / 95$ & $5 / 16 / 96$ \\
14 & gas/elect. & 63 & 200 & 1972 & 250134 & 1251 & 344.0 & $5 / 13 / 95$ & $6 / 5 / 96$ \\
15 & all-electric & 49 & 200 & 1984 & 276794 & 1384 & 300.0 & $5 / 22 / 95$ & $6 / 24 / 96$ \\
16 & all-electric & 77 & 306 & 1987 & 387762 & 1267 & 459.0 & $6 / 5 / 96$ & $7 / 1 / 96$ \\
17 & all-electric & 82 & 275 & 1987 & 351873 & 1280 & 413.0 & $6 / 18 / 96$ & $8 / 1 / 96$ \\
18 & all-electric & 43 & 168 & 1988 & 235532 & 1402 & 273.5 & $6 / 18 / 96$ & $8 / 1 / 96$ \\
19 & all-electric & 56 & 181 & 1988 & 258313 & 1427 & 292.0 & $6 / 18 / 96$ & $8 / 1 / 96$ \\
\hline TOTAL & $\mathbf{1 2 9 0}$ & $\mathbf{4 0 0 3}$ & & $\mathbf{5 5 8 4 6 1 7}$ & $\mathbf{1 3 9 5}$ & $\mathbf{6 5 9 3 . 0}$ & & \\
\hline
\end{tabular}

Notes:

1. No family housing on Feeders 8 and 10 ; meter for Feeder 7 includes Feeder 9.

2. Feeder 4 contains four units constructed in 1975 which were gas/electric prior to the retrofit, and two additional units constructed in 1977 and 1984 which were all-electric.

Level-2 data focuses on a sample of 42 apartments in 13 buildings. Data on total electricity use of the apartment and the electricity use of the HVAC outdoor unit (heat pump or central air conditioner's compressor, outdoor fan, and controls) were collected at 15-minute intervals in the pre-retrofit condition. Post-retrofit, data were collected on total electricity use of the apartment and total electricity use of the GHP (compressor, blower, ground loop pump and, desuperheater pump if connected). Level-2 data allows the determination of the coefficient of variation of savings across buildings and apartments. Figure 2.2 is a schematic representation of the preretrofit Level-2 data collection technique; Figure 2.3 represents post-retrofit data collection.

In Level 3, more detailed energy use data were collected on a subsample of 18 of the 42 Level-2 apartments ( 4 of the 13 buildings). In addition to total apartment electricity use and HVAC outdoor unit electricity use, 15-minute-interval data were collected to isolate the energy use of the water heater (electric resistance or gas), the electricity use of the indoor air handling system, and the heat energy use in the HVAC indoor unit (electric resistance or gas) in the preretrofit condition. In post-retrofit, in addition to data on total apartment electricity use and total GHP electricity use, data were collected to isolate the electricity use of the water heater and blower and compressor inside the GHP. Again, the subsample includes buildings whose floor areas, construction vintages, and other characteristics vary. This technical sample is useful for understanding the relative importance of the weather-sensitive end uses vs base loads, and it supports analysis to determine the savings attributable to the various conservation measures. Preand post-retrofit data collection is similar to that of Level 2, presented in Figs. 2.2 and 2.3. 


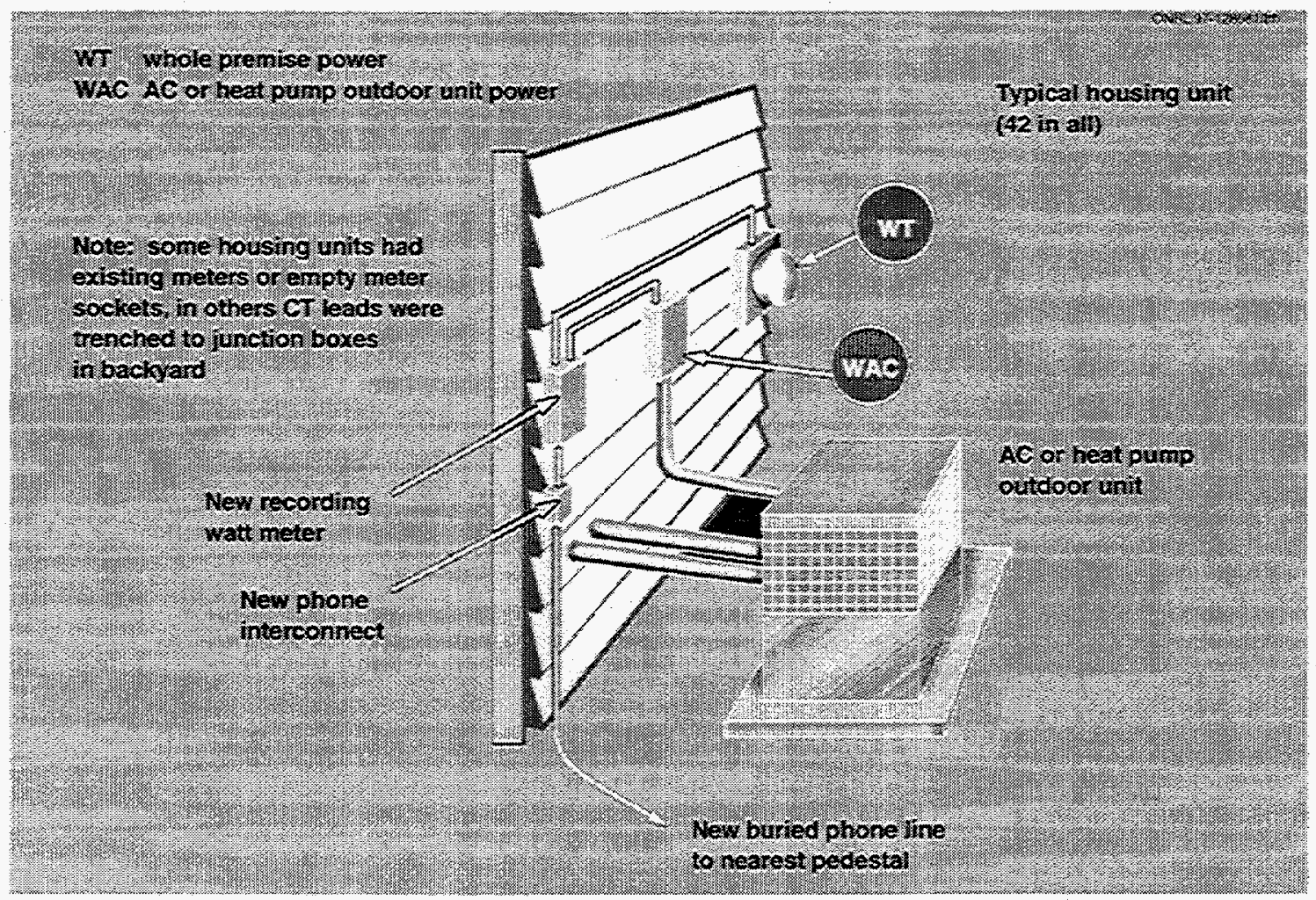

Fig. 2.2. Level-2 pre-retrofit data collection technique.

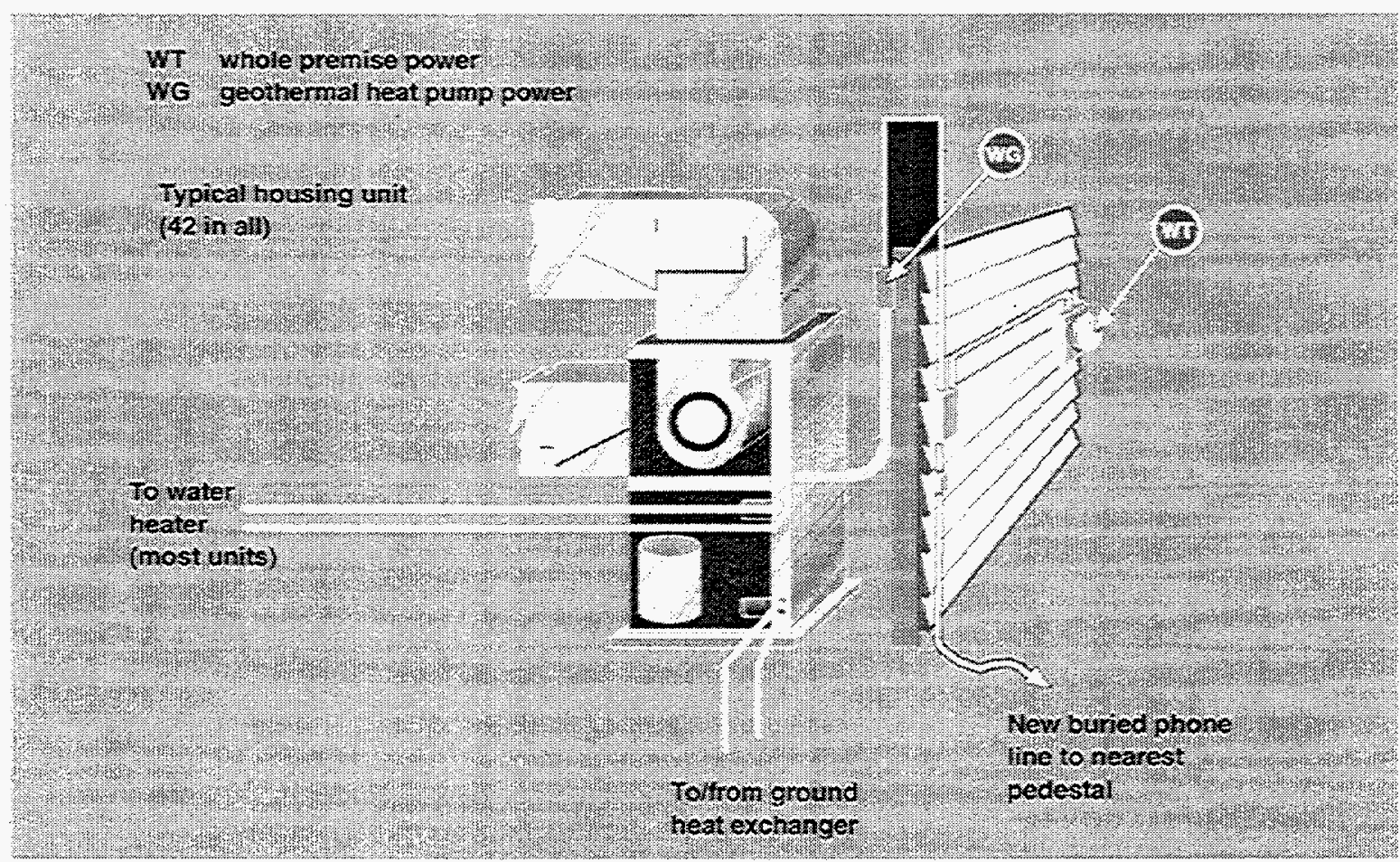

Fig. 2.3. Level-2 post-retrofit data collection technique. 


\subsection{CALCULATING ENERGY SAVINGS}

In order to determine electrical energy savings for each feeder, the 15-minute-interval energy consumption data were totaled for each day in the pre- and post-retrofit periods. Note that since construction took more than a year to complete, the pre- and post-retrofit periods are somewhat different for each feeder. The construction start and finish dates shown in Table 2.1 for each feeder (i.e., the dates when the first housing unit was started and the last housing unit was completed) were obtained from construction records; energy consumption data between these dates were excluded from the analysis.

In Fig. 2.4, daily energy consumption is plotted vs daily average temperature for a typical allelectric feeder in the pre-retrofit period. The data fall into three distinct regions: a heating region, in which energy consumption is a linear function of temperature with negative slope; a cooling region, in which energy consumption is also a linear function of temperature, but with positive slope; and a constant-use region, in which energy consumption is independent of temperature.

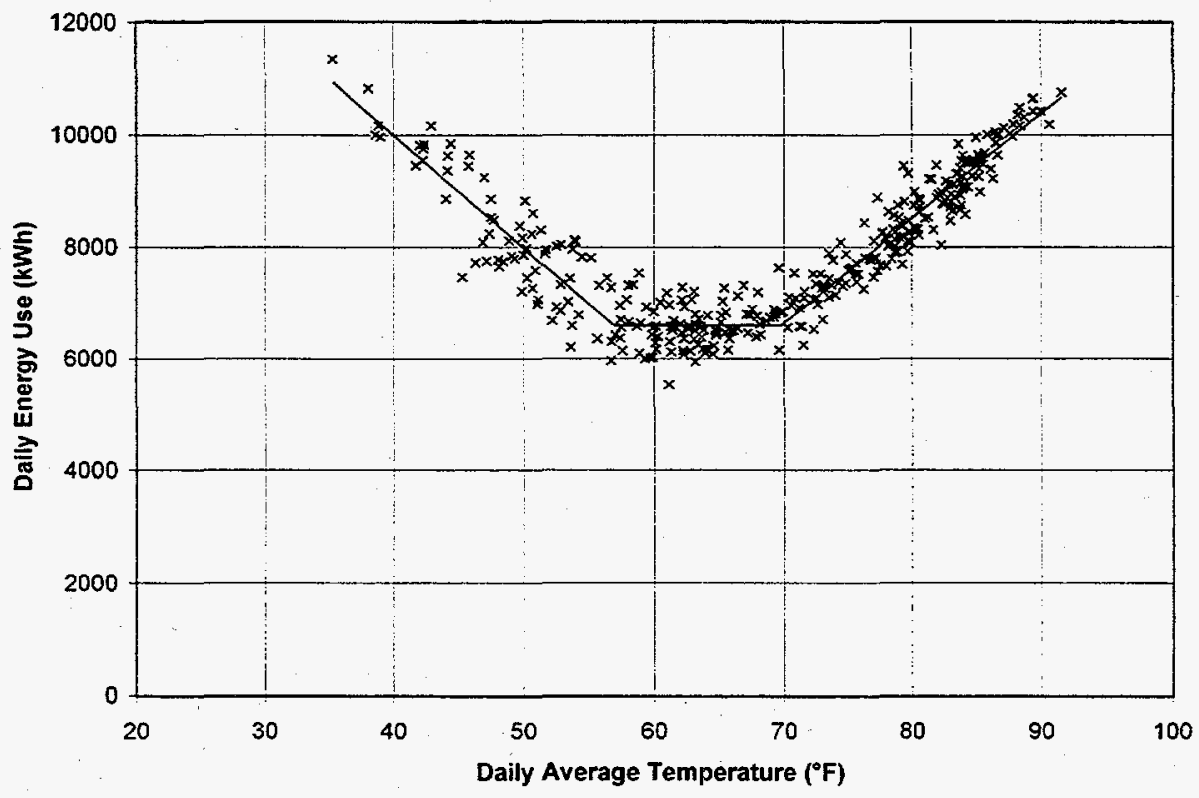

Fig. 2.4. Daily electrical energy use for a typical feeder (Feeder 1) serving housing that was allelectric before the retrofits.

The data in Fig. 2.4 suggests that a five-parameter, two-changepoint model can be used to describe the post-retrofit data for each feeder and the pre-retrofit data for those feeders that served all-electric residences. Daily energy consumption for these cases was correlated to a function of the form

$$
\begin{array}{rlr}
E= & E_{0}+m_{h}\left(T-T_{h}\right) & T<T_{h} \\
& E_{0} & T_{h} \leq T \leq T_{c} \\
& E_{0}+m_{c}\left(T-T_{c}\right) & T>T_{c},
\end{array}
$$

where $E_{0}$ is the non-weather-dependent daily energy consumption, $T_{h}$ and $T_{c}$ are the heating and cooling changepoint temperatures, and $m_{h}$ and $m_{c}$ are the slope of energy use vs daily average temperature in the heating and cooling regions, respectively.

A computer program was written to determine the parameters in Eq. (2.1) for a given data set. With an initial input of a guess for the changepoint temperatures, the algorithm calculates the nonweather-dependent consumption as the average energy consumption for all points corresponding 
to temperatures between the changepoints. Points with temperatures below the heating changepoint temperature are correlated to a line which passes $\mathrm{E}_{0}$ at the heating changepoint temperature. This determines the slope of the heating line.

Correspondingly, points at temperatures above the cooling changepoint temperature are correlated to a line which passes through $\mathrm{E}_{0}$ at the cooling changepoint temperature. Note that by using this algorithm, a trial five-parameter model is fixed once the two changepoint temperatures are selected. The program calculates the sum of squared errors between the energy consumption data and the energy consumption predicted by the trial five-parameter model. The downhill simplex method (Press et al. 1997) is used to determine the changepoint temperatures that minimize the sum of squared errors between the data and the model.

Figure 2.5 is a plot of daily electrical energy consumption vs daily average temperature for a typical feeder on which the residences were originally heated by natural gas. For these feeders, the data falls into only two regions: a cooling region, in which energy consumption is a linear function of daily average temperature, and a baseline region, in which energy consumption is independent of daily average temperature. For these feeders, a three-parameter, singlechangepoint model was used, and the data were correlated to a function of the form

$$
\begin{array}{ll}
\mathrm{E}_{0} & \mathrm{~T} \leq \mathrm{T}_{\mathrm{c}} \\
\mathrm{E}_{0}+\mathrm{m}_{\mathrm{c}}\left(\mathrm{T}-\mathrm{T}_{\mathrm{c}}\right) & \mathrm{T}>\mathrm{T}_{\mathrm{c}},
\end{array}
$$

where $E_{0}$ is the non-weather-dependent daily energy consumption, $T_{c}$ is the cooling changepoint temperature, and $m_{c}$ is the slope of energy use vs daily average temperature in the cooling region. As with the algorithm for the five-parameter correlation, selecting a changepoint temperature fixes the values of the baseline energy consumption and the cooling slope. An algorithm similar to the one described above is used to determine the changepoint temperature that results in a model with the lowest sum of squared errors.

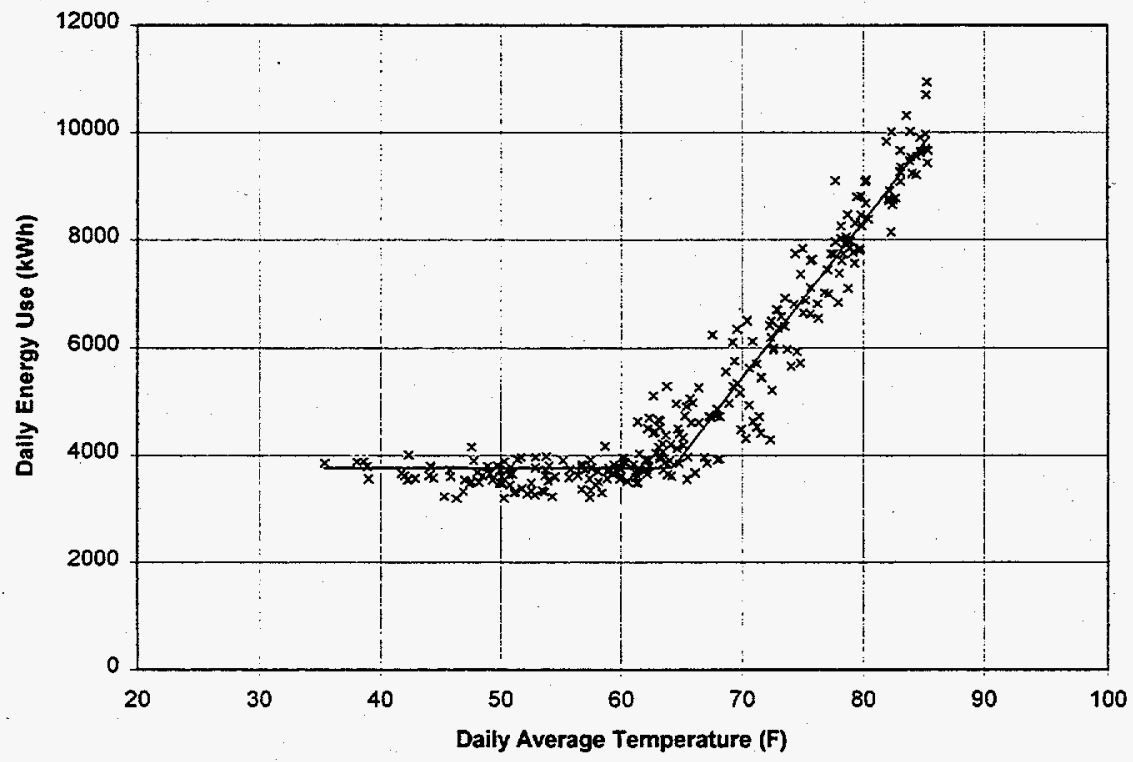

Fig. 2.5. Daily electrical use for a typical feeder serving housing which was gas/electric before the retrofits.

Daily energy consumption vs daily average temperature was correlated to a five- or threeparameter model as required for all 14 monitored feeders in their respective pre- and post-retrofit periods. The complete data set is shown in Fig. 2.6. Table 2.2 presents the parameters for each model. 
Feeder 1

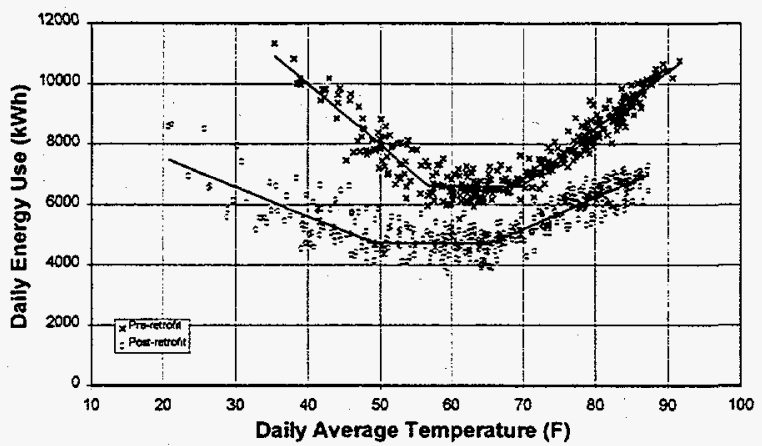

Feeder 3

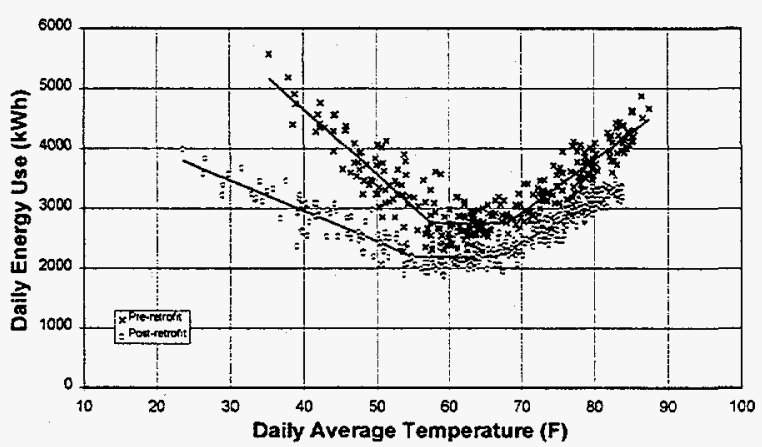

Feeder 5

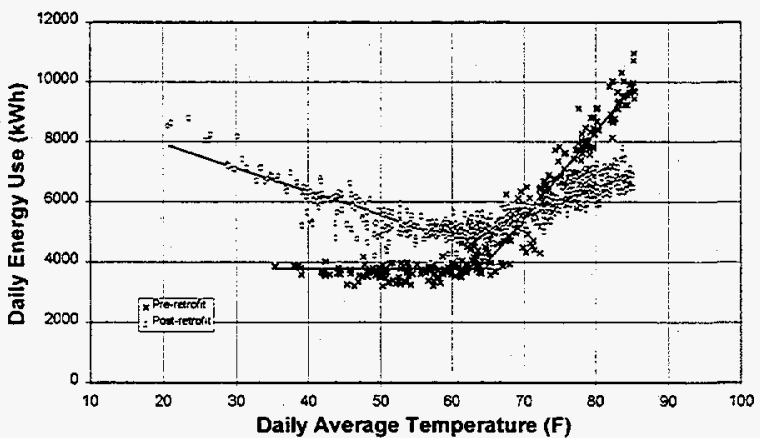

Feeder 7

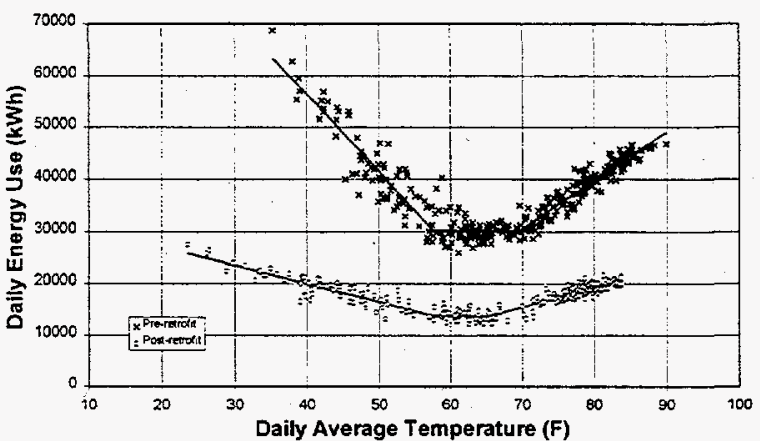

Feeder 2

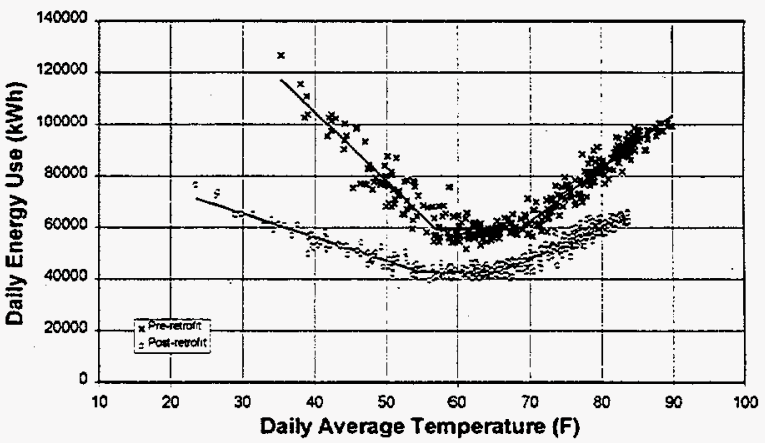

Feeder 4

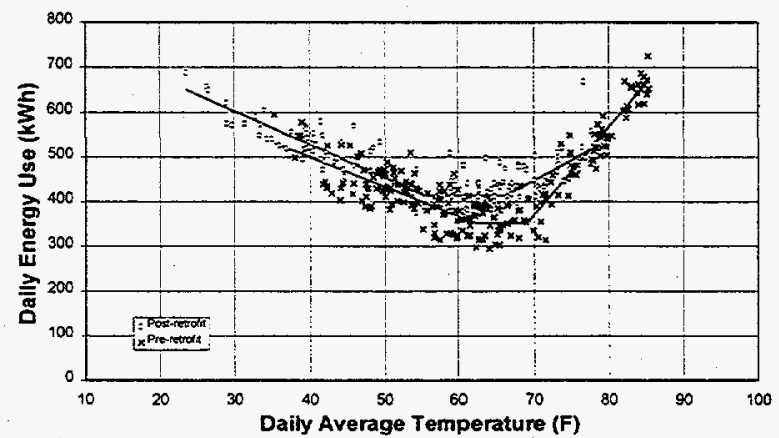

Feeder 6

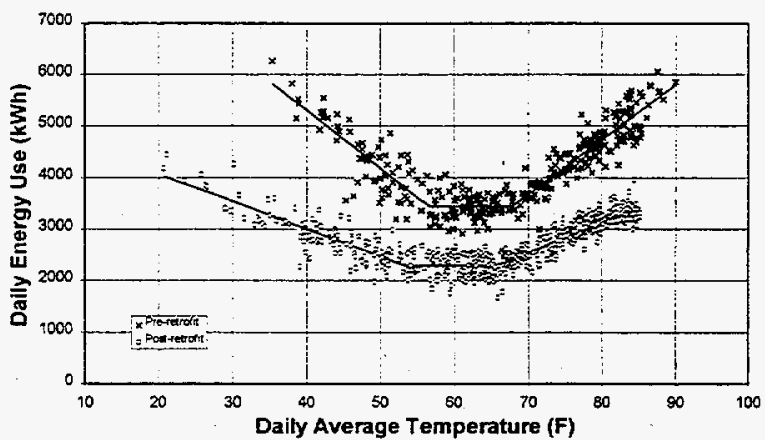

Feeder 11

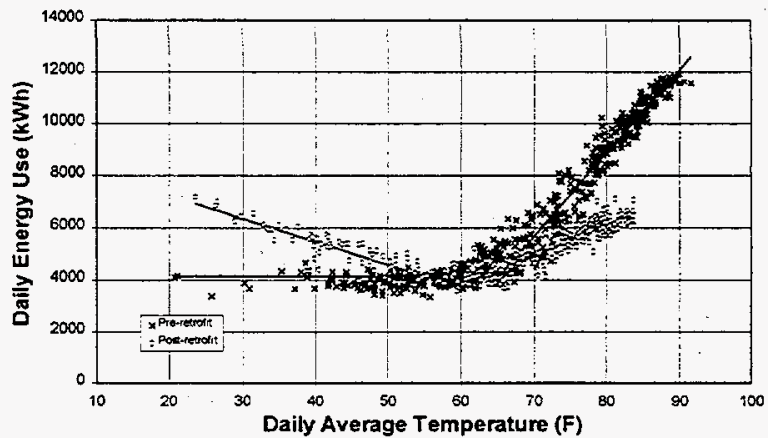

Fig. 2.6. Pre- and post-retrofit daily electrical energy use for the 14 monitored feeders. 
Feeder 12

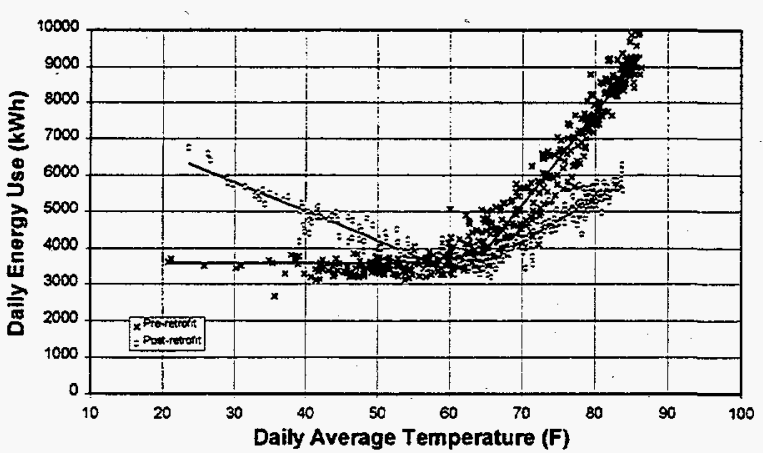

Feeder 14

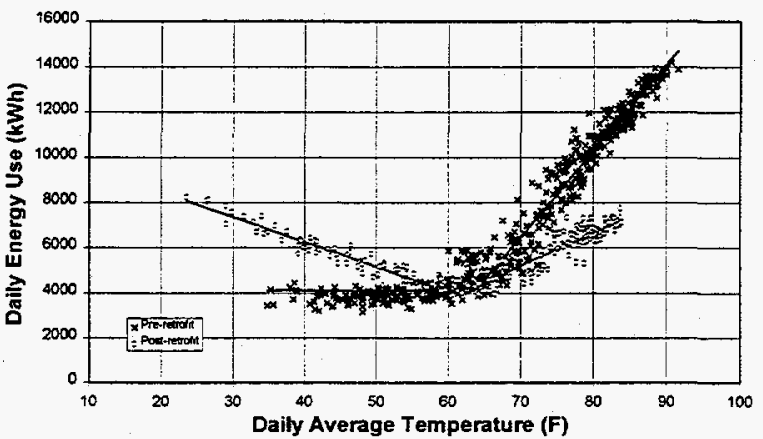

Feeder 16

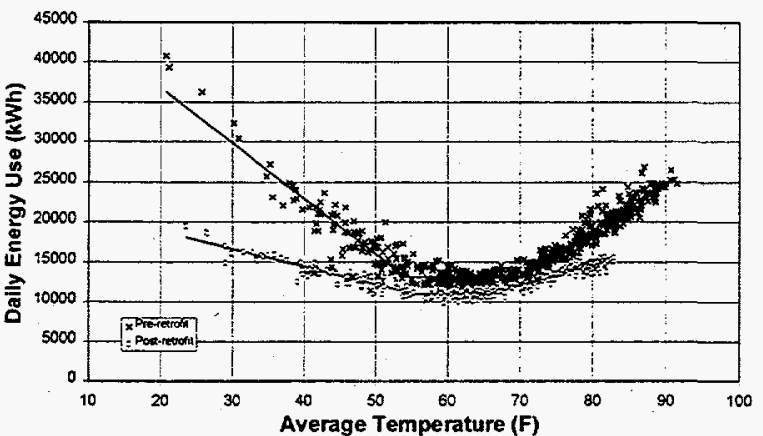

Feeder 13

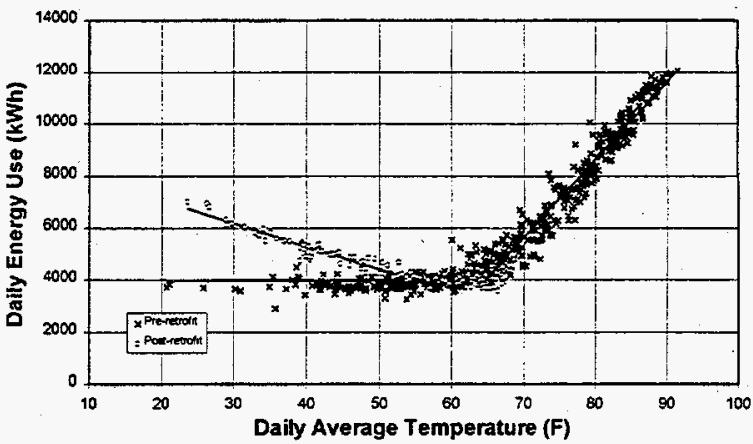

Feeder 15

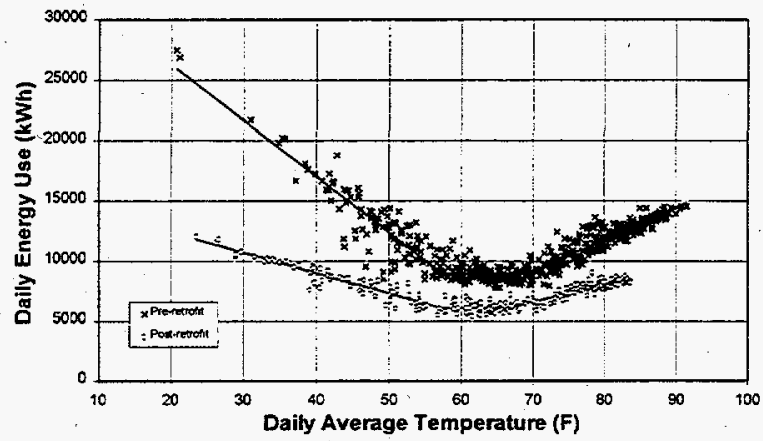

Feeder 17

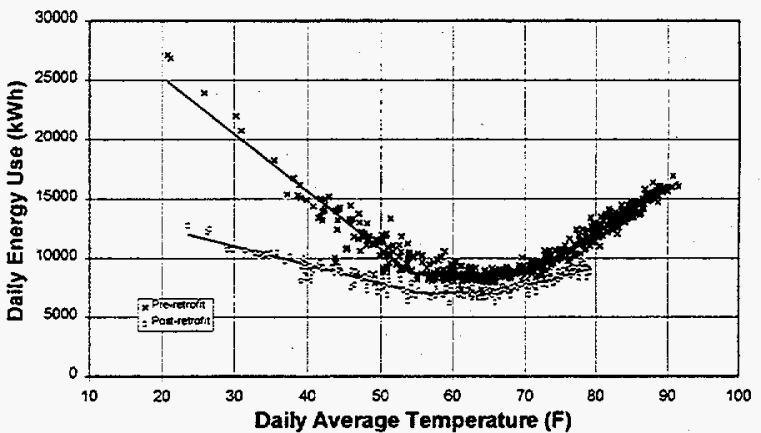

Fig. 2.6. (continued) 
Table 2.2. Constants for five-parameter, dual-changepoint model for each feeder, pre- and post-retrofit

\begin{tabular}{|c|c|c|c|c|c|c|c|c|}
\hline Feeder & Status & $\begin{array}{c}E_{0} \\
(\mathrm{kWh})\end{array}$ & $\begin{array}{c}\mathrm{T}_{\mathrm{h}} \\
\left({ }^{\circ} \mathrm{F}\right)\end{array}$ & $\begin{array}{c}T_{c} \\
\left({ }^{\circ} \mathrm{F}\right)\end{array}$ & $\begin{array}{c}\mathrm{m}_{\mathrm{h}} \\
\left(\mathrm{kWh} /{ }^{\circ} \mathrm{F}\right)\end{array}$ & $\begin{array}{c}\mathrm{m}_{\mathrm{c}} \\
\left(\mathrm{kWh} /{ }^{\circ} \mathrm{F}\right)\end{array}$ & RMSE & $r^{2}$ \\
\hline \multirow[t]{2}{*}{1} & pre & 6597.5 & 56.9 & 69.8 & -200.7 & 187.5 & 405.7 & 0.8938 \\
\hline & post & 4729.6 & 49.1 & 65.7 & -97.6 & 104.7 & 461.7 & 0.7295 \\
\hline \multirow[t]{2}{*}{2} & pre & 59304.4 & 57.0 & 68.5 & -2676.0 & 2053.3 & 4341.8 & 0.9117 \\
\hline & post & 43003.9 & 54.5 & 65.7 & -916.7 & 1132.5 & 2345.4 & 0.9176 \\
\hline \multirow[t]{2}{*}{3} & pre & 2752.3 & 57.5 & 68.1 & -108.8 & 89.3 & 271.1 & 0.8179 \\
\hline & post & 2194.5 & 54.8 & 66.6 & -51.3 & 65.5 & 168.9 & 0.8697 \\
\hline \multirow[t]{2}{*}{4} & pre & 350.9 & 62.4 & 69.1 & -6.6 & 19.7 & 37.9 & 0.8519 \\
\hline & post & 413.4 & 55.4 & 66.3 & -7.5 & 9.2 & 33.6 & 0.7600 \\
\hline \multirow[t]{2}{*}{5} & pre & 3766.5 & $\mathrm{n} / \mathrm{a}$ & 64.2 & $\mathrm{n} / \mathbf{a}$ & 290.2 & 497.9 & 0.9437 \\
\hline & post & 5009.8 & 57.0 & 65.5 & -78.8 & 100.2 & 389.1 & 0.7911 \\
\hline \multirow[t]{2}{*}{6} & pre & 3430.8 & 56.7 & 67.9 & -111.7 & 106.7 & 297.4 & 0.8382 \\
\hline & post & 2280.1 & 53.5 & 65.5 & -53.2 & 57.0 & 207.9 & 0.8104 \\
\hline \multirow[t]{2}{*}{7} & pre & 30197.2 & 57.6 & 69.6 & -1488.0 & 927.3 & 2347.4 & 0.8922 \\
\hline & post & 13708.4 & 57.6 & 65.4 & -355.0 & 365.3 & 1047.3 & 0.8703 \\
\hline \multirow[t]{2}{*}{11} & pre & 4149.7 & $n / a$ & 65.3 & $\mathrm{n} / \mathrm{a}$ & 320.8 & 531.8 & 0.9614 \\
\hline & post & 4212.6 & 53.9 & 64.3 & -89.7 & 121.0 & 365.6 & 0.8493 \\
\hline \multirow[t]{2}{*}{12} & pre & 3594.6 & $\mathrm{n} / \mathrm{a}$ & 63.7 & $\mathrm{n} / \mathrm{a}$ & 253.0 & 427.8 & 0.9553 \\
\hline & post & 3649.1 & 57.0 & 65.4 & -79.8 & 115.4 & 257.7 & 0.9054 \\
\hline \multirow[t]{2}{*}{13} & pre & 3968.9 & $\mathbf{n} / \mathbf{a}$ & 64.3 & $\mathrm{n} / \mathrm{a}$ & 297.1 & 478.3 & 0.9653 \\
\hline & post & 3994.3 & 54.6 & 65.4 & -88.3 & 140.3 & 254.0 & 0.8792 \\
\hline \multirow[t]{2}{*}{14} & pre & 4118.9 & $\mathrm{n} / \mathrm{a}$ & 63.9 & $\mathrm{n} / \mathrm{a}$ & 383.1 & 636.3 & 0.9649 \\
\hline & post & 4435.0 & 56.6 & 64.8 & -109.6 & 144.8 & 359.1 & 0.8985 \\
\hline \multirow[t]{2}{*}{15} & pre & 9000.9 & 57.2 & 69.5 & -465.5 & 264.2 & 898.5 & 0.8729 \\
\hline & post & 6120.3 & 57.0 & 66.3 & -169.7 & 135.6 & 427.6 & 0.8936 \\
\hline \multirow[t]{2}{*}{16} & pre & 13151.1 & 54.1 & 70.0 & -696.1 & 576.4 & 1329.0 & 0.9042 \\
\hline & post & 11000.2 & 55.4 & 65.7 & -221.3 & 250.7 & 630.3 & 0.8972 \\
\hline \multirow[t]{2}{*}{17} & pre & 8736.7 & 54.2 & 70.6 & -483.9 & 368.3 & 747.9 & 0.9246 \\
\hline & post & 7113.0 & 54.9 & 66.1 & -156.0 & 151.6 & 413.9 & 0.8852 \\
\hline
\end{tabular}

\subsubsection{Level-1 Energy Savings}

Once pre- and post-retrofit correlations were developed for each feeder, energy consumption was normalized to a typical meteorological year (TMY). Lufkin, Texas, is the nearest inland location to Fort Polk for which TMY data exists, and the climate is similar to Fort Polk's. The average daily temperature was calculated for each TMY day, and the daily energy consumption for 
each feeder in the pre- and post-retrofit condition was determined using the constants given in Table 2.2. Values for daily energy consumption were then totaled to give annual energy consumption for each feeder. The results of this analysis are shown in Table 2.3.

Since no data were available for Feeders 18 and 19, energy savings were estimated using data from the other all-electric feeders. It was thought initially that energy consumption in these housing units would correlate well with year of construction, but this is not the case. However, Fig. 2.7 shows that there does seem to be a strong relationship between energy consumption per housing unit and the average floor area of the units. These correlations were used to estimate electrical consumption from the housing on Feeders 18 and 19.

Based on this analysis, the total electrical energy consumption in family housing for a typical year at Fort Polk drops from 79.4 million $\mathrm{kWh}$ to 53.6 million $\mathrm{kWh}$, a reduction of about 25.8 million $\mathrm{kWh}$, or $32.5 \%$ of the pre-retrofit consumption. This energy savings results in a reduction in $\mathrm{CO}_{2}$ emissions of 20,900 tons per year, based on emission factors for the south-central region of the United States (Sand et al. 1997). Note that for units that were all-electric in the pre-retrofit period (housing on Feeders $1,2,3,6,7,15,16,17,18$, and 19) the average savings is $35.3 \%$, whereas for units that had natural gas heat before the retrofit (housing on Feeders 5, 11, 12, 13, and 14), the average savings is $16.7 \%$.

A possible shortcoming of the analysis is that the feeders may contain loads other than family housing. All feeders include streetlights, but it is known that Feeder 2, for example, serves both a sewage lift station and the offices of a maintenance contractor. Energy consumption for these nonhousing loads may not be the same for the pre- and post-retrofit periods. This seems almost certain to be the case for Feeder 4, which shows a net increase in energy consumption after the retrofits. The large reduction seen on Feeder 7 may also be due, in part, to a reduction in nonresidential loads. Another possibility is that some of the housing on Feeder 7 was switched to other feeders during the post-retrofit period. (The housing area feeders have switches and interconnections to enable power restoration when the normal configuration requires repair.) These possibilities could explain the relatively low savings on Feeders 3, 16, and 17.

The analysis also assumes that the pre- and post-retrofit periods have the same rate of occupancy. Given the rate of vacancies in the Level-2 housing units, this appears to be the case: the vacancy rate in the pre- and post-retrofit periods is about $10 \%$ per month. However, as discussed in Sect. 2.4 below, occupancy does have a significant impact on electrical energy use in family housing. Given the method of monitoring and verification used in the Fort Polk ESPC, periods with a vacancy rate higher than $10 \%$ will appear to save additional energy; in fact this apparent "savings" is due to the unoccupied housing units.

\section{Natural Gas Savings}

Unlike electrical energy use, which is submetered at 16 different locations throughout the family housing areas, natural gas consumption at Fort Polk is measured by a single meter for the entire base, of which family housing is one part. Natural gas usage in family housing is determined by a formula that allocates energy use to various administrative accounts. The only data available to us were the 55 months of historical family housing natural gas allocations provided in the contract. This data is reproduced in Table 2.4. In Fig. 2.8, the adjusted natural gas consumption per month is plotted against heating degree days per month. After eliminating the outliers (data for April 1990, July 1992, and January 1993 appear to be in error), linear regression gives the following formula for monthly natural gas consumption:

$$
E=(5.013737 \times X+1150.209) \times(n / 30),
$$


Table 2.3. Pre- and post-retrofit TMY energy use by feeder for Level-1 data

\begin{tabular}{|c|c|c|c|c|c|c|c|c|c|c|c|}
\hline & \multicolumn{3}{|c|}{ Pre-Retrofit } & \multicolumn{3}{|c|}{ Post-Retrofit } & \multicolumn{5}{|c|}{ Savings } \\
\hline & $\begin{array}{c}\text { Annual } \\
\mathrm{kWh}\end{array}$ & $\begin{array}{l}\text { Annual } \\
\mathrm{kWh} / \mathrm{ft}^{2}\end{array}$ & $\begin{array}{c}\text { Daily } \\
\text { kWh/unit }\end{array}$ & $\begin{array}{c}\text { Annual } \\
\mathrm{kWh}\end{array}$ & $\begin{array}{l}\text { Annual } \\
\mathrm{kWh} / \mathrm{ft}^{2}\end{array}$ & $\begin{array}{c}\text { Daily } \\
\text { kWh/unit }\end{array}$ & $\begin{array}{l}\text { Total } \\
\text { kWh }\end{array}$ & $\begin{array}{l}\text { Percent } \\
\text { savings }\end{array}$ & $\begin{array}{l}\text { kWh per } \\
\text { residence }\end{array}$ & $\begin{array}{c}\text { kWh per } \\
\mathrm{ft}^{2}\end{array}$ & $\begin{array}{l}\mathrm{kWh} / \text { ton } \\
\text { installed }\end{array}$ \\
\hline 1 & 2873622 & 12.43 & 39.36 & 2001455 & 8.66 & 27.42 & 872167 & $30.4 \%$ & 4361 & 3.77 & 2907 \\
\hline 2 & 27722779 & 15.92 & 62.26 & 18957249 & 10.89 & 42.57 & 8765530 & $31.6 \%$ & 7185 & 5.03 & 4308 \\
\hline 3 & 1273011 & 16.98 & 87.19 & 977428 & 13.04 & 66.95 & 295583 & $23.2 \%$ & 7390 & 3.94 & 3672 \\
\hline 4 & 170119 & 14.17 & 77.68 & 176601 & 14.71 & 80.64 & -6482 & $-3.8 \%$ & -1080 & -0.54 & -540 \\
\hline 5 & 1299381 & 8.69 & 35.60 & 1301949 & 8.71 & 35.67 & -2568 & $-0.2 \%$ & -26 & -0.02 & -14 \\
\hline 6 & 1551831 & 14.27 & 53.14 & 999095 & 9.19 & 34.22 & 552736 & $35.6 \%$ & 6909 & 5.08 & 4252 \\
\hline 7 & 13918902 & 15.35 & 66.78 & 6217805 & 6.86 & 29.83 & 7701097 & $55.3 \%$ & 13487 & 8.49 & 7799 \\
\hline 11 & 2278945 & 10.74 & 41.08 & 1912352 & 9.01 & 34.47 & 366593 & $16.1 \%$ & 2412 & 1.73 & 1363 \\
\hline 12 & 2002139 & 10.82 & 38.63 & 1678039 & 9.07 & 32.38 & 324100 & $16.2 \%$ & 2282 & 1.75 & 1334 \\
\hline 13 & 2216799 & 10.97 & 37.49 & 1852790 & 9.16 & 31.33 & 364009 & $16.4 \%$ & 2247 & 1.80 & 1374 \\
\hline 14 & 2530362 & 10.12 & 34.66 & 2076470 & 8.30 & 28.44 & 453892 & $17.9 \%$ & 2269 & 1.81 & 1319 \\
\hline 15 & 4137766 & 14.95 & 56.68 & 2687859 & 9.71 & 36.82 & 1449907 & $35.0 \%$ & 7250 & 5.24 & 4833 \\
\hline 16 & 6112001 & 15.76 & 54.72 & 4763891 & 12.29 & 42.65 & 1348110 & $22.1 \%$ & 4406 & 3.48 & 2937 \\
\hline 17 & 4015635 & 11.41 & 40.01 & 3049713 & 8.67 & 30.38 & 965922 & $24.1 \%$ & 3512 & 2.75 & 2339 \\
\hline 18 & 3466581 & 14.72 & 56.53 & 2330146 & 9.89 & 38.00 & 1136435 & $32.8 \%$ & 6764 & 4.82 & 4155 \\
\hline 19 & 3843615 & 14.88 & 58.18 & 2603741 & 10.08 & 39.41 & 1239874 & $32.3 \%$ & 6850 & 4.80 & 4246 \\
\hline TOTAL (TMY): & 79413489 & 14.22 & 54.35 & 53586583 & 9.60 & 36.68 & 25826906 & $32.5 \%$ & 6452 & 4.62 & 3917 \\
\hline
\end{tabular}

Notes:

1. Calculations based on typical meteorological year for Lufkin, Texas, which is the nearest location to Fort Polk with complete TMY data.

2. Average family housing electrical use for 1989-1992 was $81.4 \mathrm{MWh} / \mathrm{yr}$, some $2.5 \%$ higher than the 1994-1995 baseline normalized to Lufkin TMY data.

3. Percent savings varies by feeder because of a number of factors:

- Type of HVAC equipment replaced (all-electric or gas/electric)

- Retrofits installed (e.g., not all housing received additional attic insulation)

- Existence of nonhousing loads on some feeders; see note (4).

4. Meter 2 includes a sewage lift station and the offices of a maintenance contractor; Feeder 4 also likely contains significant nonhousing loads

5. No family housing on Feeders 8 and 10; meter for Feeder 7 includes Feeder 9

6. Pre- and post-retrofit energy use are estimated for Feeders 18 and 19. 


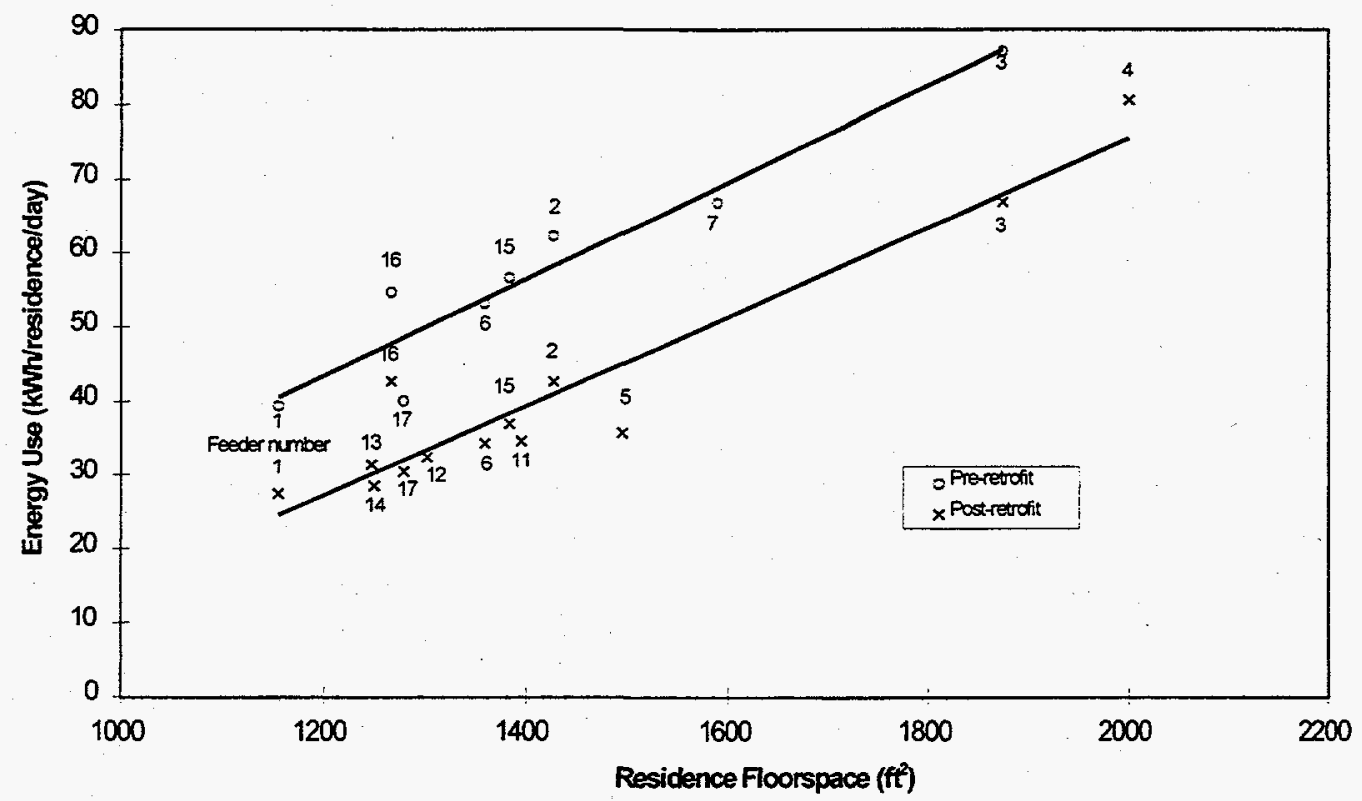

Fig. 2.7. Annual electrical use on feeders serving all-electric housing, pre- and post-retrofit.

Table 2.4. Historical natural gas use in Fort Polk family housing

\begin{tabular}{lccccc}
\hline Month & $\begin{array}{c}\text { Heating } \\
\text { degree days }\end{array}$ & $\begin{array}{c}\text { Gas use } \\
\left(1000 \mathrm{ft}^{3}\right)\end{array}$ & Month & $\begin{array}{c}\text { Heating } \\
\text { degree days }\end{array}$ & $\begin{array}{c}\text { Gas use } \\
\left(1000 \mathrm{ft}^{3}\right)\end{array}$ \\
\hline $08 / 88$ & 0 & 893 & $01 / 91$ & 548 & 5304 \\
$09 / 88$ & 0 & 1258 & $02 / 91$ & 304 & 2544 \\
$10 / 88$ & 39 & 1474 & $03 / 91$ & 189 & 2681 \\
$11 / 88$ & 152 & 2309 & $04 / 91$ & 18 & 1474 \\
$12 / 88$ & 420 & 3227 & $05 / 91$ & 4 & 1140 \\
$01 / 89$ & 333 & 2847 & $06 / 91$ & 0 & 1191 \\
$02 / 89$ & 435 & 3191 & $07 / 91$ & 0 & 1192 \\
$03 / 89$ & 300 & 3421 & $08 / 91$ & 0 & 1452 \\
$04 / 89$ & 76 & 2465 & $09 / 91$ & 1 & 1199 \\
$05 / 89$ & 0 & 1495 & $10 / 91$ & 26 & 1199 \\
$06 / 89$ & 0 & 211 & $11 / 91$ & 384 & 3173 \\
$07 / 89$ & 0 & 815 & $12 / 91$ & 358 & 2764 \\
$08 / 89$ & 0 & 789 & $01 / 92$ & 520 & 3638 \\
$09 / 89$ & 12 & 1360 & $02 / 92$ & 309 & 2244 \\
$10 / 89$ & 67 & 1424 & $03 / 92$ & 161 & 2244 \\
$11 / 89$ & 205 & 2086 & $04 / 92$ & 73 & 1418 \\
$12 / 89$ & 688 & 4268 & $05 / 92$ & 20 & 1139 \\
$01 / 90$ & 339 & 2361 & $06 / 92$ & 0 & 1394 \\
$02 / 90$ & 195 & 3117 & $07 / 92$ & 0 & 3436 \\
$03 / 90$ & 179 & 1520 & $08 / 92$ & 0 & 583 \\
$04 / 90$ & 80 & 40 & $09 / 92$ & 27 & 943 \\
$05 / 90$ & 5 & 1511 & $10 / 92$ & 17 & 1480 \\
$06 / 90$ & 0 & 1502 & $11 / 92$ & 367 & 2497 \\
$07 / 90$ & 0 & 948 & $12 / 92$ & 380 & 4633 \\
$08 / 90$ & 0 & 978 & $01 / 93$ & 476 & 981 \\
$09 / 90$ & 5 & 1193 & $02 / 93$ & 377 & 2428 \\
$10 / 90$ & 105 & 1483 & & & \\
$11 / 90$ & 191 & 2125 & & & \\
$12 / 90$ & 439 & 2125 & & & \\
\hline & & & & & \\
\end{tabular}




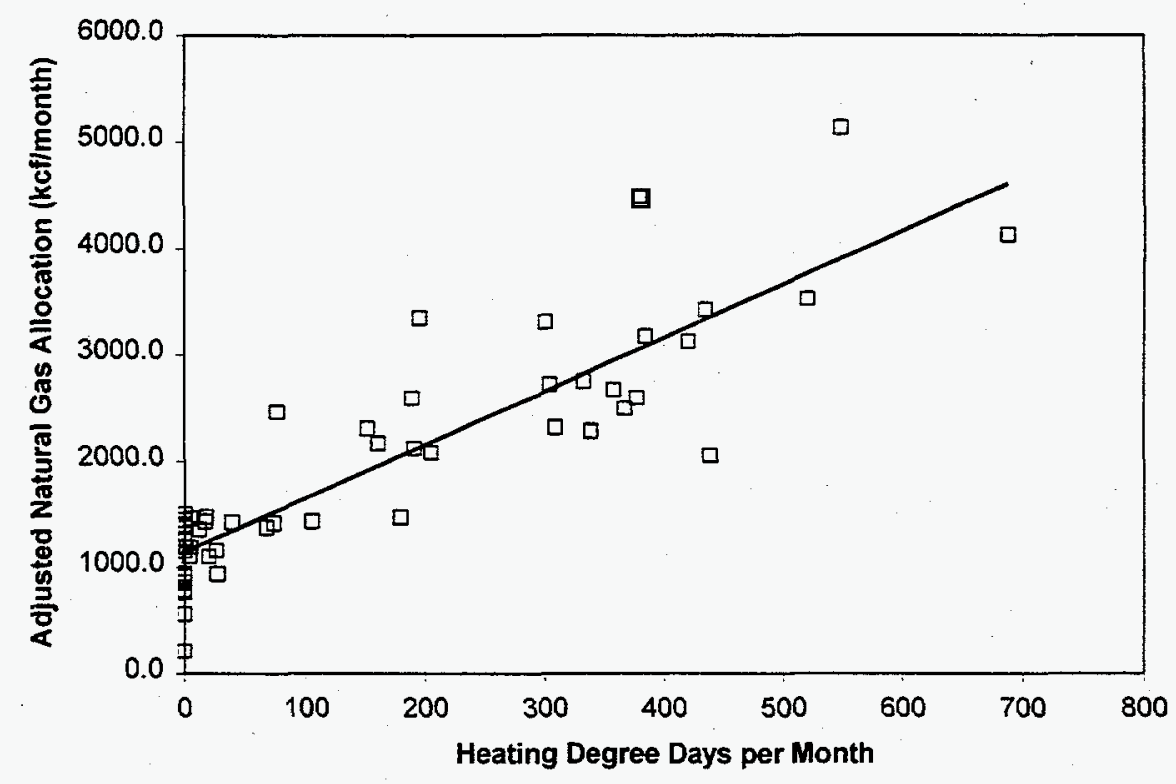

Fig. 2.8. Natural gas consumption at Fort Polk based on historical data.

where $\mathrm{E}$ is the gas consumption in thousand cubic feet, $\mathrm{X}$ is the number of heating degree days (base $65^{\circ} \mathrm{F}$ ) per month, and $\mathrm{n}$ is the number of days per month. The $\mathrm{r}^{2}$ of the regression line is 0.78. The regression line was used to estimate the natural gas savings which would result from the retrofits, assuming the historical allocations are correct. Using the TMY for Lufkin, Texas, the regression line predicts a pre-retrofit natural gas consumption in family housing of $23,588 \mathrm{kcf}$ in a typical year. Assuming a heating value of 1000 Btu per cubic foot, this is 235,880 therms.

For the purposes of the performance contract, monthly natural gas savings are determined by subtracting the actual post-retrofit natural gas consumption from a weather-corrected baseline consumption formula,

$$
E=(3.93279 \times X+1294.785) \times(n / 30),
$$

where the variables are the same as in Eq. (2.3). Although this is different from Eq. (2.3), using the Lufkin TMY, the contract baseline predicts an annual natural gas consumption of 232,780 therms. For comparison, the average annual allocation for January 1989 through December 1992 from Table 2.4 is 235,590 therms.

Prior to the retrofits, 760 housing units at Fort Polk used natural gas for space heating, water heating, and cooking. After the retrofits, only the gas-fired ranges and ovens remain. One published value for gas use in ranges and ovens is 60 therms per year (Huang et al. 1987). The Energy Information Administration, on the other hand, reports a national average of 77 therms per year, but this includes other appliances such as clothes dryers, outdoor gas grills, hot tubs, etc. (EIA 1995). Based on these figures we decided to use the lower estimate. We assumed that after the retrofits, gas-fired ranges and ovens in the 760 residences accounted for 45,600 therms of natural gas per year. The annual post-retrofit gas use will then be 45,600 therms. If the allocation formula is correct, the retrofits will save about 190,000 therms of natural gas per year.

Another way to estimate the natural gas savings is to compare pre-retrofit electrical energy use in the gas/electric residences to the all-electric residences. Based on the data in Table 2.3, in a typical pre-retrofit year, gas/electric residences used about $10.38 \mathrm{kWh} / \mathrm{ft}^{2}$, while all-electric 
residences used $15.06 \mathrm{kWh} / \mathrm{ft}^{2}$. All things being equal, the difference of $4.68 \mathrm{kWh} / \mathrm{ft}^{2}$ should represent the annual electrical energy use per square foot for space heating, water heating and cooking in the all-electric residences. EIA (1995) reports an average use of $458 \mathrm{kWh}$ per household for electrical oven/range combinations. Since there are 3243 all-electric residences with a total of $4,577,669 \mathrm{ft}^{2}$, the electric oven/ranges account for about $0.32 \mathrm{kWh} / \mathrm{ft}^{2}$. Thus we estimate that prior to the retrofits, water heating and space heating loads in the all-electric residences accounted for $4.36 \mathrm{kWh} / \mathrm{ft}^{2}$ of electrical use. A conservative assumption is that the gas/electric residences have approximately the same loads as the all-electric housing. (Actually, as the oldest housing at Fort Polk, the gas/electric housing would tend to have higher loads than the all-electric housing.) Multiplying $4.36 \mathrm{kWh} / \mathrm{ft}^{2}$ by the total floor area of the 760 gas/electric residences $\left(1,006,948 \mathrm{ft}^{2}\right)$ gives $4,390,293 \mathrm{kWh} / \mathrm{yr}$. Converting this into natural gas requires some additional assumptions.

First of all, based on our analysis of the Level-3 all-electric sites, we estimate that each gas/electric residence would have used $3826 \mathrm{kWh} / \mathrm{yr}$ for water heating prior to the retrofits, had electric water heaters been present. Multiplying this by the number of gas/electric residences gives $2,907,760 \mathrm{kWh} / \mathrm{yr}$. To convert this number to natural gas we assume an energy factor of 0.9 for an electric water heater and an energy factor of 0.55 for a gas water heater. Then the annual pre-retrofit gas use for water heating in the 760 gas/electric residences was approximately:

$$
(2,907,760 \mathrm{kWh}) \cdot(0.9 / 0.55) \cdot(3413 \mathrm{Btu} / \mathrm{kWh}) \cdot(1 \text { therm } / 100,000 \mathrm{Btu})=162,396 \text { therm } .
$$

Subtracting the energy used for hot water heating from the total leaves $1,482,533 \mathrm{kWh}$ per year for heating. Assuming that the coefficient of performance (COP) of a heat pump in heating mode is 1.4 , and for the gas furnace the efficiency is 0.7 , the annual gas use for space heating in the 760 gas/electric residences is approximately:

$$
(1,482,533 \mathrm{kWh}) \cdot(1.4 / 0.7) \cdot(3413 \mathrm{Btu} / \mathrm{kWh}) \cdot(1 \text { therm } / 100000 \mathrm{Btu})=101,198 \text { therm. }
$$

Based on this analysis, a conservative estimate of the total annual natural gas use for heating and water heating is approximately 263,000 therms. Since this is some $38 \%$ higher than the gas use for space heating and water heating we would predict based on historical natural gas allocations, we conclude that the allocation formula underestimates the natural gas use in family housing. A more reasonable estimate is that the ESPC results in an annual natural gas savings of about 260,000 therms. This savings will also reduce $\mathrm{CO}_{2}$ emissions by about 1500 tons per year, based on emissions for natural gas furnaces (L'Ecuyer et al. 1993).

\subsubsection{Level-2 Energy Savings}

In addition to the feeder-level data, 15-minute-interval data on energy consumption were collected for a sample of 42 housing units ( 1 single-family residence and 41 apartments) in 13 separate buildings. Physical characteristics of these buildings are presented in Table 2.5. Given the high degree of variability in data from individual apartments in multiple-family buildings, we decided to develop energy-use models for entire buildings rather than for individual apartments by totaling the daily energy consumption for each apartment within each monitored building. Prior to the retrofits, all of the Level-2 sites were heated by electrically driven air-source heat pumps. Thus for each of the buildings, pre-retrofit daily electrical energy use was correlated to daily average temperature assuming a five-parameter, dual-changepoint model. A separate dualchangepoint correlation of daily energy use vs daily average temperature was then developed for the post-retrofit data. The parameters for the pre- and post-retrofit models for each building are presented in Table 2.6. 
As in the Level-1 analysis, pre- and post-retrofit energy consumption from the Level-2 sites were normalized to the Lufkin, Texas, typical meteorological year. For each day in the TMY, the average daily temperature was substituted into the corresponding dual-changepoint model to determine energy use on that day. Daily energy use was then summed over the 365 days to calculate TMY electrical energy use, pre- and post-retrofit, for each building. The results of these calculations are presented in Table 2.7.

The Level-2 buildings are a random sample of the family housing population, and as such the energy savings for the sample should be representative of the savings achieved across the entire population. According to FEMP Measurement and Verification Guidelines (issued by DOE's Office of Federal Energy Management Programs), the sample size $n$ required to estimate savings for the entire population can be determined from the formula

$$
n=\frac{z^{2} c v(y)^{2}}{p^{2}}
$$

where $\mathrm{z}$ is the random deviate corresponding to the degree of confidence of the estimate, $\operatorname{cv}(\mathrm{y})$ is the coefficient of variation across the population, and $p$ is the precision level (DOE 1996a). FEMP recommends a value of $z=1.282$ (corresponding to an $80 \%$ degree of confidence) and a precision level of $20 \%$. Assuming a coefficient of variation of 0.5 , the required sample size is 11 , which indicates that the Level- 2 sample of 13 buildings is adequate to characterize the entire population.

From Table 2.7, the total annual energy savings for the Level-2 sample of 13 buildings is $308,016 \mathrm{kwh}$. This is an average energy savings per building for the Level-2 sample of 23.69 MWh per year (since the standard deviation is $13.32 \mathrm{MWh}$, the coefficient of variation is 0.56 ). Thus the Level-2 sample indicates that the total savings for the 982 buildings which were allelectric prior to the retrofits should be about $23,260 \mathrm{MWh}$. From Table 2.3, the feeder-level savings estimate for housing which was all-electric prior to the retrofits (Feeders $1,2,3,6,7,15$, $16,17,18$ and 19) is $24,330 \mathrm{MWh}$, or $35.3 \%$. The Level-2 sample predicts the TMY energy savings calculated from the feeder-level data to within $5 \%$.

The foregoing analysis assumes that energy savings are normally distributed across the population. However, it is known that energy savings is related to building area. Figure 2.9 is a plot of energy savings vs floor area for the 13 Level-2 buildings. Linear regression of the data indicates that the TMY energy savings per building in MWh can be estimated by $0.006305 \times$ $A-3.4627$, where $A$ is the building area in square feet. The total area of the 982 buildings that were all-electric in the pre-retrofit is $4,348,509 \mathrm{ft}^{2}$; thus, the linear correlation predicts a TMY energy savings of $0.006305 \times 4,348,509-982 \times 3.4627=24,016,135 \mathrm{kWh}$, or $24,016 \mathrm{MWh}$ and $34.8 \%$ of pre-retrofit energy consumption. This is just $1.3 \%$ lower than the value of $24,330 \mathrm{MWh}$ obtained from the feeder-level data. The difference between the two estimates may be explained by the fact that power from the electrical feeders is transformed to $220 \mathrm{~V}$ for the building service entrances. The lower power consumption after retrofit reduces the load on the transformers, thereby reducing their losses. Since this savings is not measured in building-level data, it is expected that savings measured at the feeder level will be somewhat higher (Barnes et al. 1996). 
Table 2.5. Characteristics of the 12 Level-2 buildings analyzed

\begin{tabular}{ccccccc}
\hline Building & Feeder & $\begin{array}{c}\text { Number of } \\
\text { units }\end{array}$ & $\begin{array}{c}\text { Total } \\
\mathrm{ft}^{2}\end{array}$ & $\begin{array}{c}\mathrm{ft}^{2} / \\
\text { unit }\end{array}$ & $\begin{array}{c}\text { Installed } \\
\text { tons }\end{array}$ & $\begin{array}{c}\text { Const. } \\
\text { vintage }\end{array}$ \\
\hline 209 & 7 & 4 & 7016 & 1754 & 6 & 1977 \\
210 & 6 & 4 & 4696 & 1174 & 6 & 1977 \\
211 & 3 & 1 & 1794 & 1794 & 2 & 1976 \\
213 & 1 & 4 & 4632 & 1158 & 6 & 1981 \\
214 & 2 & 2 & 3456 & 1728 & 4 & 1976 \\
215 & 2 & 4 & 4292 & 1073 & 6 & 1976 \\
216 & 2 & 2 & 3396 & 1698 & 4 & 1976 \\
217 & 2 & 2 & 3728 & 1864 & 4 & 1976 \\
218 & 2 & 4 & 4292 & 1073 & 6 & 1976 \\
219 & 2 & 4 & 4292 & 1073 & 6 & 1976 \\
220 & 2 & 5 & 6282 & 1256 & 7.5 & 1980 \\
221 & 16 & 4 & 5576 & 1394 & 6 & 1988 \\
223 & 19 & 2 & 2542 & 1271 & 3 & 1988 \\
\hline
\end{tabular}

Table 2.6. Constants for five-parameter dual-changepoint models for the 12 Level-2 buildings

\begin{tabular}{rlrrrrrrr}
\hline Building & Status & $\begin{array}{c}\mathrm{E}_{0} \\
(\mathrm{kWh})\end{array}$ & $\begin{array}{c}\mathrm{T}_{\mathrm{h}} \\
\left({ }^{\circ} \mathrm{F}\right)\end{array}$ & $\begin{array}{c}\mathrm{T}_{\mathrm{c}} \\
\left({ }^{\circ} \mathrm{F}\right)\end{array}$ & $\begin{array}{c}\mathrm{m}_{\mathrm{h}} \\
\left(\mathrm{kWh} /{ }^{\circ} \mathrm{F}\right)\end{array}$ & $\begin{array}{c}\mathrm{m}_{\mathrm{c}} \\
\left(\mathrm{kWh} /{ }^{\circ} \mathrm{F}\right)\end{array}$ & $\mathrm{RMSE}$ & $\mathrm{r}^{2}$ \\
\hline 209 & pre & 228.5 & 59.7 & 68.1 & -12.38 & 9.73 & 54.0 & 0.7158 \\
& post & 174.9 & 56.7 & 69.1 & -5.51 & 4.91 & 38.8 & 0.5181 \\
210 & pre & 142.0 & 51.4 & 60.4 & -4.79 & 3.78 & 26.5 & 0.6320 \\
& post & 67.7 & 51.8 & 64.7 & -2.10 & 2.61 & 22.7 & 0.4546 \\
211 & pre & 58.0 & 59.8 & 67.1 & -2.16 & 2.01 & 19.9 & 0.3838 \\
& post & 41.5 & 55.9 & 68.3 & -1.22 & 1.47 & 12.0 & 0.4122 \\
213 & pre & 133.7 & 50.1 & 74.4 & -10.07 & 3.96 & 19.8 & 0.5062 \\
& post & 85.5 & 55.6 & 61.2 & -1.49 & 1.46 & 20.3 & 0.2696 \\
214 & pre & 90.2 & 51.3 & 54.3 & -5.56 & 3.46 & 23.2 & 0.7045 \\
& post & 99.4 & 51.7 & 52.9 & -0.53 & 0.10 & 15.5 & 0.3186 \\
215 & pre & 208.2 & 58.1 & 74.9 & -5.03 & 9.28 & 41.2 & 0.5269 \\
& post & 91.4 & 58.3 & 66.1 & -1.87 & 6.42 & 25.5 & 0.7171 \\
216 & pre & 91.3 & 61.3 & 70.9 & -7.47 & 4.43 & 26.3 & 0.6635 \\
& post & 82.0 & 55.8 & 57.8 & -1.77 & 2.17 & 17.0 & 0.5594 \\
217 & pre & 122.5 & 52.2 & 68.9 & -7.18 & 3.90 & 33.3 & 0.4951 \\
& post & 72.3 & 55.8 & 73.2 & -2.38 & 3.44 & 23.7 & 0.3679 \\
218 & pre & 155.4 & 56.4 & 68.8 & -6.28 & 6.23 & 33.7 & 0.6089 \\
& post & 146.0 & 56.6 & 66.3 & -1.10 & 3.86 & 22.0 & 0.5577 \\
219 & pre & 181.1 & 61.4 & 66.2 & -6.01 & 4.45 & 36.7 & 0.4770 \\
& post & 103.6 & 56.7 & 66.9 & -2.09 & 0.08 & 19.4 & 0.3454 \\
220 & pre & 166.3 & 52.8 & 68.4 & -8.41 & 5.77 & 29.2 & 0.6343 \\
& post & 94.8 & 44.7 & 65.2 & -4.66 & 3.46 & 23.4 & 0.5357 \\
221 & pre & 165.8 & 54.2 & 66.2 & -7.42 & 4.89 & 40.3 & 0.4456 \\
& post & 110.2 & 55.6 & 73.1 & -3.69 & 6.82 & 25.7 & 0.5544 \\
& pre & 72.6 & 60.2 & 75.8 & -5.15 & 7.13 & 28.5 & 0.5581 \\
& post & 73.2 & 52.6 & 67.9 & -1.44 & 2.33 & 17.1 & 0.3282 \\
\hline
\end{tabular}


Table 2.7. Pre- and post-retrofit TMY energy use for the 13 Level-2 buildings

\begin{tabular}{|c|c|c|c|c|c|c|c|c|c|c|c|}
\hline \multirow[b]{2}{*}{ Building } & \multicolumn{3}{|c|}{ Pre-Retrofit } & \multicolumn{3}{|c|}{ Post-Retrofit } & \multicolumn{5}{|c|}{ Projected Savings } \\
\hline & $\begin{array}{c}\text { Annual } \\
\mathrm{kWh}\end{array}$ & $\begin{array}{l}\text { Annual } \\
\mathrm{kWh} / \mathrm{ft}^{2}\end{array}$ & $\begin{array}{c}\text { Daily } \\
\mathrm{kWh} / \text { uni } \\
\mathrm{t}\end{array}$ & $\begin{array}{c}\text { Annual } \\
\mathrm{kWh}\end{array}$ & $\begin{array}{l}\text { Annual } \\
\mathrm{kWh} / \mathrm{ft}^{2}\end{array}$ & $\begin{array}{c}\text { Daily } \\
\mathrm{kWh} / \mathrm{unit}\end{array}$ & $\begin{array}{l}\text { Annual } \\
\mathrm{kWh}\end{array}$ & $\begin{array}{c}\text { Annual } \\
\mathrm{kWh} / \mathrm{unit}\end{array}$ & $\begin{array}{l}\text { Annual } \\
\mathrm{kWh} / \mathrm{ft}^{2}\end{array}$ & $\begin{array}{c}\text { Annual } \\
\mathrm{kWh} / \text { ton }\end{array}$ & $\begin{array}{l}\text { Percent } \\
\text { savings }\end{array}$ \\
\hline 209 & 116,223 & 16.57 & 79.60 & 76,836 & 10.95 & 52.63 & 39,387 & 9,847 & 5.61 & 6,565 & $33.9 \%$ \\
\hline 210 & 67,541 & 14.38 & 46.26 & 32,347 & 6.89 & 22.16 & 35,194 & 8,799 & 7.49 & 5,866 & $52.1 \%$ \\
\hline 211 & 27,865 & 15.53 & 76.34 & 18,776 & 10.47 & 51.44 & 9,089 & 9,089 & 5.07 & 4,544 & $32.6 \%$ \\
\hline 213 & 55,895 & 12.07 & 38.28 & 37,289 & 8.05 & 25.54 & 18,607 & 4,652 & 4.02 & 3,101 & $33.3 \%$ \\
\hline 214 & 53,435 & 15.46 & 73.20 & 37,121 & 10.74 & 50.85 & 16,314 & 8,157 & 4.72 & 4,078 & $30.5 \%$ \\
\hline 215 & 87,721 & 20.44 & 60.08 & 49,484 & 11.53 & 33.89 & 38,237 & 9,559 & 8.91 & 6,373 & $43.6 \%$ \\
\hline 216 & 49,545 & 14.59 & 67.87 & 40,463 & 11.91 & 55.43 & 9,083 & 4,541 & 2.67 & 2,271 & $18.3 \%$ \\
\hline 217 & 55,045 & 14.77 & 75.40 & 31,548 & 8.46 & 43.22 & 23,496 & 11,748 & 6.30 & 5,874 & $42.7 \%$ \\
\hline 218 & 72,639 & 16.92 & 49.75 & 62,651 & 14.60 & 42.91 & 9,988 & 2,497 & 2.33 & 1,665 & $13.8 \%$ \\
\hline 219 & 84,333 & 19.65 & 57.76 & 39,891 & 9.29 & 27.32 & 44,443 & 11,111 & 10.35 & 7,407 & $52.7 \%$ \\
\hline 220 & 75,753 & 12.06 & 41.51 & 43,691 & 6.95 & 23.94 & 32,062 & 6,412 & 5.10 & 4,275 & $42.3 \%$ \\
\hline 221 & 76,293 & 13.68 & 52.26 & 49,597 & 8.89 & 33.97 & 26,697 & 6,674 & 4.79 & 4,449 & $35.0 \%$ \\
\hline 223 & $37 ; 277$ & 14.66 & 51.06 & 31,856 & 12.53 & 43.64 & 5,420 & 2,710 & 2.13 & 1,807 & $14.5 \%$ \\
\hline Total: & 859,565 & 15.35 & 56.07 & 551,549 & 9.85 & 35.98 & 308,016 & 7,334 & $\mathbf{5 . 5 0}$ & 4632 & $35.8 \%$ \\
\hline
\end{tabular}




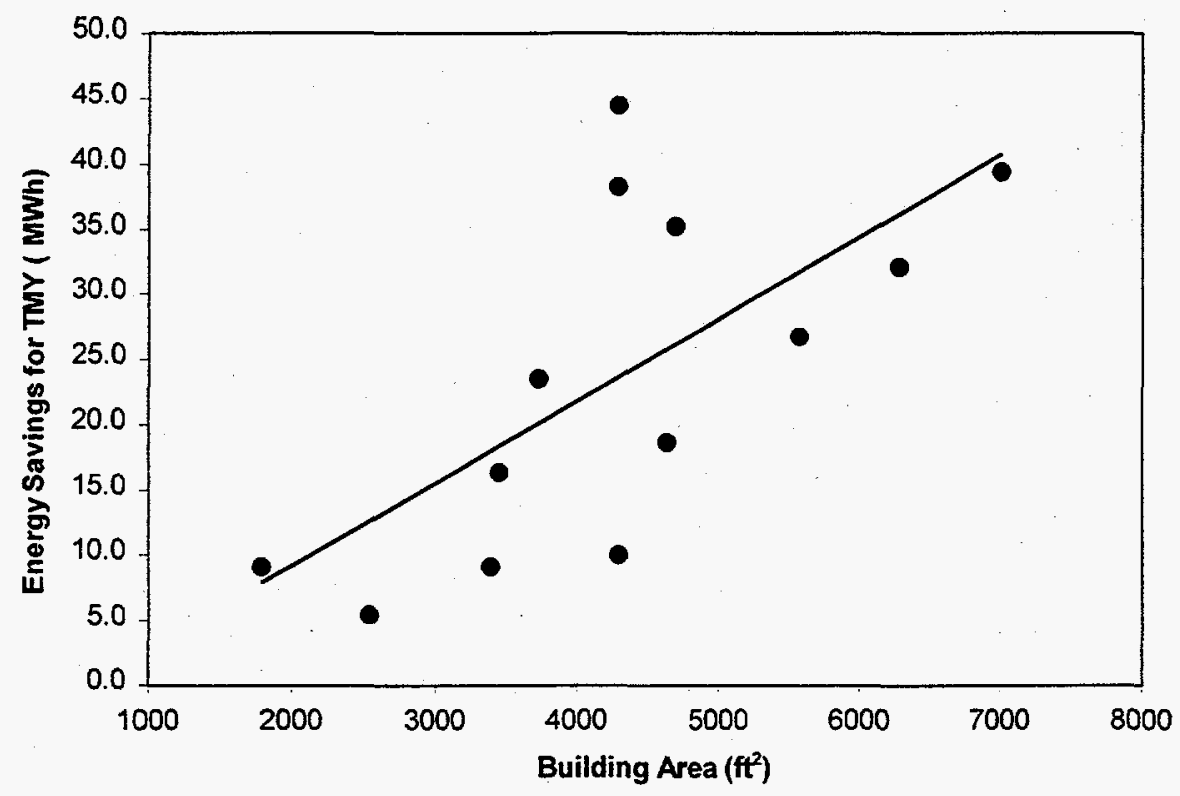

Fig. 2.9. TMY energy savings vs building floor area for the 13 Level-2 buildings.

\subsubsection{Energy Savings by Energy Conservation Measure}

With the output from the calibrated TRNSYS model of one feeder (Feeder 1) supplying 200 apartments in 46 buildings, it is possible to determine the relative impact of each of the four energy conservation measures. (This model is discussed in further detail in Sect. 4.) Table 2.8 presents a breakdown of the pre- and post-retrofit average energy use per apartment per day for space conditioning, water heating, and lighting and appliances, based on the simulation of the entire feeder. The results, shown in Fig. 2.10, indicate that, due to the retrofits, energy use for lighting and other appliances was reduced by $18 \%$, energy use for water heating was reduced by $71 \%$, and energy use for space conditioning was reduced by $27 \%$. Figure 2.11 shows the proportion of total energy savings contributed by each measure: the geothermal heat pumps (including desuperheaters) were responsible for $66 \%$ of total energy savings, lighting retrofits for $29 \%$, and low-flow shower heads for $5 \%$. Although the housing on this feeder was constructed in 1981 , no additional attic insulation was installed as part of the ESPC project because in the ESCO's judgement it would not have been cost-effective.

There are interactions between the various conservation measures, though their effect in this case is insignificant. The analysis of these interactions is discussed in Sect. 4.4.2.

Table 2.8. Average daily energy use per apartment per day (in kWh) for the modeled feeder

\begin{tabular}{lcccc}
\hline & $\begin{array}{c}\text { Space } \\
\text { conditioning }\end{array}$ & $\begin{array}{c}\text { Water } \\
\text { heating }\end{array}$ & $\begin{array}{c}\text { Lighting/ } \\
\text { appliance }\end{array}$ & Total \\
\hline Pre-retrofit & 13.81 & 7.08 & 20.52 & 41.40 \\
Post-retrofit & 10.03 & 2.05 & 16.82 & 28.90 \\
\hline
\end{tabular}




\subsubsection{ESCO-Metered Data}

As part of its own efforts to document pre- and post-retrofit energy use, the ESCO manually recorded data from existing kilowatt-hour meters on a number of housing units at Fort Polk. Two sets of meter readings were obtained from the ESCO, one from March 1995 through November 1996 covering 50 units, and another from October 1995 through November 1996 covering an additional 95 units. Beginning in October 1995, the meters were read on the same day of the month for both sets, allowing them to be combined into a single set from that date on. Since the retrofit date for each unit was known, the combined readings were then divided into pre- and postretrofit sets.

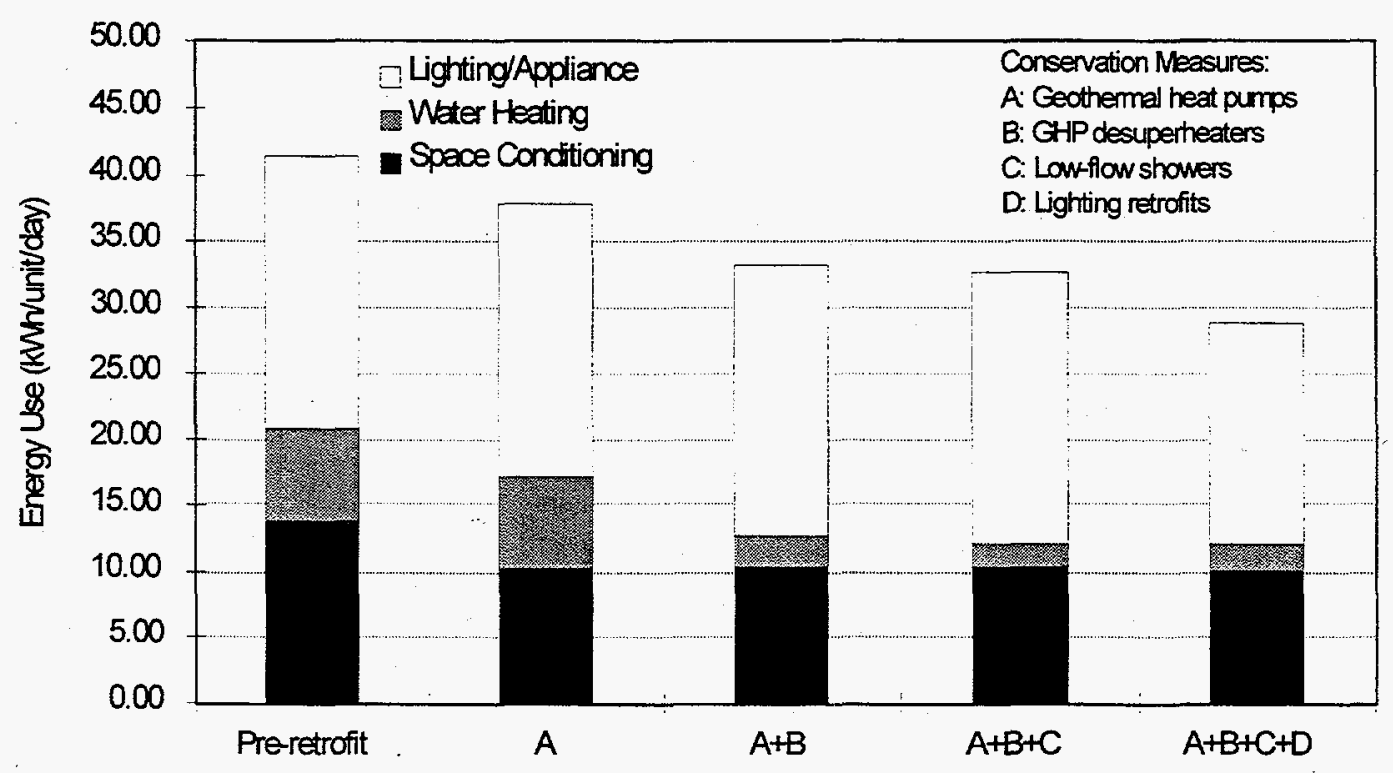

Fig. 2.10. Impact of retrofits on space conditioning, water heating, and lighting/appliance loads.

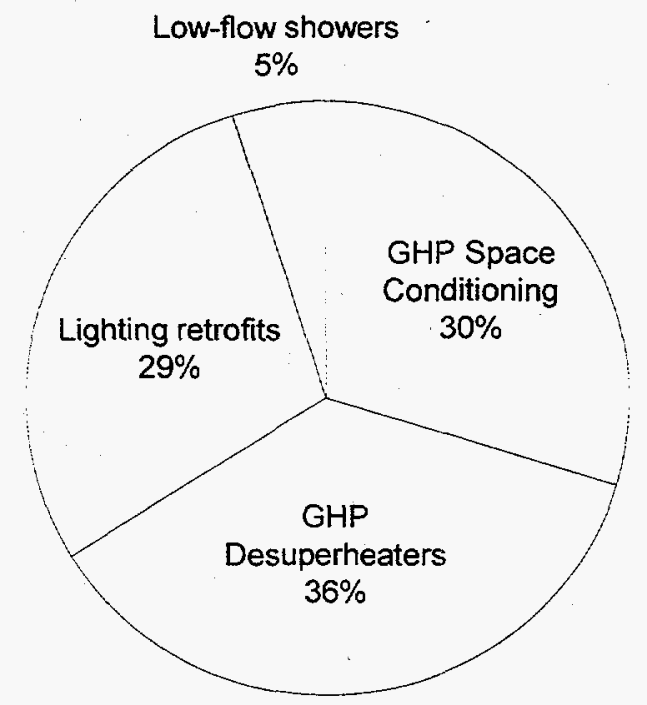

Fig. 2.11. Breakdown of energy savings by conservation measure. 
In order to develop an independent estimate of energy savings based on these meter readings, it was necessary to normalize them to a TMY. This was achieved by correlating average daily consumption (in $\mathrm{kWh} / \mathrm{ft}^{2}$ per day) from the meter readings with the average heating and cooling degree days per day in each month (base $65^{\circ} \mathrm{F}$ ) for the pre- and post-retrofit data. Note that since construction was ongoing during the period the meter readings were taken, the number of readings that fall into the pre- and post-retrofit categories varies from month to month. In each month, energy consumption was totaled for those units that had readings. This total was divided by the total square feet of living space contained in the units for which readings had been taken and by the number of days in the period. This gave the average $\mathrm{kWh} / \mathrm{ft}^{2}$ per day for the period. Figures for heating and cooling degree days per day for each period were obtained from the project's monitored weather data.

A problem with the ESCO's data was that the sample included only ten apartments that had gas/electric systems in the pre-retrofit period. Since the proportion of gas/electric apartments in the sample is much smaller than the proportion in the housing population, a separate correlation was attempted for the gas/electric apartments. However, of the ten apartments in the sample, only seven included any pre-retrofit data, and then for an average of only five months in each case. The correlation did not produce a reliable value for annual energy consumption per square foot for preretrofit gas/electric apartments, based on comparison with the figures in Table 2.3. Thus it was decided to eliminate the ten gas/electric apartments from the data.

Table 2.9 presents the results of the analysis of the ESCO's meter readings for the pre- and post-retrofit; the data is plotted in Fig. 2.12. When normalized to a TMY, the ESCO's meter readings indicate an average annual pre-retrofit energy consumption of $14.89 \mathrm{kWh} / \mathrm{ft}^{2}$ and an average annual post-retrofit consumption of $9.79 \mathrm{kWh} / \mathrm{ft}^{2}$, for a savings of $34.4 \%$, which compares closely to the values of $35.3 \%$ obtained from our feeder-level data and $34.8 \%$ from our buildinglevel data. The ESCO data were obtained from meters that were installed when the apartments were built and never calibrated or read on a regular basis thereafter, until the ESCO started to do so in 1995. Under the circumstances, the close agreement is surprising.

Table 2.9. Summary of ESCO meter readings, pre- and post-retrofit

\begin{tabular}{|c|c|c|c|c|c|c|c|}
\hline \multicolumn{4}{|c|}{ Pre-Retrofit } & \multicolumn{4}{|c|}{ Post-Retrofit } \\
\hline $\begin{array}{l}\text { Days in } \\
\text { period }\end{array}$ & $\begin{array}{l}\text { Average degree- } \\
\text { days per day }\end{array}$ & $\begin{array}{l}\mathrm{kWh} / \mathrm{ft}^{2} \\
\text { per day }\end{array}$ & $\begin{array}{c}\text { Total } \\
\mathrm{ft}^{2}\end{array}$ & $\begin{array}{l}\text { Days in } \\
\text { period }\end{array}$ & $\begin{array}{l}\text { Average degree- } \\
\text { days per day }\end{array}$ & $\begin{array}{l}\mathrm{kWh} / \mathrm{ft}^{2} \\
\text { per day }\end{array}$ & $\begin{array}{c}\text { Total } \\
\mathrm{ft}^{2}\end{array}$ \\
\hline $\begin{array}{l}28 \\
35\end{array}$ & $\begin{array}{l}9.05 \\
6.01\end{array}$ & $\begin{array}{l}0.0337 \\
0.0328\end{array}$ & $\begin{array}{l}49500 \\
49500\end{array}$ & $\begin{array}{l}28 \\
35\end{array}$ & $\begin{array}{l}9.05 \\
6.01\end{array}$ & $\begin{array}{l}0.0264 \\
0.0241\end{array}$ & $\begin{array}{l}19702 \\
19702\end{array}$ \\
\hline 35 & 14.09 & 0.0421 & 49500 & 35 & 14.09 & 0.0270 & 19702 \\
\hline 28 & 16.99 & 0.0453 & 49500 & 28 & 16.99 & 0.0322 & 18121 \\
\hline 28 & 21.10 & 0.0509 & 43740 & 28 & 21.10 & 0.0355 & 18121 \\
\hline 35 & 21.85 & 0.0512 & 38874 & 35 & 21.85 & 0.0356 & 18121 \\
\hline 30 & 14.70 & 0.0552 & 121423 & 30 & 14.70 & 0.0311 & 43319 \\
\hline 27 & 4.95 & 0.0325 & 109981 & 27 & 4.95 & 0.0235 & 61088 \\
\hline 33 & 11.08 & 0.0321 & 112736 & 33 & 11.08 & 0.0238 & 78016 \\
\hline 29 & 16.67 & 0.0447 & 111546 & 29 & 16.67 & 0.0256 & 80002 \\
\hline 33 & 20.07 & 0.0540 & 109400 & 33 & 20.07 & 0.0304 & 80002 \\
\hline 29 & 10.49 & 0.0389 & 93215 & 29 & 10.49 & 0.0247 & 82148 \\
\hline 31 & 11.22 & 0.0372 & 53214 & 31 & 11.22 & 0.0251 & 100672 \\
\hline 31 & 6.64 & 0.0409 & 31791 & 31 & 6.64 & 0.0250 & 145406 \\
\hline 31 & 12.09 & 0.0409 & 29153 & 31 & 12.09 & 0.0245 & 165639 \\
\hline \multirow[t]{5}{*}{34} & 16.46 & 0.0495 & 11095 & 34 & 16.46 & 0.0315 & 157406 \\
\hline & & & & 30 & 18.64 & 0.0275 & 180837 \\
\hline & & & & 33 & 15.06 & 0.0305 & 191567 \\
\hline & & & & 28 & 8.96 & 0.0254 & 195948 \\
\hline & & & & 37 & 3.52 & 0.0212 & 192628 \\
\hline
\end{tabular}




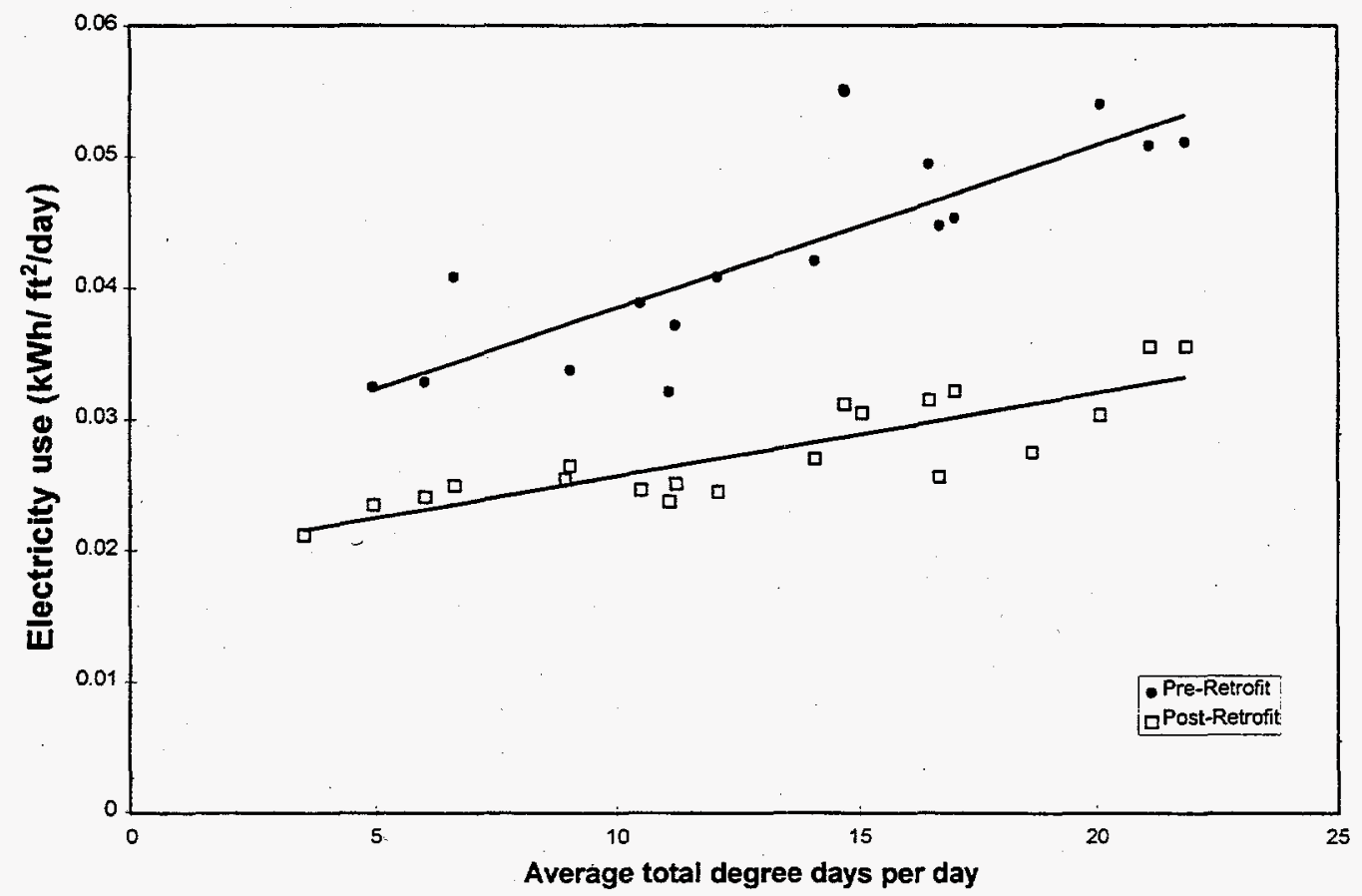

Fig. 2.12. Electricity use per square foot per day from ESCO monthly meter readings, pre- and post-retrofit.

\subsection{CALCULATING PEAK DEMAND SAVINGS}

In general, electrical demand is a complex phenomenon that depends on a number of variables such as time of day and day of the week, outdoor temperature, average temperature during a number of past hours, and average temperature during a number of past days. Utilities commonly use five years or more of historical data for their demand models (Kim 1982). A rigorous analysis of electrical demand savings of the Fort Polk project would require the development of such models for both the pre- and post-retrofit for each feeder. As in the case of annual energy consumption, the models would then be normalized to a typical meteorological year to determine the savings.

For the purposes of this evaluation, we used a simpler approach, more appropriate for the project (one year of pre-retrofit and about one year of post-retrofit data). Daily average temperature was assumed to be the dominant variable in determining peak electrical demand. The 15-minute-interval energy consumption data allowed us to determine daily electrical demand profiles for each feeder. The hour of interest (coincident with serving utility peak demand) was taken to be 4 to 5 p.m. Demand profiles from three pre-retrofit and three post-retrofit days with essentially identical temperatures were selected and used to establish three-day-average pre- and post-retrofit profiles. Demand savings was determined as the difference between the three-dayaverage profiles averaged over the 4 to 5 p.m. time period.

Pre- and post-retrofit demand profiles for a typical all-electric feeder, Feeder 2, are shown in Fig. 2.13. The average temperature for the pre- and post-retrofit periods corresponds to the highest temperature observed in the post-retrofit period. The post-retrofit data are not available at the most extreme (highest) daily average temperatures observed in the pre-retrofit period on some feeders because the summer of 1996 was relatively mild, and retrofit construction on some feeders 
was not completed until well into August 1996. Since the demand savings of interest is the demand savings on the extreme days, it was necessary to repeat our matched group analysis (three days pre/post at essentially identical average daily temperatures) at several daily average temperatures and then extrapolate to the most extreme daily average temperature observed in the pre-retrofit data $\left(91.58^{\circ} \mathrm{F}\right)$. Figure 2.14 shows the results of this analysis for Feeder 2.

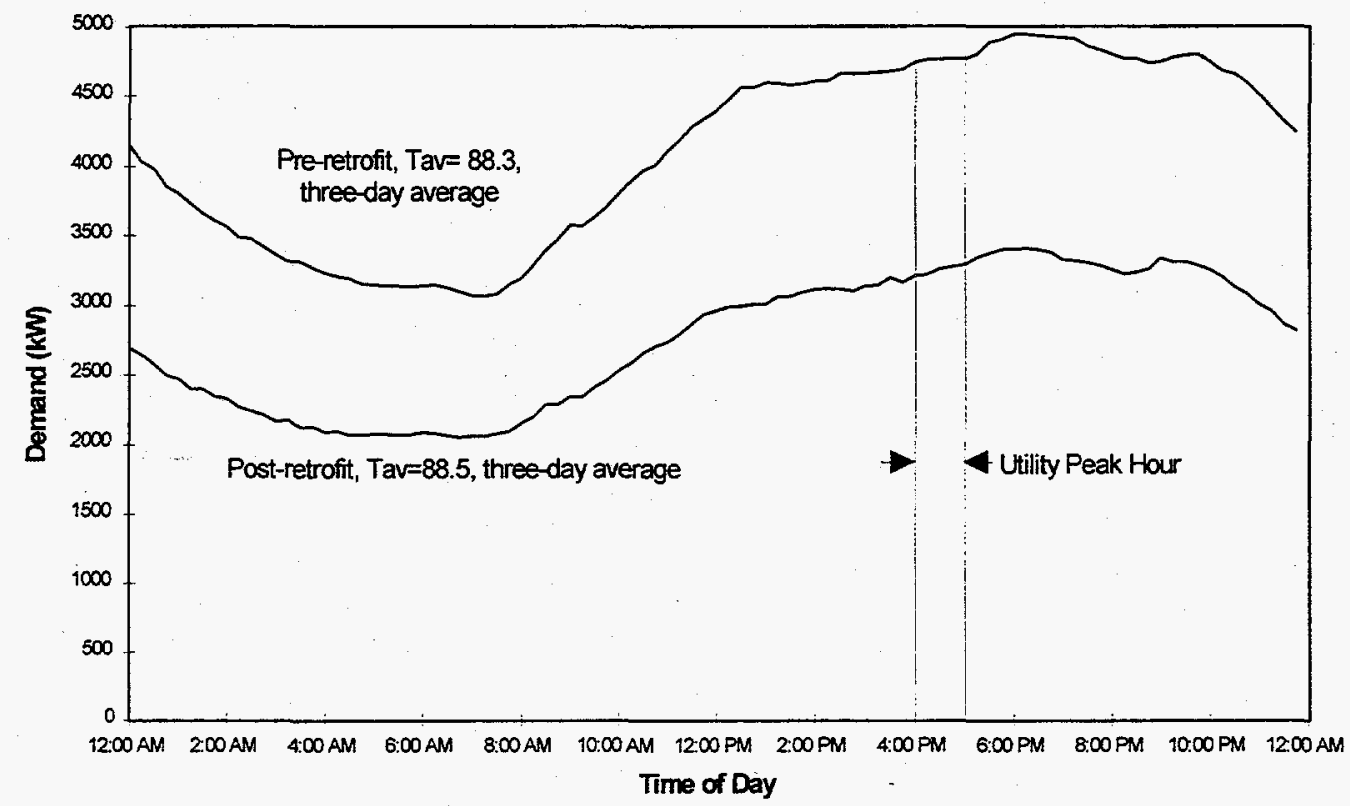

Fig. 2.13. Pre- and post-retrofit demand profiles for three-day average "peak day," Feeder 2.

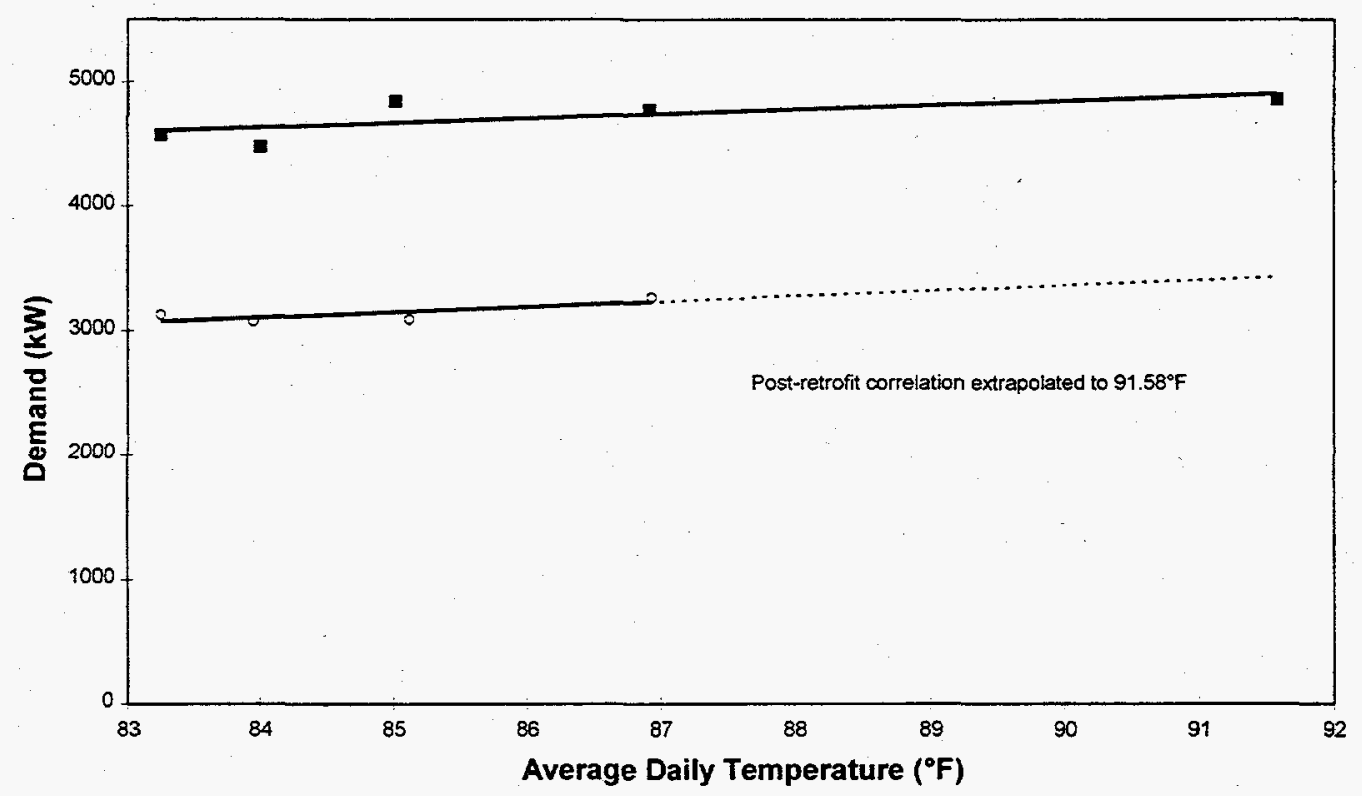

Fig. 2.14. Demand during utility peak hour vs daily average temperature, pre- and post-retrofit. 
The results of the feeder-by-feeder analysis of peak demand are shown in Table 2.10. The total peak demand reduction for the family housing area is estimated at $7.55 \mathrm{MW}$, or $43.5 \%$ of the pre-retrofit peak demand. The energy and demand savings correspond to an improvement in the whole-community annual electric load factor from about 0.52 to 0.62 .

Table 2.10. Peak demand, annual consumption, and load factor by feeder, pre- and post-retrofit

\begin{tabular}{|c|c|c|c|c|c|c|c|c|}
\hline \multirow[b]{2}{*}{ Feeder } & \multicolumn{3}{|c|}{ Pre-Retrofit } & \multicolumn{3}{|c|}{ Post-Retrofit } & \multirow{2}{*}{$\begin{array}{l}\text { Demand } \\
\text { reduction }\end{array}$} & \multirow{2}{*}{$\begin{array}{c}\text { Percent } \\
\text { reduction }\end{array}$} \\
\hline & $\begin{array}{c}\text { Peak } \\
\mathrm{kW}\end{array}$ & $\begin{array}{l}\text { Annual } \\
\mathrm{kWh}\end{array}$ & $\begin{array}{l}\text { Load } \\
\text { factor }\end{array}$ & $\begin{array}{c}\text { Peak } \\
\mathrm{kW}\end{array}$ & $\begin{array}{c}\text { Annual } \\
\mathrm{kWh}\end{array}$ & $\begin{array}{l}\text { Load } \\
\text { factor }\end{array}$ & & \\
\hline 1 & 600 & 2873622 & 0.55 & 405 & 2001455 & 0.56 & 194 & $32.4 \%$ \\
\hline 2 & 5639 & 27722779 & 0.56 & 3376 & 18957249 & 0.64 & 2263 & $40.1 \%$ \\
\hline 3 & 248 & 1273011 & 0.59 & 213 & 977428 & 0.52 & 35 & $14.1 \%$ \\
\hline 4 & 54 & 170119 & 0.36 & 28 & 176601 & 0.73 & 26 & $48.6 \%$ \\
\hline 5 & 499 & 1299381 & 0.30 & 287 & 1301949 & 0.52 & 212 & $42.5 \%$ \\
\hline 6 & 276 & 1551831 & 0.64 & 200 & 999095 & 0.57 & 75 & $27.3 \%$ \\
\hline 7 & 2490 & 13918902 & 0.64 & 1125 & 6217805 & 0.63 & 1366 & $54.8 \%$ \\
\hline 11 & 774 & 2278945 & 0.34 & 395 & 1912352 & 0.55 & 379 & $49.0 \%$ \\
\hline 12 & 603 & 2002139 & 0.38 & 354 & 1678039 & 0.54 & 249 & $41.3 \%$ \\
\hline 13 & 702 & 2216799 & 0.36 & 341 & 1852790 & 0.62 & 361 & $51.4 \%$ \\
\hline 14 & 865 & 2530362 & 0.33 & 438 & 2076470 & 0.54 & 427 & $49.3 \%$ \\
\hline 15 & 782 & 4137766 & 0.60 & 448 & 2687859 & 0.68 & 334 & $42.7 \%$ \\
\hline 16 & 1475 & 6112001 & 0.47 & 809 & 4763891 & 0.67 & 666 & $45.2 \%$ \\
\hline 17 & 900 & 4015635 & 0.51 & 493 & 3049713 & 0.71 & 408 & $45.3 \%$ \\
\hline 18 & 694 & 3466581 & 0.57 & 429 & 2330146 & 0.62 & 265 & $38.2 \%$ \\
\hline 19 & 770 & 3843615 & 0.57 & 479 & 2603741 & 0.62 & 290 & $37.7 \%$ \\
\hline Total & 17371 & 79413489 & 0.52 & 9820 & 53586583 & 0.62 & 7551 & $43.5 \%$ \\
\hline
\end{tabular}

Notes:

1. Pre- and post-retrofit annual consumption and demand estimated for Feeders 18 and 19.

2. Post-retrofit demand was estimated for Feeder 13 because of an equipment failure during peak cooling season.

\subsection{EFFECT OF VACANCY RATE ON APPARENT ENERGY SAVINGS}

Although our pre- and post-retrofit data shows that electrical energy use in family housing at Fort Polk is highly dependent on daily average temperature, comparison with the historical data suggests that not all of the variation is explained by weather. Table 2.11 shows the metered annual energy use in Fort Polk family housing for 1989 through 1992, along with the predicted energy consumption based on our feeder-level daily energy consumption models. The predicted values were calculated using historical data on measured average daily temperature at Fort Polk. The standard deviation of the model error is 3.5 million $\mathrm{kWh}$ per year, or about $4.3 \%$ of the average annual electrical energy use during the period.

While some of the variation may be attributed to inaccurate meter readings (Gordon 1997), a more significant source of variability in annual energy use may be the rate of occupancy in family housing. Table 2.12 presents the number of vacant units per month from October 1995 through May 1997 (Gordon 1998). The average number of vacant units per month is 617 , and the standard deviation is 148 vacancies per month. The data, which are plotted in Fig. 2.15, suggest that the major variation in occupancy is from year to year rather than month to month. All other things 
Table 2.11. Comparison of historical metered electrical energy use with predicted use

\begin{tabular}{cccc}
\hline Year & $\begin{array}{c}\text { Metered } \\
\left(10^{6} \mathrm{kWh}\right)\end{array}$ & $\begin{array}{c}\text { Predicted } \\
\left(10^{6} \mathrm{kWh}\right)\end{array}$ & $\begin{array}{c}\text { Error } \\
\left(10^{6} \mathrm{kWh}\right)\end{array}$ \\
\hline 1989 & 79.7 & 81.4 & 1.8 \\
1990 & 86.5 & 80.4 & -6.1 \\
1991 & 83.5 & 80.9 & -2.6 \\
1992 & 75.9 & 77.4 & 1.5 \\
\hline
\end{tabular}

Table 2.12. Vacant housing units per month

\begin{tabular}{rcc}
\hline Month & Vacant Units & $\begin{array}{c}\text { Vacancy } \\
(\%)\end{array}$ \\
\hline Oct 95 & 408 & $10.2 \%$ \\
Nov 95 & 436 & $10.9 \%$ \\
Dec 95 & 469 & $11.7 \%$ \\
Jan 96 & 465 & $11.6 \%$ \\
Feb 96 & 438 & $10.9 \%$ \\
Mar 96 & 445 & $11.1 \%$ \\
Apr 96 & 423 & $10.6 \%$ \\
May 96 & 494 & $12.3 \%$ \\
Jun 96 & 638 & $15.9 \%$ \\
Jul 96 & 719 & $18.0 \%$ \\
Aug 96 & 725 & $18.1 \%$ \\
Sept 96 & 725 & $18.1 \%$ \\
Oct 96 & 735 & $18.4 \%$ \\
Nov 96 & 764 & $19.1 \%$ \\
Dec 96 & 803 & $20.1 \%$ \\
Jan 97 & 781 & $19.5 \%$ \\
Feb 97 & 771 & $19.3 \%$ \\
Mar 97 & 750 & $18.7 \%$ \\
Apr 97 & 696 & $17.4 \%$ \\
May 97 & 660 & $16.5 \%$ \\
\hline
\end{tabular}

being equal, energy consumption in family housing should be proportional to the number of occupied housing units. From Table 2.3, the mean pre-retrofit energy use per housing unit at Fort Polk is $54.35 \mathrm{kWh} /$ day, or $19,838 \mathrm{kWh} /$ year. Thus if the number of occupied units varies by 148 per year, we would expect the variation in weather-corrected annual electrical energy use to be on the order of $(19,838)(148)=2.9$ million $\mathrm{kWh}$ per year. This suggests that the model error of 3.5 million $\mathrm{kWh}$ per year may be primarily due to varying occupancy.

Figure 2.15 shows that the vacancy rate from June 1996 through May 1997 was roughly double what it had been previously. Since about half of our post-retrofit data was collected during the low-vacancy period before June 1996 (for some feeders post-retrofit data collection began as early as September 1995), we would expect our model predictions for post-retrofit energy consumption to be somewhat higher than the actual energy consumption during months with high vacancy.

To estimate post-retrofit energy use in a year such as 1997 with an average of 732 vacancies per month (87.1\% occupancy), we developed a simple approach to correct our feeder models given the data in Table 2.12. First, since no data were available on vacancy rates for the individual feeders, we assumed that the vacancy rate was the same across all feeders. Then, for each feeder 


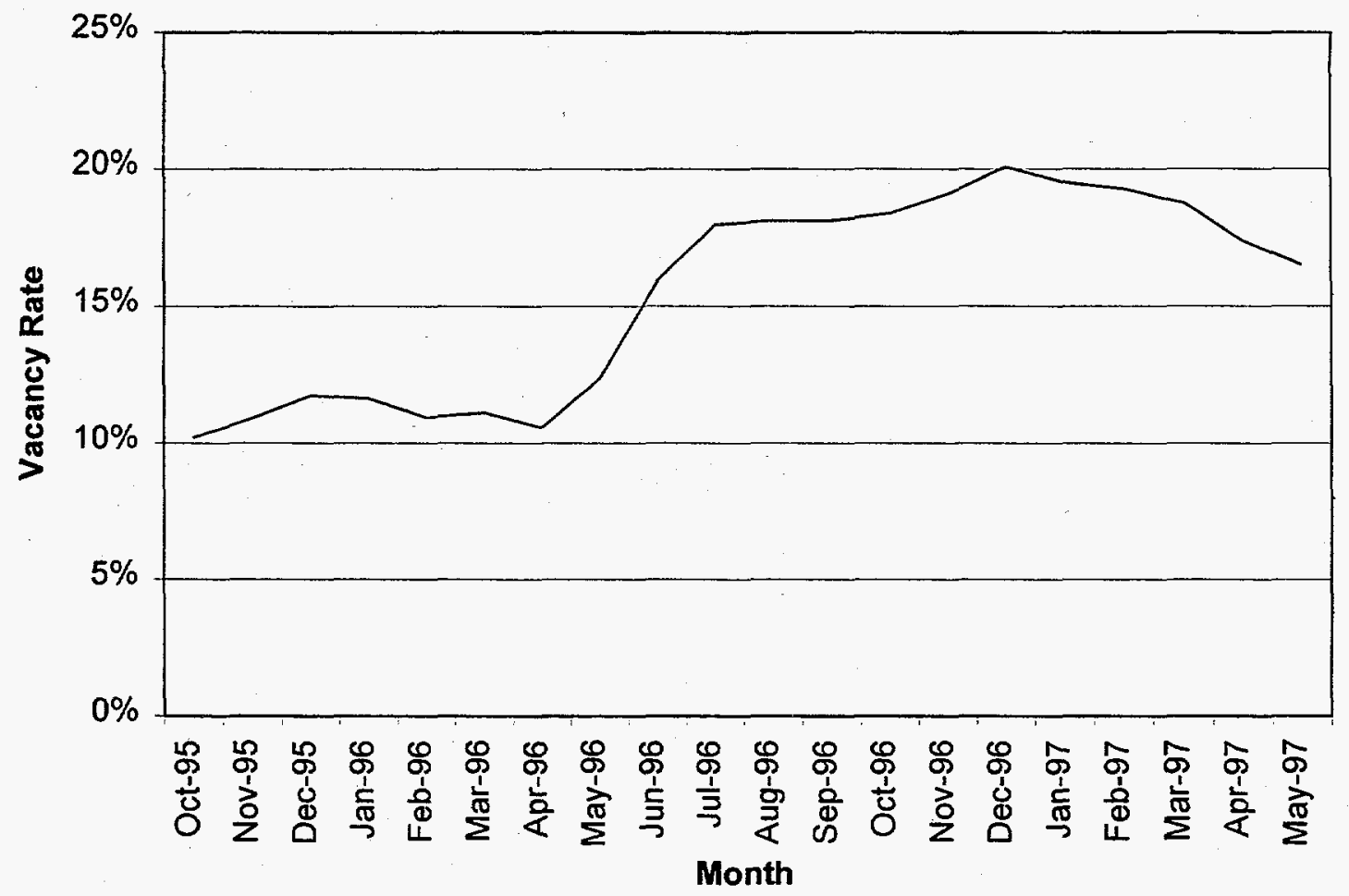

Fig. 2.15. Vacancy rate by month.

we determined the average percentage of vacant apartments during the period when post-retrofit data were collected. (As discussed in Sect. 2.2, the post-retrofit data collection period was different for each feeder.) For example, post-retrofit data collection began on Feeder 1 in September 1995 and continued through February 1997. From Table 2.12, the average vacancy during this period was $15 \%$. However, since weather is the major determinant of energy use, the monthly percentages were weighted by the total number of degree days in each month. For the post-retrofit data collection period on Feeder 1, the degree-day adjusted vacancy rate was $14.9 \%$; the adjusted occupancy was then $85.1 \%$. Assuming the occupancy during 1997 was $81.7 \%$, we multiply the predicted energy use for Feeder 1 in 1997 by a correction factor of $0.961(0.817 /$ 0.851 ). In other words, we expect annual energy use on Feeder 1 during a year with $81.7 \%$ occupancy to be about $96 \%$ of the energy use during a year with $85.1 \%$ occupancy.

Calculations for all of the feeders are presented in Table 2.13. (Note that the figures for "unadjusted energy consumption" have been adjusted for weather but not for occupancy; the calculations are based on actual weather conditions for 1997.) Had family housing occupancy for 1997 been the same as it was during our post-retrofit data collection period, we would expect the annual energy use for 1997 to be about 53.2 million $\mathrm{kWh}$. With $81.7 \%$ occupancy we expect an annual energy consumption of about 50.6 million $\mathrm{kWh}$. Despite the number of assumptions made in this simple correction, the method seems to work remarkably well. Actual metered electrical energy use for family housing during 1997 was 50,660,114 kWh (Gordon 1998).

This analysis shows that the occupancy rate in family housing has a significant impact on energy use. The reduced occupancy during 1997 results in an additional "apparent savings" of 2.6 million $\mathrm{kWh}$. One of the advantages of measurement and verification (M\&V) approaches under the current ESPC statutory authority, over the previous shared-savings authority, is that M\&V is used to verify that the guaranteed level of savings is delivered over a period of time (typically a 
year). During the annual review, actual meter readings can be reconciled with the contract baseline conditions (normal weather, normal occupancy, etc.) before verifying the guarantee. Under the old shared-savings authority where $M \& V$ was used to directly calculate the monthly ESCO payment, either the process of generating and approving monthly invoices was involved, or wildly varying monthly payments based on actual weather and occupancy resulted.

Table 2.13. Annual energy use by feeder for 1997 adjusted for occupancy rate

\begin{tabular}{cccrr}
\hline Feeder & $\begin{array}{c}\text { Degree-day } \\
\text { weighted vacancy } \\
\text { rate }\end{array}$ & Correction factor & $\begin{array}{c}\text { Unadjusted } \\
1997 \text { energy use } \\
(\mathrm{kWh})\end{array}$ & $\begin{array}{c}\text { High-vacancy } \\
1997 \text { energy use } \\
(\mathrm{kWh})\end{array}$ \\
\hline 1 & $14.9 \%$ & 0.961 & $1,996,773$ & $1,918,237$ \\
2 & $10.8 \%$ & 0.916 & $18,826,433$ & $17,242,286$ \\
3 & $17.2 \%$ & 0.987 & 969,831 & 957,541 \\
4 & $9.8 \%$ & 0.906 & 175,566 & 159,065 \\
5 & $14.9 \%$ & 0.961 & $1,295,184$ & $1,244,243$ \\
6 & $14.9 \%$ & 0.961 & 992,553 & 953,514 \\
7 & $10.3 \%$ & 0.911 & $6,181,647$ & $5,628,466$ \\
11 & $17.8 \%$ & 0.994 & $1,897,033$ & $1,886,075$ \\
12 & $16.6 \%$ & 0.980 & $1,664,709$ & $1,630,644$ \\
13 & $18.4 \%$ & 1.002 & $1,835,539$ & $1,838,512$ \\
14 & $16.5 \%$ & 0.979 & $2,059,883$ & $2,015,981$ \\
15 & $18.8 \%$ & 1.006 & $2,676,140$ & $2,691,627$ \\
16 & $18 \%$ & 1.006 & $4,736,553$ & $4,763,963$ \\
17 & $16.1 \%$ & 0.974 & $3,033,983$ & $2,954,716$ \\
18 & $15.4 \%$ & 0.996 & $2,315,099$ & $2,236,532$ \\
19 & $15.4 \%$ & 0.996 & $2,586,887$ & $2,499,108$ \\
Total & & & $\mathbf{5 3 , 2 4 3 , 8 0 2}$ & $\mathbf{5 0 , 6 2 0 , 5 1 2}$ \\
\hline
\end{tabular}




\section{MAINTENANCE SAVINGS}

\subsection{BACKGROUND}

Until 1994, the HVAC equipment in Fort Polk's family housing was maintained by a series of private service contractors. For the most part, the experience with these contracts was less than satisfactory. According to Army personnel, some contractors tended to underestimate the labor required to maintain equipment in the 4003 housing units, resulting in poor service to the residents. Costs were also underestimated, resulting in financial difficulties for some contractors. The ESPC was seen as one way to resolve these problems. Since the ESCO will be entirely responsible for maintaining the HVAC equipment during the contract period, the maintenance savings are equal to the estimated baseline maintenance costs.

Because historical baseline maintenance costs for Fort Polk's family housing could not be separated from the total cost of facility maintenance, the Army developed an estimate of the maintenance costs based on bids received on a request for proposals (Aldridge 1995). The baseline maintenance cost was determined to be $\$ 335.83$ per housing unit per year, or about 24.1 cents $/ \mathrm{ft}^{2}$ per year for the approximately $5,600,000 \mathrm{ft}^{2}$ of family housing. From the Army's point of view, this entire amount will be saved each year, since the ESCO assumes responsibility for all family housing HVAC equipment. The shared savings contract specifies the percentage of this savings that the Army will pay the ESCO each month, shown in the schedule in Table 3.1.

Through the ESPC the Army has effectively capped its future expenditures for maintenance of family housing HVAC equipment. Averaged over the 20 years, the Army will pay the ESCO about $77 \%$ of the baseline maintenance costs, which amounts to $\$ 261.95$ per housing unit per year, or about 18.1 cents $/ \mathrm{ft}^{2}$ per year. For comparison, the American Society of Heating, Refrigeration, and Air-Conditioning Engineers (ASHRAE) Handbook (1995a) lists a mean cost for HVAC system maintenance costs of 32 cents $/ \mathrm{ft}^{2}$ per year, with a median cost of 24 cents $/ \mathrm{ft}^{2}$ per year, in 1983 dollars. Data from a 1994 survey concerning commercial buildings performed by the Building Owners and Managers Association (BOMA 1995) shows an average HVAC maintenance cost of 29 cents $/ \mathrm{ft}^{2}$ per year for federal, state, and local government buildings. Thus the Army's estimate of the baseline maintenance costs for Fort Polk's family housing is lower than these values. The true value of the baseline maintenance costs is very important because they represent about $40 \%$ of the total cost savings of this ESPC project (the rest being energy cost savings). Consequently, we developed an independent estimate of the baseline maintenance costs.

In developing our independent estimate of baseline maintenance costs, we began by estimating the number of compressor-bearing outdoor units of air-source heat pumps (ASHPs) and central air conditioners (CACs) that would require replacement each year. Since no historical maintenance data were available, a survey was made of the existing ASHP and CAC outdoor units to determine their ages. The dates of manufacture of the outdoor units at 3879 of the 4003 residences were taken from the nameplate on each unit. A full census was not possible because some housing was connected to a "solar farm" and had no outdoor units and because some outdoor units were inaccessible -in a fenced yard with dog, for example. The average age of the 3879 outdoor units was determined to be 13.4 years. The survey results are shown in Fig. 3.1. 
Table 3.1. Fraction of maintenance savings to be paid to ESCO in each month of the ESPC

\begin{tabular}{clllllllllllll}
\hline & \multicolumn{1}{c}{ Year } & Jan & Feb & Mar & Apr & May & Jun & Jul & Aug & Sep & Oct & Nov & Dec \\
\hline 1 & 0 & 0 & 0 & 0.80 & 0.80 & 0.80 & 0.80 & 0.80 & 0.80 & 0.80 & 0.80 & 0.80 \\
2 & 0.85 & 0.85 & 0.85 & 0.85 & 0.85 & 0.85 & 0.85 & 0.85 & 0.85 & 0.85 & 0.85 & 0.85 \\
3 & 0.90 & 0.90 & 0.90 & 0.90 & 0.90 & 0.90 & 0.90 & 0.90 & 0.90 & 0.90 & 0.90 & 0.90 \\
4 & 0.85 & 0.85 & 0.85 & 0.85 & 0.85 & 0.85 & 0.85 & 0.85 & 0.85 & 0.85 & 0.85 & 0.85 \\
5 & 0.85 & 0.85 & 0.85 & 0.85 & 0.85 & 0.85 & 0.85 & 0.85 & 0.85 & 0.85 & 0.85 & 0.85 \\
6 & 0.85 & 0.85 & 0.85 & 0.85 & 0.85 & 0.85 & 0.85 & 0.85 & 0.85 & 0.85 & 0.85 & 0.85 \\
7 & 0.85 & 0.85 & 0.85 & 0.85 & 0.85 & 0.85 & 0.85 & 0.85 & 0.85 & 0.85 & 0.85 & 0.85 \\
8 & 0.80 & 0.80 & 0.80 & 0.80 & 0.80 & 0.80 & 0.80 & 0.80 & 0.80 & 0.80 & 0.80 & 0.80 \\
9 & 0.80 & 0.80 & 0.80 & 0.80 & 0.80 & 0.80 & 0.80 & 0.80 & 0.80 & 0.80 & 0.80 & 0.80 \\
10 & 0.80 & 0.80 & 0.80 & 0.80 & 0.80 & 0.80 & 0.80 & 0.80 & 0.80 & 0.80 & 0.80 & 0.80 \\
11 & 0.75 & 0.75 & 0.75 & 0.75 & 0.75 & 0.75 & 0.75 & 0.75 & 0.75 & 0.75 & 0.75 & 0.75 \\
12 & 0.75 & 0.75 & 0.75 & 0.75 & 0.75 & 0.75 & 0.75 & 0.75 & 0.75 & 0.75 & 0.75 & 0.75 \\
13 & 0.75 & 0.75 & 0.75 & 0.75 & 0.75 & 0.75 & 0.75 & 0.75 & 0.75 & 0.75 & 0.75 & 0.75 \\
14 & 0.75 & 0.75 & 0.75 & 0.75 & 0.75 & 0.75 & 0.75 & 0.75 & 0.75 & 0.75 & 0.75 & 0.75 \\
15 & 0.70 & 0.70 & 0.70 & 0.70 & 0.70 & 0.70 & 0.70 & 0.70 & 0.70 & 0.70 & 0.70 & 0.70 \\
16 & 0.70 & 0.70 & 0.70 & 0.70 & 0.70 & 0.70 & 0.70 & 0.70 & 0.70 & 0.70 & 0.70 & 0.70 \\
17 & 0.70 & 0.70 & 0.70 & 0.70 & 0.70 & 0.70 & 0.70 & 0.70 & 0.70 & 0.70 & 0.70 & 0.70 \\
18 & 0.65 & 0.65 & 0.65 & 0.65 & 0.65 & 0.65 & 0.65 & 0.65 & 0.65 & 0.65 & 0.65 & 0.65 \\
19 & 0.65 & 0.65 & 0.65 & $\mathbf{0 . 6 5}$ & 0.65 & 0.65 & 0.65 & 0.65 & 0.65 & 0.65 & 0.65 & 0.65 \\
20 & 0.65 & 0.65 & 0.65 & 0.65 & 0.65 & 0.65 & 0.65 & 0.65 & 0.65 & 0.65 & 0.65 & 0.65 \\
\hline
\end{tabular}

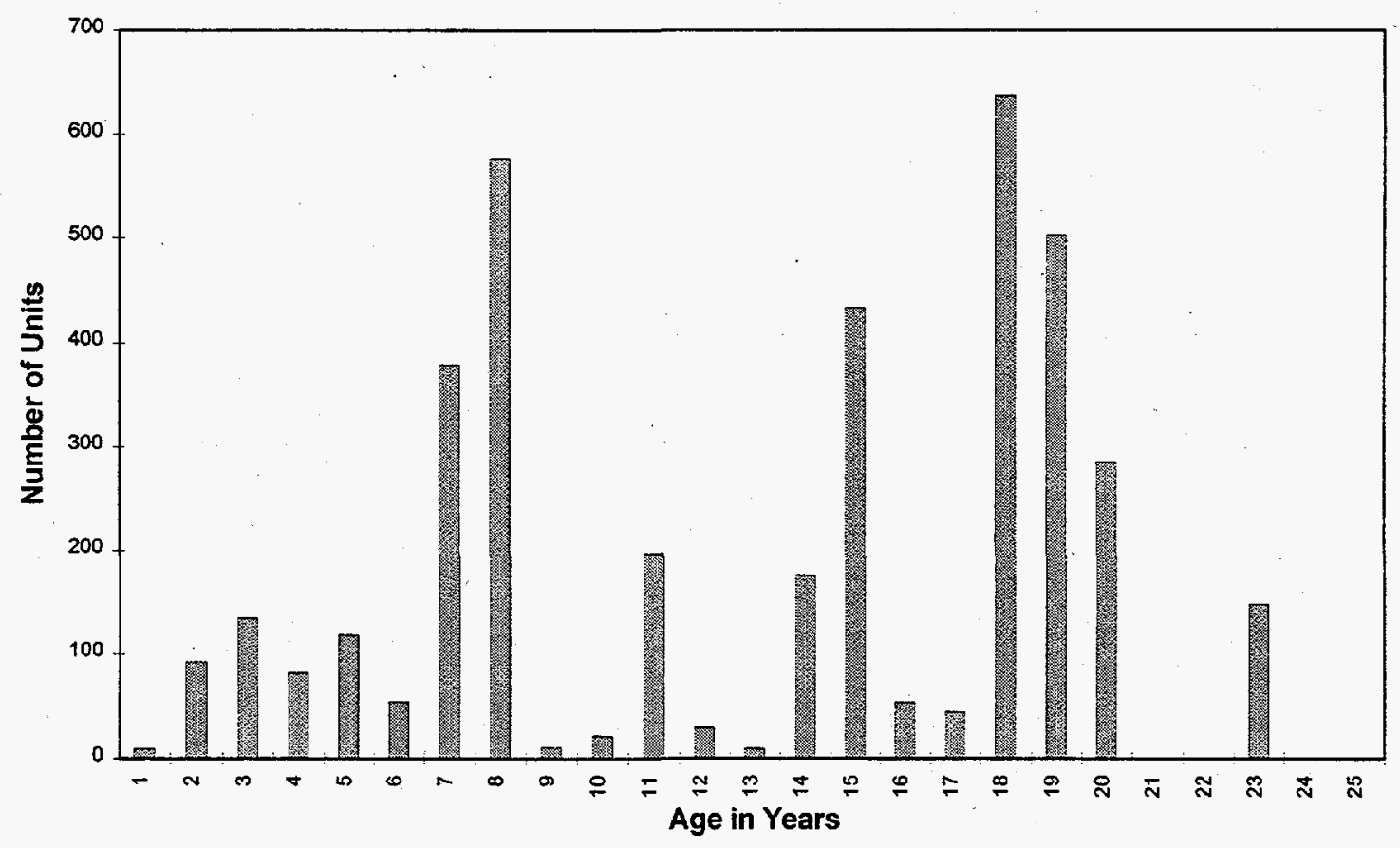

Fig. 3.1. Age of pre-retrofit outdoor units in family housing. 
Comparing the construction date of each residence with the manufacture date of its ASHP or $\mathrm{CAC}$ allowed us to determine whether the outdoor unit was original equipment or a replacement. The data showed that 679 of the units $(17.5 \%)$ had been replaced at least once since the residence was constructed. Assuming some key facts, the dates of manufacture of the 679 replacement units can be used to derive statistics on the reliability of the compressor-bearing outdoor units. The assumptions are these:

- The 679 residences that had outdoor units replaced had them replaced only once since the residence was constructed. In general this is not likely to be true. In fact, it might be assumed that as many as 119 of the 679 apartments, or $17.5 \%$, had them replaced twice. Of these, approximately 21 may have had three replacement units. However, in the absence of data on the history of replacements at each residence, we accepted this assumption, recognizing that it might produce a service life estimate somewhat higher than the true service life of the population.

- The year of manufacture of the current outdoor unit is the year in which the unit was installed and the year in which the original unit failed. The validity of this assumption depends on whether the replacement heat pumps were new equipment manufactured during the year in which they were installed or had been purchased previously and held in inventory. At most, this assumption should introduce an error of only one to two years. Note that this will tend to make the service life estimate somewhat lower than the true service life of the population.

Under these assumptions, for each observed replacement occurrence, we estimated the age at replacement of the original outdoor unit as the difference between the year of manufacture of the replacement unit and the year of construction of the residence. The distribution of the age at replacement of the 679 outdoor units is shown in Fig. 3.2.

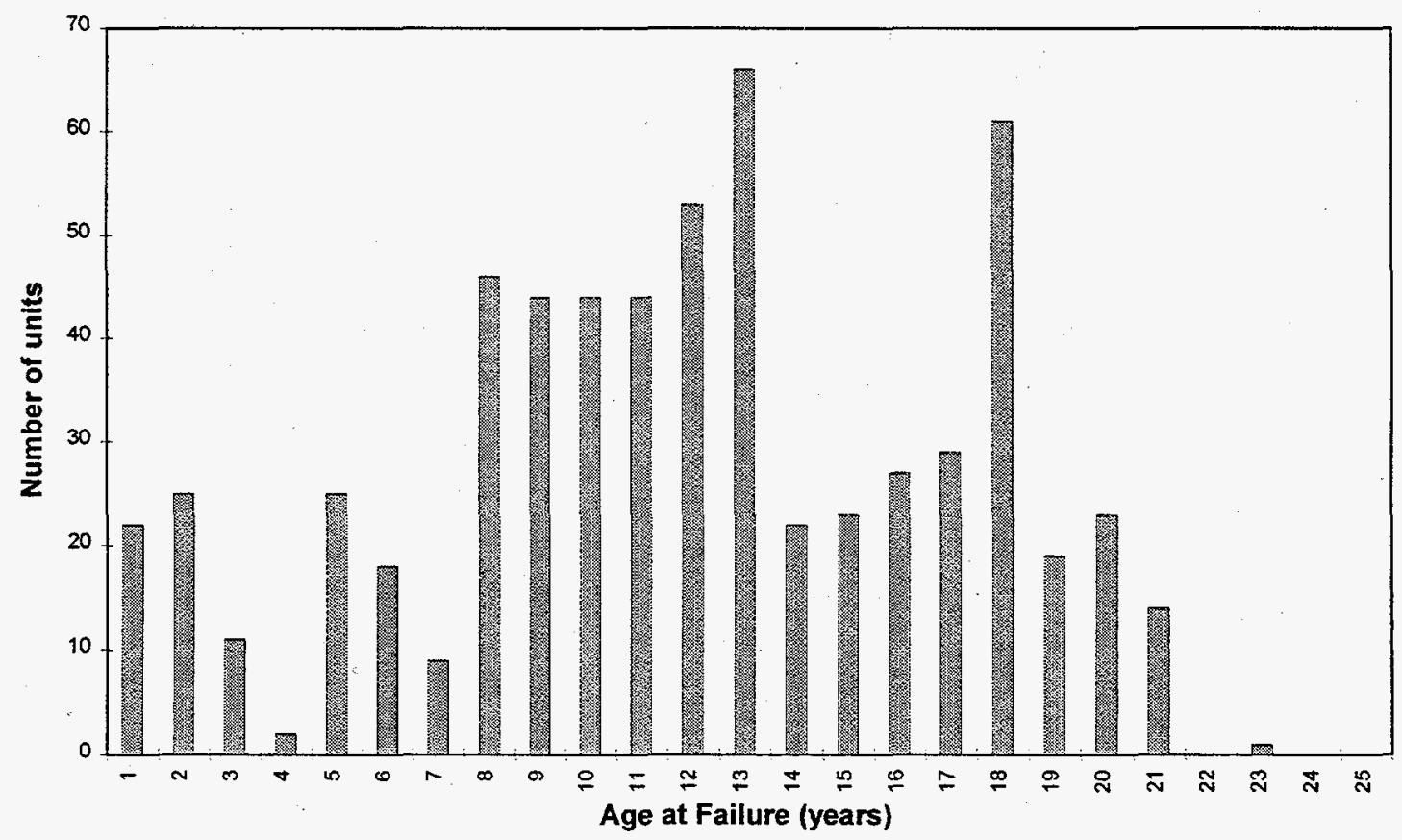

Fig. 3.2. Age of outdoor units at failure. 
Since the outdoor units were installed in various construction phases between 1972 and 1988 , an actuarial method (Nelson 1982) was used to determine the reliability of the outdoor units. This method has been used by the Electric Power Research Institute (EPRI 1990) and others (Bucher et al. 1990; Pientka 1987; Lovvorn and Hiller 1985) to determine the reliability of refrigerant vapor compressors and complete compressor-bearing outdoor units. Fig. 3.3 shows the fraction of original outdoor units remaining in service as determined by this method. The curve is assumed to follow a Weibull distribution, with

$$
R(t)=\exp \left[-(t / \alpha)^{\beta}\right]
$$

where $R(t)$ is the fraction remaining in service. Taking the natural logarithm of both sides of the equation gives

$$
\ln (R)=-(t / \alpha)^{\beta}
$$

and taking the natural logarithm again gives

$$
\ln (-\ln (R))=\beta \ln t-\beta \ln \alpha .
$$

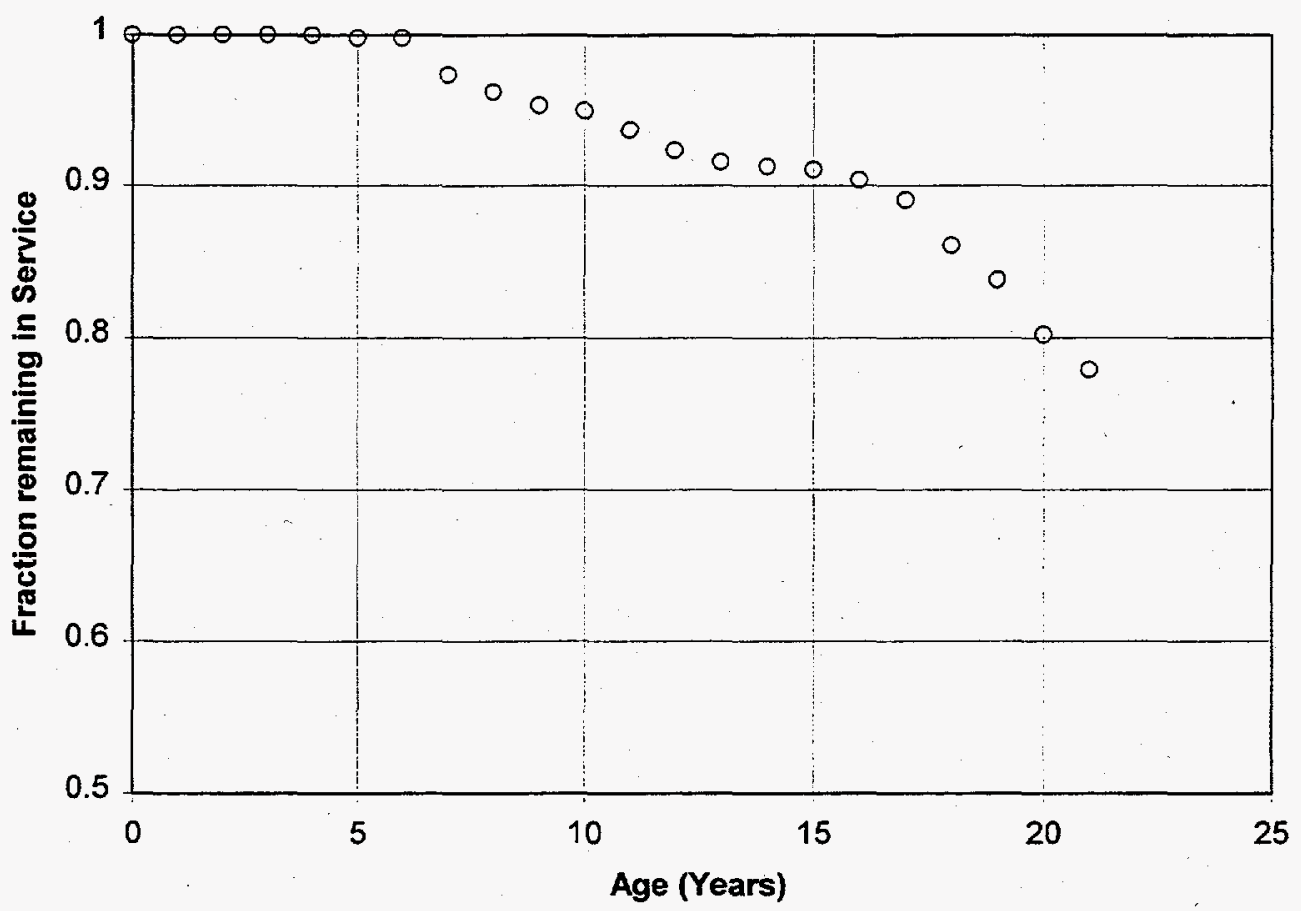

Fig. 3.3. Fraction of outdoor units remaining in service as a function of their age.

If a plot of $\ln (-\ln (R))$ vs $\ln t$ forms a straight line-the portion of interest being the long-term data-then the distribution can be modeled by a Weibull function, and the parameters $\alpha$ and $\beta$ can be determined. Such a plot is shown in Fig. 3.4. The last five points fit quite well to a straight line, and a linear function fitted to these points gives $\alpha=33.237, \beta=2.686$. From these values, 


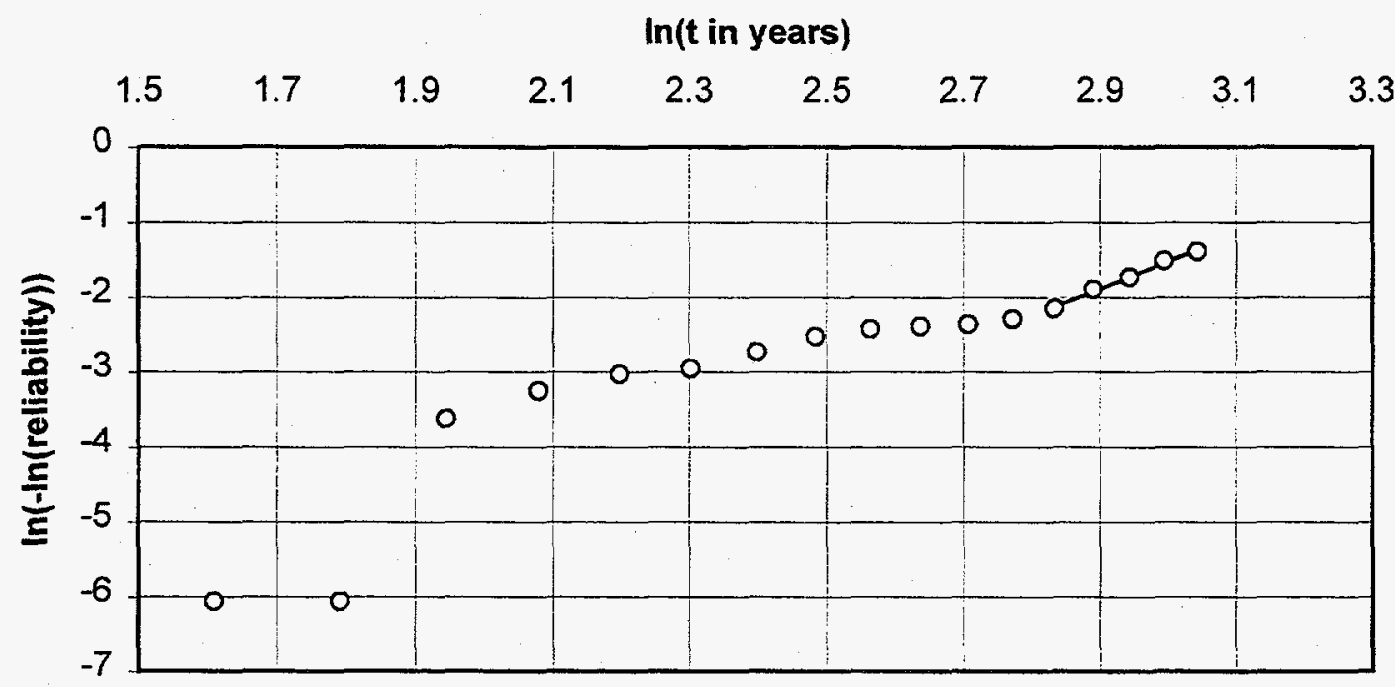

Fig. 3.4. Weibull plot of outdoor unit reliability vs time.

the mean service life of the outdoor units at Fort Polk is calculated at 29 years. This calculation gives a somewhat greater value than the 20 -year mean life determined by Lovvorn for ASHPs (Lovvorn and Hiller 1985), possibly because of errors introduced by the assumptions outlined above, because the outdoor units in our sample are of more recent manufacture, or because about $20 \%$ of them are CACs. Climate may be another factor in the longer service life calculated for these heat pumps, since they rarely run in the heating mode and require fewer defrost cycles. Also, actuarial approaches to determining service life may be inherently optimistic because, unlike in human populations, planned termination and replacement of aging mechanical equipment is common. For comparison, ASHRAE lists the service life of residential air-to-air heat pumps as 15 years (ASHRAE 1995a). To the extent that the service life determined here is optimistic, the estimated baseline maintenance costs and project maintenance savings will be conservative.

Once the parameters of the Weibull distribution were determined, a spreadsheet model was developed to determine the likely number of replacements during each year. The spreadsheet begins in year zero with the distribution of heat pumps as determined from the survey. The expected number of failures in each age class is determined from the Weibull distribution, and the failed units are assumed to be replaced with new ones at mid-year. In the following year, the new units have age 1 and the remaining units in each age class are one year older. As an example, suppose that in year 0 the entire population consists of 100 outdoor units of age 10 . If the expected number of failures is 20 , then in year 1 the population will consist of 20 units of age 1 and 80 units of age 11 .

Figure 3.5 shows the expected number of outdoor unit replacements as calculated by the spreadsheet, given the initial age distribution. In the first year, 61 outdoor units are expected to be replaced. Since the population is aging, the number of expected replacements grows to 90 by year 12. As failed units are replaced with new ones, the average age of the population decreases, and by year 20 the expected number of replacements decreases to 85 . 


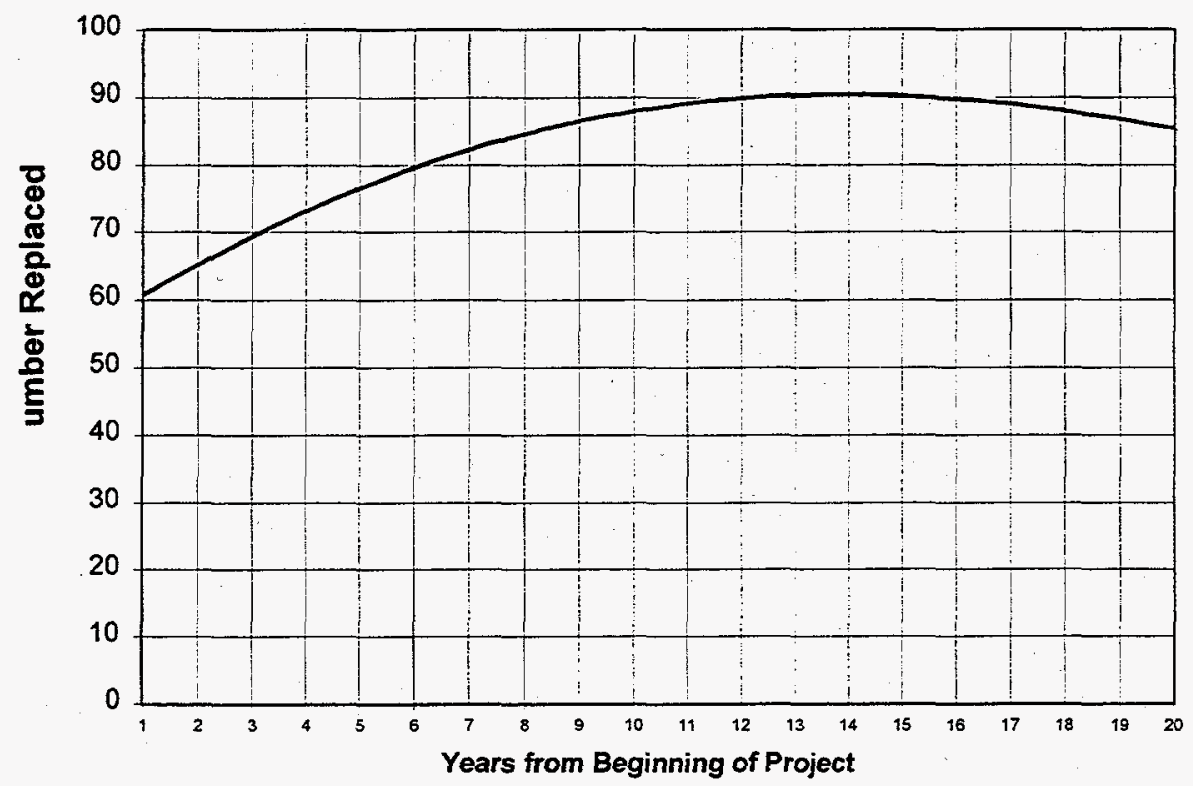

Fig. 3.5. Expected number of outdoor units replaced per year.

\subsection{ESTIMATE OF MAINTENANCE COSTS}

The ESCO assumed responsibility for maintenance of Fort Polk's family housing HVAC equipment in April 1994, about 12 months prior to the start of retrofit construction, and records have been kept of all maintenance activities since that time. To develop a model of the baseline maintenance costs, we audited the records from May 1994 through April 1995 for a random sample of 175 residences. The ESPC retrofit construction, including HVAC conversions to GHPs, started in July 1995 for the apartments in our sample, so all maintenance performed by the ESCO during this period was on the pre-existing ASHPs and gas furnace/CAC combinations. Data were collected on the date and type of service performed on each call. Data from the sample were scaled up to determine the labor requirements for the 4003 units in the family housing area. Figure 3.6 shows the expected number of service calls per day by month for the entire area. As expected, the frequency of service calls is greater during the summer months, but the maintenance staff remains busy during the entire period from May through November. Based on this data, each residence requires an average of 3.2 service calls per year. While this seems rather high, it should be noted that residents of military family housing are discouraged from performing the minor repairs that homeowners usually perform on their own equipment.

Table 3.2 lists the percentage of service calls by activity for the survey sample. The table also shows an estimate of the work hours and materials costs for each type of activity. These estimates were provided by a local HVAC service contractor (Butler 1996). The weighted average of service times is 1.23 hours per call, with an average of $\$ 34$ in material costs per call. An overhead of $25 \%$ on service time for travel and administrative tasks brings the average service time per call to 1.54 hours. 


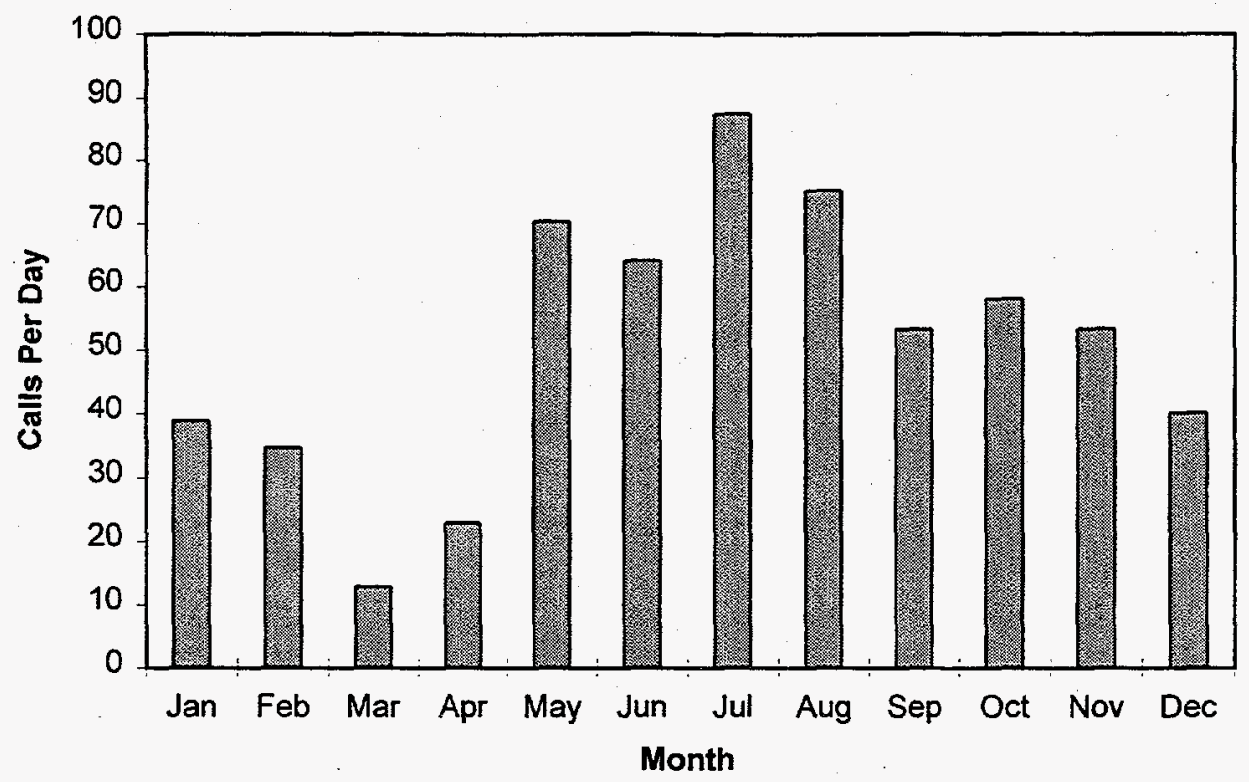

Fig. 3.6. Average number of service calls per day, pre-retrofit, in family housing.

Table 3.2. Maintenance activities, duration, and associated costs

\begin{tabular}{lccc}
\hline \multicolumn{1}{c}{ Activity } & Frequency & $\begin{array}{c}\text { Hours per } \\
\text { call }\end{array}$ & $\begin{array}{c}\text { Materials } \\
\text { costs }\end{array}$ \\
\hline Flush condensate pan/drain line & $16.4 \%$ & 0.50 & \\
Charge system with refrigerant & $13.1 \%$ & 2.00 & 25 \\
Clean indoor coil & $11.3 \%$ & 1.00 & \\
Check system / no apparent problem & $10.2 \%$ & 0.50 & \\
Light gas furnace pilot & $6.5 \%$ & 0.50 & \\
Replace outdoor fan motor & $5.1 \%$ & 1.50 & 125 \\
Repair/replace compressor wiring & $4.7 \%$ & 1.50 & 10 \\
Repair/adjust indoor thermostat/wiring & $4.7 \%$ & 1.00 & \\
Repair refrigerant leak/charge system & $3.3 \%$ & 1.50 & 25 \\
Reset circuit breaker & $2.9 \%$ & 0.50 & \\
Repair/replace outdoor fan motor wiring & $2.5 \%$ & 1.00 & 10 \\
Replace indoor thermostat & $2.5 \%$ & 1.00 & 75 \\
Clean outdoor coil & $1.8 \%$ & 1.00 & \\
Clean furnace heat exchanger & $1.8 \%$ & 2.00 & \\
Repair defrost cycle & $1.8 \%$ & 2.00 & 10 \\
Repair/replace wiring to auxiliary heater & $1.5 \%$ & 2.00 & 15 \\
Replace indoor fan motor & $1.5 \%$ & 2.00 & 150 \\
Repair/replace indoor fan motor wiring & $1.5 \%$ & 1.00 & 10 \\
Replace 1.5-2.0 refrigeration-ton compressor & $1.5 \%$ & 6.00 & 550 \\
Replace outdoor unit & $0.0 \%$ & 4.00 & 1600 \\
Repair furnace pilot assembly & $1.1 \%$ & 1.00 & 50 \\
Repair indoor fan & $1.1 \%$ & 1.00 & 10 \\
Replace outdoor coil & $0.7 \%$ & 4.00 & 400 \\
Replace gas furnace & $0.7 \%$ & 6.00 & 500 \\
Replace furnace heat exchanger & $0.4 \%$ & 2.00 & 300 \\
Repair outdoor fan motor & $0.4 \%$ & 1.00 & 10 \\
Replace indoor coil & $0.4 \%$ & 4.00 & 400 \\
Replace furnace gas valve & $0.4 \%$ & 2.00 & 100 \\
Repair gas leak & $0.4 \%$ & 1.00 & 10 \\
Weighted Average & & 1.23 & $\$ 334$ \\
\hline
\end{tabular}




\begin{tabular}{|r|l|r|}
\cline { 2 - 3 } \multicolumn{1}{c|}{} & \multicolumn{2}{c|}{ LABOR COSTS } \\
\hline a & Base Hourly Rate & $\$ 17.00$ \\
\hline b & Fringe Benefits & $5.0 \%$ \\
\hline c & Worker's Comp. Ins. & $6.1 \%$ \\
\hline d & Fixed Overhead & $14.6 \%$ \\
\hline e & Operating Overhead & $28.5 \%$ \\
\hline f & Hourly rate with oH & $\$ 26.21$ \\
\hline g & Number of men & 13 \\
\hline h & Hours/year & 2080 \\
\hline i & Annual Labor Cost & $\$ 708,597$ \\
\hline
\end{tabular}

\begin{tabular}{|r|l|r|}
\cline { 2 - 3 } \multicolumn{1}{c|}{} & \multicolumn{2}{c|}{ MATERIAL COSTS } \\
\hline $\mathrm{j}$ & Service calls/unityr & 3.22 \\
\hline $\mathrm{k}$ & Number of units & 4003 \\
\hline $\mathrm{T}$ & Mat' cost per call & $\$ 33.98$ \\
\hline $\mathrm{m}$ & Bare mat' costyear & $\$ 437,980$ \\
\hline $\mathrm{n}$ & Sales Tax & $5.0 \%$ \\
\hline 0 & Total Material costs & $\$ 459,879$ \\
\hline
\end{tabular}

\begin{tabular}{|c|c|c|c|}
\hline & \multicolumn{3}{|c|}{ OPERATING OVERHEAD } \\
\hline$t$ & Manager's Salary & $\$$ & 60,000 \\
\hline $\bar{u}$ & Fringe benefits & & $5.0 \%$ \\
\hline$\overline{\mathrm{v}}$ & Fixed Overhead & & $14.6 \%$ \\
\hline $\bar{w}$ & Worker's Comp Ins. & & $10.0 \%$ \\
\hline $\bar{x}$ & Manager w/OH & $\$$ & 77,760 \\
\hline $\bar{y}$ & Building & $\$$ & 24,000 \\
\hline $\bar{z}$ & Vehicles & $\$$ & 41,600 \\
\hline $\bar{a} \mathbf{a}$ & Utilities & $\$$ & 2,000 \\
\hline$\overline{a b}$ & Telephones & $\$$ & 3,000 \\
\hline $\mathrm{ac}$ & Office Equipment & $\$$ & 70,000 \\
\hline ad & $\sec y^{1}$ & $\$$ & 15,000 \\
\hline$\overline{\mathrm{ae}}$ & Sec'y 2 & $\$$ & 20,000 \\
\hline af & Fringe benefits & & $5.0 \%$ \\
\hline ag & Fixed Overhead & & $14.6 \%$ \\
\hline ah & Worker's Comp & & $4.0 \%$ \\
\hline ai & Secy's wlovh & $\$$ & 43,260 \\
\hline aj & Total Operating OH & $\$$ & 201,620 \\
\hline ak & Overhead Rate & & $28.5 \%$ \\
\hline
\end{tabular}

\begin{tabular}{|c|l|r|}
\cline { 2 - 3 } \multicolumn{1}{c|}{ TOTAL COSTS } \\
\hline $\mathrm{p}$ & Labor and materials & $\$ 1,168,475$ \\
\hline $\mathrm{q}$ & Insurance Costs & $7.5 \%$ \\
\hline $\mathrm{r}$ & Profit & $10.0 \%$ \\
\hline & \multicolumn{2}{|}{$\$ 1,372,959$} \\
\hline $\mathrm{s}$ & TOTAL \\
\hline & \multicolumn{2}{|}{24.6} \\
\hline & Cost, l/sq. ft. & \\
\hline
\end{tabular}

\begin{tabular}{|l|}
\hline \multicolumn{1}{|c|}{ Notes } \\
\hline$i=a^{*} g^{*} h^{*}(1+b+c+d+e)$ \\
\hline $0=j^{*} k^{*}(1+n)$ \\
\hline$z=g^{*} \cdot 32^{*} 10000$ \\
\hline$x=t^{*}(1+u+v+w)$ \\
\hline$a j=(a d+a e)^{*}(1+a f+a g+a h)$ \\
\hline$a j=x+y+z+a a+a b+a c+a i$ \\
\hline$a k=a j h$ \\
\hline$p=0+i$ \\
\hline$s=p^{*}(1+q+r)$ \\
\hline
\end{tabular}

Fig. 3.7. Baseline maintenance cost estimate for year 1 .

It was determined that a staff of 12 regular service technicians would be needed to perform the required maintenance and to make one preventive maintenance call per year to each residence. During the months of May, June, July, and August, three additional technicians would be required to handle the increased number of calls. This averages to 13 full-time employees, in addition to office staff. Data from R. S. Means Inc. (1992) were used to develop an estimate of the total cost per year of performing the maintenance on the 4003 residences of $\$ 1,373,290$. Details of the estimate are presented in Fig. 3.7.

This estimate of baseline maintenance costs for the first year of the ESPC is based on maintenance activities actually performed by the ESCO from May 1994 through April 1995. However, the maintenance requirements of the population of outdoor units changes over time, as Fig. 3.5 indicates. But note that the maintenance records examined show no outdoor units being replaced. Because the ASHPs and furnace/CACs were being maintained only until they could be 
replaced by GHP units, the ESCO did not replace entire outdoor units, choosing instead to replace components as needed.

In order to adjust the first-year estimate to account for this ESCO behavior, some further assumptions must be made. Note that $1.5 \%$ of the service calls were for compressor replacement. Out of a total of 12,890 calls, an average of 3.22 calls per residence per year, approximately 193 compressors were replaced. Since Fig. 3.5 indicates that 61 outdoor units would have been replaced during this year, we assume that in $32 \%$ of the cases ( 61 out of 193 ), the entire outdoor unit would have been replaced had the ESCO not been planning to replace everything with GHPs in the near future. Thus we add the activity "outdoor unit replacement" to the list of Table 3.2. The time for replacement of an entire outdoor unit is estimated to be 4 hours, with a cost of $\$ 1600$ for the typical 1.5-ton unit. Adding this task does not affect the labor requirements but does raise the average cost per service call. With these new materials costs, the total first-year baseline maintenance cost becomes $\$ 1,450,054$.

The baseline maintenance costs in subsequent years are estimated by allowing the frequency of "outdoor unit replacements" to change according to the expected number of outdoor unit replacements per year from Fig. 3.5. The resulting estimated baseline maintenance costs in each year of the ESPC are as listed in Table 3.3. Also listed are costs per unit per year, for comparison with the Army's baseline. The average of the 20 values is $\$ 369.05$ per housing unit per year, or 26.0 cents $/ \mathrm{ft}^{2}$ per year. The difference of $9.9 \%$ between this average and the Army's calculated baseline seems to be within the accuracy of the model, given its assumptions.

Table 3.3. Maintenance cost estimates by year

\begin{tabular}{ccc}
\hline $\begin{array}{c}\text { Years from start } \\
\text { of project }\end{array}$ & $\begin{array}{c}\text { Annual maintenance } \\
\text { cost }\end{array}$ & $\begin{array}{c}\text { Annual cost per } \\
\text { housing unit }\end{array}$ \\
\hline 1 & $\$ 1,450,054$ & $\$ 362.24$ \\
2 & $\$ 1,455,088$ & $\$ 363.50$ \\
3 & $\$ 1,460,122$ & $\$ 364.76$ \\
4 & $\$ 1,465,155$ & $\$ 366.01$ \\
5 & $\$ 1,468,931$ & $\$ 366.96$ \\
6 & $\$ 1,473,964$ & $\$ 368.21$ \\
7 & $\$ 1,476,481$ & $\$ 368.84$ \\
8 & $\$ 1,480,256$ & $\$ 369.79$ \\
9 & $\$ 1,482,773$ & $\$ 370.42$ \\
10 & $\$ 1,484,032$ & $\$ 370.73$ \\
11 & $\$ 1,485,290$ & $\$ 371.04$ \\
12 & $\$ 1,486,549$ & $\$ 371.36$ \\
13 & $\$ 1,486,549$ & $\$ 371.36$ \\
14 & $\$ 1,486,549$ & $\$ 371.36$ \\
15 & $\$ 1,486,549$ & $\$ 371.36$ \\
16 & $\$ 1,485,290$ & $\$ 371.04$ \\
17 & $\$ 1,485,290$ & $\$ 371.04$ \\
18 & $\$ 1,484,032$ & $\$ 370.73$ \\
19 & $\$ 1,482,773$ & $\$ 370.42$ \\
20 & $\$ 1,480,256$ & $\$ 369.79$ \\
20-year average & $\$ 1,477,299$ & $\$ 369.05$ \\
\hline
\end{tabular}

Given the values in Table 3.3, the life-cycle cost to the Army of maintaining the family housing HVAC equipment over 20 years is $\$ 15,609,989$ on a present-value basis, using the 
standard 7\% discount rate specified by the government (BLCC 1998). With the contracted baseline and the schedule of payments in Table 3.1, the life-cycle cost of the payments the Army will make to the ESCO is $\$ 11,076,395$ on a present-value basis. This represents a net presentvalue cost savings to the Army of $\$ 4,533,594$ over the life of the contract. 


\section{USING CALIBRATED ENGINEERING MODELS TO PREDICT ENERGY SAVINGS}

Accurate predictions of the energy savings to be expected from ESPCs can reduce risk, decrease financing costs, and help avoid post-construction disputes over performance contract baseline adjustments. This section demonstrates an improved method of estimating energy savings before construction takes place. Using an engineering model calibrated to field data on pre-retrofit energy use, the method can predict actual energy savings with a high degree of accuracy. This is verified with post-retrofit energy use data from Fort Polk. The method can also be used to determine the relative impact of the various energy conservation measures installed in a comprehensive energy conservation project. As an example, the breakout of savings from the geothermal heat pumps, desuperheaters, lighting retrofits, and low-flow hot water outlets is provided for one of the feeders at Fort Polk.

\subsection{INTRODUCTION}

It is well known that predictions of savings from energy conservation programs are often optimistic, especially in the case of residential retrofits. Fels and Keating (1993) cite several examples of programs that achieved as little as $20 \%$ of the predicted energy savings. Factors in the sometimes large discrepancies between actual and predicted savings include changes in occupancy, take-back effects (in which more efficient system operation leads occupants to choose higher levels of comfort), and changes in base energy use (for example, through purchase of additional appliances such as washing machines and clothes dryers). An even larger factor may be the inaccuracy inherent in the engineering models commonly used to estimate building energy consumption if these models are not first calibrated to site-monitored energy use data.

The improved savings estimating approach described here is based on an engineering model calibrated to field-collected data from the pre-retrofit period. A dynamic model of pre-retrofit energy use was developed for all housing and nonhousing loads on an entire electrical feeder at Fort Polk. The feeder serves 46 buildings containing a total of 200 individual apartments. The model included the heat-transfer characteristics of the buildings, the pre-retrofit air-source heat pump, a hot-water-consumption model, and a profile for electrical use by lights and other appliances. Energy consumption for all 200 apartments was totaled, and by adjusting thermostat setpoints and outdoor-air-infiltration parameters, the models were matched to field-collected energy consumption data for the entire feeder. The energy conservation measures were then implemented in the calibrated model: the air-source heat pumps were replaced by geothermal heat pumps with desuperheaters; hot water loads were reduced to account for the low-flow shower heads; and lighting loads were reduced to account for fixture delamping and replacement with compact fluorescent lights. Analysis of pre- and post-retrofit data indicates that the retrofits have saved $30.3 \%$ of pre-retrofit electrical energy consumption on the modeled feeder. The method outlined here predicts this savings within $1 \%$ of its measured value, using only pre-construction energy consumption data and post-retrofit data from one pilot test site.

The technique was also applied to a feeder serving housing which used natural gas for heating and water heating prior to the retrofits. Here calibration to field-monitored data was more difficult, since no data were available on natural gas consumption. Energy use models for 142 apartments in 38 buildings were calibrated to pre-retrofit feeder-level electrical energy consumption only. When the retrofits were implemented in the apartment models, the resulting feeder model predicted electrical post-retrofit energy consumption some $9 \%$ higher than the 
monitored post-retrofit consumption. The model predicted a savings of $9.5 \%$ of pre-retrofit electrical energy in a TMY, whereas the feeder-level data showed that the savings would be $16.2 \%$. However, the housing on this feeder was built in 1975 , the second-oldest vintage in family housing, and project resources did not allow auditing the construction records to determine the extent of any addition of attic insulation, so no addition was assumed in the model. The lower modeled savings may be the result of this assumption.

\subsection{MODELING OF AN ALL-ELECTRIC FEEDER}

Figure 4.1 shows a site plan for the buildings on Feeder 1 at Fort Polk. The area contains three unique building types: 12 buildings designated as type 1, a four-plex; 18 buildings designated as type 2, another four-plex; and 16 buildings of type 3, a five-plex. Although type 1 and type 2 buildings have identical floorplans, they differ in the design of the roof and in the location of carports. Since the roof design was expected to have an effect on space conditioning loads, the two types were modeled separately. Table 4.1 lists the type and compass orientation of each building (south-facing buildings are at 0 degrees; the orientation is measured counter-clockwise from south).

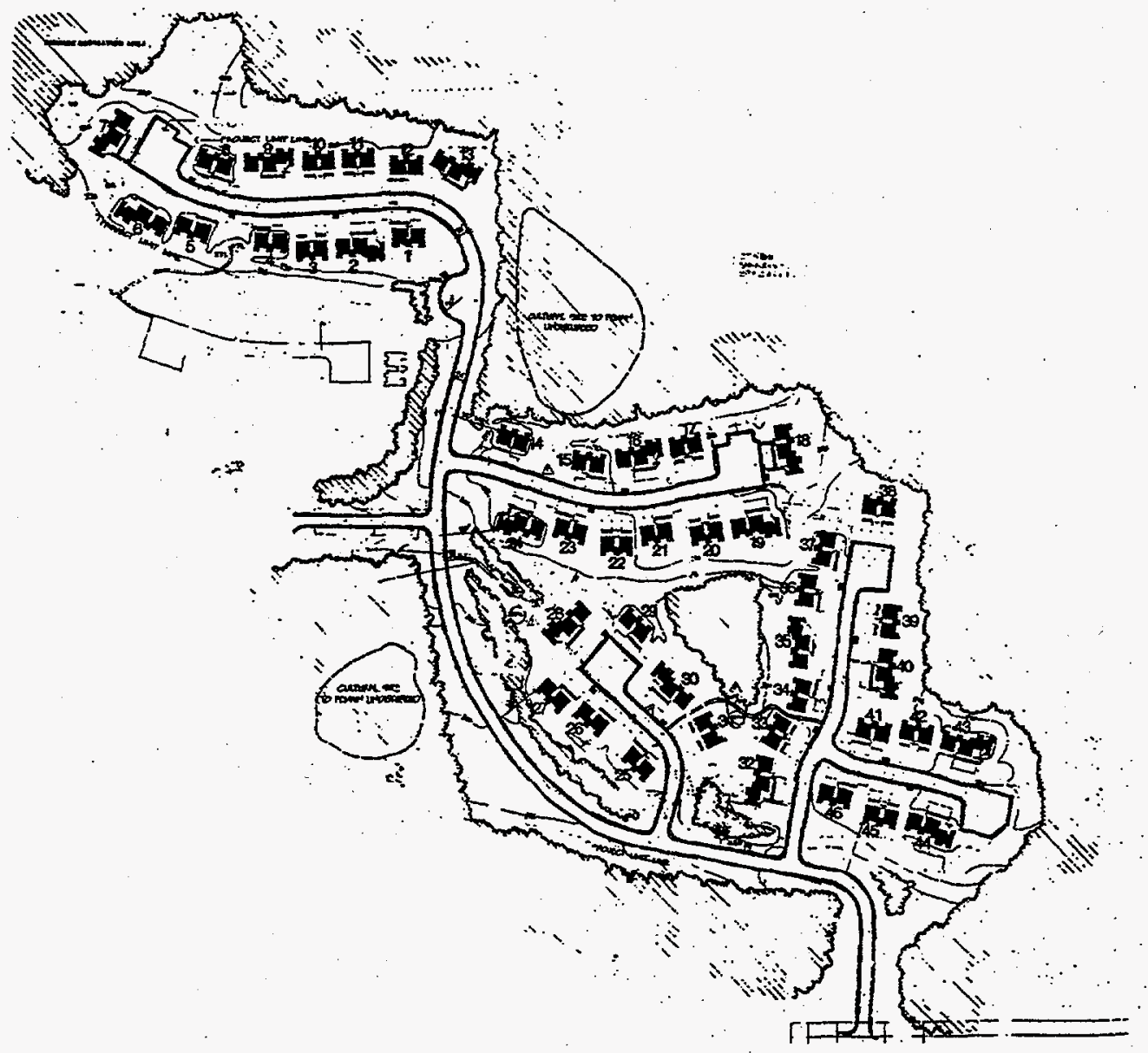

Fig. 4.1. Site plan for the area served by Feeder 1. 
Table 4.1. Construction type and compass orientation of the buildings on Feeder 1

\begin{tabular}{ccc|ccc}
\hline Building & Type & Orientation & Building & Type & Orientation \\
\hline 1 & 2 & $180^{\circ}$ & 24 & 3 & $200^{\circ}$ \\
2 & 3 & $180^{\circ}$ & 25 & 2 & $230^{\circ}$ \\
3 & 1 & $180^{\circ}$ & 26 & 2 & $220^{\circ}$ \\
4 & 2 & $180^{\circ}$ & 27 & 2 & $220^{\circ}$ \\
5 & 2 & $180^{\circ}$ & 28 & 3 & $320^{\circ}$ \\
6 & 3 & $210^{\circ}$ & 29 & 2 & $50^{\circ}$ \\
7 & 3 & $300^{\circ}$ & 30 & 3 & $50^{\circ}$ \\
8 & 2 & $20^{\circ}$ & 31 & 1 & $60^{\circ}$ \\
9 & 3 & $0^{\circ}$ & 32 & 3 & $280^{\circ}$ \\
10 & 1 & $0^{\circ}$ & 33 & 1 & $300^{\circ}$ \\
11 & 1 & $0^{\circ}$ & 34 & 2 & $280^{\circ}$ \\
12 & 2 & $0^{\circ}$ & 35 & 3 & $280^{\circ}$ \\
13 & 3 & $30^{\circ}$ & 36 & 2 & $280^{\circ}$ \\
14 & 2 & $21^{\circ}$ & 37 & 2 & $280^{\circ}$ \\
15 & 2 & $10^{\circ}$ & 38 & 1 & $10^{\circ}$ \\
16 & 3 & $0^{\circ}$ & 39 & 1 & $100^{\circ}$ \\
17 & 1 & $0^{\circ}$ & 40 & 3 & $100^{\circ}$ \\
18 & 3 & $90^{\circ}$ & 41 & 2 & $10^{\circ}$ \\
19 & 3 & $170^{\circ}$ & 42 & 1 & $10^{\circ}$ \\
20 & 1 & $170^{\circ}$ & 43 & 3 & $10^{\circ}$ \\
21 & 2 & $170^{\circ}$ & 44 & 3 & $190^{\circ}$ \\
22 & 1 & $180^{\circ}$ & 45 & 1 & $190^{\circ}$ \\
23 & 2 & $200^{\circ}$ & 46 & 2 & $190^{\circ}$ \\
\hline
\end{tabular}

Among the three building types there are only two unique apartment floorplans: apartment type $\mathrm{A}$, containing $1142 \mathrm{ft}^{2}$ of living space, and apartment type $\mathrm{B}$, containing $1114 \mathrm{ft}^{2}$. One apartment of type B exists in each of the five-plexes; all other apartments in all buildings are of type A. Thus, in total there are 184 apartments of type A and 16 apartments of type B. As-built plans for all three building types were made available for use in modeling the building performance.

Prior to the retrofits, the apartments on this feeder used electric air-source heat pumps and electric water heaters. None of these units used natural gas or contained fireplaces, so the feeder meter captures all of the energy used in the 200 apartments.

Figure 2.4 presents the pre-retrofit electrical energy consumption on the feeder for a period of approximately one year, as monitored at the site. Each data point represents the total energy consumed on the feeder for one day; this value is plotted versus the average temperature for that day. Fitting a dual-changepoint model (discussed in Sect. 2.2) to the data shown in Fig. 2.4 gives the following relation between daily total energy use, $\mathrm{E}$, and daily average temperature, $\mathrm{T}$ :

$$
\begin{aligned}
& E=6597.5-200.7 \times(T-56.9) \quad\{T<56.9\} \\
& 6597.5 \\
& 6597.5+187.5 \times(\mathrm{T}-69.8) \\
& \{56.9 \leq \mathrm{T} \leq 69.8\} \\
& \{\mathrm{T}>69.8\}
\end{aligned}
$$




\subsubsection{Apartment-Level Energy Use Models}

In order to model the energy used in space conditioning equipment, controls, and water heating for the 200 apartments on the selected feeder, the TRNSYS (Klein et al. 1996) simulation software was employed. TRNSYS is a modular system-simulation package in which the user specifies the components that constitute the system and the manner in which these components are interconnected. In TRNSYS, components may be physical pieces of equipment such as pumps or controllers; or utility modules, such as occupancy forcing functions, shading effects due to overhangs and wingwalls, and weather data readers.

For this study, each of the three building types was treated as a separate simulation. The component models were chosen to be the building and its associated forcing functions (weather, occupancy, infiltration, water draw), heat pumps for each apartment (air-source heat pumps for the pre-retrofit simulations and geothermal with desuperheaters for the post-retrofit simulations), thermostats for each apartment, domestic hot water storage tanks, and pumps and fans for each apartment.

Although the ambient temperature and relative humidity were measured at the site, these values were not used in the simulations because of the lack of solar radiation measurements. Instead, TMY weather data from Lufkin, Texas, were used for the simulations, as Lufkin represents the closest inland TMY site to Fort Polk.

The TMY weather, which is a monthly best-fit average of 30 years of weather data, contains ambient temperature, relative humidity, incident solar radiation, and wind speed values at hourly increments for a year. The incident solar radiation on each of the exterior surfaces of the apartment buildings was processed and subject to overhang and wingwall shading effects, as each of the three building types has many such features.

The ground temperature for the simulations was modeled with the Kusuda correlation (Kusuda and Archenbach 1965). This correlation requires inputs of the mean annual surface temperature, the amplitude of the surface temperature, and the phase delay, and it calculates the hourly distribution of ground temperature with depth. For reference, the published values of these properties (ASHRAE 1977) for Alexandria, Louisiana, are the following:

Mean annual soil surface temperature: Amplitude of surface temperature:

Day of minimum surface temperature: $69^{\circ} \mathrm{F}$

$17^{\circ} \mathrm{F}$

February 1

Prior to the retrofits, each of the apartments was equipped with a nominal 1.5-ton split-system air-source heat pump. The heat pumps were manufactured in 1981. An air-source heat pump model was written for this study so that the manufacturer's catalog data for the installed heat pumps could be read from a look-up table and interpolated, based on operating conditions, to provide the heating and cooling capacities and system power. Inputs to the model include the ambient and zone conditions (temperature and humidity), the conditioned air flow rate (assumed constant at its rated value of 650 CFM), and the control signal from the thermostat. Outputs from the model include the calculated values of exiting air temperature and humidity and the equipment capacity and power draw.

At the 18 Level-3 residences included in the evaluation (none of which, incidentally, were located on the modeled feeder), data were collected at 15-minute intervals for the total residence electrical use, the energy used by the HVAC system, and the energy used by the water heater. Because the simulation would determine HVAC and hot water energy use from the building and equipment characteristics, it was necessary to derive an electrical load profile for the other appliances. This was obtained by subtracting the energy used by the HVAC system and the water 
heater from the total apartment energy use in each 15-minute interval. We refer to the non-HVAC, non-domestic-hot-water electrical energy use as the "lighting/appliance load." In addition to residential lighting, it includes such things as clothes washers, clothes dryers, hair dryers, stereos, radios, and televisions.

The lighting/appliance load data were used in two ways. First, average weekday and weekend daily profiles were developed for the 18 Level-3 residences over the approximately one-year preretrofit monitoring period. (Since construction was ongoing during data collection, and the sites were randomly distributed across the base, the length of the pre-retrofit period varied by apartment.) On each weekday in the pre-retrofit period, an average was taken of the electrical energy use in each 15-minute period, for each apartment. The same average was taken for each weekend day. These average profiles are shown in Fig. 4.2. Since it was assumed that lighting/appliance energy use would be a function of apartment floorspace, the profiles were normalized by dividing each value by the average apartment floor area.

While the appliance use per day per apartment was highly variable (with standard deviation of $7.5 \mathrm{kWh}$ per day), there was a slight positive correlation between total daily energy use and apartment floorspace. The data is presented in Fig. 4.3. Note that each data point in the figure represents the average daily appliance energy use of several apartments with the same floor area. Although the correlation coefficient $\left(r^{2}\right)$ was only about 0.2 , we decided to use the regression equation to determine total daily appliance draw for the modeled apartments. In the absence of demographic data, apartment floor area was the only way to account for the variability seen in the data. Thus, to determine the daily appliance electrical profile for the modeled apartments, the normalized profile based on all the Level-3 apartments was used, with each 15-minute value multiplied by a constant that depended on the apartment floor area.

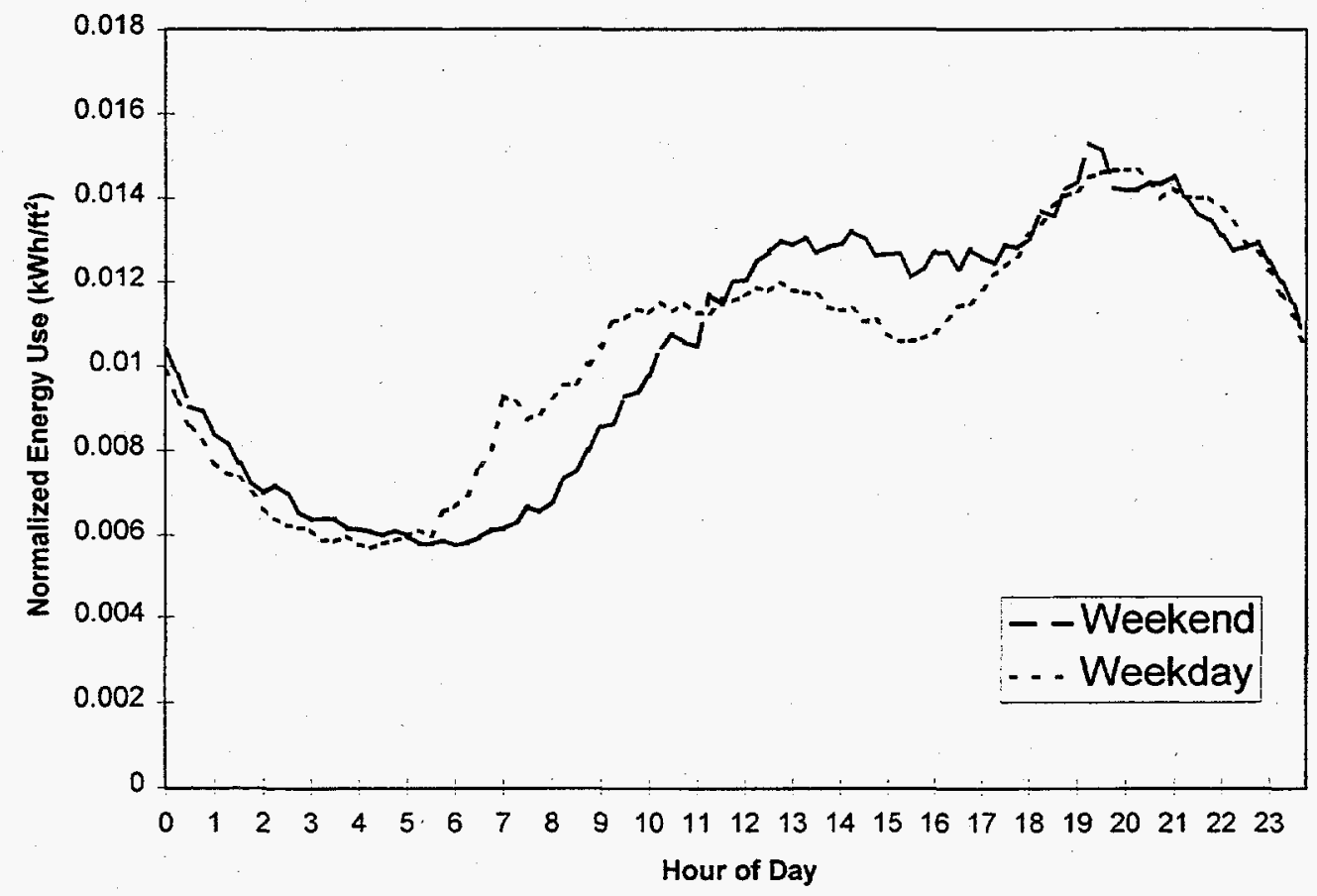

Fig. 4.2. Average electrical energy use per square foot per hour for lighting and other appliances. 


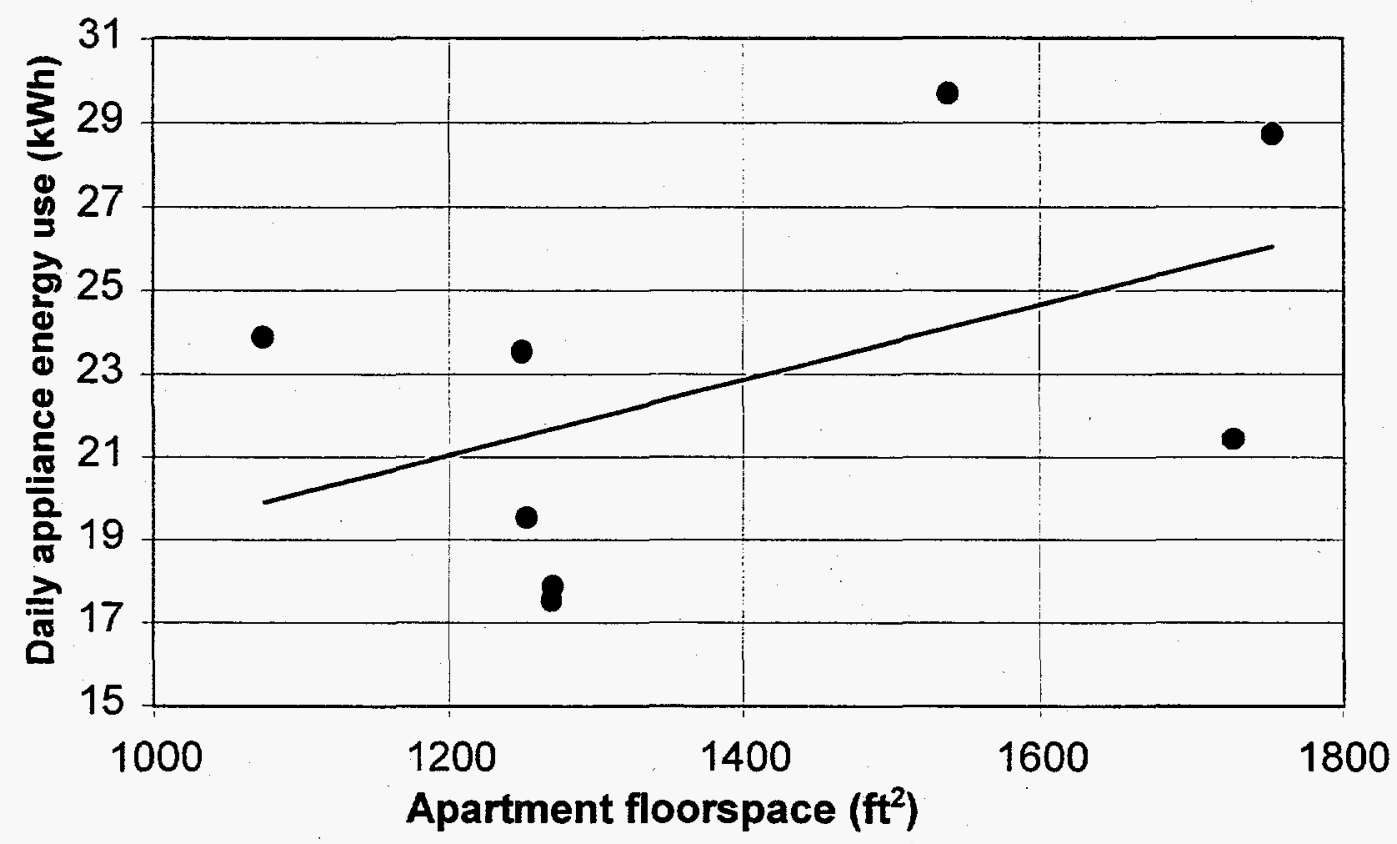

Fig. 4.3. Average daily electrical energy use for lights and other appliances by apartment floorspace.

The weekday and weekend electrical lighting/appliance load profiles of Fig. 4.2 were used as an input to the TRNSYS models. In order to account approximately for exhaust fans and porch/entry lighting, only $90 \%$ of the electrical energy was returned to the building as a heat gain.

As with the appliance energy use, the daily hot water draw profile used in the modeled apartments is an average of data collected at 18 Level-3 sites, adjusted by apartment floorspace. However, the data collected at the Level-3 sites represented hot water tank electrical energy use rather than hot water draw. In order to convert electrical use into hot water use, we assumed that the lowest energy use during the day represented standby losses. Then assuming an inlet temperature of $68^{\circ} \mathrm{F}$ (the average value seen at the energy-balance site) and a tank setpoint temperature of $130^{\circ} \mathrm{F}$, the hot water use during every 15 -minute interval could be determined. For the apartments on Feeder 1, the average daily pre-retrofit hot water use was determined to be 36.2 gal. For comparison, ASHRAE (1995b) reports an average daily use of 42 gal for apartment buildings of 20 or fewer units. The lower figure derived from the Fort Polk data may be due to less than full occupancy in the apartments monitored, or showers being taken at the fitness facilities instead of at home, or the $130^{\circ} \mathrm{F}$ tank setpoint assumption (an assumption of $121^{\circ} \mathrm{F}$ would be consistent with 42 gal per day). The average weekday and weekend water draw profiles for the modeled apartments are presented in Fig. 4.4. They compare well with the ASHRAE profile (1995b) for a typical residence.

The weekday and weekend hot water draw profiles of Fig. 4.4 were used as an input to the TRNSYS models. Each apartment is assumed to contain a standard 52-gal electric water heater with two $3300-W$ heating elements. 


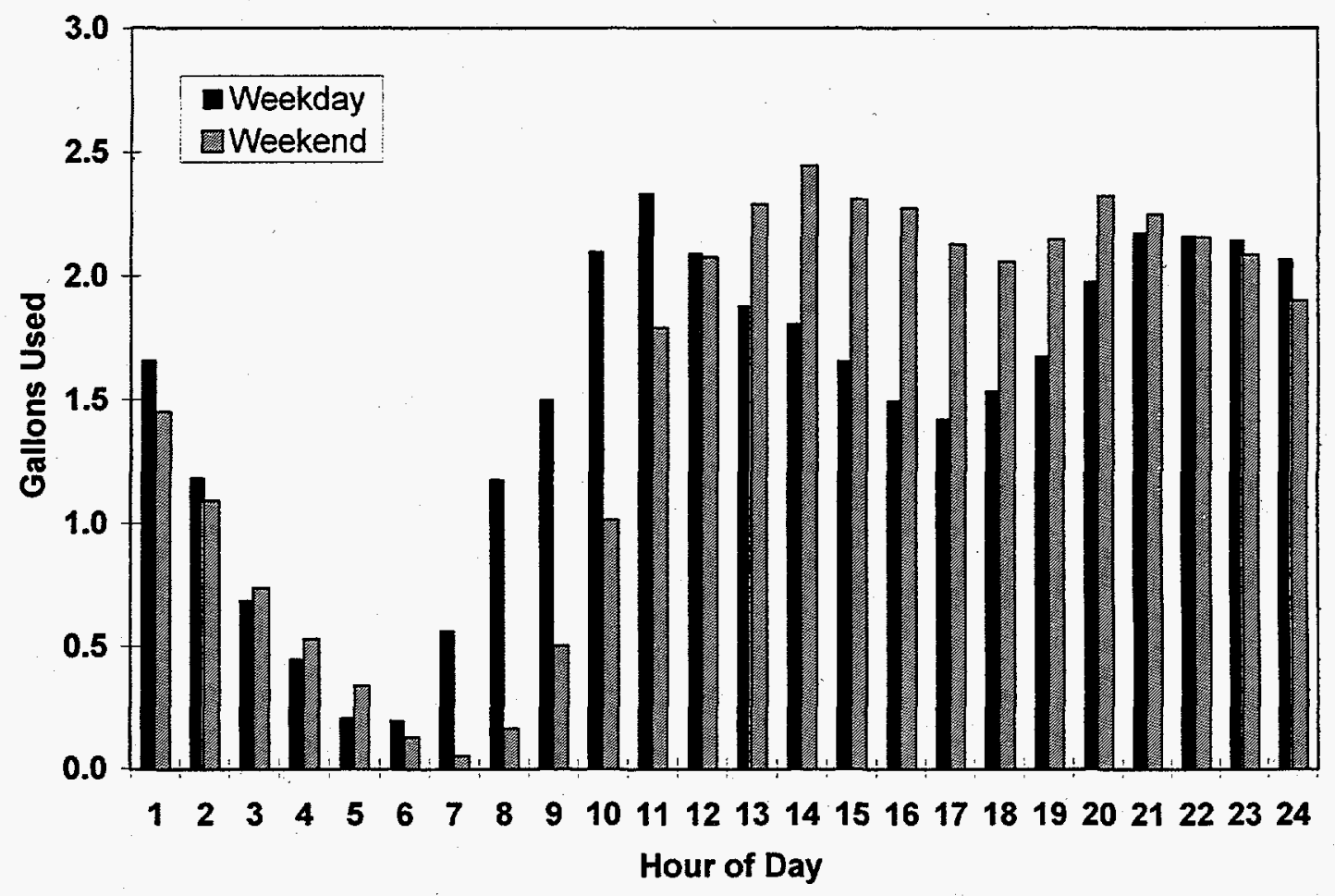

Fig. 4.4. Weekend and weekday hourly hot water draw for the average Fort Polk residence.

\subsubsection{Streetlights and Other Nonhousing Loads}

In addition to serving 200 apartments, the feeder under consideration provides electrical energy for 68 streetlights: 52 lamps rated at $116 \mathrm{~W}$ and 16 lamps at $302 \mathrm{~W}$. In order to include these loads in the total energy use of the feeder, a separate TRNSYS model was developed that simply turned on all of the streetlights each day at dusk and turned them off at dawn, using the value of solar radiation from the TMY file to determine the time of sunrise and sunset. Between 109 and $152 \mathrm{kWh}$ per day are added to the total housing load, depending on the length of the day throughout the year.

In general, the sum of the electrical energy in the 200 apartments will not equal the electrical energy as monitored at the feeder - even when streetlights are considered - because of line losses and transformer losses. Although no information on these losses was available, they are expected to be small, in the range of 1 to $2 \%$. This loss was not modeled: since the models were calibrated to feeder-level data, the energy consumption predicted for the apartments may be 1 to $2 \%$ higher than actual energy consumption.

\subsubsection{Model Calibration to Pre-Retrofit Data}

The floor plans, construction details, and compass orientation of each of the 46 buildings, as well as the average 15-minute hot water draw and appliance electrical loads, provided sufficient information for the energy use to be modeled. Nevertheless, several unknowns still remained. No information was available about occupancy (number of occupants per apartment) or vacancy rate. Since the population of family housing at Fort Polk is given as 12,000 for the 4003 housing units, the average occupancy was assumed to be three individuals per apartment, even though the 
modeled apartments are slightly smaller than the average family housing unit at the base. Thermostat setpoints were also unknown.

The TRNSYS software allows the adjustment of a number of other parameters affecting energy use such as occupancy schedules, shading schedules for windows by curtains and blinds, and moisture capacitance of furnishings. Aside from thermostat setpoints, the single parameter that has perhaps the largest effect on energy consumption is outdoor air infiltration. Since the rate of outdoor air infiltration was unknown for the modeled apartments, we decided that the feeder model would be calibrated to the monitored pre-retrofit feeder energy use data by varying outdoor air infiltration. Thus, in this simulation, the outdoor air infiltration likely captures the effect of a number of other parameters (including vacancies) and probably does not represent the true infiltration rate of the apartments.

In order to reduce the number of computer runs required, the building compass orientations were run at intervals of $45^{\circ}$. Table 4.2 presents the building types and the number of each type at each $45^{\circ}$ increment. Thus, building type 1 was simulated at orientations of $0^{\circ}, 45^{\circ}, 90^{\circ}, 180^{\circ}$, $315^{\circ}$, and so forth. This reduced the number of cases run to 17 . Each of the 17 cases was then weighted according to the number of buildings it represented. The daily streetlight energy use was added to this weighted sum to determine the energy use for the entire feeder.

A constant of 0.05 air changes per hour was originally used to calibrate the model to the actual data. The output matched the monitored data quite well in the cooling season, but simulated energy use was low in the heating season. For this reason, a separate infiltration model was used for the heating season. The model assumed a constant of 0.05 air changes per hour plus a separate factor of 0.02 multiplied by the temperature difference between the room and ambient temperatures. Thermostat setpoints were fixed at $72^{\circ} \mathrm{F}$ in heating and $76^{\circ} \mathrm{F}$ in cooling, which agrees with monitored data from other apartments at the site. Figure 4.5 compares the modeled data for the entire feeder, pre-retrofit, with the feeder-level data collected on-site. Assessed visually, the calibrated TRNSYS model appears to agree quite well with the actual pre-retrofit energy consumption of the feeder. For a typical meteorological year, the model predicts energy consumption of 3.02 million $\mathrm{kWh}$, or an average of $41.4 \mathrm{kWh}$ per apartment per day. The monitored data, when normalized to a typical meteorological year, gives an annual energy use of 2.87 million $\mathrm{kWh}$, or about $39.4 \mathrm{kWh}$ per apartment per day. Thus on an annual basis, the calibrated TRNSYS model is able to predict energy consumption to within about $5 \%$ of the monitored data.

Table 4.2. Orientations simulated for each building type

\begin{tabular}{cccc}
\hline & \multicolumn{3}{c}{ Building type } \\
\cline { 2 - 4 } Orientation & 1 & 2 & 3 \\
\hline $0^{\circ}$ & 5 & 5 & 3 \\
$45^{\circ}$ & 1 & 1 & 2 \\
$90^{\circ}$ & 1 & 0 & 2 \\
$135^{\circ}$ & 0 & 0 & 0 \\
$180^{\circ}$ & 4 & 6 & 4 \\
$225^{\circ}$ & 0 & 3 & 1 \\
$270^{\circ}$ & 0 & 3 & 2 \\
$315^{\circ}$ & 1 & 0 & 2 \\
\hline
\end{tabular}




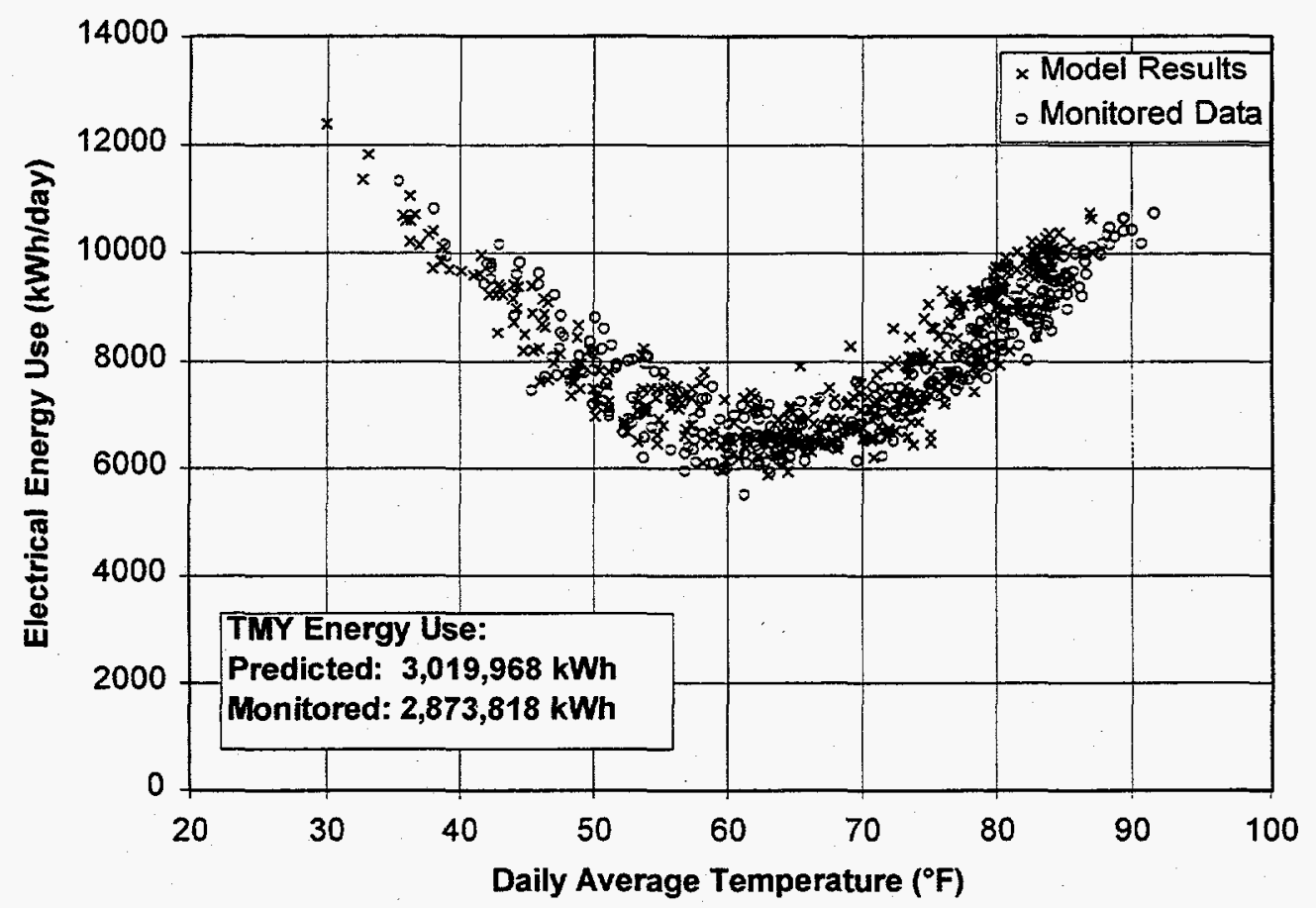

Fig. 4.5. Feeder 1 pre-retrofit daily electrical energy use vs daily average temperature. Monitored data and calibrated simulation model.

When fitted to a dual-changepoint model of daily energy use vs daily average temperature, the TRNSYS model gives the following equation:

$$
\begin{array}{lll}
E=\quad 7007.50-209.27 \times(T-54.1) & \{T<54.1\} \\
7007.50 & \{54.1 \leq \mathrm{T} \leq 70.6\} \\
7007.50+237.10 \times(T-70.1) & \{\mathrm{T}>70.6\}
\end{array}
$$

Comparison with Eq. (4.1) shows that the "base load" constant derived from the TRNSYS simulations is about $8 \%$ higher than the constant derived from the monitored data. Also, the breakpoint for the heating region is about $3^{\circ} \mathrm{F}$ lower than the breakpoint derived from the monitored data. With further adjustments of setpoint temperatures, air-infiltration factors, and other parameters, it would have been possible to match the monitored pre-retrofit heating data to a higher degree of accuracy. But the intent here is to demonstrate that reasonably accurate predictions of savings are possible after only modest efforts to calibrate the model. An error of just $5 \%$ was obtained by varying only one parameter (air infiltration).

\subsubsection{Implementation of Energy Conservation Measures}

Once the model was calibrated to pre-retrofit data, the energy conservation retrofits were implemented in the model. Air-source heat pumps were replaced with geothermal heat pumps that included desuperheaters to provide additional heat to the hot water tank. The lighting load was reduced to account for fixture delamping and replacement of existing fixtures with compact fluorescent lights (CFLs). Finally, the hot water load was reduced to account for the low-flow shower heads. The following sections describe how each of these measures was implemented in the model. 


\section{Geothermal Heat Pump Model}

The geothermal (ground-source) heat pumps that anchored the energy conservation retrofit at Fort Polk account for the largest impact on energy savings in the project. A GHP model written for TRNSYS as part of the overall evaluation was used for the post-retrofit simulations. (Sect. 5 discusses our heat pump modeling work and Sect. 5.1 describes the heat pump systems in detail.) Figures 4.6 and 4.7 present diagrams of a typical ground heat exchanger configuration.

The geothermal heat pump model uses a look-up table approach for both heating and cooling modes to determine the manufacturer's published catalog data for capacity, power, and water heat transfer. Inputs to the model include temperature and flow rate of the entering water; temperature, humidity ratio, and flow rate of the entering air; and the control signal from the thermostat. Outputs from the model include temperature and flow rate of leaving water; temperature, humidity ratio, and flow rate of exiting air; and the equipment capacity and power draw. Energy balance and psychrometric calculations at each iteration ensure that the air-side and water-side results from the model at each time step are reasonable.

For geothermal heat pump system simulations, the most important component model is the ground heat exchanger. Although several ground heat exchanger models were available, the duct ground heat storage model (Hellstrom et al. 1996) developed at the University of Lund, Sweden, was chosen for this study because it is well documented and validated, and it considers multibore interactions and long-term (multiyear) effects. This model was used to predict ground heat exchanger performance against measured data in our heat pump modeling study with excellent results (see Sect. 5).

\section{Lighting Retrofits}

Lighting retrofits in the 200 apartments included delamping of some conventional fixtures and replacement of lamps in other fixtures by CFLs. The retrofits are described in Table 4.3. In order to determine the reduction in electrical energy use, the average pre-retrofit electrical energy profile, which accounts for all electrical use exclusive of the HVAC and water heating systems, was adjusted to correspond to the retrofits. In the apartments under consideration, the total daily consumption for lighting/appliance uses is $20.5 \mathrm{kWh}$. According to a reference from the U.S. Department of Energy (DOE 1994), lighting should account for $24.2 \%$ of this total, or about $5.0 \mathrm{kWh} /$ day, leaving $15.5 \mathrm{kWh} /$ day for other uses such as cooking, refrigeration, radios, and televisions.

In each apartment, lighting power was reduced from $1845 \mathrm{~W}$ to $458 \mathrm{~W}$. If lighting is to account for $5.0 \mathrm{kWh}$ in the pre-retrofit period, then, on average, these $1845 \mathrm{~W}$ must have been in use for 2.71 hours per day. Assuming lights are in use for the same number of hours after the retrofits, then post-retrofit lighting use will account for $(458 \mathrm{~W})(2.71 \mathrm{~h})=1.2 \mathrm{kWh} /$ day. Assuming electrical use for other appliances remained constant, then the daily lighting/appliance electrical use in the post-retrofit will be $16.7 \mathrm{kWh} /$ day, or about $81 \%$ of the pre-retrofit use. Since lights are used mostly in the morning and the evening, it would have been possible to develop a lighting schedule. However, considering that the pre-retrofit profile was developed by averaging one year's worth of daily profiles for 18 different apartments inhabited by occupants with varying work schedules, we decided to simply multiply each 15 -minute consumption in the pre-retrofit lighting/appliance profile by 0.81 to obtain the post-retrofit energy use. 


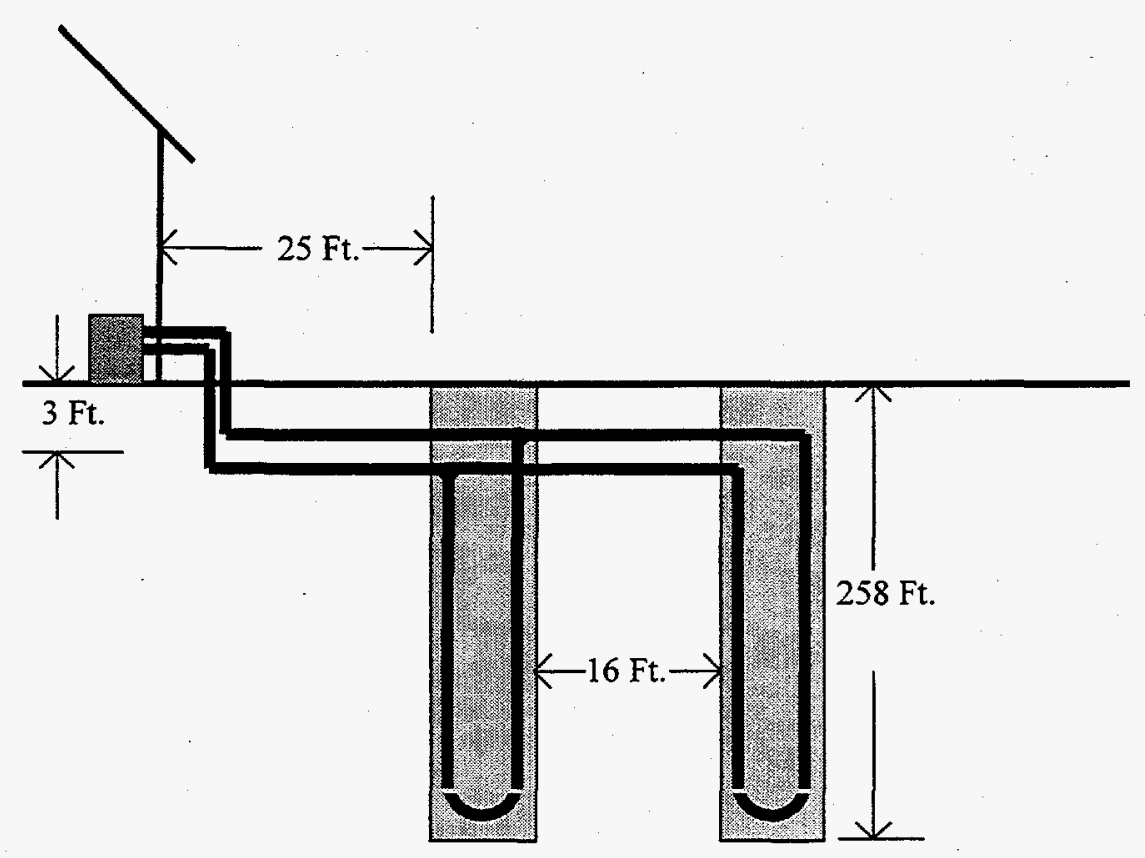

Fig. 4.6. Side view of the ground heat exchanger configuration.

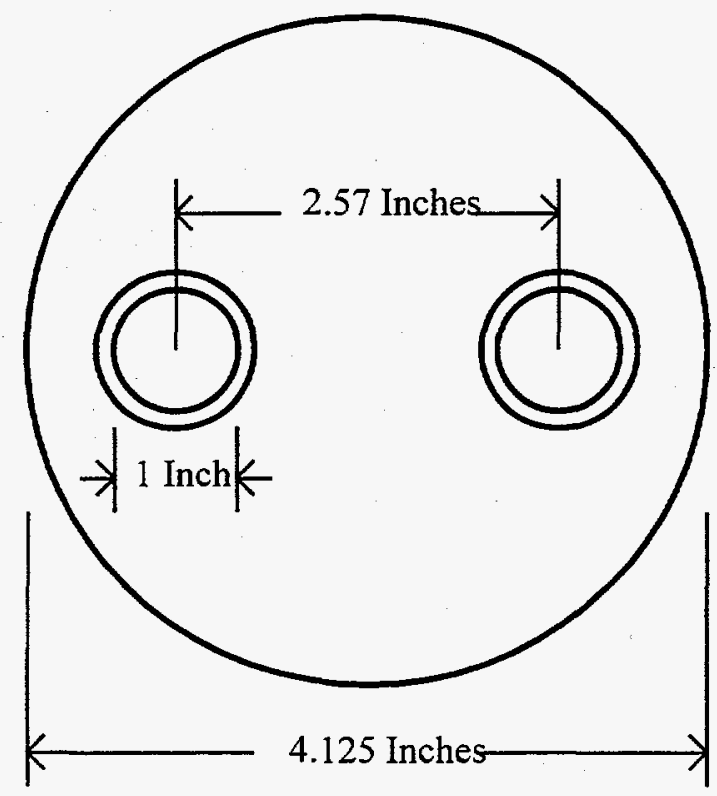

Fig. 4.7. Top view of a U-tube vertical ground heat exchanger. 
Table 4.3. Lighting retrofits installed in apartments on Feeder 1

\begin{tabular}{llcccccc}
\hline Room & Fixture type & $\begin{array}{c}\text { Lamps per } \\
\text { fixture }\end{array}$ & $\begin{array}{c}\text { Watts per } \\
\text { lamp }\end{array}$ & $\begin{array}{c}\text { Number of } \\
\text { fixtures }\end{array}$ & $\begin{array}{c}\text { Pre-retrofit } \\
\text { watts }\end{array}$ & $\begin{array}{c}\text { Retrofit } \\
\text { type }\end{array}$ & $\begin{array}{c}\text { Post-retrofit } \\
\text { watts }\end{array}$ \\
\hline Kitchen & Ceiling, fluor. & 2 & 48 & 1 & 96 & delamp & 68 \\
Kitchen & Range hood & 1 & 25 & 1 & 25 & CFL & 13 \\
Dining & Ceiling surface & 5 & 100 & 1 & 500 & CFL & 65 \\
Family & Pendant, fluor. & 2 & 66 & 1 & 132 & delamp & 66 \\
Bath & Wall, fluor. & 1 & 46 & 1 & 46 & CFL & 26 \\
Closets & Ceiling, keyless & 1 & 60 & 1 & 60 & CFL & 13 \\
Bedrooms & Ceiling surface & 2 & 60 & 3 & 360 & CFL & 78 \\
Kitchen & Under cab., fluor & 1 & 25 & 2 & 50 & delamp & 25 \\
Hall & Ceiling surface & 1 & 60 & 2 & 120 & CFL & 26 \\
Hall & Wall bracket & 1 & 60 & 1 & 60 & CFL & 13 \\
Utility & Ceiling, fluor. & 2 & 48 & 1 & 96 & CFL & 13 \\
Patio & Wall bracket & 1 & 60 & 1 & 60 & CFL & 13 \\
Ext. entry & Wall bracket & 1 & 60 & 2 & 120 & CFL & 13 \\
Carport & Ceiling, keyless & 1 & 60 & 2 & 120 & CFL & 26 \\
Total per apartment & & & & $\mathbf{1 8 4 5}$ & & $\mathbf{4 5 8}$ \\
\hline
\end{tabular}

\section{Low-Flow Shower Heads}

In order to determine the effects of the low-flow shower heads, the starting point was the preretrofit hot water draw profile developed from the hot water tank energy use profile. The draw profile indicates that the average residence on this feeder uses about 36.2 gal of hot water per day. According to a reference from DOE (1994), hot water use for showers accounts for about $59 \%$ of total residential hot water use on a national basis. Thus, it is assumed that the average pre-retrofit residence at Fort Polk uses approximately 21.4 gal per day for showers and 14.8 gal for other uses. The ESCO calculated that the shower heads installed would reduce water use per shower from 9.6 gal to 6.0 gal, figuring an average of 2.2 showers per day per apartment. If the number and length of showers per day remain constant after the retrofits, hot water use for showers should drop to 13.4 gal per day. The total post-retrofit hot water use would then be 28.2 gal per day, or about $78 \%$ of its pre-retrofit value.

Again, since most showers are likely to occur in the early morning and late evening, it would have been possible to develop a schedule and adjust the pre-retrofit water draw accordingly. However, considering that the pre-retrofit profile was developed by averaging daily profiles of 18 apartments over one year, we decided to simply multiply each 15 -minute draw in the pre-retrofit hot water draw profile by 0.78 to obtain the post-retrofit hot water draw.

\section{Desuperheater}

In the post-retrofit simulations, water is also heated by being drawn from the bottom of the storage tank and sent to the desuperheater of the geothermal heat pump when it is operating. The heated water is then returned to the top of the tank. The desuperheater in the geothermal heat pump is modeled with a constant heat transfer coefficient calculated from the manufacturer's catalog data. Values for desuperheater refrigerant temperatures in heating and cooling modes were based on conversations with the manufacturer. 


\section{Attic Insulation}

According to the subcontractor who performed the retrofits, degraded attic insulation was repaired on a small number of upper-floor apartments on this feeder, but additional insulation was not added. Since no information was available either on the number of apartments that received these repairs or on the quantity of insulation replaced, no attempt was made to model this retrofit.

\subsubsection{Post-Retrofit Energy Use}

\section{Total Energy Savings}

With all of the energy conservation measures implemented in the apartment models, the energy use was determined for each apartment on each day of a typical meteorological year. The parameters for occupancy, infiltration, and thermostat setpoints were the same as those used to model the pre-retrofit energy consumption. The same 17 cases were run; the streetlight energy use was added to the weighted sum of the cases to determine the total load on the feeder.

Figure 4.8 is a plot of daily energy use vs daily average temperature as predicted by the calibrated TRNSYS model. Also plotted is the actual post-retrofit data monitored from the feeder. While the TRNSYS model predicts higher energy use in heating, there appears to be excellent agreement with the monitored data in cooling, which is the dominant operating mode in Fort Polk's climate. For a typical meteorological year, the calibrated TRNSYS model predicts annual energy use for the feeder's 200 apartments of 2.11 million $\mathrm{kWh}$, or $28.9 \mathrm{kWh}$ per apartment per day. The monitored post-retrofit data, when normalized to a TMY, predicts an annual energy consumption of 2.00 million $\mathrm{kWh}$, or $27.4 \mathrm{kWh}$ per apartment per day. As in the pre-retrofit, the TRNSYS simulation is about $5 \%$ higher than the monitored energy use corrected to a TMY.

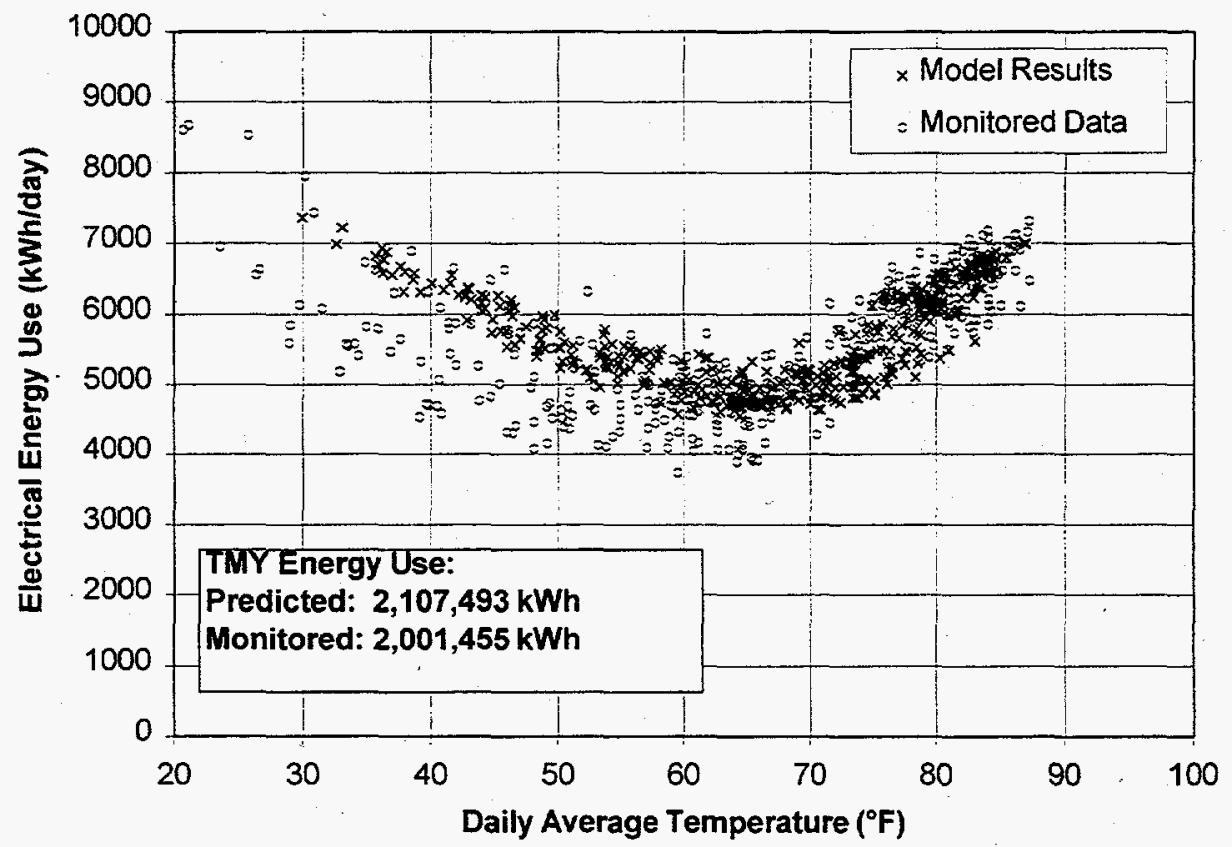

Fig. 4.8. Feeder 1 post-retrofit daily electrical energy use vs daily average temperature. Monitored data and calibrated simulation model. 
Analysis of the monitored pre- and post-retrofit data for this feeder shows that for a typical meteorological year, the retrofits result in a savings of $872,000 \mathrm{kWh}$ for this feeder, which is about $30.3 \%$ of the pre-retrofit annual consumption. Comparing the pre- and post-retrofit annual consumption predicted by the calibrated TRNSYS simulations, the model presented here would have predicted a savings of $912,000 \mathrm{kWh}$, or $30.2 \%$ of the predicted pre-retrofit consumption. Applying this savings to the pre-retrofit monitored energy consumption data, the model would have predicted an annual post-retrofit consumption of 2,005,502 $\mathrm{kWh}$ on this feeder for a typical year. This is in excellent agreement with the normalized post-retrofit data collected at the site.

\section{Energy Savings by Energy Conservation Measure}

With the output from the calibrated TRNSYS model, we determined the relative impact of each of the four energy conservation measures installed in the housing units. Table 2.8 presents a breakdown of the average energy use per apartment per day for space conditioning, water heating, and lighting/appliances, pre- and post-retrofit, based on the simulation of the entire feeder. The results indicate that, due to the retrofits, energy use for lighting and other appliances was reduced by $18 \%$, energy use for water heating was reduced by $71 \%$, and energy use for space conditioning was reduced by $27 \%$.

We recognized, however, that there are interactions between the various conservation measures installed in these apartments. For example, the $71 \%$ reduction in energy use for water heating was due to both the desuperheater and the low-flow shower heads. To account for these interactions, the calibrated feeder model was used to determine the change in energy consumption for each end use when the conservation measures were added one by one. The results are given in Table 4.4 and presented graphically in Fig. 2.10. Adding the geothermal heat pumps (measure A) reduces the average daily energy consumption for space conditioning by $3.61 \mathrm{kWh}$ per apartment. Addition of the desuperheaters (measure B) reduces the average daily energy use for water heating by $4.69 \mathrm{kWh}$ per apartment. Adding the low-flow showers (measure $\mathrm{C}$ ) reduces energy use for water heating by an additional $0.61 \mathrm{kWh} /$ day. However, adding the lighting retrofits increases the energy use for water heating by $0.27 \mathrm{kWh} /$ day. This is because the lighting retrofits reduce the amount of time the heat pump runs on an annual basis (cooling hours decrease more than heating hours increase), and the energy not provided by the desuperheater must be made up by the tank heating elements. On the other hand, the energy use for space conditioning drops by 0.31 $\mathrm{kWh} /$ day as a result of the lighting retrofits.

Table 4.4. Daily average energy use per apartment ( $\mathrm{kWh}$ ) as retrofits are added successively. $\mathbf{A}=$ geothermal heat pumps;

B = desuperheaters; $C=$ low-flow shower heads; $\mathrm{D}=$ lighting retrofits.

\begin{tabular}{lcccc}
\hline & $\begin{array}{c}\text { Space } \\
\text { conditioning }\end{array}$ & $\begin{array}{c}\text { Water } \\
\text { heating }\end{array}$ & $\begin{array}{c}\text { Lighting/ } \\
\text { appliance }\end{array}$ & Total \\
\cline { 2 - 5 } Pre-retrofit & 13.81 & 7.08 & 20.52 & 41.40 \\
A & 10.20 & 7.08 & 20.52 & 37.80 \\
A+B & 10.34 & 2.39 & 20.52 & 33.25 \\
A+B+C & 10.34 & 1.78 & 20.52 & 32.63 \\
A+B+C+D & 10.03 & 2.05 & 16.82 & 28.90 \\
\hline
\end{tabular}


This analysis shows that while interactions do occur between the various conservation measures, in this case, their effect is not significant. Thus it is reasonable to conclude that of the $872,000-\mathrm{kWh}$ reduction in annual electrical energy use for the housing on this feeder, approximately $576,000 \mathrm{kWh}$ is due to the geothermal heat pump $(259,000 \mathrm{kWh}$ for space conditioning and $317,000 \mathrm{kWh}$ for water heating), $253,000 \mathrm{kWh}$ is due to the lighting retrofits, and $43,000 \mathrm{kWh}$ is due to the low-flow shower heads. This is presented graphically in Fig. 2.11.

\section{Comparison with Monitored Data}

Pre- and post-retrofit data were available for one of the buildings on the modeled feeder; the data included total electrical use and energy used by the HVAC system. When normalized to a typical meteorological year, the data shows good agreement with the TRNSYS model for this building (note that the TRNSYS model was matched to pre-retrofit data for the entire feeder, and not for this particular site). As shown in Table 4.5, TRNSYS can predict total energy and energy used by the HVAC system within $5 \%$ of the monitored values for both pre- and post-retrofit conditions.

Table 4.5. Comparison of monitored apartment average daily energy use ( $\mathrm{kWh}$ ) and simulation results

\begin{tabular}{llcc}
\hline & & Monitored & TRNSYS \\
\hline Pre-retrofit & Total & 38.2 & 40.5 \\
& HVAC & 14.6 & 13.2 \\
Post-retrofit & Total & 27.3 & 28.0 \\
& HVAC & 9.5 & 9.4 \\
\hline
\end{tabular}

\subsection{MODELING OF A GAS/ELECTRIC FEEDER}

To determine whether the calibrated simulation technique could be used to predict savings on a feeder serving housing that used natural gas for space heating and water heating in the preretrofit, a model was developed for Feeder 12. The housing on Feeder 12 was constructed in 1975 , and contains four unique building types: type A, a four-plex with two upper and two lower apartments; type $B$, a duplex with side-by-side apartments; type $C$, another side-by-side duplex with larger apartments, and type E, a six-plex with side-by-side, townhouse-style apartments. Among these four types, some were finished with stucco facing, and others with brick. Table 4.6 shows the square footage of the apartments in each building type and the number of each type included in the study.

Table 4.6. Building types on Feeder 12

\begin{tabular}{lcccc}
\hline Building type & $\begin{array}{c}\mathrm{Ft}^{2} \text { per } \\
\text { apartment }\end{array}$ & $\begin{array}{c}\text { Stucco } \\
\text { facing }\end{array}$ & $\begin{array}{c}\text { Brick } \\
\text { facing }\end{array}$ & Total \\
\hline A (four-plex) & 1093 & 15 & 4 & 19 \\
B (duplex) & 1292 & 3 & 2 & 5 \\
C (duplex) & 1581 & 20 & 2 & 22 \\
E (six-plex) & 1620 & 1 & 1 & 2 \\
\hline
\end{tabular}




\subsubsection{Pre-Retrofit Equipment}

Each of the 142 apartments was equipped with a nominal 2-ton central air conditioner. An airconditioner model was written for this study so that the manufacturer's catalog data for the installed air conditioners could be read from a look-up table and interpolated, based on operating conditions, to provide the cooling capacity and system power. Heating was provided by a $50,000-$ Btu/h natural-gas furnace with $75 \%$ combustion efficiency, and water heating was provided by a 52-gal tank with the same combustion efficiency.

As with Feeder 1, a TRNSYS model was developed for each building, including its heating and cooling system, hot water tank, and lighting/appliance load. To model the hot water draw and lighting/appliance loads, the same profiles were used as those described above for Feeder 1, with total daily draw dependent on the floorspace of each apartment. A one-year simulation of each apartment was then run at various compass orientations corresponding to the orientations of the existing housing. To model the entire feeder, a streetlighting profile identical to the one used for Feeder 1 was added to the sum of the energy use from each building.

\subsubsection{Pre-Retrofit Energy Consumption}

As with Feeder 1, outdoor air infiltration was used to match the simulation results to the Level-1 pre-retrofit data. However, since no data on natural gas use was available, the simulation results were matched only to the feeder-level electrical consumption. The closest match to the feeder-level data was obtained when air infiltration on all of the apartments was set to 0.1 air changes per hour. The results are presented in Fig. 4.9.

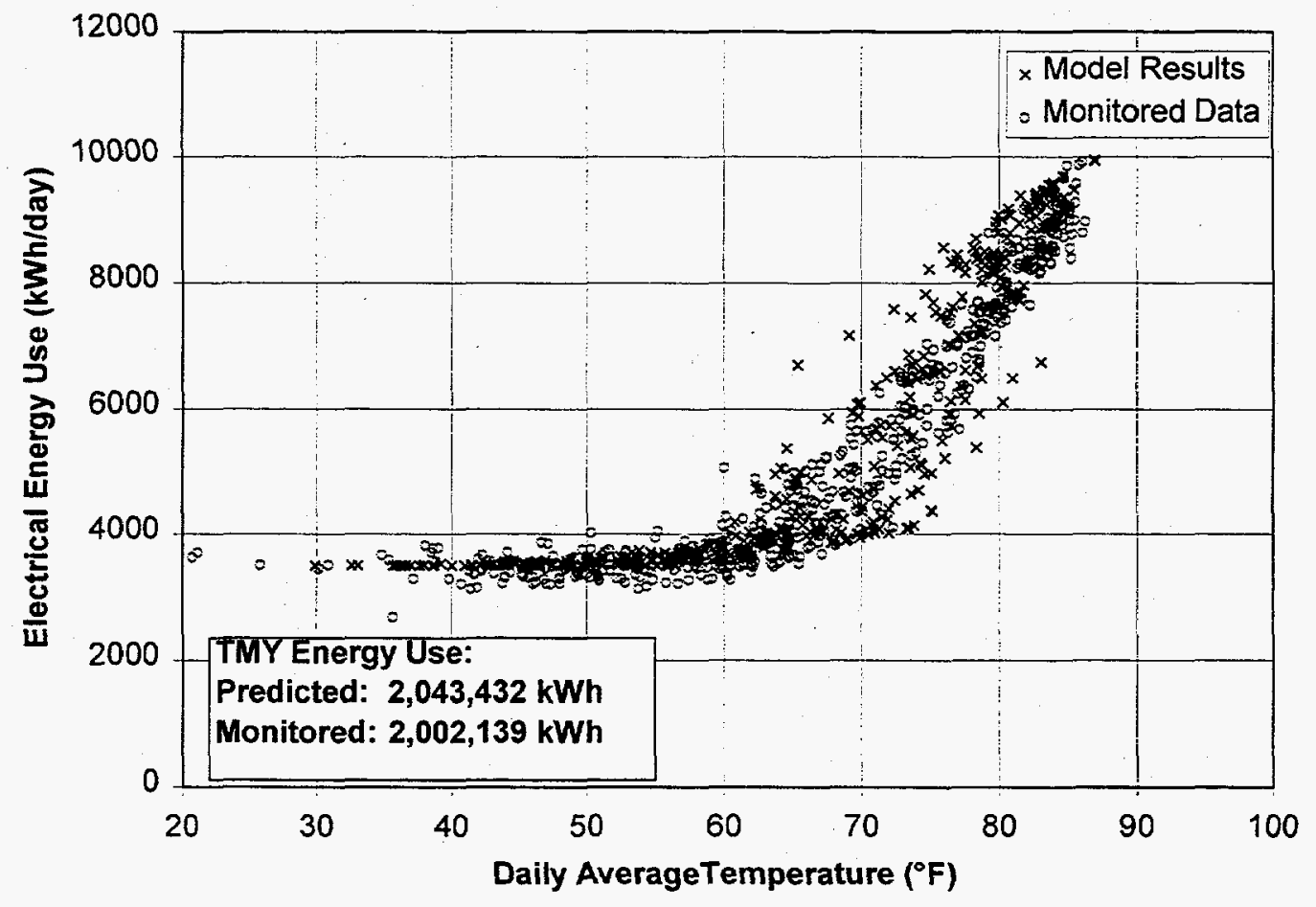

Fig. 4.9. Feeder 12 pre-retrofit daily electrical energy use vs daily average temperature. Monitored data and calibrated simulation model. 
Daily energy use as predicted by the model was correlated to daily average temperature using the program described in Sect. 2. The correlation is:

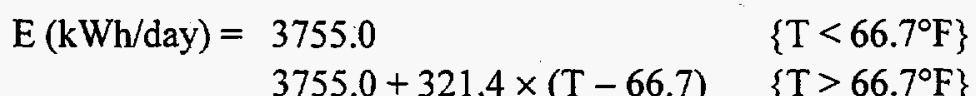

For comparison, the correlation derived from the feeder-level data is:

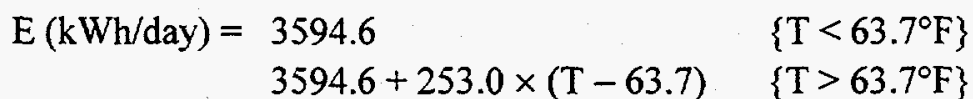

The model predicts the baseline energy consumption to within $4.5 \%$ of the value measured at the feeder level; as with Feeder 1, the breakpoint temperature was about $3^{\circ} \mathrm{F}$ lower than the temperature derived from the feeder-level data. Again, with further adjustments of setpoint temperatures, air-infiltration factors, and other parameters, it would have been possible to match the monitored pre-retrofit heating data to a higher degree of accuracy.

Although the estimate of pre-retrofit annual electrical consumption is at the same level of accuracy as the estimate for Feeder 1, it is recognized that the calibration for Feeder 12 omits the heating season entirely because of the lack of data on gas consumption. In the calibration of Feeder 1, different values of air infiltration were used to match the simulation output to the monitored data during the heating and cooling seasons. Since this was not possible for Feeder 12, we suspected that when the retrofits were implemented, the post-retrofit simulation model would predict energy use with less accuracy in the heating season than in the cooling season.

\subsubsection{Post-Retrofit Equipment}

Once the apartments were calibrated to the pre-retrofit data, the retrofits were implemented in the model. Furnace/central air combinations were replaced with 1.5- or 2-ton geothermal heat pumps. The gas-fired water tanks were replaced with electric tanks, and the hot water draw profile was reduced to account for installation of low-flow shower heads. The lighting/appliance load was reduced to account for fixture delamping and installation of compact fluorescent lighting. Desuperheaters were installed in only 29 of the 42 buildings. The retrofits are summarized in Table 4.7.

\subsubsection{Post-Retrofit Energy Consumption}

Figure 4.10 presents daily energy consumption as predicted by the model for each day in a typical meteorological year. For comparison, the field-monitored data is also plotted. It is seen that the model overpredicts post-retrofit energy consumption by about $10 \%$. The model predicts a savings of only $9.5 \%$ for a TMY, while the feeder-level data indicates the savings would be $16.2 \%$. The five-parameter correlation for the model output is:

$$
\begin{array}{lll}
E= & 4253.1-60.5 \times(T-62.8) & \{T<62.8\} \\
4253.1 & \{62.8 \leq T \leq 71.2\} \\
4253.1+161.7 \times(T-71.2) & \{T>71.2\}
\end{array}
$$


Table 4.7. Orientation of Feeder 12 buildings and retrofits installed

\begin{tabular}{|c|c|c|c|c|c|c|c|c|c|}
\hline \multirow[b]{2}{*}{ Address } & \multicolumn{4}{|c|}{ Units with stucco facing } & \multicolumn{5}{|c|}{ Units with brick facing } \\
\hline & Type & $\begin{array}{c}\text { Compass } \\
\text { orientation }\end{array}$ & $\begin{array}{c}\text { Heat pump } \\
\text { nominal tons }\end{array}$ & desup. & Address & Type & $\begin{array}{l}\text { Compass } \\
\text { orientation }\end{array}$ & $\begin{array}{l}\text { Heat pump } \\
\text { nominal tons }\end{array}$ & desup. \\
\hline 5202 & $\mathrm{~A}$ & $0^{\circ}$ & 1.5 & no & 5104 & $\mathrm{~A}$ & $45^{\circ}$ & 1.5 & no \\
\hline 5209 & $A$ & $0^{\circ}$ & 1.5 & no & 5204 & $A$ & $90^{\circ}$ & 1.5 & no \\
\hline 5225 & A & $0^{\circ}$ & 1.5 & no & 5226 & $A$ & $225^{\circ}$ & 1.5 & no \\
\hline 5213 & $A$ & $45^{\circ}$ & 1.5 & no & 5201 & A & $270^{\circ}$ & 1.5 & no \\
\hline 5215 & A & $45^{\circ}$ & 1.5 & no & 5232 & $\mathbf{B}$ & $0^{\circ}$ & 2.0 & yes \\
\hline 5224 & $\mathrm{~A}$ & $45^{\circ}$ & 1.5 & no & 5238 & $\mathrm{~B}$ & $270^{\circ}$ & 2.0 & yes \\
\hline 5108 & A & $90^{\circ}$ & 1.5 & no & 5211 & $\mathrm{C}$ & $0^{\circ}$ & 2.0 & yes \\
\hline 5212 & $A$ & $90^{\circ}$ & 1.5 & no & 5118 & $\mathrm{C}$ & $135^{\circ}$ & 2.0 & yes \\
\hline 5216 & $\mathrm{~A}$ & $90^{\circ}$ & 1.5 & no & 5219 & $\mathrm{E}$ & $90^{\circ}$ & 2.0 & yes \\
\hline 5116 & $\mathrm{~A}$ & $180^{\circ}$ & 1.5 & no & & & & & \\
\hline 5206 & $\mathrm{~A}$ & $180^{\circ}$ & 1.5 & no & & & & & \\
\hline 5207 & $\mathrm{~A}$ & $180^{\circ}$ & 1.5 & no & & & & & \\
\hline 5221 & A & $225^{\circ}$ & 1.5 & no & & & & & \\
\hline 5110 & A & $270^{\circ}$ & 1.5 & no & & & & & \\
\hline 5203 & A & $270^{\circ}$ & 1.5 & no & & & & & \\
\hline 5120 & B & $90^{\circ}$ & 2.0 & yes & & & & & \\
\hline 5114 & B & $180^{\circ}$ & 2.0 & yes & & & & & \\
\hline 5236 & B & $180^{\circ}$ & 2.0 & yes & & & & & \\
\hline 5122 & C & $90^{\circ}$ & 2.0 & yes & & & & & \\
\hline 5124 & $\mathrm{C}$ & $90^{\circ}$ & 2.0 & yes & & & & & \\
\hline 5208 & $\mathrm{C}$ & $90^{\circ}$ & 2.0 & yes & & & & & \\
\hline 5217 & $\mathrm{C}$ & $90^{\circ}$ & 2.0 & yes & & & & & \\
\hline 5220 & C & $90^{\circ}$ & 2.0 & yes & & & & & \\
\hline 5248 & C & $135^{\circ}$ & 2.0 & yes & & & & & \\
\hline 5246 & C & $180^{\circ}$ & 2.0 & yes & & & & & \\
\hline 5234 & $\mathrm{C}$ & $180^{\circ}$ & 2.0 & yes & & & & & \\
\hline 5102 & $\mathrm{C}$ & $225^{\circ}$ & 2.0 & yes & & & & & \\
\hline 5112 & $\mathrm{C}$ & $225^{\circ}$ & 2.0 & yes & & & & & \\
\hline 5242 & $\mathrm{C}$ & $225^{\circ}$ & 2.0 & yes & & & & & \\
\hline 5244 & $\mathrm{C}$ & $225^{\circ}$ & 2.0 & yes & & & & & \\
\hline 5205 & $\mathrm{C}$ & $225^{\circ}$ & 2.0 & yes & & & & & \\
\hline 5230 & $\mathrm{C}$ & $225^{\circ}$ & 2.0 & yes & & & & & \\
\hline 5106 & C & $270^{\circ}$ & 2.0 & yes & & & & & \\
\hline 5240 & $\mathrm{C}$ & $270^{\circ}$ & 2.0 & yes & & & & & \\
\hline 5210 & $\mathrm{C}$ & $270^{\circ}$ & 2.0 & yes & & & & & \\
\hline 5214 & $\mathrm{C}$ & $270^{\circ}$ & 2.0 & yes & & & & & \\
\hline 5218 & C & $270^{\circ}$ & 2.0 & yes & & & & & \\
\hline 5222 & $\mathrm{C}$ & $270^{\circ}$ & 2.0 & yes & & & & & \\
\hline 5228 & $\mathrm{E}$ & $45^{\circ}$ & 1.5 & yes & & & & & \\
\hline
\end{tabular}




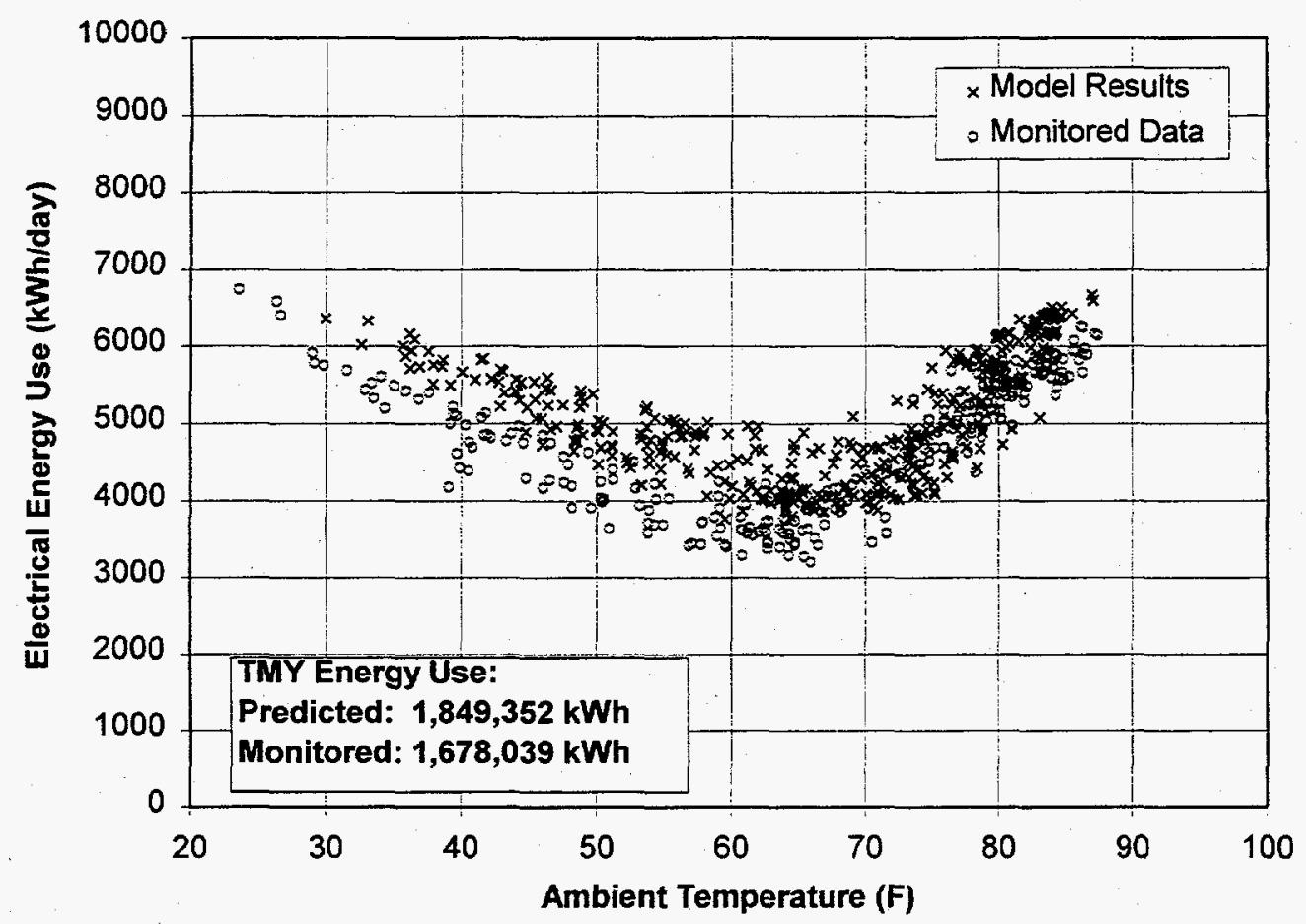

Fig. 4.10. Feeder 12 post-retrofit daily electrical energy use vs daily average temperature. Monitored data and calibrated simulation model.

For comparison, the five-parameter correlation derived from the monitored data for Feeder 12 is:

$$
\begin{aligned}
E= & 3649.1-115.4 \times(T-57.0) \\
& 3649.1 \\
& 3649.1+257.7 \times(T-65.4)
\end{aligned}
$$

Here one source of error seems to be the $17 \%$ overprediction of daily energy use in the baseline region. We believe this is due to the lack of pre-retrofit data for the heating season. Had we been able to calibrate the pre-retrofit model with feeder-level natural gas consumption data, we likely would have chosen a different air infiltration factor for the heating season, as was the case for Feeder 1. In the absence of data on natural gas consumption, we assumed that the air infiltration was the same for both heating and cooling. This reduced the accuracy both in the heating region and in the baseline region, since the baseline includes operation of the equipment for both heating and cooling. In addition, the housing on this feeder was built in 1975, making it the second oldest vintage in family housing. Project resources did not allow auditing the construction records to determine the extent of any addition of attic insulation, so no addition was assumed in the model. The lower modeled savings may be the result of this assumption.

\subsection{IMPLICATIONS FOR FUTURE USE OF CALIBRATED MODELS}

Clearly, the calibrated simulation model approach works best when data for both the heating and cooling seasons are available. When we were able to calibrate the model to an entire year of data, the model predicted the energy savings to a high degree of accuracy. When only data from the cooling season were available, the accuracy of the models is less certain. 
The results of this work depended on several data sets. In order to calibrate the TRNSYS model, pre-retrofit data on daily energy use vs daily average temperature for the entire feeder was required. While about one year's data was available for this study, the experience at Fort Polk suggests that the feeder energy use profile can be characterized with as little as six months of data; however, this may not be the case in all climates. The data collection does not need to be continuous. All that is needed is a sample of days that are in the heating, baseline, and cooling regions.

Since the lighting/appliance loads account for about $46 \%$ of the pre-retrofit electrical use on the all-electrical feeder, the 15-minute-interval profile of daily lighting/appliance energy use was also an important contribution to the accuracy of the model. This profile was developed using one year of 15-minute-interval data from 18 separate apartments. The profile presented in Fig. 4.2 with suitable corrections for apartment floorspace - could be used for other projects in military family housing. The figure presents the kilowatt-hours used during every 15 -minute period for the typical Fort Polk residence during a typical day. In other housing types, it would be necessary to examine the number and type of electric lights and appliances in a representative number of apartments to determine whether this profile would be suitable.

The hot water draw profile presented in Fig. 4.4 compares well with published values and could likely be used in future military housing projects. For other housing types, it may be necessary to monitor energy consumption of the domestic hot water tank in a representative number of apartments to determine whether this profile would be suitable. Factors such as climate may have an impact on hot water use. Nevertheless, since water heating accounts for only about $15 \%$ of energy use on the feeder, an incorrect hot water draw profile will have a correspondingly small effect on predicted total energy use.

Finally, it is recognized that the calibrated BHEx component model was perhaps the most important factor in the accuracy of the overall model. The calibration to our monitored site data on an operating GHP system produced soil heat transfer properties that were quite different from those estimated from measurements by others at the site using standard short-term testing methods available at the time the Fort Polk project was developed (see Sect. 5). In future projects involving geothermal heat pumps, it may be necessary to use improved short-term soil property tests or improved analysis on the short-term test data, or to collect at least six months of 15-minuteinterval data from at least one pilot test GHP unit. 


\section{GEOTHERMAL HEAT PUMP SYSTEM MODELS, CALIBRATED TO DATA}

Section 4 demonstrates an improved method of estimating energy savings before construction takes place. The method relies on engineering models calibrated to field data-specifically, preretrofit feeder energy consumption data and post-retrofit data from one pilot test site. During the development of large projects such as Fort Polk, it is feasible to install the full GHP-centered retrofit package in one apartment as a pilot test. This section describes the engineering model of one apartment served by a GHP system, and the process of calibrating that model to post-retrofit data from a test site. The apartment-level model is the building block for the feeder-level model described in Sect. 4.

The apartment-level model represents the housing unit (heating, cooling, water heating, and lighting/appliance loads), geothermal heat pump, BHEx, thermostat, and the blower and ground loop pump inside the GHP. Each of these components was modeled and then calibrated to detailed field data. The calibrated component models were then interconnected to form the system model. The system model was then found to compare well with apartment-level data.

The system model incorporates a BHEx component model that is capable of addressing most elements of vertical borehole ground heat exchanger design, including soil property impacts, multibore interactions, long-term consequences of annual heat imbalance, bore spacing, bore diameter, pipe spacing, pipe diameter, and grout properties. The outputs from the calibrated system model have already been used to test and compare BHEx design methods (Sect. 6).

"Energy-balance" data, or data needed to fully or partially verify energy balances around each component throughout the system, were monitored at five apartments in one selected five-plex building. The data from one of these apartments, the one that had the longest post-retrofit data collection period and was occupied for that entire period, was chosen to calibrate the model described here. This apartment, one of the ground-floor apartments in the two-story building, has a conditioned floor area of $1052 \mathrm{ft}^{2}$.

The five-plex was not retrofitted in advance of the rest of the housing and instrumented for energy balance data as a pilot test. But if it had been, the calibrated apartment-level model would have been available to support improved energy savings estimates prior to construction as described in Sect. 4.

\subsection{CONFIGURATION OF THE GEOTHERMAL HEAT PUMP}

The GHP in the apartment monitored for calibration data has a nominal 1.5-ton (17,300-Btuh) total cooling capacity and energy efficiency rating (EER) of 15.4 at ARI (Air-Conditioning and Refrigeration Institute) 330 rating conditions, and an 11,800-Btuh heating capacity and 3.5 coefficient of performance (COP) at ARI 330 rating conditions. This GHP used water as the ground heat exchanger working fluid and came equipped with a desuperheater for supplying domestic hot water. Two U-tube BHEx's connected in a parallel arrangement were used to exchange heat with the ground. Each U-tube BHEx was placed in a vertical borehole of 4.125 -in. diameter and 258-ft depth. These boreholes were spaced $16 \mathrm{ft}$ apart, $25 \mathrm{ft}$ from the exterior wall, and were backfilled with a bentonite-based grout after the installation of the U-tubes. The U-tubes themselves are of nominal 1-in. SDR-11 polyethylene pipe (1.08-in. ID; 1.31 -in. OD) with a nominal center-to-center spacing of $2.565 \mathrm{in}$. The known center-to-center U-tube spacing is at the bottom of the BHEx (the bottom of the bore). No extraordinary measures were taken to maintain this spacing along the length of the bore. The horizontal runouts to the boreholes and the 
horizontal piping between the bores are buried at a depth of $3 \mathrm{ft}$, with outbound and return legs in separate trenches. Figures 4.6 and 4.7 show the configuration of the ground heat exchanger.

\subsection{ENERGY-BALANCE MONITORING}

The detailed energy-balance monitoring began in late 1995 and continued through February 1997. The following parameters were measured and recorded as 15-minute averages or totals:

- whole-apartment power

- total GHP power

- GHP compressor power

- water heater element power

- blower status

- ground loop pump status

- ambient temperature
- GHP entering water temperature (when on)

- ground heat exchanger temperature difference

- desuperheater pump status

- desuperheater inlet temperature (when on)

- desuperheater temperature difference (when on)

- reversing valve status

- ambient relative humidity

One-time measurements of the following key parameters were also recorded:

- blower power draw

- loop pump power draw

- desuperheater pump power draw

- ground loop flow rate

- desuperheater loop flow rate

Because of the possibility that desuperheater operation might confound some of the calibration steps, the desuperheater was intentionally disabled for most of the recording period. The calibrations reported here are for periods when the desuperheater was not operating.

\subsection{DETAILED ENGINEERING MODEL}

We used the public-domain simulation software TRNSYS (Klein et al. 1996) as the platform for the detailed models because it can operate at any time step, which allows the use of ground heat exchanger models that require small time steps for stability and accuracy, and because it is relatively easy to drive with measured data. TRNSYS is a modular system simulation package in which the user describes the system's components and their interconnections. Components may be equipment, such as a pump or thermostat, or utility modules, such as occupancy forcing functions, weather data readers, integrators, or printers. New component models for the heat pump and BHEx are easily added to the existing component libraries to expand the capabilities of the program to include residential GHP systems.

Unlike most of the commonly used building energy analysis tools, TRNSYS can operate in either "temperature level" or "energy rate" control (Klein et al. 1996). In energy-rate control, the heating/cooling loads are calculated only on the basis of the net heat losses/gains from the conditioned space. The user specifies the setpoint temperatures for heating and cooling. The program then calculates the amount of energy required to keep the conditioned space at these setpoints. The calculated loads are then passed to the conditioning equipment, which exactly meets these loads at every time step. The advantage in using energy-rate control is that the loads for a given structure can be calculated once and then reused in subsequent equipment and plant simulations. However, the detailed interaction between the conditioned space and the equipment is not treated directly. 
In temperature-level control, which we use in our model, the temperature of the conditioned space is a function of ambient conditions as well as of the inputs of the equipment. In this mode, a controller is required to command the equipment. For these reasons, temperature-level control results in a more realistic and detailed simulation of the interaction between the conditioned space and the equipment. The equipment is either on or off in each time step and delivers whatever capacity would be expected given the operating conditions at that time. An earlier study (Hughes et al. 1980) demonstrated the value of using temperature-level control in heat pump system studies.

The software performs the dynamic transient analysis at user-defined time steps, iterating at each time step until the system of equations created by the interconnection of the component model inputs and outputs is solved. After considering accuracy, stability requirements, typical equipment cycle times, recorded data intervals, and simulation speed, we chose a time step of 15 minutes.

\subsubsection{Components of the System}

The performance of each of the components of the system must be characterized before the system can be characterized. In this case, the system components are defined as the building and its associated forcing functions, the heat pump, the BHEx, the thermostat, the ground loop pump, and the heat pump blower. The operation of these components and weather factors are briefly described below. For reference, a TRNSYS assembly panel schematic of the system information flow is included as Fig. 5.1.

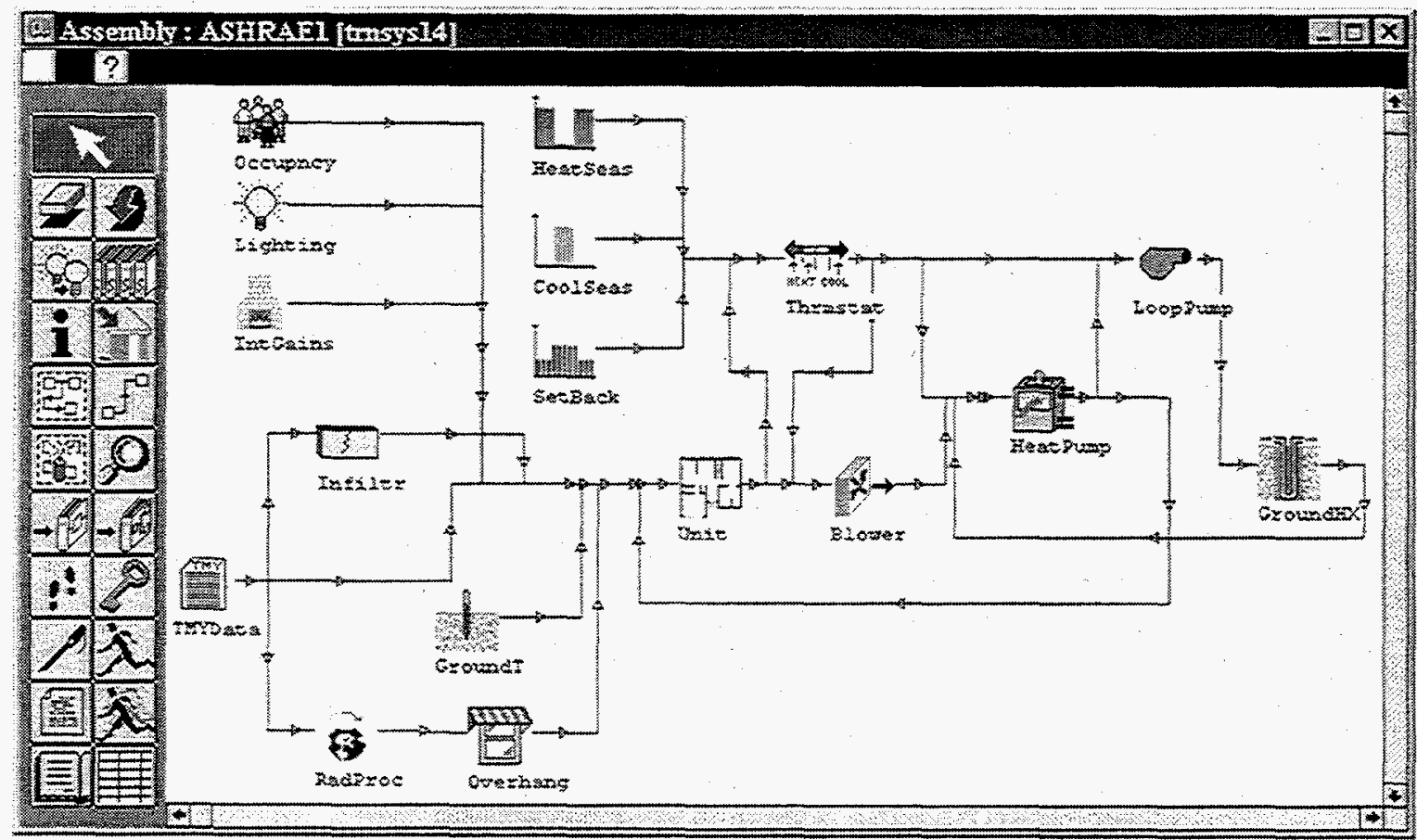

Fig. 5.1. Schematic of modeled geothermal heat pump system. 


\section{Weather}

Although the ambient temperature and relative humidity were measured at the site, these values were not used in simulations using the detailed heating/cooling load model because of the lack of solar radiation measurements. (The measured temperature and relative humidity data were used in simulations using a simplified load model that can be driven with just these inputs.) Instead, TMY weather from Lufkin, Texas, was used for the simulations. (Sect. 4.2.1 discusses TMY data.) As the time step for the simulation is less than the one-hour weather data interval, TRNSYS interpolates the weather data. The effects of incident solar radiation on each of the exterior surfaces, subject to overhang and wingwall shading effects, was included in the model.

For reference, the $99 \%$ design temperatures for Alexandria, Lousisiana are (ASHRAE 1989):

$\begin{array}{ll}\text { Winter design temperature: } & 23^{\circ} \mathrm{F} \\ \text { Summer design temperature: } & 95^{\circ} \mathrm{F} \\ \text { Daily temperature range: } & 20^{\circ} \mathrm{F}\end{array}$

A new TRNSYS component based on the Kusuda correlation (Kusuda 1965) was developed to estimate the undisturbed ground temperature as a function of depth and time of year for the simulation. This new model takes as input the annual average surface temperature, the amplitude of the annual surface temperature variation, and the phase delay, and calculates the hourly distribution of ground temperature with depth. We used ASHRAE (1977) reference values for Alexandria, Louisiana:

Mean soil surface temperature:

Amplitude of surface temperature:

Day of minimum surface temperature: $69^{\circ} \mathrm{F}$

$17^{\circ} \mathrm{F}$

32

\section{Building Load Model}

The detailed heating and cooling load model chosen for this simulation was the standard multizone building load model in TRNSYS. This model implements a nongeometrical balance model with one air node per zone. The model accounts for the effects of both short-wave and long-wave radiation exchange, internal generation (sensible and latent), occupancy effects, infiltration effects, ventilation effects, and convective exchanges. The walls, ceilings, and floors are modeled according to the ASHRAE transfer function approach (ASHRAE 1977).

The building model was assumed to have one thermal zone representing the conditioned volume of the modeled apartment. [Analysis had shown negligible energy differences when compared against the same apartment modeled with ten thermal zones, seven conditioned zones (kitchen/dining, family room, two bedrooms, bathroom, hallway, and utility room), and three unconditioned zones (storage areas).] The interactions between this single thermal zone and the apartments next door and upstairs, the ambient, and the ground (slab floor) were also considered.

The internal gains to the space from lighting, equipment, and occupancy were scheduled on the basis of the time of day. The infiltration to the zone was modeled on the basis of a modified ASHRAE method (ASHRAE 1977) that calculates the air changes per hour as a function of the wind speed and the temperature difference between ambient and conditioned space.

Operating TRNSYS in temperature-level control makes the thermal interaction between the zone and the conditioning equipment dynamic. Most other building energy analysis programs pass calculated building loads to the equipment/plant models, but TRNSYS uses a feedback loop 
in which the zone temperature is a function of the equipment response (on/off, capacity if on, etc.), which is itself dependent on the zone temperature.

\section{Thermostats}

We used the standard TRNSYS thermostat model, which accounts for hysteresis effects. When the temperature rises above the setpoint for cooling, for example, the thermostat calls for cooling and continues to do so until the temperature falls below the cooling setpoint temperature minus a user-specified dead-band temperature. Night setback and setup were not modeled because they are not used at Fort Polk.

\section{Ground Loop Pump}

A simple constant-flow pump model was used to simulate the ground loop pump. When the thermostat calls for conditioning, the pump flow value is a steady $4.64 \mathrm{gal} / \mathrm{min}$, the one-time measurement from the site. Startup and shutdown power and flow transients were disregarded, as was the effect of varying pressure drop due to temperature-dependent changes in water properties. The power consumed by the ground loop pump was assumed constant, calculated as described in later sections. All the ground loop pump power was assumed to be converted to flow energy (i.e., dissipated as heat into the fluid rather than radiated from the pump housing). Therefore, calculations to determine the required ground heat exchanger length will be slightly conservative when cooling is the dominant factor, as it is in Fort Polk. The pump model assumes that the power instantaneously reaches its steady-state value at the beginning of an on-cycle and instantaneously drops to zero at the end of an on-cycle.

\section{Blower}

A simple constant-flow device was also used to simulate the blower. When the thermostat calls for conditioning, the blower moves $600 \mathrm{ft}^{3} / \mathrm{min}$ of air across the heat pump coil, the nominal value from the catalog of performance data for this heat pump. This value was used because reliable measurements of air flow rates were not available. Startup and shutdown power and flow transients were disregarded, as was the effect of varying pressure drop due to changes in air properties caused by temperature and humidity. The power consumed by the blower was a constant, calculated as described in later sections. All the blower power was assumed to be converted to energy used to increase the temperature of the air stream. The blower model assumes that the power instantaneously reaches its steady-state value at the beginning of an on-cycle and instantaneously drops to zero at the end of an on-cycle.

\section{Heat Pump}

A new water source heat pump model was written for TRNSYS for this project. The heat pump model uses a look-up table approach in both heating and cooling modes to incorporate the manufacturer's published catalog data for capacity, power, and water heat transfer. Inputs to the model include the temperature and flow rate of water entering the heat pump; the temperature, humidity ratio, and flow rate of air entering the heat pump; and the control signal from the thermostat. Outputs from the model include the calculated values of temperature and flow rate of water exiting the heat pump; temperature, humidity ratio, and flow rate of air exiting the heat pump; and equipment capacity and power draw. 
The input values the first table asks for are water flow rate in gallons per minute and entering water temperature. In heating mode, the steady-state heating capacity, the steady-state heat pump power (blower + controls + compressor), and the steady-state rate of heat absorption from the water are interpolated from the data set. In cooling mode, the total steady-state cooling capacity, the sensible steady-state cooling capacity, the steady-state heat pump power (blower + controls + compressor), and the steady-state rate of heat rejection to the water are interpolated from the data set.

The second table asks for the known air flow rate to obtain the published correction factors for steady-state capacity, steady-state power, and the steady-state heat rejection/absorption.

The final table asks for the dry-bulb temperature (heating mode) or the dry-and wet-bulb temperatures (cooling mode) of entering air to determine the published correction factors. In cooling mode, the correction factors for steady-state capacity (both total and sensible), and the correction factors for steady-state heat rejection to the water are read from the table. In heating mode, the correction factors for steady-state heating capacity, steady-state heat of absorption from the water, and steady-state power are read from the table.

In order to allow for typical discrepancies between published catalog capacities and measured capacities, the heat pump model scales the calculated steady-state capacity values by a userdefined fraction. The heat pump model assumes that the heat pump power draw instantaneously reaches its steady-state value at the beginning of an on-cycle and instantaneously drops to zero at the end of an on-cycle. The model also assumes that the capacity rises asymptotically to the steady-state value at the start of an on-cycle and drops to zero instantly at the end of an on-cycle. The time constant of the capacity rise is input by the user. Energy balance and psychrometric calculations at each iteration assure that the results from the model at each time step are reasonable.

\section{Vertical Borehole Ground Heat Exchanger}

For vertical GHP systems, the most important component model is the BHEx. We chose the duct ground heat storage model (DST) to represent the BHEx for this study because it is well documented and validated, and it considers multibore interactions and long-term (multiyear) effects. Developed at Lund University in Sweden, DST has been updated and modified several times and has been used with excellent results (Hellstrom 1983; Mazzarella 1991; Hellstrom et al. 1996; Hellstrom 1989; Pahud and Hellstrom 1996; Pahud et al. 1996).

In DST, a BHEx is defined as a system in which heat or cold is stored directly in the ground. The heat transfer from the borehole system to the surrounding ground is approximated by pure conduction. The storage volume (the volume of earth containing the boreholes) has the shape of a cylinder with a vertical axis of symmetry. The boreholes are assumed to be uniformly placed within this storage volume. There is convective heat transfer in the boreholes and conductive heat transfer in the ground. It is convenient to treat the thermal process in the ground as a superposition of a global problem onto a local one. The global problem is to handle the largescale heat flows in the storage and the surrounding ground, whereas the local problem is to account for the heat transfer between the heat carrier fluid and the storage. The local problem uses local solutions around the boreholes and a steady-flux part, by which the number of local solutions, and thus computation time, can be reduced without significant loss of accuracy. The global and the local problems are solved with the use of the explicit finite-difference method, whereas the steady-flux part is solved analytically. The total temperature at one point is obtained by a superposition of these three solutions.

The short-term effects of the injection/extraction through the boreholes are simulated with the local solutions, which depend only on a radial coordinate and consider a cylindrical volume 
exclusively ascribed to each borehole. As the model assumes a relatively large number of boreholes, most of the boreholes are surrounded by other boreholes. Consequently, a zero heat flux at the outer boundary attributed to the symmetrical positions of the neighboring boreholes is prescribed. This assumption may lead to the under-prediction of heat transfer to the ground in cooling mode for installations with only a few boreholes.

The heat transfer from the fluid to the ground in the immediate vicinity of the borehole is calculated with a heat transfer resistance. A steady-state heat balance (performed each time step) for the heat carrier fluid gives the temperature variation along the flow path. The local solution may take into account a radial stratification of the storage temperatures (due to a coupling in series of the boreholes), as well as increased resolution in the vertical direction. The local heat transfer resistance from the fluid to the ground (or borehole thermal resistance) may depend on the flow conditions, that is, it can be dependent on both temperature and flow. It may also take into account the unfavorable internal heat transfer between the downward and upward legs of the $U$ tube in a borehole.

The three-dimensional heat flow in the ground is simulated using a two-dimensional mesh with a radial and a vertical coordinate. The model assumes homogeneous and constant thermal properties within a horizontal ground layer. Several ground layers are permitted, and the thermal properties may vary from layer to layer. Insulation may be placed on the top and sides of the storage volume. A time-varying temperature is given for the ground surface.

\subsection{CALIBRATING THE ENGINEERING MODEL}

Although a detailed model of the thermal system at the modeled apartment provides a very useful tool in developing trends and evaluating the system operation, the same model calibrated to measured site data greatly increases the confidence in the answers that the model provides. Because of its modular nature, calibrating the system in TRNSYS implies calibrating each of the individual component models. The process used to calibrate each of the important system components is described briefly below.

\subsubsection{Controllers}

Even with the heat pump compressor, blower, and loop pump off, the packaged heat pump unit draws power because of the heat pump controls. To quantify this power draw, intervals when the heat pump compressor, blower, and loop pump were off for the entire 15-minute interval were extracted from the data. When plotted for the year, the large difference between control power in heating and cooling modes appears to be due to the reversing valve for the heat pump. Figure 5.2 shows these differences for the month of April, the only month with both heating and cooling cycles, along with the position of the reversing valve $(0=$ heating, $1=$ cooling). For modeling purposes, average controller power draws of $6 \mathrm{~W}$ in heating mode and $20 \mathrm{~W}$ in cooling mode were assumed. This controller power draw and the blower power draw (determined as described below) were subtracted from the calculated heat pump power (read from the catalog data at each time step) to determine the modeled heat pump compressor power.

\subsubsection{Blower}

During part of the monitoring period, special controls prevented occupants from directly controlling the compressor. Changing the thermostat setting only affected the blower.

Compressor operation was driven by a return-air temperature sensor. This period of data was used to calibrate the blower model. The 15-minute periods when the blower was on but the compressor 
and ground-loop pump were off were extracted from the data set. During these periods, the measured power consumption of the packaged heat pump unit is equal to the power consumption of the blower motor plus the controller power. The blower power can then be estimated as the power consumption in the 15 -minute recording period minus the controller power

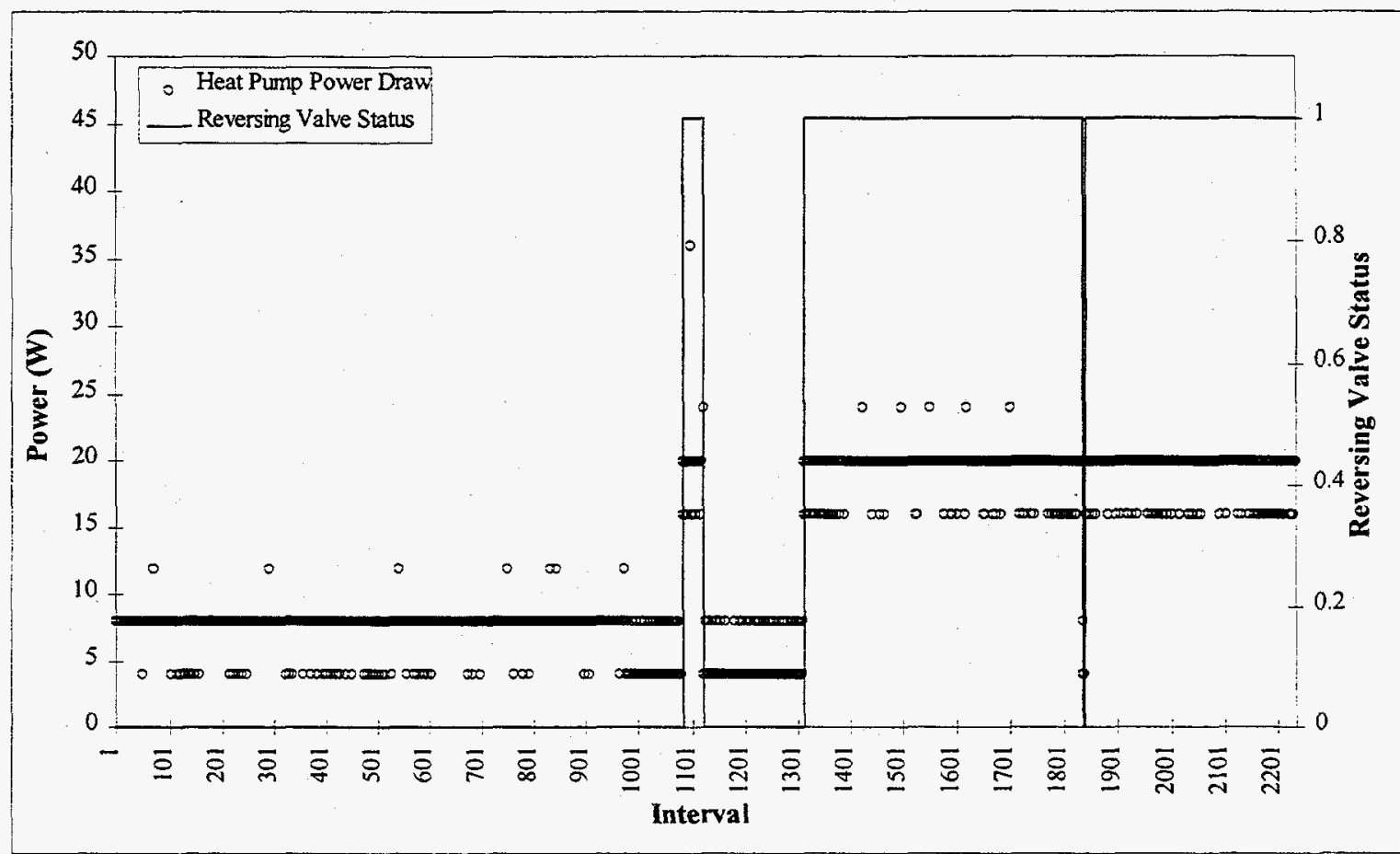

Fig. 5.2. Controller power draw in watts for each 15-minute interval in the month of April.

divided by the blower run time. When plotted for the calibration period, the blower power draw was found to decay from a value of $\sim 160 \mathrm{~W}$ in February to $\sim 130 \mathrm{~W}$ in April. The blower power draw could not be checked after April, when standard compressor controls were restored. The one-time site measurement, taken early in the year, of $160 \mathrm{~W}$ compares well to the early calculations. The decay in blower power draw was thought to be caused by an increasingly dirty air filter.

A calibration value of $130 \mathrm{~W}$ was selected as a better representation of actual operation. To investigate whether there were start-up spikes in blower power, the intervals where just the blower was on and had just turned on were extracted from the data. The average value at start-up appears to be indistinguishable from the calculated steady-state value. The assumption that the power instantaneously reaches its steady-state value of $130 \mathrm{~W}$ at turn-on, remains at that value until turnoff, and then immediately drops to zero appears adequate.

Reliable one-time measurements of air flow rate were not available. The value of $600 \mathrm{ft} / \mathrm{min}$ was used for the calibration. The manufacturer's catalog data reveals that a $15 \%$ change in air flow rate results in only a $1 \%$ change in total capacity, water heat transfer, and power consumption. The air flow rate was therefore assumed to reach its steady-state value instantaneously at blower turn-on, remain at that value until turn-off, and then immediately drop to zero. 


\subsubsection{Thermostat}

The occupants initially had no direct control over the heating and cooling setpoints. The thermostats controlled only the blower; a return-air thermostat controlled the heat pump compressor. However, many tenants found ways to work around these controls (shining heat lamps onto the return air sensor, for example). The system was converted to standard compressor controls (thermostat cycles compressor) in April.

In an attempt to determine the heating and cooling setpoints for the year, the indoor temperature at the initiation and termination of heating and cooling periods was extracted from the data and plotted for each month. The thermostat setpoints and dead bands were extremely important in determining the building energy loads and the heat pump cycle times (which affect the maximum heat pump entering water temperature predictions). As suspected, the data, shown in Table 5.1, indicated varying thermostat setpoints in each month after control reverted to the occupants.

Figures 5.3 and 5.4 show the turn-on and turn-off temperatures for cooling in the months of May and August. The lack of a discernible temperature difference between turn-on and turn-off in August is due to the heat pump turning on and off during every 15-minute interval.

With no distinct setpoints emerging from the data, the thermostat model in TRNSYS was modified to accept unique monthly values of the heating and cooling setpoints and the thermostat deadbands. Heating and cooling seasons did emerge from the data: the heating season ran from October through mid-April.

Table 5.1. Monthly thermostat setpoints in heating and cooling modes $\left({ }^{\circ} \mathbf{F}\right)$

\begin{tabular}{lcccc}
\hline \multicolumn{1}{c}{ Month } & Heat ON & Heat OFF & Cool ON & Cool OFF \\
\hline March & 72.2 & 76.5 & N/A & N/A \\
April & 73.3 & 76.2 & 80.0 & 76.3 \\
May & N/A & N/A & 80.8 & 77.2 \\
June & N/A & N/A & 81.3 & 76.8 \\
July $^{a}$ & N/A & N/A & 70.7 & 70.7 \\
August $^{a, b}$ & N/A & N/A & 70.6 & 70.6 \\
September $^{c}$ & N/A & N/A & 77.0 & 76.7 \\
October $^{\text {November }}$ & 78.6 & 78.9 & N/A & N/A \\
Nover $^{2}$ & 66.0 & 68.2 & N/A & N/A \\
\hline
\end{tabular}

'The heat pump ran in each of the 15-minute recorded intervals for the entire month with no discernible room temperature differences found between when the equipment turned on and turned off.

${ }^{b} T$ The setpoint temperatures in August show three unique steps: a cooling setpoint of $\sim 70^{\circ} \mathrm{F}$ for a very short period in the beginning of the month with no discernible turn-on and turn-off temperatures, a relatively long period where the space was maintained at $\sim 74^{\circ} \mathrm{F}$ with no discernible turn-on and turn-off temperatures, and a short period at the end of the month where the space was maintained at $\sim 62^{\circ} \mathrm{F}$ with no discernible turn-on and turn-off temperatures.

The setpoint temperatures in September shows a unique step: a short period where the cooling turn on temperature of $\sim 64^{\circ} \mathrm{F}$ with a cooling turn off at $\sim 64.5^{\circ} \mathrm{F}$ is observed followed by a relatively long period where the space is maintained at $\sim 78^{\circ} \mathrm{F}$ with no discernible turn-on and turn-off temperatures.

${ }^{d}$ The heat pump ran in only two of the 15 -minute intervals for the month, making it impossible to determine the setpoints and deadbands. 


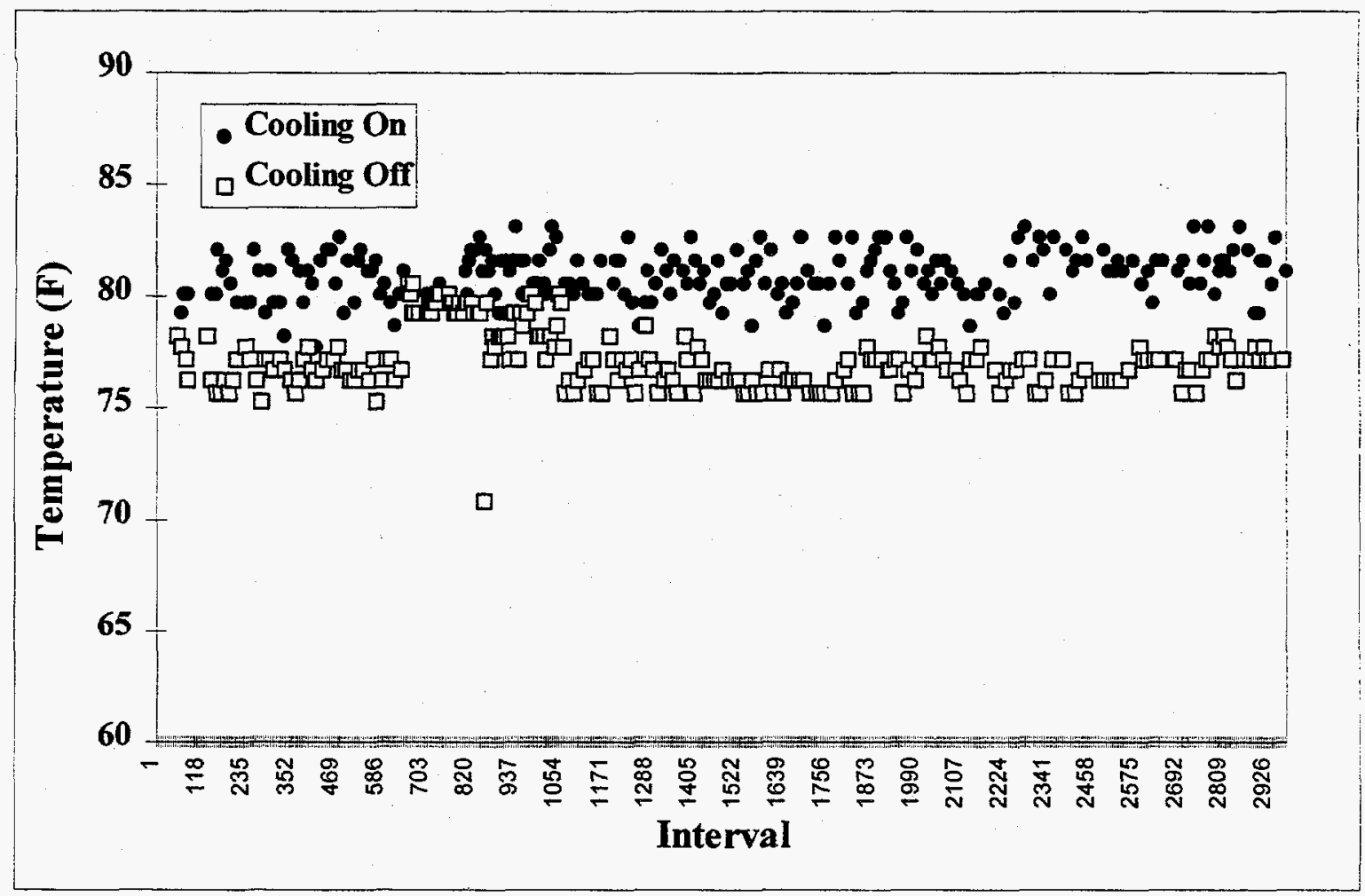

Fig. 5.3. Room temperatures for cooling turn-on and turn-off for the month of May.

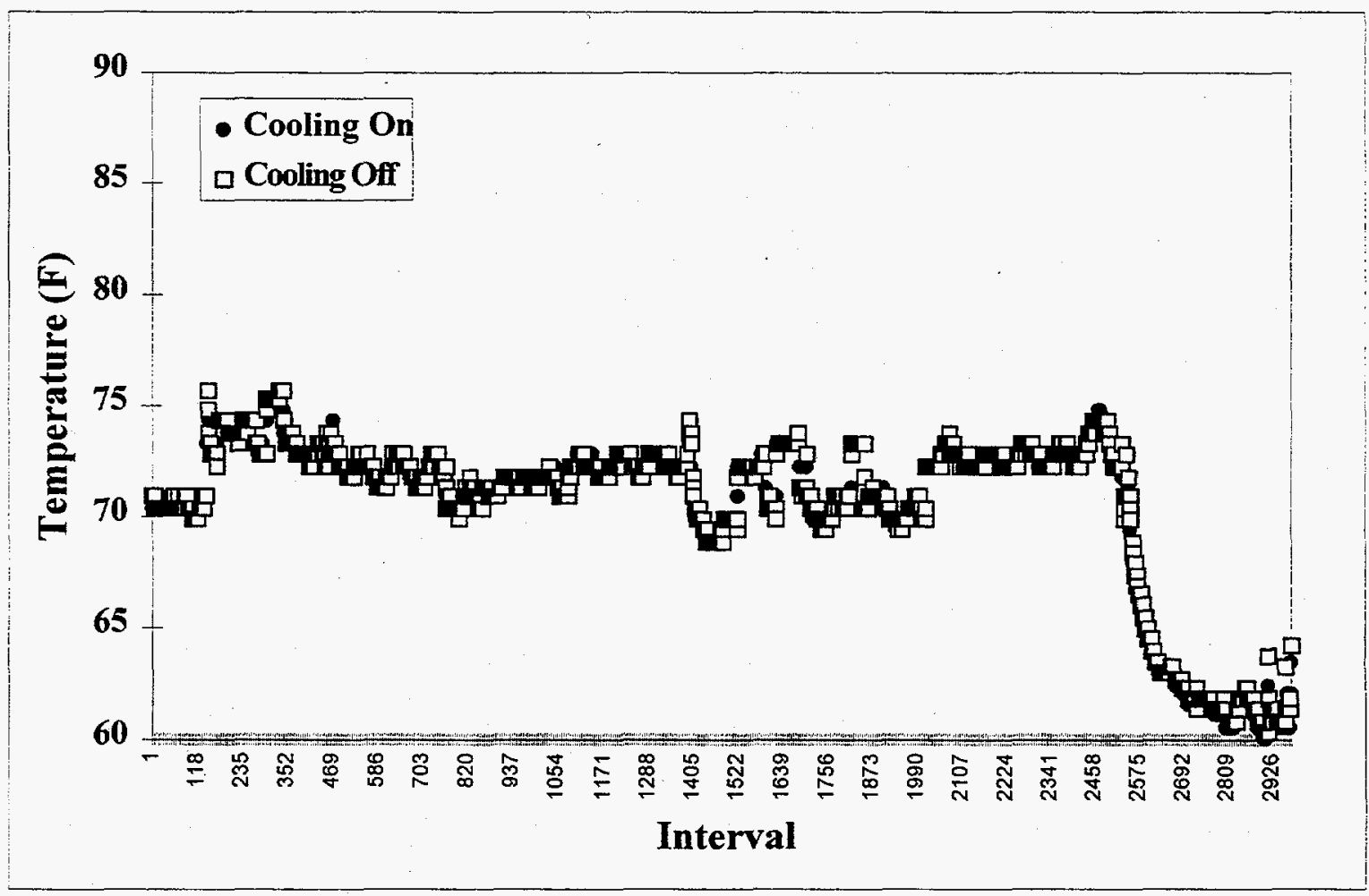

Fig. 5.4. Room temperatures for cooling turn-on and turn-off for the month of August. 


\subsubsection{Ground Loop Pump}

Data intervals showing continuous heat pump operation were used to verify the one-time field measurement of loop pump power draw. During these intervals, the power consumption of the loop pump is equal to the packaged heat pump consumption minus the consumption of the compressor, the blower, and the controls. The one-time site measurement of loop pump power $(220 \mathrm{~W})$, confirmed by plots of measured loop pump power, was used for the calibrated value. The power also was assumed to instantaneously reach its steady-state value at turn-on, remain at that value until turn-off, and immediately drop to zero.

The ground loop pump flow rate was assumed to equal the value from the one-time measurement when the pump was on, and zero when the pump was off.

\subsubsection{Vertical Borehole Ground Heat Exchanger}

The calibration of the detailed BHEx model was intended to be relatively straightforward. We chose to construct a BHEx model that only represented the vertical elements of the ground heat exchanger and did not represent the piping runouts to the ground heat exchangers or the horizontal buried pipes between the ground heat exchangers. Where possible, known values of the physical BHEx parameters were used: heat exchanger geometric data (borehole diameter and depth, header depth, borehole spacing, U-tube pipe sizes and shank spacing); and thermal properties of the polyethylene pipe and the grout (backfill) material (thermal conductivity, density, and specific heat). The undisturbed deep-earth temperature and the soil thermal properties (thermal conductivity, density, and specific heat) were varied to try and achieve a best fit between measured and modeled performance. The best fit is one that best matches the 15 -minute recorded data to the model predictions for heat pump entering water temperature. This best-fit approach does not arrive at true soil properties for each of the various layers along the borehole, but rather arrives at average soil properties over the length of the bore, which are the effective properties when a pure conduction BHEx model is forced to match data that include effects beyond conduction (e.g., groundwater movement) that may be present, and that include effects of horizontal runouts and piping that were purposely left out of the model because they are small, relative to the BHEx.

Our goal here was to determine effective average soil properties that enabled our BHEx model, with any inaccuracies it may contain, to nonetheless track data and provide an accurate representation of BHEx behavior at the site. Since none of the practical BHEx design methods account for horizontal runouts and piping connections, these effective average soil properties are suitable for use in such methods (see Sect. 6).

With an accurate estimate of the heat pump exiting water temperature (which is the ground heat exchanger inlet temperature), the process of calibrating the BHEx model would have been simple. However, after much investigation we determined that the temperature-difference data used to calculate the heat pump leaving water temperature from the measured entering water temperature were inaccurate at operational flow rates. Without these data, our only alternative was to estimate the amount of energy transfer to/from the soil by using the heat pump manufacturer's catalog data. This estimation was left to the heat pump component model, which allowed use of a user-defined fraction of the catalog steady-state capacity. For the purposes of this work, $95 \%$ of the catalog heating and cooling capacities were used for the steady-state heat pump capacities. The model also assumes that the capacity ramps up asymptotically at the start of an oncycle and drops to zero instantly at the end of an on-cycle. The time constant calculation is described in the heat pump calibration section.

The measured loop temperature data was recorded in 15-minute averages with loop pump runtimes also recorded for the 15-minute period. The TRNSYS program operates in discrete time steps; the heat pump is either on or off for each time step. It was therefore necessary to run TRNSYS on a 
sub-15-minute time step, so we discretized the data into 1-minute increments for the soil calibration. To try and match actual cycling times as well as possible, we arranged the run-times based on the state of the heat pump at the current, previous, and next 15-minute periods.

During each 1-minute time step, the heat pump leaving water temperature is calculated based on the measured 15-minute-average heat pump entering water temperature and the heat pump's calculated heat rejection/absorption, which is a function of the heat pump entering water temperature and time. This heat pump leaving water temperature, the one-time measurement of the flow rate, and the measured ambient conditions drive the ground heat exchanger model to produce a predicted heat pump entering water temperature.

With these inputs from the monitored data and the heat pump model, and with the soil thermal properties and deep-earth temperature as varied parameters, the model-predicted temperature was compared to the collected data on outlet temperature from the ground heat exchanger. The simple statistical comparison to determine "best fit" was done by squaring the difference between the predicted values and the collected data for each 15-minute interval and summing the squares over the length of the simulation. The soil properties with the lowest value were selected as the best-fit values.

The results of our first attempt at a best match of the soil properties for this apartment correspond almost exactly to the ASHRAE heavy saturated soil: a density of $200 \mathrm{lb} / \mathrm{ft}^{3}$, a specific heat of $0.20 \mathrm{Btu} / \mathrm{lbm} \cdot{ }^{\circ} \mathrm{F}$, and a thermal conductivity of $1.40 \mathrm{Btu} / \mathrm{h} \cdot \mathrm{ft} \cdot{ }^{\circ} \mathrm{F}$. The corresponding deepearth temperature was found to be about $62^{\circ} \mathrm{F}$. This first BHEx calibration was performed using data from the month of May, a month when the heat pump ran only in cooling mode. With the known borehole geometry and the best-fit soil properties, a pipe-to-soil thermal resistance of 0.2281 $\mathrm{h} \cdot \mathrm{ft} \cdot{ }^{\circ} \mathrm{F} / \mathrm{Btu}$ was calculated by the DST model.

Using these effective average soil properties as inputs for the model, the average temperature difference between measured and predicted values was $0.145^{\circ} \mathrm{F}$ over the month-long test period. Figure 5.5 shows the predicted and measured 15-minute averages for three days near the end of the May soil calibration test.

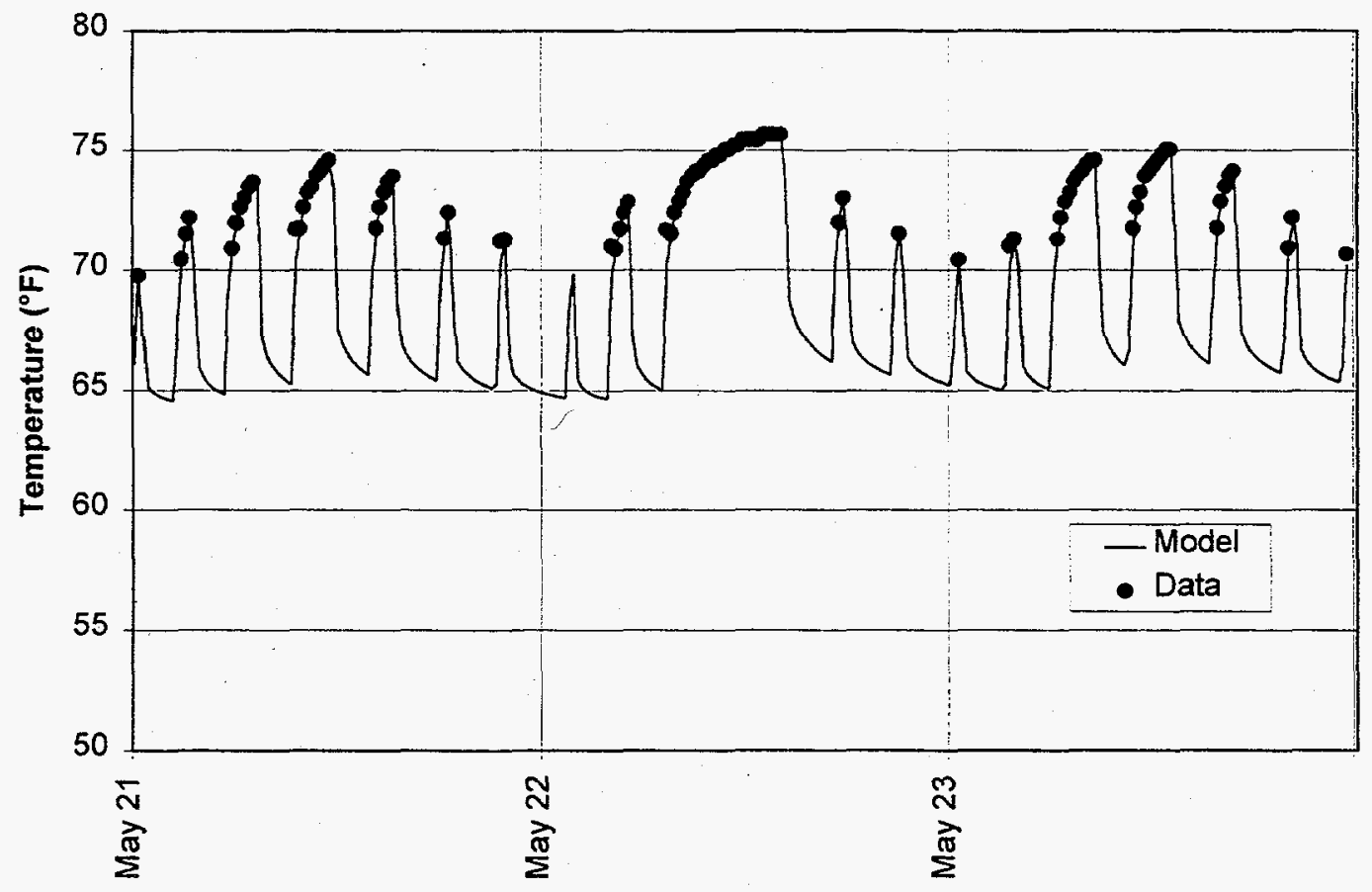

Fig. 5.5. Predicted vs measured heat pump entering water temperatures for three days in the month-long soil-calibration test. 
These effective average soil properties (for the South Fort area), determined using inverse heat transfer techniques on May data, are very different from the results of an independent analysis of the soil done before the GHP installations at three locations around the base (Gordon 1997). The results from that analysis are shown below with our results for comparison.

\begin{tabular}{lllc} 
& \multicolumn{1}{c}{ Soil type } & $\begin{array}{c}\text { Deep-earth } \\
\text { temperature }\end{array}$ & $\begin{array}{c}\text { Thermal conductivity } \\
(\mathrm{Btu} / \mathrm{h} \cdot \mathrm{ft} \cdot \circ \mathrm{F})\end{array}$ \\
\hline 1995 Study & & & \\
South Fort & Sand & $67.8^{\circ} \mathrm{F}$ & 1.156 \\
Mid Fort & Clay & $67.8^{\circ} \mathrm{F}$ & 0.802 \\
North Fort & Clay/Sand & $67.8^{\circ} \mathrm{F}$ & 0.964 \\
TRNSYS & & & \\
South Fort & Heavy saturated & $62^{\circ} \mathrm{F}$ & 1.40 \\
\hline
\end{tabular}

\subsubsection{Heat Pump}

Lacking an accurate temperature difference measurement across the ground heat exchanger, the calibration of the heat pump model proved difficult. We originally intended to strip from the data set all the points where the heat pump ran for the entire 15-minute interval. Using the measured heat pump water temperature difference and total power draw, the one-time measurement of water flow rate, and the calibrated steady-state values of blower and loop pump power draw, the actual operating capacity of the machine could have been determined as a function of the measured heat pump entering water temperature. This operating capacity curve would then have been compared against the model-predicted capacity as a function of entering water temperature and adjusted accordingly. Without the temperature difference measurement, an assumption had to be made about the value of the steady-state capacity for the installed machine. For this work, $95 \%$ of the manufacturer's reported catalog capacity was used as the steady-state value.

One aspect of the heat pump model that could be checked was the compressor power as a function of entering water temperature. All the data points where the compressor ran for the entire 15-minute interval were extracted from the data set and plotted against the measured value of the heat pump entering water temperature. Driving the model with the one-time measurement of water flow rate and varying the heat pump entering water temperature, the predicted steady-state compressor power curve was determined. As can be seen in Fig. 5.6, the original modeled value of compressor power in cooling mode was on the high side (labeled as "Catalog" in Fig. 5.6). To better match the recorded values of compressor power in cooling mode, the heat pump model was redone to include a linear fit from the data. The heat pump model's predicted compressor power in cooling mode (labeled as "Model" in Fig. 5.6) is then plotted against entering water temperature in Fig. 5.6. There are not enough data points in heating mode to compare against the model, so we used the catalog value for compressor power in the heating mode.

Although the absolute value of the recorded heat pump water temperature difference was flawed, the measured heat pump entering water temperature could still be used in the heat pump cyclic analysis. To determine the capacity ramp-up function, we calculated the machine capacity for each of the intervals in the longest heat pump run-time cycle observed in the data (about 8 hours). The capacity of the heat pump, or the heat transfer from the air, was calculated based on an energy balance taken around the packaged heat pump unit. The capacity is equal to the heat transfer to the water minus the power of the blower, the controls, the compressor, and the loop pump, and was fitted to a function of the form:

$$
\text { Capacity }=k 1 \times \text { Time } /(k 2+\text { time }) \text {. }
$$




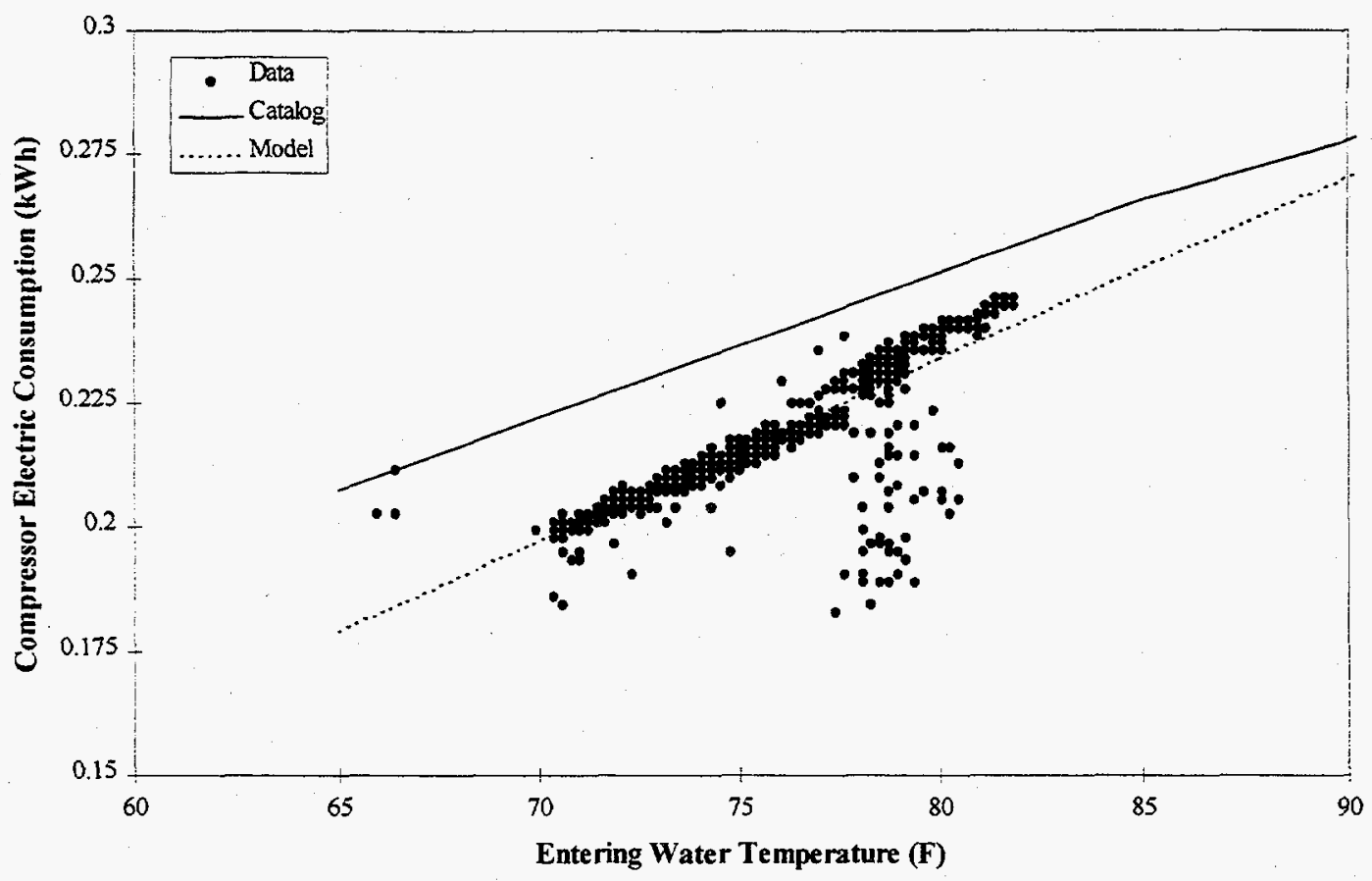

Fig. 5.6. Energy consumption of the heat pump compressor as a function of heat pump entering water temperature in cooling mode.

To approximate the observed asymptotic behavior, the heat pump model capacity calculation was modified to account for ramp-up by using this curve fit. In the model, k1 from Eq. 5.1 is represented by the steady-state capacity (calculated in the model) and $k 2$ was set to 0.114265 (the curve-fit coefficient).

\subsubsection{Building Model}

Calibrating the detailed building model required calculating the amount of heat injected into and removed from the building. In heating mode, the rate at which heat was injected into the building was assumed to be $95 \%$ of the steady-state value of the catalog heat of absorption rate from the water plus the electrical energy consumption rate of the heat pump. The steady-state heat of absorption rate was taken from curve-fits to the manufacturer's data at the measured value of heat pump entering water temperature. The heat pump electrical consumption was recorded in the data set. The amount of energy to the space was calculated by multiplying the steady-state heat of absorption rate by the run time and adding the electrical energy consumption of the heat pump. Plotting the average energy rate to the zone against the corresponding ambient temperature bins gives a heating load line. Calculation of the cooling load line was analogous to calculation of the heating load line.

With the "measured" heating and cooling load lines established, the calibration of the building model could proceed. The calibration of the building model proved to be the most difficult of all. There are hundreds of parameters that could be adjusted to try to match the cooling and heating load lines. Most of these building model parameters are based on the characteristics of the building (such as geometries, wall and window thermal properties, etc.) and were left to their modeled values. This left a group of parameters including internal gains (lighting, equipment, and occupancy) and infiltration to fit against the collected data. Once set, the internal gains (which 
have a daily profile) were assumed to be identical for cooling and heating seasons, while distinct values of infiltration (a function of ambient temperature and wind speed) were established for the heating and cooling seasons. To establish the load lines for the modeled building, all of the conditioning equipment was stripped from the model, and the building was allowed to operate in energy-rate control mode. In energy-rate control, the space is assumed to be at its setpoint, and the amount of energy required to keep it there is calculated by the program. The heating and cooling load lines were calculated for the modeled building and compared with the load lines resulting from the measured data. The model's infiltration parameters were then adjusted until the load lines matched. Originally, the infiltration rate was simply a function of a constant, the wind speed, and the indoor-to-outdoor temperature difference. But to better match the observed heating and cooling load lines, the infiltration was redefined as a function of the square of the indoor-tooutdoor temperature difference. The heating and cooling load lines are shown in Fig. 5.7 for both the modeled system and the observed data.

\subsubsection{System Calibration}

With all the individual component models calibrated against the measured data, the performance of the entire system model was checked. In a GHP system, the main indicators of system performance are the maximum temperature of water entering the heat pump and the total energy consumed by the packaged heat pump unit (compressor + blower + loop pump + controls). The maximum temperature measured at the site was $85.1^{\circ} \mathrm{F}$. The model predicted significantly lower temperatures, with a maximum of $81.1^{\circ} \mathrm{F}$.

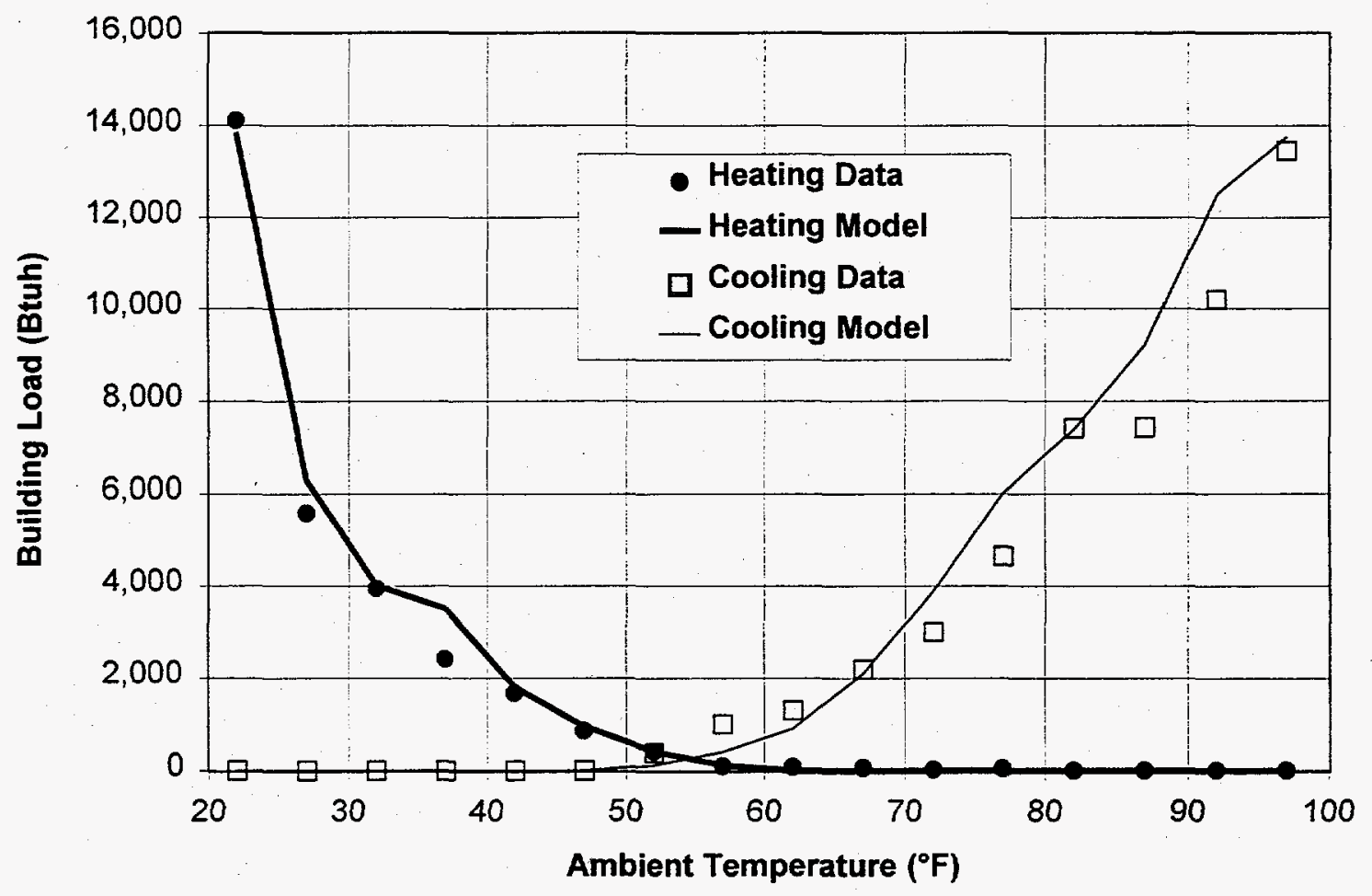

Fig. 5.7. Average heating and cooling load line comparisons. 
In an attempt to resolve the differences between the measured and predicted temperatures of entering water, both the effects of the ambient temperature and the validity of the assumption of a $62^{\circ} \mathrm{F}$ deep-earth temperature were investigated. The model originally used TMY weather data because the detailed building model used for the study required the ambient conditions (temperature, humidity, and wind speed) as well as the solar radiation. Only the ambient temperature and relative humidity were measured at the site. A simple "lumped capacitance" building model was created for this study so that the model could be driven by the outdoor conditions measured at the site.

The lumped capacitance building model required the overall building loss coefficient (UA), the thermal capacitance, the moisture capacitance, the ambient temperature and relative humidity, the infiltration rate, the internal sensible and latent heat generation, and the heat injection or extraction of the space conditioning equipment to predict the temperature and humidity of the conditioned space. Because the detailed model incorporated all the construction properties of the apartment building, the UA and the thermal and moisture capacitances were adjusted in the simple model until both models responded similarly to step changes in ambient temperature and relative humidity. This adjustment was performed assuming no infiltration and identical internal heat generation in both models. With the calculated loss coefficients and capacitances, the infiltration of the simple model was adjusted until the average heating and cooling load lines matched the average heating and cooling load lines determined from actual measurements (shown in Fig. 5.7).

Next the effect of the deep-earth temperature assumption was explored. The original calibration of the BHEx model was performed using data from May, the end of the heating season and the beginning of the cooling season. The soil heat removal during the heating season had masked the true undisturbed deep-earth temperature, and the inverse heat transfer analysis arrived at a lower value of $62^{\circ} \mathrm{F}$. The thermal conductivity tests discussed previously were measurements on newly installed BHEx's with no thermal history. In October 1995, the undisturbed deep-earth temperature near the site was determined to be $67.8^{\circ} \mathrm{F}$. Running the model with the "lumped" building data, measured weather, and the new assumption for undisturbed deep-earth temperature dramatically reduces the differences between the measured and predicted temperatures of water entering the heat pump. The monthly results are shown in Fig. 5.8. The maximum predicted entering water temperature for the year is now $85.9^{\circ} \mathrm{F}$. This compares well with the measured maximum of $85.1^{\circ} \mathrm{F}$.

Once sufficient data became available, the soil properties were determined based on the entering and leaving water temperatures for all heating and cooling cycles over one year of operation of the GHP. Based on this data, the undisturbed ground temperature was found to be $67.8^{\circ} \mathrm{F}$, exactly the value measured at the site. However, the thermal conductivity of the soil was determined to be $1.41 \mathrm{Btu} / \mathrm{hr}-\mathrm{ft}-{ }^{\circ} \mathrm{F}$, with thermal diffusivity of $0.04 \mathrm{ft}^{3} / \mathrm{hr}$. These properties, which correspond to heavy saturated soil, are different from the values estimated from short-term tests.

The total heat pump power consumption (blower + ground loop pump + compressor + controls), as modeled and as measured, is shown in Fig. 5.9. The power consumption comparison is an excellent measure of how well the system model approximates the data, since power consumption is a function of the building load, the ambient conditions, the BHEx performance, and the heat pump performance. The difference between the total heat pump power predicted and that measured over the calibration period was less than $0.2 \%(713.5 \mathrm{kWh}$ measured, $711.8 \mathrm{kWh}$ predicted). 


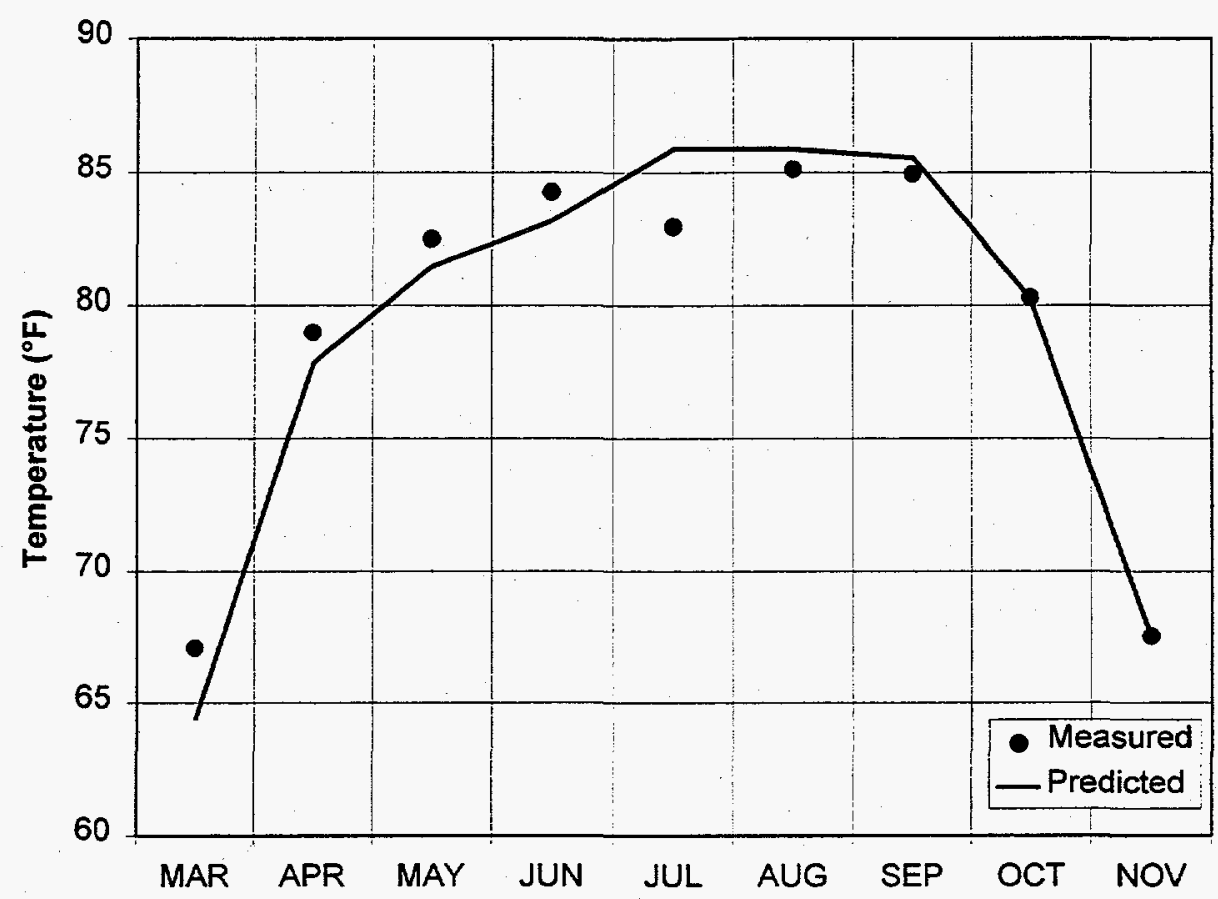

Fig. 5.8. Predicted and measured maximum heat pump entering water temperatures.

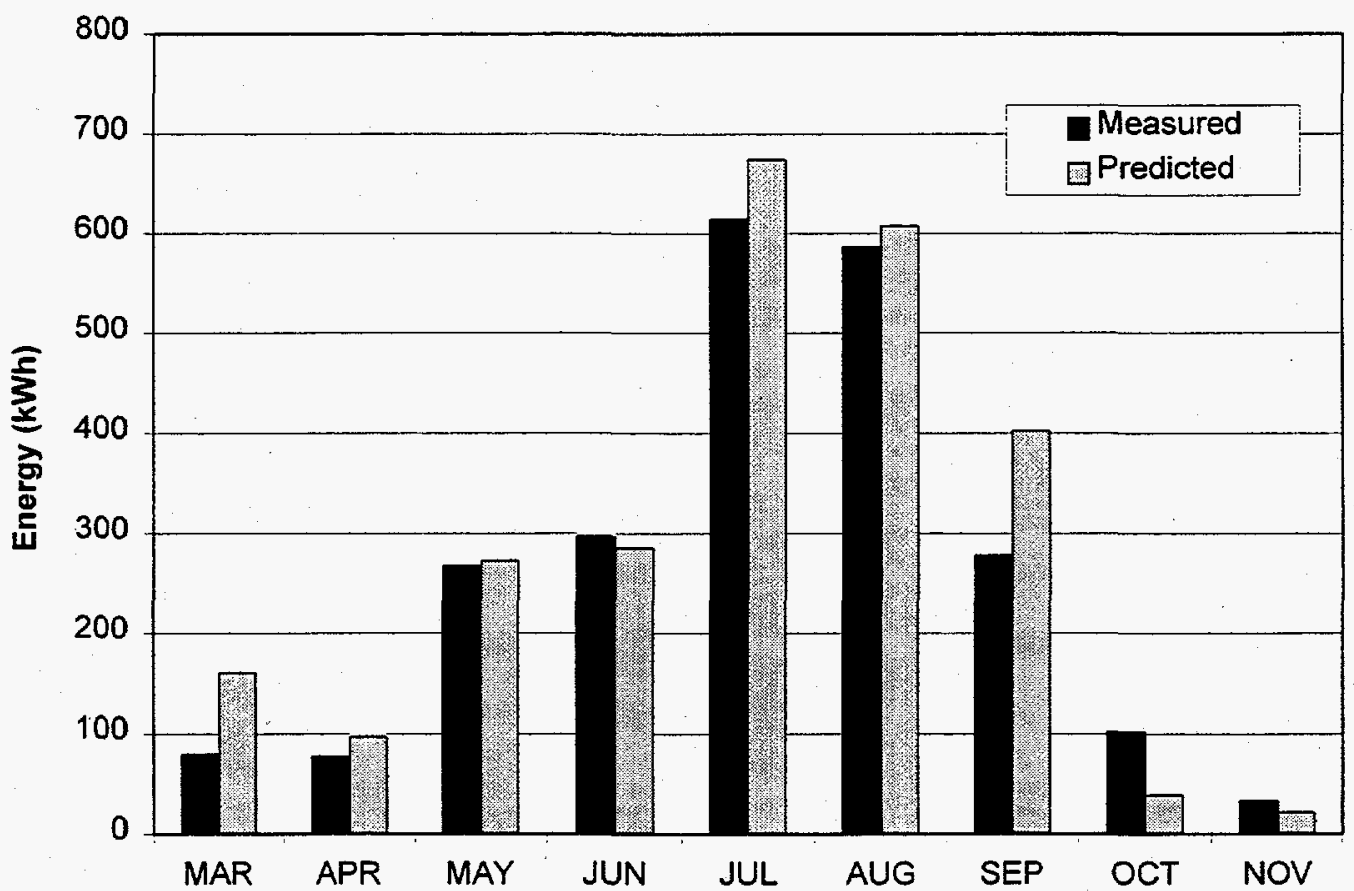

Fig. 5.9. Predicted and measured heat pump power consumption. 


\subsection{MODEL CAPABILITIES}

With an apartment-level model calibrated to measured data, project developers can have greater confidence in their ability to properly design BHEx's and predict savings prior to construction. The following examples demonstrate the capabilities of the calibrated model with the lumped building model and the deep-earth temperature of $67.8^{\circ} \mathrm{F}$.

\subsubsection{Effects of Soil Thermal Properties Assumptions}

The results for three ASHRAE soil types are presented in Fig. 5.10 and show a $22^{\circ} \mathrm{F}$ difference in predicted maximum heat pump entering water temperature. With these great differences between the soil types, some sort of industry-accepted BHEx effective average soil property test would certainly be beneficial. The BHEx soil test available at the time the Fort Polk project was designed indicated soils similar to ASHRAE "heavy damp soil" (ASHRAE 1989). The calibrated model indicates soils more like ASHRAE's "heavy saturated soil." It is likely that the data collected during the existing BHEx soil test are appropriate, with the exception of test duration, but that the analysis of the data to arrive at effective average soil properties needs to be improved. The BHEx model developed for this project may be useful in that regard.

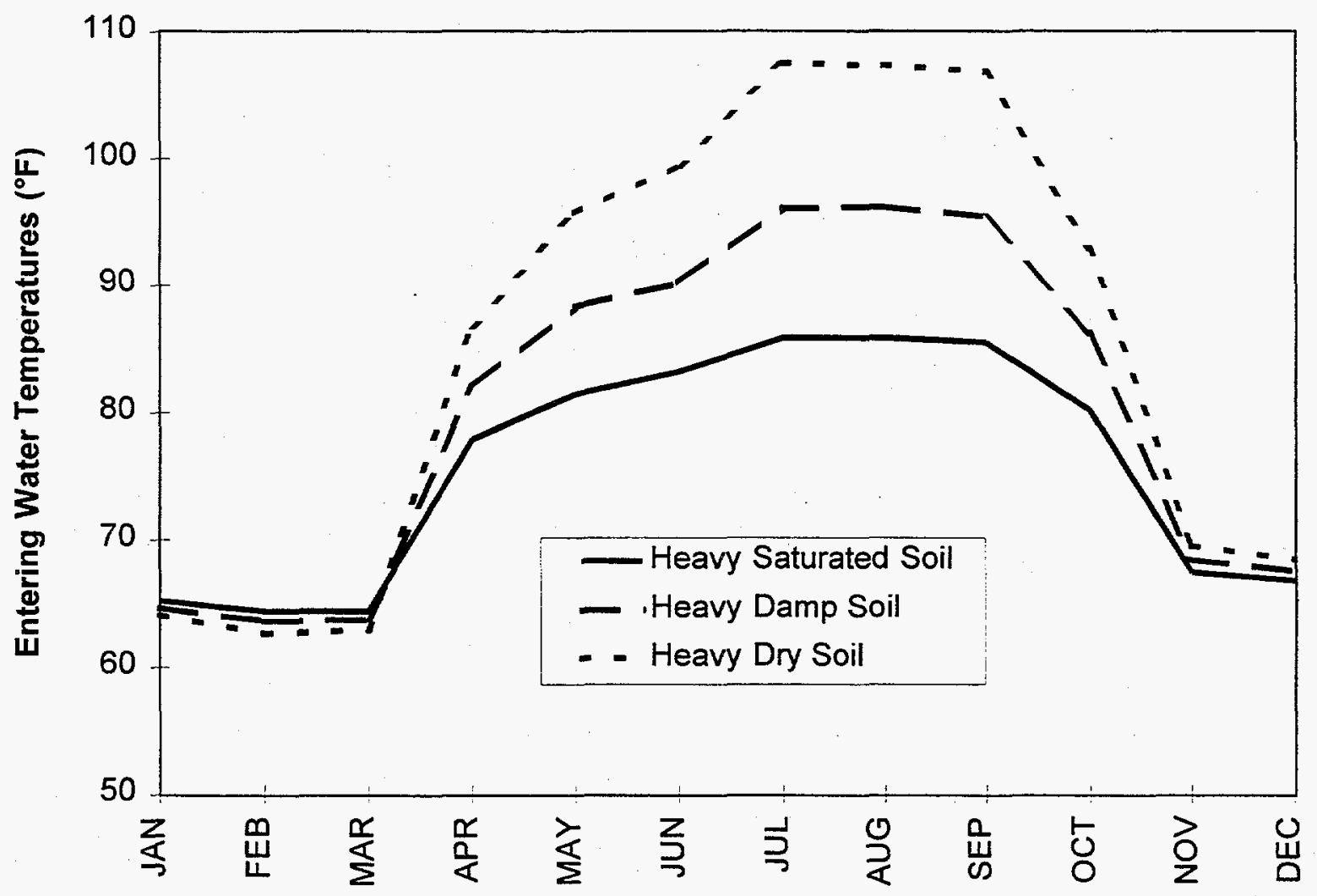

Fig. 5.10. Maximum heat pump entering water temperatures for three different soil types. 


\subsubsection{Ten-Year System Performance}

Both the predicted minimum and maximum heat pump entering water temperatures show an approximate $2^{\circ} \mathrm{F}$ rise over a ten-year simulation period. These results were generated by the model driven with 12 months of ambient temperature and humidity data collected at Fort Polk, repeated 10 times. The data collection period was not long enough to verify or refute this prediction. Note that the BHEx model, which is based on the DST model from Sweden, considers conduction in the ground formation, but ignores the presence and movement of groundwater beyond the influence this may have on short-term data sets used to inverse effective average soil properties. Significant groundwater movement would have the effect of reducing the ten-year temperature rise. On the other hand, as the equipment ages its performance may degrade, and more heat may need to be rejected to the ground to satisfy the same cooling load.

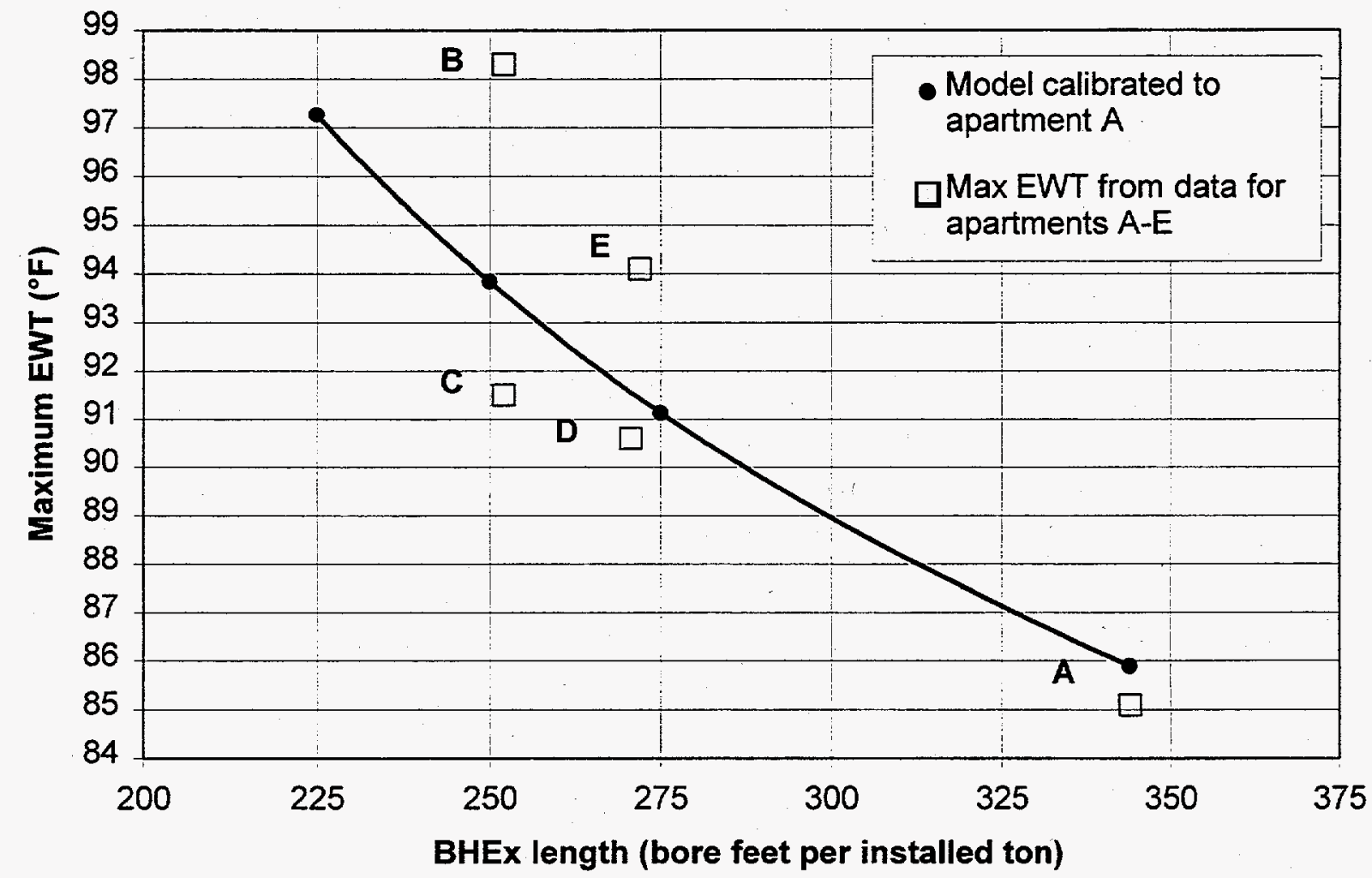

Fig. 5.11. Predicted maximum EWT for various BHEx lengths (one-year analysis).

\subsubsection{BHEx Size}

In a cooling-dominated climate such as Fort Polk's, the BHEx for a geothermal heat pump is usually sized to ensure that the entering water temperature to the heat pump does not exceed $95^{\circ} \mathrm{F}$. The maximum EWT of $85.1^{\circ} \mathrm{F}$ measured at the apartment-A energy-balance site indicates that the BHEx was oversized for this apartment. To determine the effect of BHEx length on maximum EWT, the calibrated (to apartment A) model was run with 4 different BHEx lengths for one year. The results are shown in Fig. 5.11. Assuming a temperature rise of $4^{\circ} \mathrm{F}$ over 20 years, two boreholes of 206 feet each 
(corresponding to 275 bore feet per ton) would have provided sufficient heat exchanger length for this apartment during the monitored post-retrofit weather year, which was milder than normal. This is about equal to the installed average of 275 bore feet per ton for the entire project.

Note that measured maximum EWTs at apartments A, B, C, D, and E indicate the expected upward trend with shorter BHEx lengths, but with the expected variation due to occupant behavior and setpoints, which affect GHP runtime. The measured duration curves for EWT over all run hours are presented in Fig. 5.12 for apartments A, B, C, D, and E. Note that although the maximum EWT at B was $98.3^{\circ} \mathrm{F}$, EWT was above $94^{\circ} \mathrm{F}$ for only $0.1 \%$ of the run hours.

Site 220A GHP Entering Water Temperature 3/96 - 2/97 GHP Runtime $=2254 \mathrm{Hrs}$, Max EWT $=85.1^{\circ} \mathrm{F}$

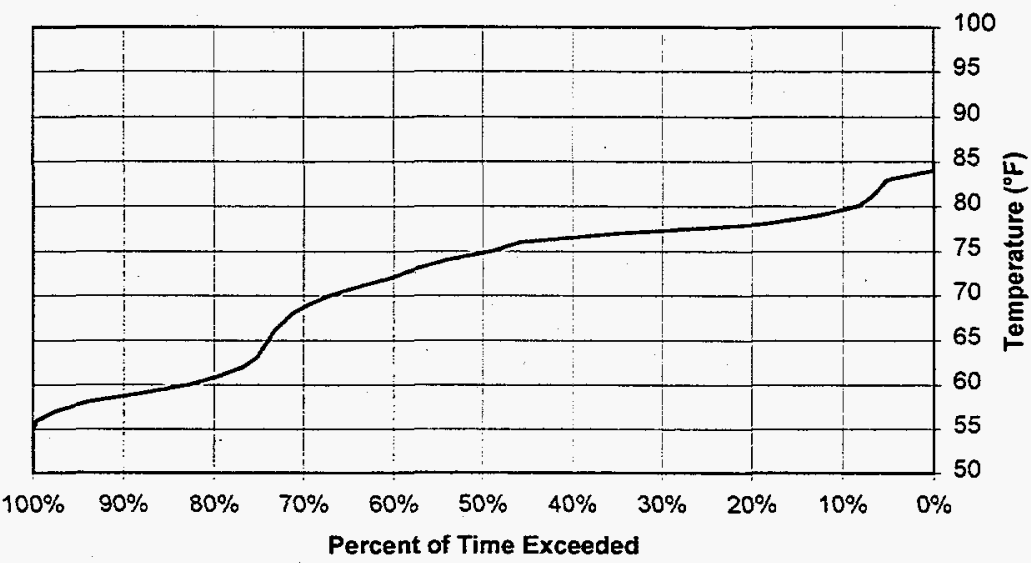

Site 220B GHP Entering Water Temperature 3/96 - 2/97 GHP Runtime $=2319 \mathrm{Hrs}$, Max EWT $=98.3^{\circ} \mathrm{F}$

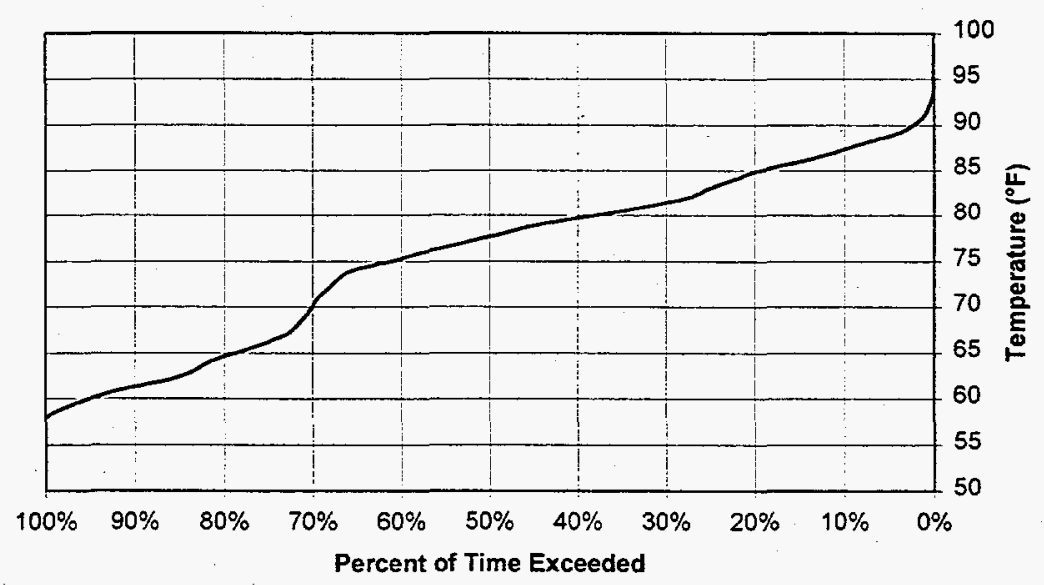

Fig. 5.12. Measured duration curves for EWT over all GHP run hours. (Figure continued on next page.) 
Site 220C GHP Entering Water Temperature 3/96 - 2/97 GHP Runtime $=1960 \mathrm{Hrs}$, Max EWT $=91.5^{\circ} \mathrm{F}$

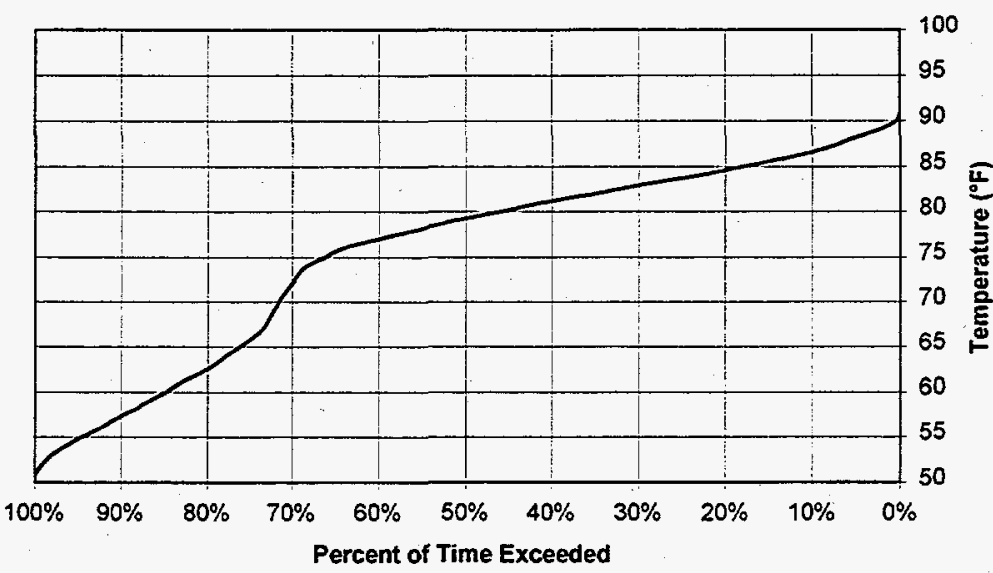

Site 220D GHP Entering Water Temperature 3/96 - 2/97 GHP Runtime $=1889 \mathrm{Hrs}, \operatorname{Max} \mathrm{EWT}=90.6^{\circ} \mathrm{F}$

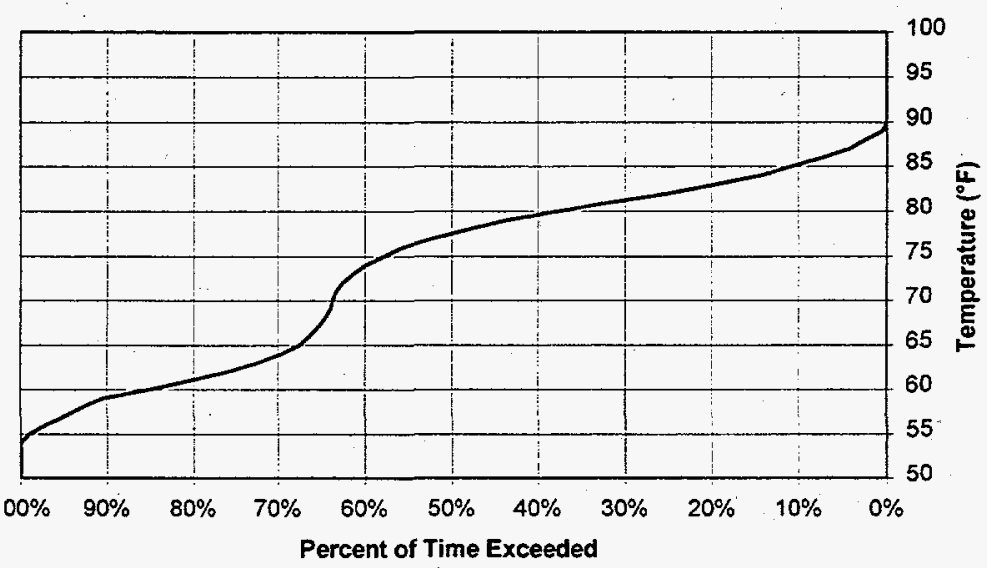

Site 220E GHP Entering Water Temperature 3/96 - 2/97 GHP Runtime $=2689 \mathrm{Hrs}, \operatorname{Max}$ EWT $=94.1^{\circ} \mathrm{F}$

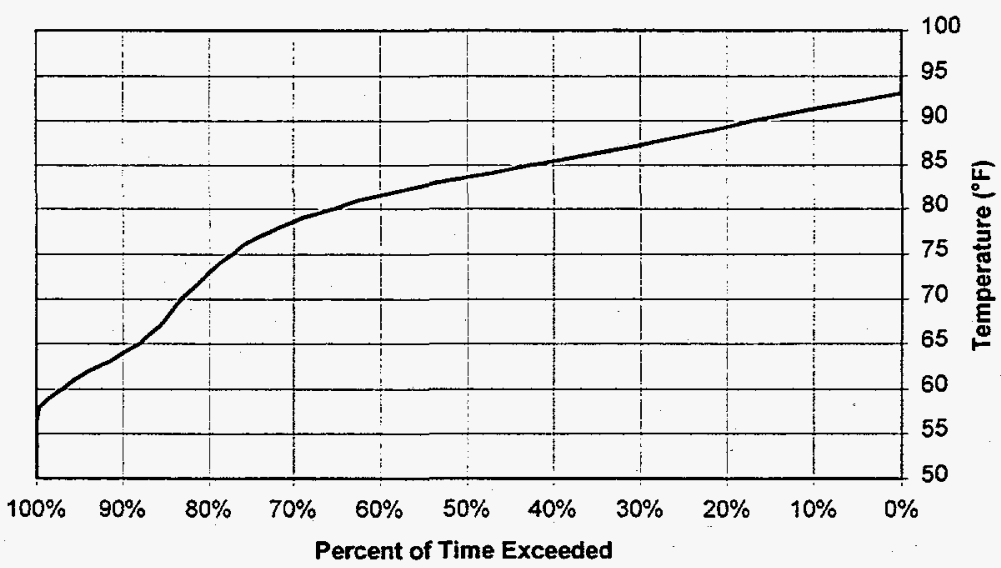

Fig. 5.12. (Continued from previous page.) 


\section{COMPARISON OF PRACTICAL BHEX DESIGN METHODS TO A FORT POLK DATA/MODEL BENCHMARK}

\subsection{INTRODUCTION}

The calibration of an apartment-level engineering model against energy-balance data, described in detail in Sect. 5, produced a useful data/model benchmark for practical BHEx design methods. This section describes the comparison of five practical methods with the data/model benchmark and with one another in order to establish the degree of consistency among the methods available in 1994 when the Fort Polk project was designed.

\subsection{INPUTS TO THE PRACTICAL SIZING PROGRAMS}

The five practical BHEx design methods will be referred to here by a letter designation (A to E) instead of by application title. Each of the five practical methods requires a different set of user inputs. The general factors that influence the design size of the BHEx are:

1. weather,

2. building design loads,

3. building loads (monthly and annual),

4. soil thermal properties,

5. working fluid,

6. ground loop properties (both geometric and thermal), and

7. installed heat pump.

The values used for these input and the methods of deriving them from the calibrated apartment-level engineering model are discussed in this section.

\subsubsection{Weather}

Unlike the detailed model, none of the five practical programs required detailed hourly weather information. In fact, only two of the practical methods ( $D$ and $E$ ) require any type of weather information at all. Each of these requires the winter and summer design temperatures and the daily temperature range. Alexandria, Louisiana, is the closest city to Fort Polk with reported weather information; below are the accepted $99 \%$ design values for Alexandria, Louisiana.

Winter design temperature: $23^{\circ} \mathrm{F}$

Summer design temperature: $95^{\circ} \mathrm{F}$

Daily temperature range: $20^{\circ} \mathrm{F}$

The weather inputs to the five practical programs and the detailed model are summarized below.

Program A: Does not require weather information.

Program B: Does not require weather information.

Program C: Does not require weather information. 
Program D: The design temperatures were added as specified above and the hourly temperature bins were calculated from the Lufkin, Texas, TMY weather that was used to drive the detailed model.

Program E: Alexandria, Louisiana, was chosen from list a of available sites with properties as specified above.

TRNSYS: Used TMY weather for Lufkin, Texas, the closest inland TMY weather station.

\subsubsection{Building Design Loads}

The detailed building model was calibrated to the measured data by adjusting the parameters of the infiltration model until the resulting average load lines matched the average load lines observed at the site. The average heating and cooling load lines from the calibrated model and the measured data are plotted against the binned ambient temperature in Figs. 6.1 and 6.2.

The design temperatures for the site are $23^{\circ} \mathrm{F}$ in heating and $95^{\circ} \mathrm{F}$ in cooling. The design heating and cooling loads cannot be read from Figs. 6.1 and 6.2 at these design temperatures because the figures represent the average load lines, not the maximum. The calibrated building model, however, predicts a design heating load of $15,760 \mathrm{Btu} / \mathrm{h}$ and a design total cooling load (sensible and latent) of 19,348 Btu/h. The data support these relatively large design loads for this apartment, since the heat pump was observed running for periods of several hours (up to 8) in both heating and cooling modes, with a nominal heat pump heating capacity of $11,800 \mathrm{Btu} / \mathrm{h}$ and a nominal cooling capacity of $17,300 \mathrm{Btu} / \mathrm{h}$. The building heating and cooling design loads are inputs required by Programs $\mathrm{D}$ and $\mathrm{E}$.

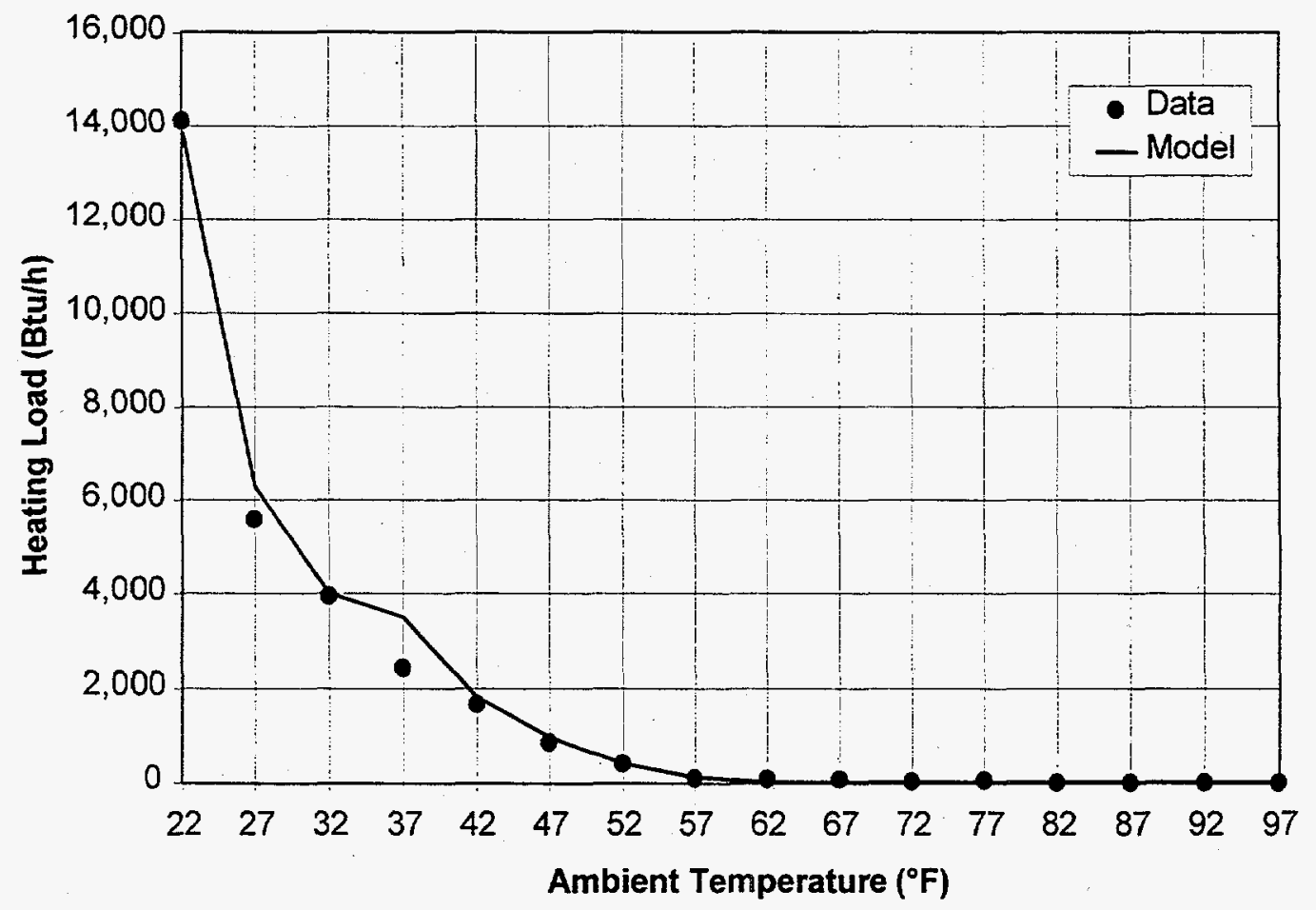

Fig. 6.1. Average heating load line comparison. 


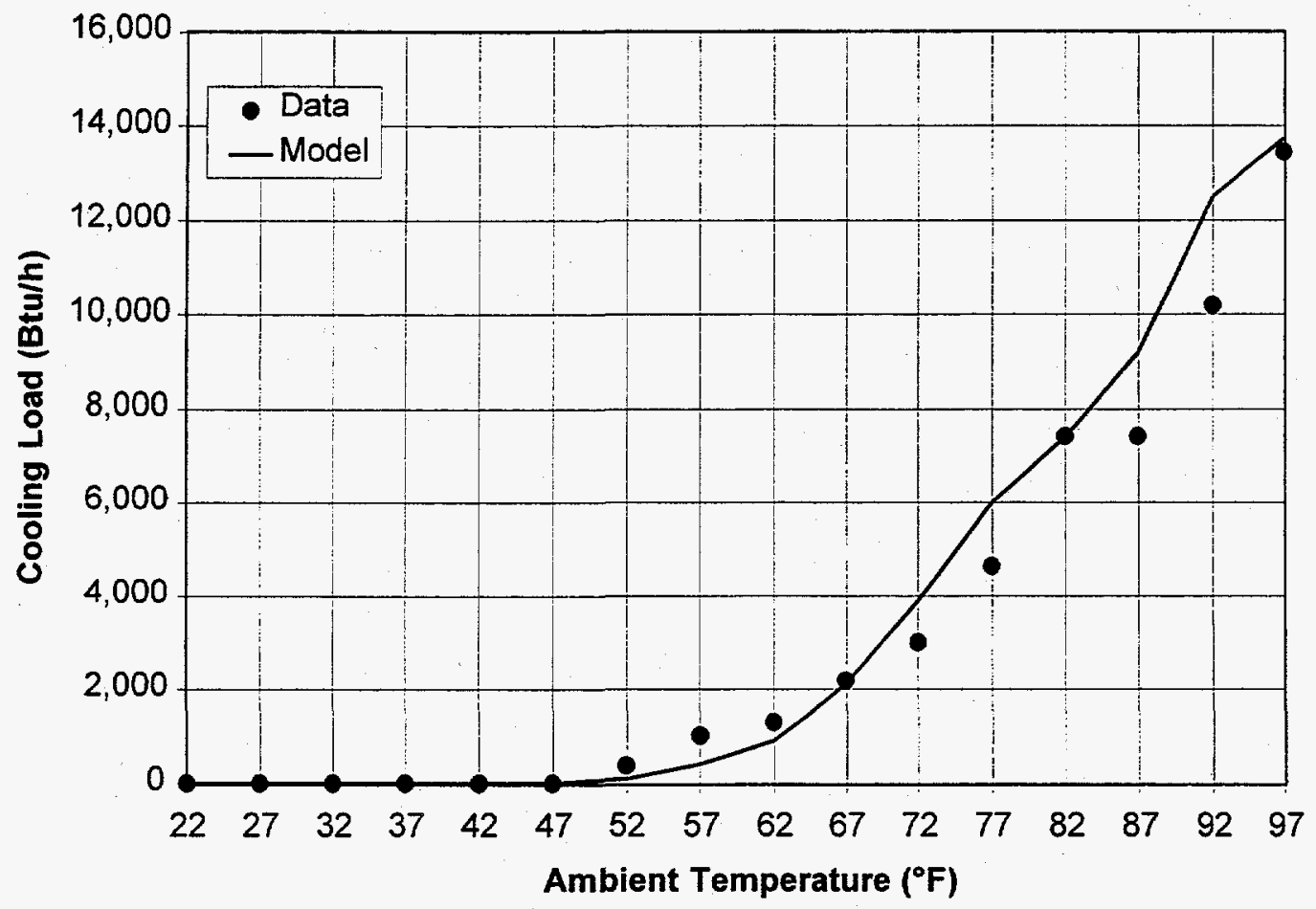

Fig. 6.2. Average total cooling load (sensible and latent) line comparison.

Program $\mathrm{D}$ also requires the winter and summer balance-point temperatures for the building. In Fig. 6.1, the winter balance-point temperature (the ambient temperature at which the building heating load is exactly met by the internal gains) is about $60^{\circ} \mathrm{F}$. This value is within the program's recommended range of 50 to $65^{\circ} \mathrm{F}$. The $60^{\circ} \mathrm{F}$ balance-point temperature indicated by Fig. 6.1 is with the relatively constant heating setpoint of near $70^{\circ} \mathrm{F}$ from the measured data taken at the site. This $10^{\circ} \mathrm{F}$ difference can be attributed directly to the solar and internal gains of the space. Unfortunately, due to the wide range of cooling setpoint temperatures actually measured in the building, the summer balance-point temperature was more difficult to calculate. A cooling balance-point temperature of $64^{\circ} \mathrm{F}$ was chosen for the calculations, as this represents the average cooling setpoint $\left(74^{\circ} \mathrm{F}\right)$ minus the effect of the solar and internal gains $\left(10^{\circ} \mathrm{F}\right)$. This cooling balance-point temperature falls within the typical range of 50 to $70^{\circ} \mathrm{F}$ recommended by the program. The BHEx design lengths calculated by this program are extremely sensitive to these balance-point temperatures.

Program $\mathrm{C}$ requires the average building loads in the four bins that define the design day: 8 a.m. to noon, noon to 4 p.m., 4 p.m. to 8 p.m., and 8 p.m. to 8 a.m. The values used were taken from the detailed model results on the day of maximum heating and cooling loads. The design day load profiles are shown in Fig. 6.3 and summarized in Table 6.1. Program C does not allow the calculated building loads to be used with only one heat pump for maximum entering water temperatures (EWTs) above $95^{\circ} \mathrm{F}\left(35^{\circ} \mathrm{C}\right)$, because under these conditions the heating and cooling loads are higher than the heat pump capacities. 


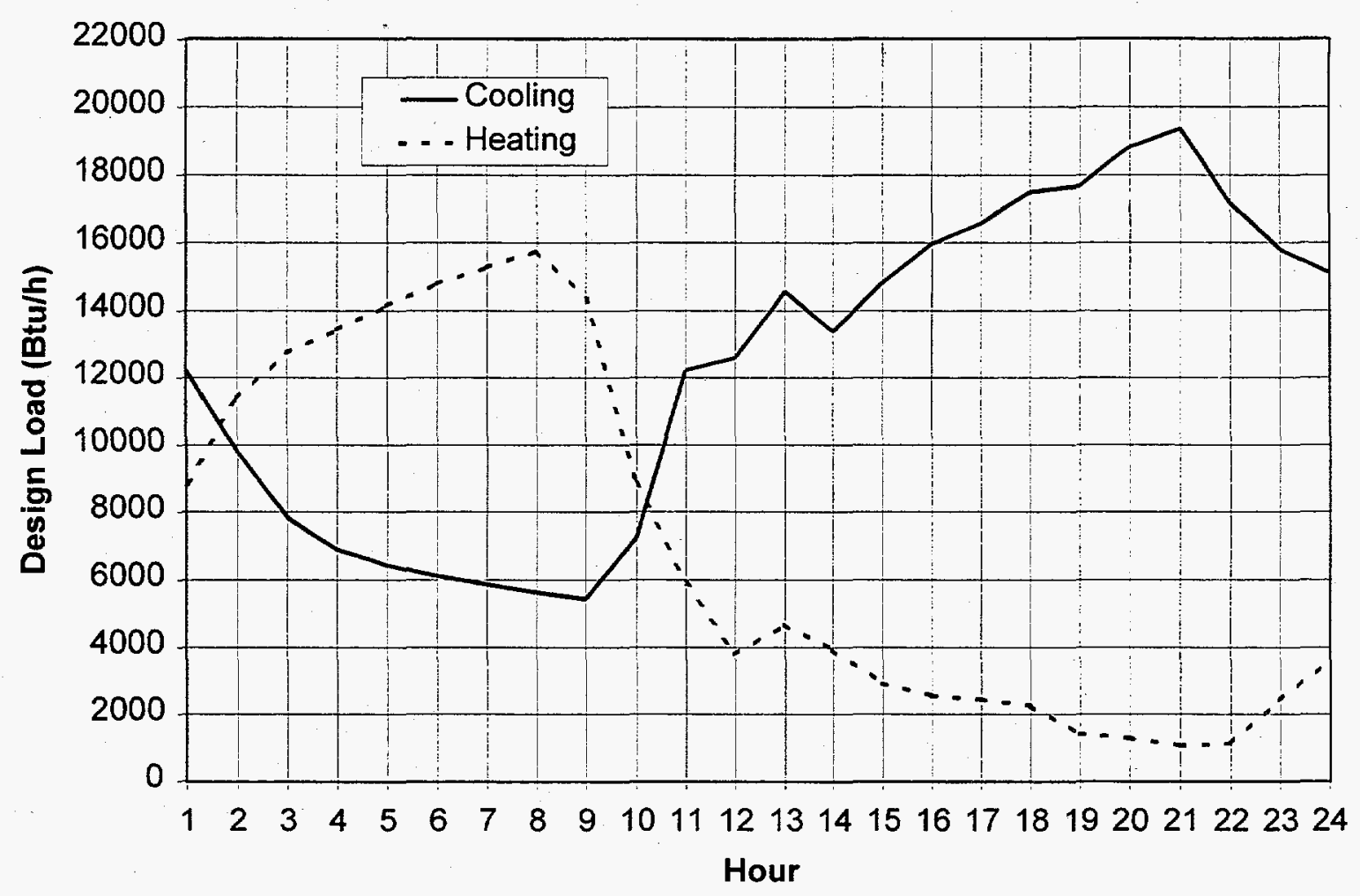

Fig. 6.3. Hourly heating and cooling loads during the heating and cooling design days.

Table 6.1. Design heating and cooling loads for Program C

\begin{tabular}{ccc}
\hline Bin & $\begin{array}{c}\text { Heating design values } \\
(\mathrm{kBtu} / \mathrm{h})\end{array}$ & $\begin{array}{c}\text { Cooling design values } \\
(\mathrm{kBtu} / \mathrm{h})\end{array}$ \\
\hline 8 a.m. to Noon & 11.2 & 7.6 \\
Noon to 4 p.m. & 3.8 & 13.8 \\
4 p.m. to 8 p.m. & 2.2 & 16.9 \\
8 p.m. to 8 a.m. & 8.3 & 11.8 \\
\hline
\end{tabular}

\subsubsection{Building Monthly Loads}

Program B requires monthly building loads as inputs. With the calibrated apartment model, determination of the monthly heating and cooling loads was straightforward. The model was run for one year, and the energy delivered to/removed from the zone was integrated in heating and cooling modes for each month of the year (Table 6.2). Program E requires the annual heating and cooling loads, that is, the sums of the monthly values listed in Table 6.2. 
Table 6.2. Monthly heating and cooling loads

\begin{tabular}{lrr}
\hline Month & $\begin{array}{c}\text { Heating load } \\
(\mathrm{kBtu})\end{array}$ & $\begin{array}{c}\text { Cooling load } \\
(\mathrm{kBtu})\end{array}$ \\
\hline January & 2,962 & 0 \\
February & 1,878 & 0 \\
March & 1,174 & 0 \\
April & 0 & 286 \\
May & 0 & 1,818 \\
June & 0 & 2,856 \\
July & 0 & 6,214 \\
August & 0 & 6,229 \\
September & 0 & 4,114 \\
October & 296 & 332 \\
November & 121 & 0 \\
December & 1,030 & 0 \\
Annual Total & 7,461 & 21,849 \\
\hline
\end{tabular}

\section{Heat Pump Runtime}

Program $C$ requires the equivalent full load heat pump run-time in both heating and cooling modes. Using the detailed simulation, the heat pump run-time was integrated into monthly totals in both modes. In the months for which the monitored data set was complete, the integrated heat pump run-time values from the model were compared with the measured values. The results from this comparison showed a difference of less than $15 \%$ in the run-times. Although a difference of $15 \%$ seems high, note that the model is driven with TMY weather conditions for Lufkin, Texas, not those measured at the site. The model output was 538 full load heating hours and 1852 full load cooling hours. These values were inputs to Program C.

\section{Ground Loop Monthly Loads}

Program A requires the monthly totals of heat rejection to the ground from the heat pump (cooling mode) and heat absorption from the ground to the heat pump (heating mode). With the calibrated apartment model, determining the monthly rejection/absorption was straightforward. The model was run for one year, and the heat rejection to and absorption from the ground was integrated for each month of the year. The resulting values are listed in Table 6.3.

\subsubsection{Soil Properties}

As explained in Sect. 5, the best-fit effective average soil thermal properties corresponded almost exactly to the ASHRAE (1991) heavy saturated soil: a density of $200 \mathrm{lbm} / \mathrm{ft}^{3}$, a specific heat of $0.20 \mathrm{Btu} / \mathrm{lbm} \cdot{ }^{\circ} \mathrm{F}$, a thermal conductivity of $1.40 \mathrm{Btu} / \mathrm{h} \cdot \mathrm{f} \cdot{ }^{\circ} \mathrm{F}$, and a thermal diffusivity of $0.035 \mathrm{ft}^{2} / \mathrm{h}$. The subsurface formation was largely clay with some sand. 
Table 6.3. Monthly heat absorbed by and rejected to ground

\begin{tabular}{lrr}
\hline Month & $\begin{array}{c}\text { Heat absorbed } \\
(\mathrm{kBtu})\end{array}$ & $\begin{array}{c}\text { Heat rejected } \\
(\mathrm{kBtu})\end{array}$ \\
\hline January & 2,201 & 0 \\
February & 1,393 & 0 \\
March & 867 & 0 \\
April & 0 & 331 \\
May & 0 & 2,133 \\
June & 0 & 3,369 \\
July & 0 & 7,724 \\
August & 0 & 7,751 \\
September & 0 & 5,089 \\
October & 201 & 410 \\
November & 89 & 0 \\
December & 761 & 0 \\
Annual Total & 5,512 & 26,807 \\
\hline
\end{tabular}

The thermal conductivity values for sand and clay from three of the five design sizing programs are given below. From these reported conductivity values, a value of $1.40 \mathrm{Btu} / \mathrm{h} \cdot \mathrm{ft} \cdot{ }^{\circ} \mathrm{F}$ is certainly reasonable.

Program B: Thermal conductivity of Sand, $1.30-1.50 \mathrm{Btu} / \mathrm{h} \cdot \mathrm{ft} \cdot{ }^{\circ} \mathrm{F}$ Thermal conductivity of Clay, $1.30-1.50 \mathrm{Btu} / \mathrm{h} \cdot \mathrm{ft} \cdot{ }^{\circ} \mathrm{F}$

Program C: Thermal conductivity of Sand, $1.20-1.50 \mathrm{Btu} / \mathrm{h} \cdot \mathrm{ft} \cdot{ }^{\circ} \mathrm{F}$ Thermal conductivity of Clay, $1.00-1.40 \mathrm{Btu} / \mathrm{h} \cdot \mathrm{ft} \cdot{ }^{\circ} \mathrm{F}$

Program D: Thermal conductivity of Sand, $1.75-2.00 \mathrm{Btu} / \mathrm{h} \cdot \mathrm{ft} \cdot{ }^{\circ} \mathrm{F}$ Thermal conductivity of Clay, $0.82-0.93 \mathrm{Btu} / \mathrm{h} \cdot \mathrm{ft} \cdot{ }^{\circ} \mathrm{F}$

One of the five practical methods, Program E, reports that the deep-earth temperature (average surface temperature) for Alexandria, Louisiana, is $69^{\circ} \mathrm{F}$. As discussed in Sect. 5 , the undisturbed deep-earth temperature at Fort Polk is $67.8^{\circ} \mathrm{F}$. For the purposes of this comparison, we decided to bound this value and compare the programs at $62^{\circ} \mathrm{F}$ and $69^{\circ} \mathrm{F}$.

Program $\mathrm{E}$ also indicates that the amplitude of the surface temperature is $17^{\circ} \mathrm{F}$, with the minimum surface temperature occurring at day 32 of the year. Since no data were collected that either substantiated or refuted the long-term average amplitude and the day of minimum temperature values, these values were used in all the programs, including the detailed BHEx model.

We decided to perform this comparison with heavy saturated soil. The inputs to accomplish this with the five practical methods are summarized below:

Program A: Added a new soil type to the available list, since the heavy saturated soil thermal diffusivity in the program was inconsistent with other sources.

Program B: Selected heavy saturated soil from the list of soil types. 
Program C: Requires inputs of thermal conductivity and thermal diffusivity. The values for heavy saturated soil were used.

Program D: Saturated sand was substituted for heavy saturated soil, which was not an available option.

Program E: Saturated soil was substituted for heavy saturated soil, which was not an available option. Only the deep-earth temperature corresponding to Alexandria, Louisiana $\left(69^{\circ} \mathrm{F}\right)$ could be run because this value is hardwired into the program.

TRNSYS: Thermal conductivity, density, and specific heat for heavy saturated soil were entered.

The soil temperature inputs to the five methods are summarized as follows:

Program A: Requires the average surface temperature, surface temperature amplitude, and day of minimum surface temperature.

Program B: Requires only the average surface temperature.

Program C: Requires only the average surface temperature.

Program D: Requires only the average surface temperature.

Program E: Requires the average surface temperature, surface temperature amplitude, and day of minimum surface temperature. These values are automatically chosen on the basis of the selected weather city, which was Alexandria, Louisiana.

TRNSYS: Requires the average surface temperature, surface temperature amplitude, and day of minimum surface temperature.

\subsubsection{Working Fluid}

Water is the working fluid for the GHPs installed at the Fort Polk site. The working fluid inputs to the five practical methods are summarized as follows:

Program A: The program does not allow the user to select water. Therefore, a new antifreeze that has the properties of water was added to the list.

Program B: Water was chosen from list of available fluids.

Program C: Assumes a working fluid (not clear which one).

Program D: Water was chosen from list of available fluids.

Program E: Assumes a working fluid (methanol 20\%).

TRNSYS: Takes the fluid thermal properties (density, specific heat, and thermal conductivity) as inputs. 


\subsubsection{BHEx Configuration}

The five practical sizing programs require different inputs to define the BHEx configuration. Four of the programs require geometric and thermal property information, which is readily available. Two of the programs require the user to input the borehole thermal resistance (the resistance to heat transfer from the working fluid to the borehole wall), which we estimated with the detailed model. The estimated value of thermal resistance for the chosen pipe, borehole geometry, and thermal properties was $0.2281 \mathrm{~h} \cdot \mathrm{ft} \cdot{ }^{\circ} \mathrm{F} / \mathrm{Btu}$. Two of the programs require the $\mathrm{B} / \mathrm{H}$ ratio, that is, the ratio of borehole depth to inter-borehole spacing. For the installed system, the $\mathrm{B} / \mathrm{H}$ ratio is 0.062 . A value of 0.05 was used for the program that allowed only selected values of the $\mathrm{B} / \mathrm{H}$ ratio. The ground loop configuration inputs are summarized as follows:

Program A: The type of U-tube pipe and the U-tube configuration were chosen from lists of available types. The distance between U-tube centers, the distance below the ground surface of the top of the U-tube, and the number of boreholes are inputs to the program.

Program B: The borehole configuration (two in a line) and $\mathrm{B} / \mathrm{H}$ ratio $(0.05)$ are chosen from lists of available types. The borehole radius and borehole thermal resistance are inputs to the program.

Program C: The borehole thermal resistance, equivalent diameter, borehole configuration, separation distance, and number of boreholes per parallel loop (one) are inputs to the program. The equivalent diameter was chosen from a table of equivalent diameters on the basis of the Utube pipe type and size.

Program D: The pipe size, pipe type, and borehole configuration are chosen from lists of available types. The borehole multiplier is required as an input to the program.

Program E: The borehole configuration and pipe size are chosen from lists of available types. The number of boreholes is internally selected, one borehole per ton.

TRNSYS: The user enters the thermal and geometric parameters of the pipe, the thermal properties of the borehole backfill material, and the geometry of the borehole.

The thermal conductivity of the polyethylene pipe used by Program A was different from that used in the detailed model, and was different from those of the other sources as well. Using the detailed model, the assumed value from the detailed model was compared with the default value from Program A, and bore sizing differences on the order of $1 \mathrm{ft}$ were observed. Since the resulting error was small, no attempt was made to force Program A to use the same pipe thermal conductivity value as the other programs.

\subsubsection{Heat Pump}

Each of the five practical methods required a different method of inputting the heat pump characteristics. The heat pump input information to each of the programs is summarized as follows: 
Program A: Requires the nominal total installed heat pump capacity (1.5 ton) and the total heat pump water flow rate.

Program B: Requires quadratic curve-fit coefficients for power and capacity in heating and cooling modes. The detailed model was exercised at the measured site flow rate and the results were fitted to a curve to determine the coefficients for the program.

Program C: An external utility program in this package was run to generate a new heat pump data file for the installed system. Inputs to this utility were capacity and power at two flow rates and two inlet water temperatures.

Program D: Because the heat pump installed at the site is not part of the equipment database that came with this program, the user must enter the heating and cooling capacities of the heat pump and the COP/EER at each design entering water temperature for which the BHEx length will be calculated. These values were produced by exercising the heat pump component of the detailed model at the measured flow rate.

Program E: Selected the unit from the internal equipment database.

TRNSYS: A detailed component model of the heat pump was created for this study. Refer to Sect. 5 for a discussion of this model.

The curve-fit coefficients required by Program B were determined by an external utility program because the internal curve-fitting routine in Program B gave unrealistic results.

\subsection{COMPARISON OF RESULTS}

Each of the five practical BHEx design methods reports the required borehole length as a function of the user-specified maximum allowable water temperature entering the heat pump unit. For the purposes of this comparison, the design lengths were calculated using a one-year analysis period:

- at entering water temperatures of $85,90,95,100$, and $105^{\circ} \mathrm{F}$, and

- at undisturbed deep-earth temperatures of $62^{\circ}$ and $69^{\circ} \mathrm{F}$.

The results from this comparison show a range of borehole lengths for two boreholes serving a 1.5-ton heat pump-ranging from $83.6 \mathrm{ft}$ per bore (at a maximum EWT of $105^{\circ} \mathrm{F}$, with a deepearth temperature of $62^{\circ} \mathrm{F}$ ) to $388.8 \mathrm{ft}$ per bore (at a maximum EWT of $85^{\circ} \mathrm{F}$, with a deep-earth temperature of $69^{\circ} \mathrm{F}$ ). The results from the comparisons are shown in Tables 6.4 and 6.5 and are graphed in Figs. 6.4 and 6.5.

The great variation in the results can be seen by reading across the rows of Tables 6.4 and 6.5 . Differences on the order of a factor of 1.8 are observed between the detailed model and some of the practical BHEx design methods. 
Table 6.4. Design borehole lengths in feet per bore for various maximum EWTs at an undisturbed deep-earth temperature of $69^{\circ} \mathrm{F}$

\begin{tabular}{lcccccc}
\hline & Program A & Program B & Program C & Program D & Program E & TRNSYS \\
\hline $85^{\circ} \mathrm{F}$ & 221.1 & 164.3 & 307.0 & 388.8 & 242.5 & 304.0 \\
$90^{\circ} \mathrm{F}$ & 163.1 & 138.6 & 249.0 & 297.0 & 197.5 & 241.3 \\
$95^{\circ} \mathrm{F}$ & 129.3 & 120.4 & 211.0 & 242.8 & 165.0 & 198.0 \\
$100^{\circ} \mathrm{F}$ & 107.3 & 106.8 & N/A & 206.0 & 142.5 & 172.8 \\
$105^{\circ} \mathrm{F}$ & 91.8 & 96.3 & N/A & 179.3 & 125.0 & 148.6 \\
\hline
\end{tabular}

Note: According to the various methods, two boreholes of the indicated length would be required for the benchmark apartment with a nominal 1.5 -ton heat pump.

Table 6.5. Design borehole lengths in feet per bore for various maximum EWTs at an undisturbed deep-earth temperature of $62^{\circ} \mathrm{F}$

\begin{tabular}{llllccc}
\hline & Program A & Program B & Program C & Program D & Program E & TRNSYS \\
\hline $85^{\circ} \mathrm{F}$ & 147.6 & 128.6 & 229.0 & 268.3 & N/A & 218.0 \\
$90^{\circ} \mathrm{F}$ & 119.4 & 112.8 & 196.0 & 223.0 & N/A & 182.0 \\
$95^{\circ} \mathrm{F}$ & 100.4 & 100.7 & 172.0 & 191.3 & N/A & 158.0 \\
$100^{\circ} \mathrm{F}$ & 86.9 & 91.3 & N/A & 168.0 & N/A & 142.0 \\
$105^{\circ} \mathrm{F}$ & Program failure & 83.6 & N/A & 150.0 & N/A & 130.0 \\
\hline
\end{tabular}

Note: According to the various methods, two boreholes of the indicated length would be required for the benchmark apartment with a nominal 1.5 -ton heat pump.

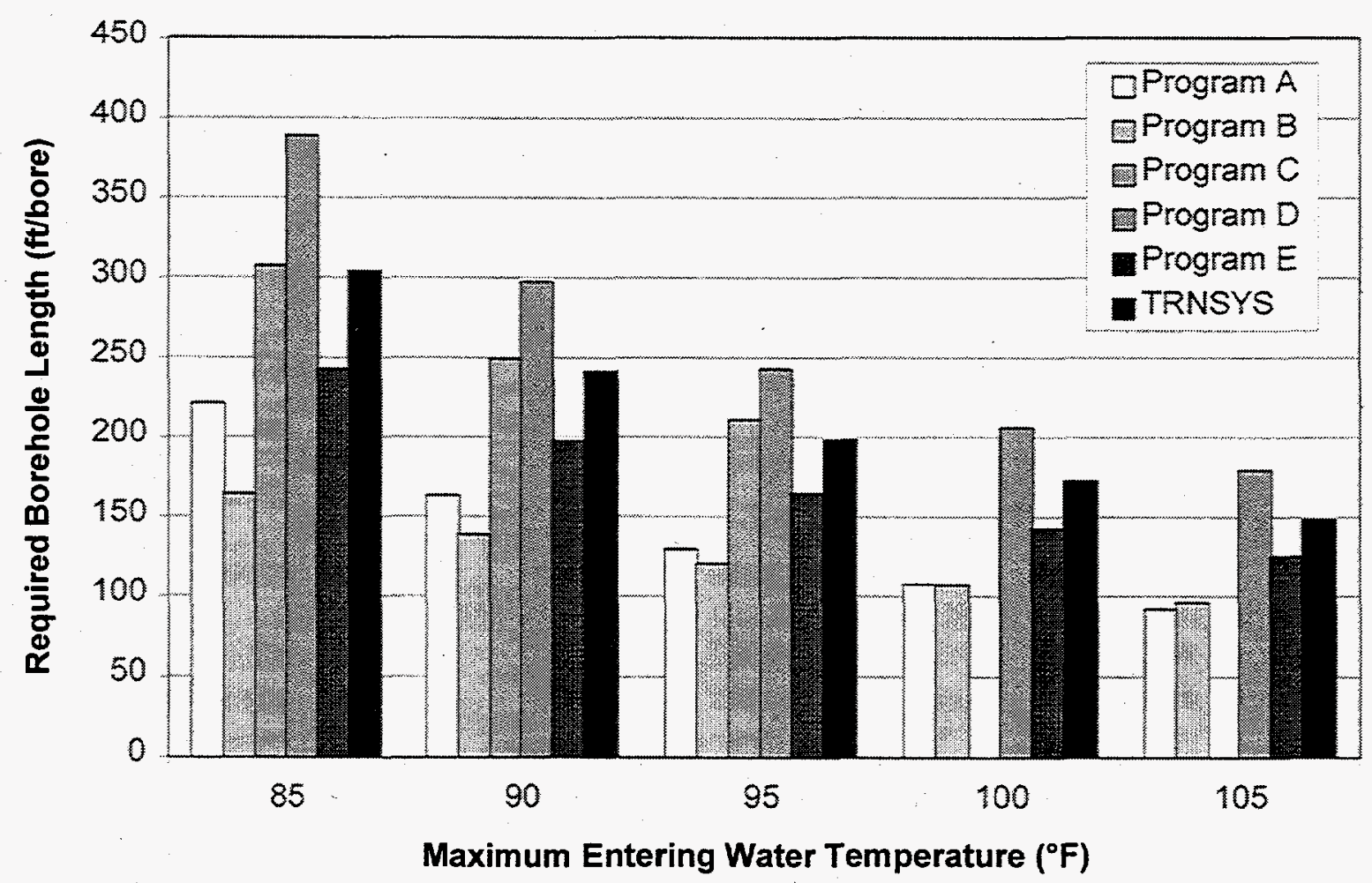

Fig. 6.4. Design borehole lengths for various maximum EWTs at an undisturbed deep-earth temperature of $69^{\circ} \mathrm{F}$. 


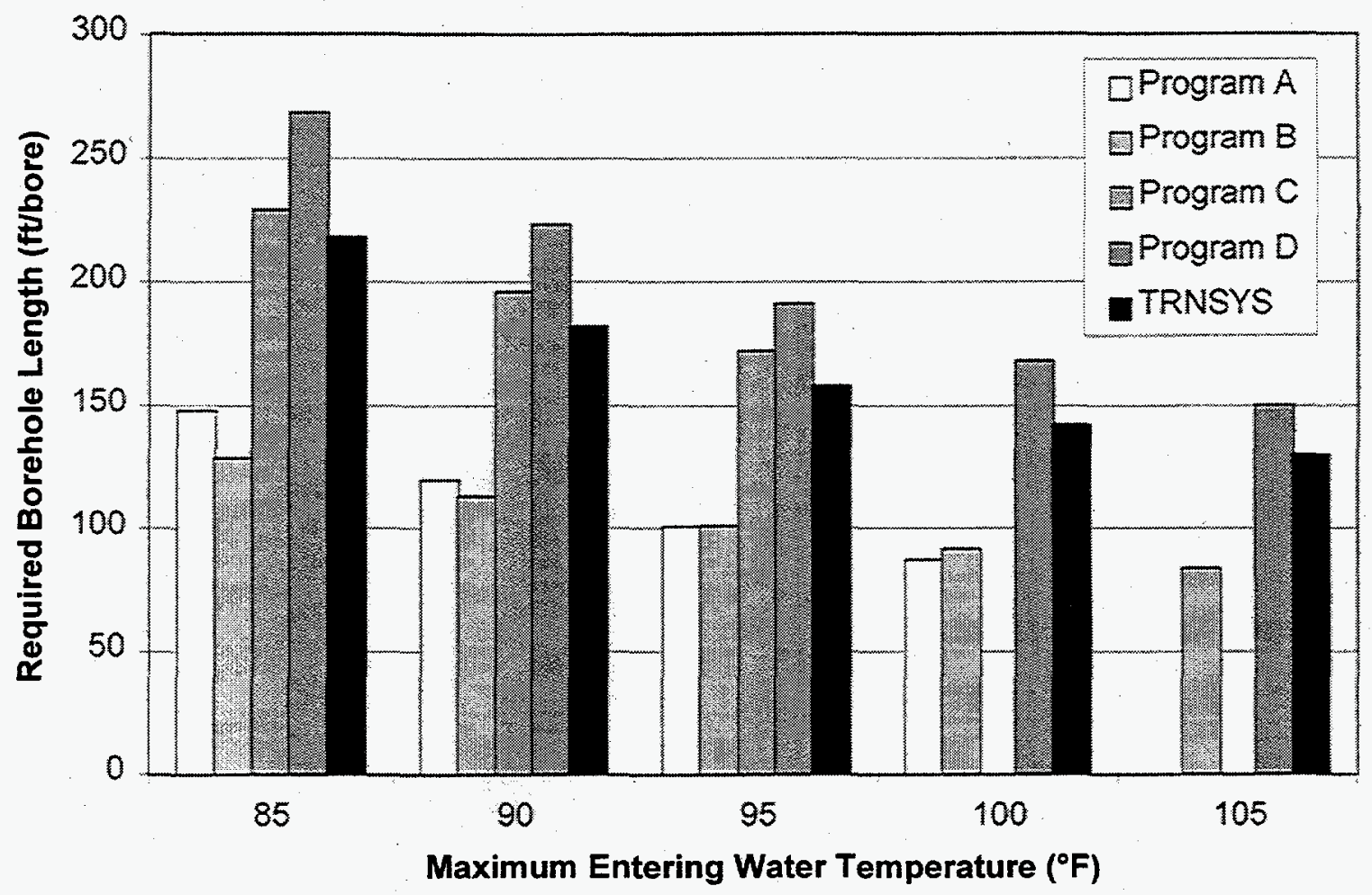

Fig. 6.5. Design borehole lengths for various maximum EWTs at an undisturbed deep-earth temperature of $62^{\circ} \mathrm{F}$.

\subsection{CONCLUSIONS}

When the Fort Polk project was engineered, BHEx design was largely experience-based. A small cadre of experienced designers could develop effective BHEx designs by adjusting the outputs of the practical BHEx design methods they used based on experience. Because of the uncertainty, the ESCO responsible for the project obtained multiple opinions from among this experienced group of professionals.

Although costly, this approach was effective. Assuming the apartment used in the comparison is representative, interpolating the TRNSYS results at a $90^{\circ} \mathrm{F}$ maximum EWT between Tables 6.4 and 6.5 to obtain borehole length at a $67.8^{\circ} \mathrm{F}$ deep-earth temperature results in $231 \mathrm{ft}$ per bore. Performing the same interpolation at $95^{\circ} \mathrm{F}$ results in $191 \mathrm{ft}$ per bore. Since there are two bores and a 1.5-ton heat pump, these values equal $308 \mathrm{ft} /$ ton and $255 \mathrm{ft} /$ ton, respectively, based on a singleyear analysis. As per Sect. 5, TRNSYS indicates a $2^{\circ} \mathrm{F}$ rise over ten years due to the large annual heat unbalance (see Table 6.3; heat rejected to the BHEx exceeds heat absorbed by a factor of 4.86). If one assumes that the effects of groundwater movement wash out part of the heat buildup, one could conclude that the $2^{\circ} \mathrm{F}$ rise would occur over 20 or more years rather than 10 . If $95^{\circ} \mathrm{F}$ is the maximum acceptable, interpolating between 308 and $255 \mathrm{ft} /$ ton results in $276 \mathrm{ft} /$ ton at $93^{\circ} \mathrm{F}$ in the first year. On average, the project was installed at $275 \mathrm{ft} / \mathrm{ton}$.

Note that Fig. 5.11 and associated discussion concluded that $275 \mathrm{ft} /$ ton would have held apartment $\mathrm{A}$ to a maximum EWT of $91^{\circ} \mathrm{F}$ during the monitored post-retrofit weather year, which was milder than normal, and to a maximum of $95^{\circ} \mathrm{F}$ after 20 mild years. The previous paragraph concludes that about $275 \mathrm{ft} /$ ton would hold apartment $\mathrm{A}$ to a maximum EWT of $93^{\circ} \mathrm{F}$ during a 
Lufkin, Texas, TMY, and to a maximum of $97^{\circ} \mathrm{F}$ after $20 \mathrm{TMY}$ years. The designers apparently judged, based on experience, that the models over-predict heat buildup.

Clearly, the pool of designers that could have been expected to arrive at this BHEx design in 1994 was not very large. Expanding the pool of qualified designers is an important part of expanding the GHP industry. Our comparison demonstrates that even with consistent (to the extent possible) inputs, some of the five practical BHEx design methods and the detailed model/data benchmark calculated very different required borehole lengths. Except for the experienced few, designers are not in a position to adjust BHEx design method results to arrive at effective designs. We conclude that further well-documented calibration/comparison exercises are needed to give the developers of BHEx design methods an opportunity to improve and release next-generation BHEx design methods with the experience built in, so that the pool of designers that can develop effective designs can be expanded more rapidly than would otherwise be possible. 


\section{MEASUREMENT AND VERIFICATION OF ENERGY SAVINGS}

\subsection{INTRODUCTION}

Measurement and verification of energy savings (M\&V) is a fundamental component of energy savings performance contracting and has become more prominent since the Fort Polk project was initiated. The type of contract implemented at Fort Polk-the "shared savings" contract, wherein M\&V is used to determine the amount of monthly payments to the ESCO-has since been supplanted by a contract form wherein $\mathrm{M} \& \mathrm{~V}$ is used to verify that guaranteed savings are achieved over a period of time, which is typically a year (see the Federal Regulation at Title 10 CFR Part 436).

Several major protocols for M\&V were developed and published after the Fort Polk project was begun and the data acquisition systems associated with our evaluation were installed, such as the International Performance Measurement and Verification Protocol, the FEMP M\&V Guideline for Federal Energy Projects, and ASHRAE Guideline 14. Still, many potential customers of ESPCs remain uncertain of the purposes, practices, and requirements of $M \& V$. In this section we use examples and data from the Fort Polk project to demonstrate the four basic options defined under these protocols for determining energy savings:

\section{Option A: Performance is estimated based on engineering calculations, sometimes supplemented with short-term measurements.}

Option B: Uses ongoing field measurements on individual retrofits or a sample of individual retrofits.

Option C: Uses ongoing field measurements at the site, building, or apartment level (i.e., data from utility or customer/ESCO meters).

Option D: Uses an engineering model calibrated to energy use data at the site, building, apartment, or end-use level.

We demonstrate use of these options with examples to highlight their advantages and disadvantages in determining savings from different energy conservation measures (ECMs), or groups of measures, in an actual project. This discussion is intended to assist federal customers and ESCOs in evaluating their $M \& V$ options for future energy retrofit projects that are centered on geothermal heat pumps and are implemented as ESPCs.

All ESPCs must include site-specific M\&V plans that address: (1) how an energy-use baseline will be established, (2) how energy savings that result from project installation will be determined, (3) how energy savings will be translated into dollar savings to verify that the guaranteed energy cost savings have been delivered, and (4) how the baseline will be adjusted if the operation of the subject buildings changes significantly. Figure 7.1 illustrates the elements of determining energy savings. No matter which $M \& V$ option is used, the three fundamental measures to determine performance are energy-use baseline, post-retrofit performance, and adjusted baseline.

Before ECMs are installed, the baseline energy usage is determined from engineering calculations or measurements and analysis. The parties to the contract agree on baseline equations that adequately represent pre-retrofit energy usage and estimate energy usage that would occur in the future if no ECMs were installed. The parties also agree on specific measurements, calculations, or stipulations that will be used to determine post-retrofit performance. In addition the parties must reach agreement on how the energy-use baseline will be adjusted in case of changes in factors beyond the ESCO's control, such as 


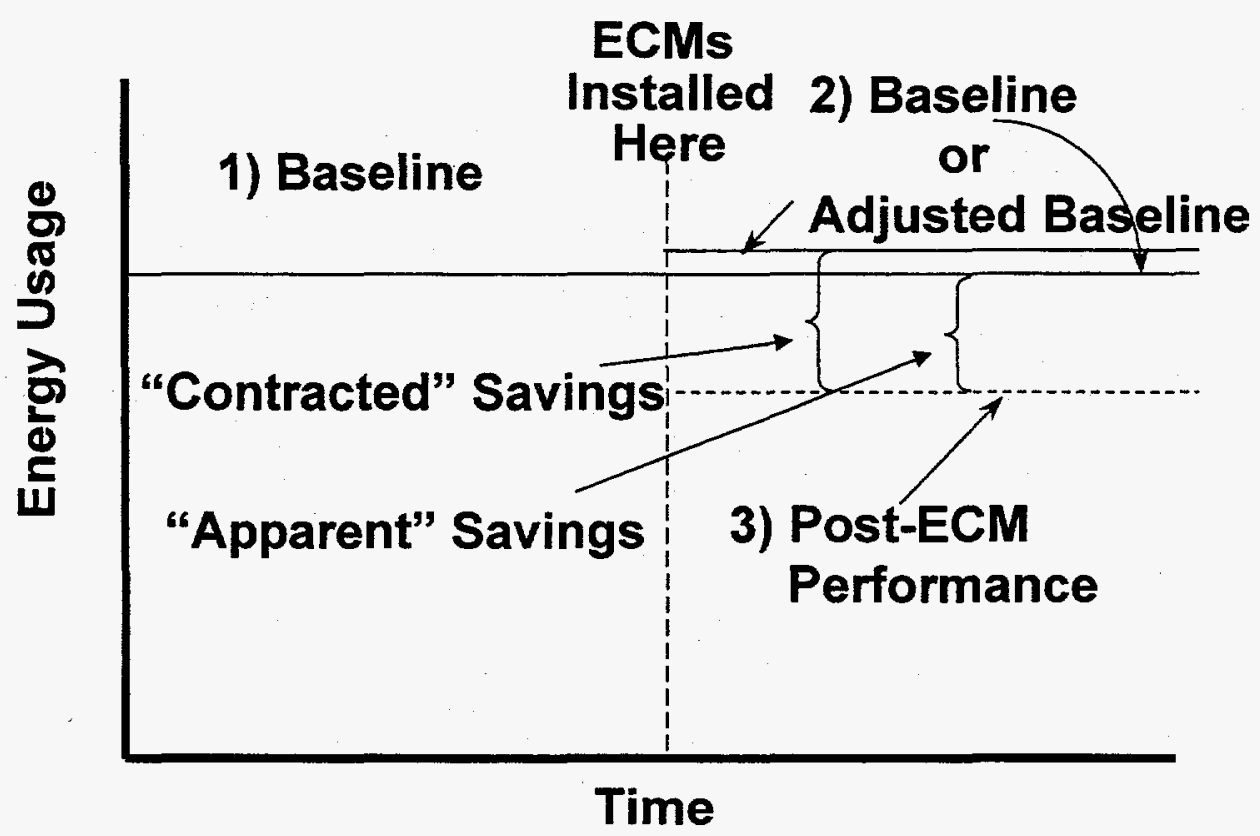

Fig. 7.1. Elements of determining energy savings.

occupancy rate, comfort control setpoints, and increases in energy use over time that are not related to the ECMs installed under the contract.

M\&V plans typically specify tasks to be undertaken before and after ECM installation. Pre-retrofit tasks may include: (1) quantifying baseline energy use (e.g., over a two-week period measuring the runtime of each lighting fixture in a random sample of apartments and using spot watt measurements on all fixtures to calculate an average observed runtime across all fixtures); and (2) verifying baseline conditions (e.g., for the same sample of apartments, taking inventory of all lighting fixtures and their nameplate information). Typical post-retrofit tasks include: (1) verifying installation and operation (e.g., inspecting to confirm that new CFLs were installed and are operated by the light switches); (2) quantifying post-installation energy use (e.g., documenting post-retrofit installed lighting nameplate wattage); (3) quantifying energy savings [e.g., assuming pre- and post-retrofit average runtimes are equal, savings equal (pre-retrofit watts minus post-retrofit watts) $\times$ (average runtime)]; and (4) verifying ongoing potential to generate savings (e.g., annually verifying in a random sample of apartments that the CFLs are still installed and operable).

The site-specific M\&V plan set out in the contract also allocates responsibilities between the customer and ESCO, and sets the rules for determining whether or not these responsibilities are met. The cost and practicality of implementing Options A, B, C, and D to determine energy savings vary by project. In every project the customer and ESCO must balance cost and precision while selecting options and negotiating the final agreement. The customer and ESCO must also agree on how energy savings are to be translated into dollar savings. Unlike shared savings contracts, where $M \& V$ determines the monthly payment, the newer form of ESPCs generally specify that equal monthly payments will be made to the ESCO based on the assumption that the guaranteed energy cost savings level is being met over an annual period. The role of M\&V in this kind of ESPC is to verify at the end of each year that the guaranteed energy cost savings were delivered. If savings exceed the guaranteed level, no ESCO payment adjustments are needed. In the case of a savings shortfall, the next year's monthly ESCO payments are usually debited by $1 / 12^{\text {th }}$ of the shortfall. 
In energy savings performance contracts, the distinction between "apparent" and "contracted" energy savings is related to the energy-use baseline. "Apparent" savings equal the energy-use baseline minus the post-retrofit performance (as measured, calculated, or stipulated); "contracted" savings equal the adjusted baseline minus post-retrofit performance.

If the $M \& V$ plan specified in the ESPC does not require measurements to determine post-retrofit performance (as in the simplest variation of Option A), no baseline adjustments will ever be required and "apparent" and "contracted" savings will always be identical. However, if measurements are required and they capture effects beyond the ESCO's control and responsibility under the terms of the contract, then adjustments to the baseline may be required. Option $\mathrm{C}$ commonly requires baseline adjustments because the savings that are "apparent" from analyzing the data may differ from the "contracted" savings under the contract. For example, if the federal customer is responsible for operating space-conditioning equipment at cooling and heating setpoints of $78^{\circ} \mathrm{F}$ and $68^{\circ} \mathrm{F}$, respectively, but instead operates at setpoints of $74^{\circ} \mathrm{F}$ and $72^{\circ} \mathrm{F}$, an upward adjustment to the baseline may be required. In some projects it is possible to take Option-B measurements at the ECM level so that the measurements only capture the responsibilities of the ESCO, thus avoiding the need for baseline adjustments.

\subsection{OPTION A}

For some ECMs it is not desirable to base energy savings determination on measurements; the measurements may be too costly or too difficult to perform, or may offer only marginally greater precision. In such cases savings can be estimated based on engineering calculations and stipulations, using a method agreed upon by the customer and the ESCO. The total savings are determined by multiplying the estimated energy savings per ECM by the total number installed. In the terminology of $M \& V$ protocols, this type of plan is designated as Option $A$.

\subsubsection{Option A for Low-Flow Shower Heads}

An example of an Option-A plan from Fort Polk is the M\&V of savings from low-flow shower heads. Option $A$ is chosen through a process of elimination. As discussed in Sect. 4, based on our analysis of site-level data, this particular measure saved about $322 \mathrm{kWh}$ per residence per year. This is less than $2 \%$ of the pre-retrofit annual electrical energy use in a typical residence at Fort Polk. A $2 \%$ savings would be difficult to measure with an Option-C approach either at the level of the electrical feeders or from watt-hour meter readings from individual apartments. Given that several ECMs were installed, determining savings from low-flow shower heads by using Option- $\mathrm{C}$ measurements would be impossible.

An Option-A approach to determining savings would be to take short-term measurements of electrical energy use at the hot water tanks in a sample of apartments, as we did, for at least two weeks before and after retrofit. The variation in use of hot water tank energy observed in the Level-3 data indicates that 10 to 12 apartments would have to be monitored to obtain a reasonably accurate estimate of savings for the entire housing population. It would be best to collect this short-term data and install this ECM in the sample during the project development phase, before any other ECMs are installed in these apartments. For example, geothermal heat pump desuperheaters were to be installed in most apartments during the construction phase, so certainly the post-retrofit data on the low-flow shower head sample needed to be collected before desuperheaters were installed. However, considering the level of savings expected from low-flow shower heads, one could argue that it is more important to spend limited project development resources elsewhere. Thus, the customer and the ESCO might agree on an OptionA energy savings determination approach based on engineering calculations rather than on short-term measurements. 


\subsubsection{Engineering Calculations}

At Fort Polk, the energy savings due to new low-flow shower heads can be estimated as follows: Based on figures presented by ASHRAE (1991), the typical residence would be expected to use 42 gal of hot water per day. (This is higher than the hot water use we derived from the Level-3 data, but here we are assuming no such data are available.) On a national basis, showers are estimated to account for $43.7 \%$ of total hot water use in residences (Koomey et al. 1994). Thus we estimate that the average residence at Fort Polk uses about 18.4 gal of hot water per day for showers. Calculations based on information supplied by the manufacturer indicate that the shower heads will reduce water use from 9.6 gal to 6.0 gal per shower. If the number and length of showers per day remain constant after the retrofits, average daily hot water use for showers will drop to $11.5 \mathrm{gal}$, which represents a savings of 6.9 gal per day or 2519 gal per residence per year. With an average supply temperature of $68^{\circ} \mathrm{F}$ and a tank setpoint temperature of $125^{\circ} \mathrm{F}$, the annual savings for each residence is estimated as

$$
(2519 \mathrm{gal}) \times(8.345 \mathrm{lb} / \mathrm{gal}) \times\left(1 \mathrm{Btu} / \mathrm{lb}{ }^{\circ} \mathrm{F}\right) \times\left(57^{\circ} \mathrm{F}\right) \times(1 \mathrm{kWh} / 3413 \mathrm{Btu})=351 \mathrm{kWh} \text {. }
$$

The total savings from the low-flow shower heads in the 4003 residences is then estimated to be $1,405,053 \mathrm{kWh}$. (Here we have ignored losses from the tank and piping system; although small, these losses could easily be included in the analysis, should one of the parties to the ESPC insist on it.)

\subsubsection{Advantages and Disadvantages of Option $A$}

The primary advantage of an Option-A M\&V plan based on engineering calculations is its low cost. As long as the customer and the ESCO agree on how to make the estimate, the only costs involved in determining savings are the up-front engineering and negotiation costs. (It may also be desirable to collect some spot field data to improve the accuracy of the estimate; for example, in the case of the lowflow shower heads, it is important to know the average hot water supply temperature and makeup water temperature.)

A disadvantage of Option $A$ is that there is no provision to verify energy savings. In the case of lowflow shower heads, a reduced occupancy rate may result in fewer showers being taken and correspondingly lower savings. The M\&V plan could call for measuring occupancy rate in some way, such as measuring population per square foot of family housing, and including its effect in the calculation of "apparent" savings. But ESPCs generally assign responsibility for occupancy rate to the customer, so the question becomes: Why complicate the savings calculation only to adjust the baseline to arrive at the original savings answer again? "Take-back effects" can also affect savings. For example, residents may respond to restricted hot water flow by taking longer showers. The impact of "take-back" can be anticipated and perhaps corrected for by assuming that showers will be $10 \%$ longer with low-flow shower heads.

\subsubsection{Summary of Option-A M\&V for Low-Flow Shower Heads}

To summarize, a reasonable Option-A M\&V plan for low-flow shower heads might be described as follows. The pre-ECM tasks of quantifying baseline energy use and verifying baseline conditions are satisfied by agreeing on engineering calculations to determine energy savings, accepting a handbook value for daily hot water use, and performing spot measurements to verify average hot water supply temperature and makeup water temperature. The installation and operation of the low-flow shower heads is verified during inspections to accept construction by verifying that in each apartment the devices are installed and operate satisfactorily when the faucet is turned on. We can reasonably assume that hot water supply and makeup water temperatures are the same before and after installation. The customer 
and ESCO may agree that shower time will be $10 \%$ higher in the post-retrofit period. The resulting annual energy savings estimate, translated into dollars, becomes the guaranteed energy cost savings.

The parties to the contract agree on annual payments to the ESCO that must be less than the annual guaranteed energy cost savings. In the first year, monthly payments to the ESCO are the annual ESCO payment divided by 12 . The ongoing potential of the low-flow shower heads to save energy can be verified by annually performing inspections in a random sample of apartments. By definition, the ESCO has met its guaranteed savings level unless the inspections reveal conversions back to conventional shower heads. If the contract assigns responsibility for continuing operation of low-flow shower heads to the ESCO, the ESCO would need to propose an acceptable plan of action to restore them on an ongoing basis or would be subject to a debit to the next year's payments for not meeting the guarantee.

\subsection{OPTION B}

In an Option-B M\&V plan, the goal is to take ongoing measurements at the ECM level in a way that isolates the ESCO responsibilities (e.g., ECM performance) from the customer responsibilities (e.g., operation). In a project like Fort Polk, with 1290 buildings and 4003 apartments, this necessarily involves pre- and post-retrofit measurements on a statistically valid sample. The total savings are determined by multiplying the estimated savings per ECM (obtained by analyzing the data from the sample) by the total number of such ECM devices installed.

\subsubsection{Option B for Lighting Retrofits}

An example of an ECM that could be suitable for Option-B M\&V would be the lighting retrofits installed at Fort Polk. Table 4.3 in Sect. 4 lists the 14 types of fixtures that were retrofitted in the apartments on Feeder 1, as well as the pre- and post-retrofit power draw from each fixture based on nameplate information. As shown in Sect. 4, based on our analysis of site-level data, this particular measure saves about $1265 \mathrm{kWh}$ per residence per year on Feeder 1 . This is about $8.4 \%$ of the pre-retrofit annual electrical energy use in a typical apartment on Feeder 1 . An $8.4 \%$ savings would be difficult to measure using an Option- $C$ plan either at the level of the electrical feeders or from watt-hour meter readings of individual apartments because several other ECMs were also installed. An Option-B alternative would be to support savings determination with ongoing measurements of electrical energy use at the major end-use level in a sample of apartments.

To simplify the discussion, we describe here only sampled apartments that were all-electric before and after the retrofits. We collected 15-minute-interval data on electricity use of the total apartment, HVAC systems, and water heaters. The lighting/appliance consumption is defined as the total apartment consumption less energy use for HVAC and water heating. A problem with this practical ongoing Option-B measurement is that it is not able to isolate lighting from appliance loads. The electrical circuits in the apartments mix lighting with electrical outlets. Working around this problem requires a detailed lighting survey.

\subsubsection{Isolating the Lighting Load}

During the pre-ECM project development phase, a detailed lighting survey can be used to quantify the baseline lighting energy use in the sample of apartments that are being monitored to measure energy consumption by end use. Stick-on devices can be used to measure the runtime of each lighting fixture over a two-week period. Hand-held clamp-on devices can be used to measure the watt draw of each lighting fixture when on, so that the mix of bulb sizes and number of burned-out bulbs are captured in measurement. This information allows the calculation of pre-ECM average daily lighting $\mathrm{kWh}$ over the two-week period in each sampled apartment. 
Lighting will change over the year with day length. A reasonable adjustment can be applied to obtain a better annual estimate: Divide the daily watt draw of all fixtures in an apartment into daily lighting $\mathrm{kWh}$ to obtain daily average runtime of all fixtures during the two-week period. Look up the annual average hours between sunrise and sunset, and the hours between sunrise and sunset at the midpoint of the two-week survey period. Use the ratio of these two values to scale the two-week apartment-level values of daily average runtime of all fixtures to annual daily averages. The baseline annual lighting $\mathrm{kWh}$ for all housing is then built up from the sample of apartments, recognizing that lighting $\mathrm{kWh}$ depends on apartment size. The apartment-level annual lighting $\mathrm{kWh}$ values are scatterplotted against apartment size in square feet, and a best-fit linear regression equation is determined. The regression equation is used to calculate the annual lighting $\mathrm{kWh}$ of each apartment size in family housing, and these values are multiplied by the number of apartments (per size) and summed to obtain the baseline annual lighting $\mathrm{kWh}$ for all housing.

\subsubsection{Engineering Calculations of Energy Savings}

An engineering estimate of energy saved by the lighting retrofits must also be made during project development. In this case the estimate could be based on the following. For the sample of apartments with detailed lighting surveys and ongoing lighting/appliance monitoring, determine the nameplate values of watt draw for the CFLs to be installed and sum for each apartment. It is reasonable to assume that the apartment-level annual daily average runtime of all fixtures derived above for the pre-retrofit period would also apply after the CFLs are installed. Multiply watts by hours to obtain lighting $\mathrm{kWh}$ by apartment. The post-retrofit annual lighting $\mathrm{kWh}$ for all housing is then built up from the sample of apartments as it was for pre-retrofit energy use for lighting. Estimated annual energy savings from lighting retrofits across all housing equals pre-retrofit annual lighting $\mathrm{kWh}$ minus post-retrofit annual lighting $\mathrm{kWh}$. The resulting annual energy savings estimate is translated into dollars. The customer and the ESCO may agree that a guaranteed energy cost savings level $5 \%$ lower than the estimate is reasonable. The agreed-upon annual ESCO payment must be less than the guaranteed annual energy cost savings. First-year monthly payments to the ESCO are $1 / 12^{\text {th }}$ of the annual ESCO payment.

\subsubsection{Adjusting the Baseline}

Theoretically, an ongoing Option-B measurement at the ECM level can be done in a way that captures only the responsibilities assigned to the ESCO under the contract. If this were done, the ongoing measurement would be extremely useful at annual audit time to enforce the guarantee without having to adjust the baseline. However, the feasible ongoing measurement in this case cannot isolate lighting from appliance loads. If the observed annual lighting/appliance $\mathrm{kWh}$ rises over time, the cause could be a customer responsibility under the contract, such as growing appliance loads or a higher number of lighting operating hours. The lighting survey approach described above amounts to an Option-A M\&V plan for lighting. The extra expense of the ongoing Option-B monitoring provides no additional value toward verifying that the lighting retrofit is delivering its guaranteed savings. The ongoing monitoring could be justified if it were needed for Option-B M\&V plans for the HVAC and water heating retrofits. This is a possibility for projects of this type, though not the one selected by Fort Polk and the ESCO. The ongoing monitoring could also be justified if it were the least expensive way to calculate baseline adjustments for "plug-load creep," the phenomenon of rising energy use with purchases of new appliances. Since the lighting survey provides a robust estimate of lighting $\mathrm{kWh}$ in both pre- and post-retrofit periods, the ongoing measurement of lighting/appliance $\mathrm{kWh}$ in the sample of apartments provides an estimate of appliance loads over time. Baseline adjustments for appliance plugload creep are discussed in more detail in Sect. 7.4, under Option C. 


\subsubsection{Summary of Option-B M\&V for Lighting Retrofits}

In summarizing Option-B M\&V of energy savings from lighting retrofits, let us assume that ongoing monitoring is justified because the data is needed to support other areas of the overall M\&V plan. Under these circumstances, a reasonable Option-B $M \& V$ plan for lighting might be described as follows. The pre-retrofit tasks of quantifying baseline energy use and verifying baseline conditions are satisfied by performing a detailed lighting survey on a random sample of apartments. The survey would include onetime measurements of pre-retrofit fixture watt draw and two weeks of runtime measurement. The parties then agree on engineering calculations to estimate pre- and post-retrofit lighting $\mathrm{kWh}$ for all housing, lighting $\mathrm{kWh}$ savings, and lighting energy cost savings. As part of this process, the parties agree to use catalog values for CFL watt draw and to assume that runtime remains the same pre- and post-retrofit. The parties also agree that the guaranteed energy cost savings will be $5 \%$ less than the estimated energy savings, and that the annual ESCO payment must be less than the guaranteed annual energy cost savings.

The installation and operation of the CFLs is verified during inspections to accept construction by turning each light switch on and verifying that CFLs are installed and delivering the required lighting levels. First-year monthly payments to the ESCO are $1 / 12^{\text {th }}$ of the annual ESCO payment. The ongoing potential of the CFLs to save energy can be verified annually by performing inspections on a random sample of apartments. By definition, the ESCO has delivered the guaranteed savings unless the inspections reveal conversions back to incandescent bulbs. If so, and the contract assigns responsibility for continued operation of CFLs to the ESCO, the ESCO would need to propose an acceptable plan of action to restore them on an ongoing basis or would be subject to a debit to the next year's payments for failing to meet the guarantee.

The ongoing lighting/appliance measurement can be manipulated in several ways: Assuming lighting hours remain the same, the change in appliance loads from the previous year would be determined. Assuming appliance loads remain the same, the change in lighting hours would be estimated. These values would be available for comparison with estimates generated elsewhere in the overall M\&V plan.

\subsection{OPTION C}

Whereas Option-A and Option-B M\&V approaches attempt to verify that guaranteed cost savings are achieved by each ECM, Option $C$ uses ongoing field measurements at the site, building, or apartment level to verify that the entire package of ECMs is delivering the guaranteed cost savings. The Fort Polk project did use Option $C$, but the $M \& V$ objective under the shared-savings-type contract was to determine the monthly payment. The following discussion on Option $\mathrm{C}$ is relevant to future federal ESPC projects where the objective is to verify that the guaranteed energy cost savings are delivered each year. To simplify the discussion, we use only all-electric housing in our examples.

Before committing to an Option-C M\&V plan, the customer and ESCO must be confident that the package of ECMs will result in energy savings large enough to be discernible in site-, building-, or apartment-level data. This very comprehensive project meets that criterion because its ECMs address about $65 \%$ of the load, including cooling, heating, water heating, lighting, and the attic portion of the envelope. About half of the energy in the treated end uses was actually saved by the project across all housing (as shown in Sect. 3), but a project developer will have only energy savings estimates on which to judge. Often estimates are developed individually for each ECM with no or only vague consideration of ECM interactions. The preceding discussions of Option- $A$ and Option- $B$ plans provide examples of how this might be done for low-flow shower heads and lighting.

Calibrated engineering models can be used to develop energy savings estimates. This approach, which allows ECM interactions to be considered with greater precision, is described in Sect. 4 and is integral to Option-D M\&V plans discussed below. Whatever method is used to estimate energy savings, 
the customer and ESCO must apply their experience and judgment when agreeing on guaranteed savings levels. In cases where crude estimates are made per ECM without consideration of interactions, with little historical data, and with only limited short-term and spot measurements to support them, guaranteed levels $30 \%$ below estimates may be advisable. When well-calibrated engineering models are used, a $5 \%$ discount or less may be possible. The guaranteed energy savings level is then translated into guaranteed energy cost savings over a 12-month period, and the customer and ESCO agree on an annual ESCO payment that is less than the guarantee. In the first year the monthly payment to the ESCO equals $1 / 12^{\text {th }}$ of the agreed-upon annual ESCO payment.

\subsubsection{Determining Baseline Consumption}

The objective of the Option-C M\&V plan is to provide information for the year-end audit to verify whether the guaranteed energy cost savings were delivered during the year. At Fort Polk, the Army had manually recorded monthly meter readings of the cumulative $\mathrm{kWh}$ flowing into family housing through 16 electric distribution feeders over a 4.5-year period, and planned to continue these manual readings during and after retrofit construction. The pre-retrofit data was available for development of baseline equations, which project the baseline into the post-retrofit period. Energy savings are then determined as the projected baseline minus the actual post-retrofit monthly reading.

Manually recorded historical data often require manipulation by an experienced professional to be properly applied in the development of baseline equations. Manual historical data collection is often more "casual" than automated data collection, because personnel assigned to the task typically have many responsibilities of higher priority than "reading meters." ESCOs typically initiate their own manual recordings as soon as they become involved in a project because data recorded on the same day and time each month is less costly to rehabilitate and use. For example, data from all 16 feeders at Fort Polk were not necessarily recorded on the same day, and the days of data collection varied from month to month. During some months certain meters were not read and zeroes were entered for their electrical use until a recording of cumulative consumption was made in a subsequent month. In other cases, the figure from the previous month was entered to plug the hole in the data until actual recordings resumed. Irregularities such as these must be sorted out before the data are used to develop baseline equations.

We recommend that project developers using feeder-level data to develop baselines should consider developing separate baseline equations for each feeder for several reasons: First, the connected loads on some feeders may be predominantly facilities treated by the project (e.g., all housing except for streetlights), but other feeders may serve other significant loads as well (e.g., sewer lift stations, supply water pumping stations, offices, fast food restaurants). Accurate determination of savings on "clean" feeders will help reconstruct or estimate savings on feeders where other loads mask true savings. Second, it is important that baseline equations be as simple as possible yet remove as much of the variation between predicted and actual energy use as possible. For example, the equation used at Fort Polk was a simple regression between monthly $\mathrm{kWh}$ and total degree days (sum of monthly heating and cooling degree days, base $65^{\circ} \mathrm{F}$ ). A simple weather index such as total degree days can eliminate more of the variation due to weather when it is applied monthly to feeders serving populations of housing that have only one type of space conditioning system (e.g., air-source heat pumps) rather than a mixture of types. Other causes of variation include changes in occupant behavior, occupancy rate, number of holiday and weekend days, and changes in streetlight operating hours from month to month. These other variations will still be there, but at least the variation due to weather will be minimized if each feeder is considered separately.

We have one caveat to the recommendation to develop baseline equations for each feeder. In the case of feeders serving only a few apartments (say 10 or fewer), variation is driven by occupant behavior and can be decreased with greater aggregation, so we recommend combining the data from small feeders with others that serve apartments equipped with the same type of space-conditioning equipment. 


\subsubsection{Comparison of Baseline Equations}

To support our recommendation to use simple baseline equations, we compared the RMSE (root mean square error) of three regression equations: the contract equation, a true least-squares quadratic equation, and a true least-squares linear equation. RMSE is a statistical measure of variation-the lower the value the better. The comparison is done across all housing at Fort Polk. The contract baseline equation was developed by the ESCO during project development. Although the Army supplied historical data on total electrical consumption from these feeders for a period of 55 months, from August 1988 through February 1993 (see Fig. 7.2), the ESCO used a subset of this data to develop the baseline formula, which is specified as

$$
\mathrm{kWh} / \text { month }=\left(-6.40743 \times \mathrm{X}^{2}+13095.7 \times \mathrm{X}+2,899,270\right) \times(\mathrm{n} / 30)
$$

where $\mathrm{X}$ is the total number of heating degree days and cooling degree days (both base $65^{\circ} \mathrm{F}$ ) occurring during the month at the base airstrip, and $\mathrm{n}$ is the number of days in the month. The minimum and maximum values of $X$ over the historical data period were 120 and 690, respectively. The RMSE of Eq. (7.1) is $1,236,125 \mathrm{kWh}$, or about $18.5 \%$ of the average monthly consumption.

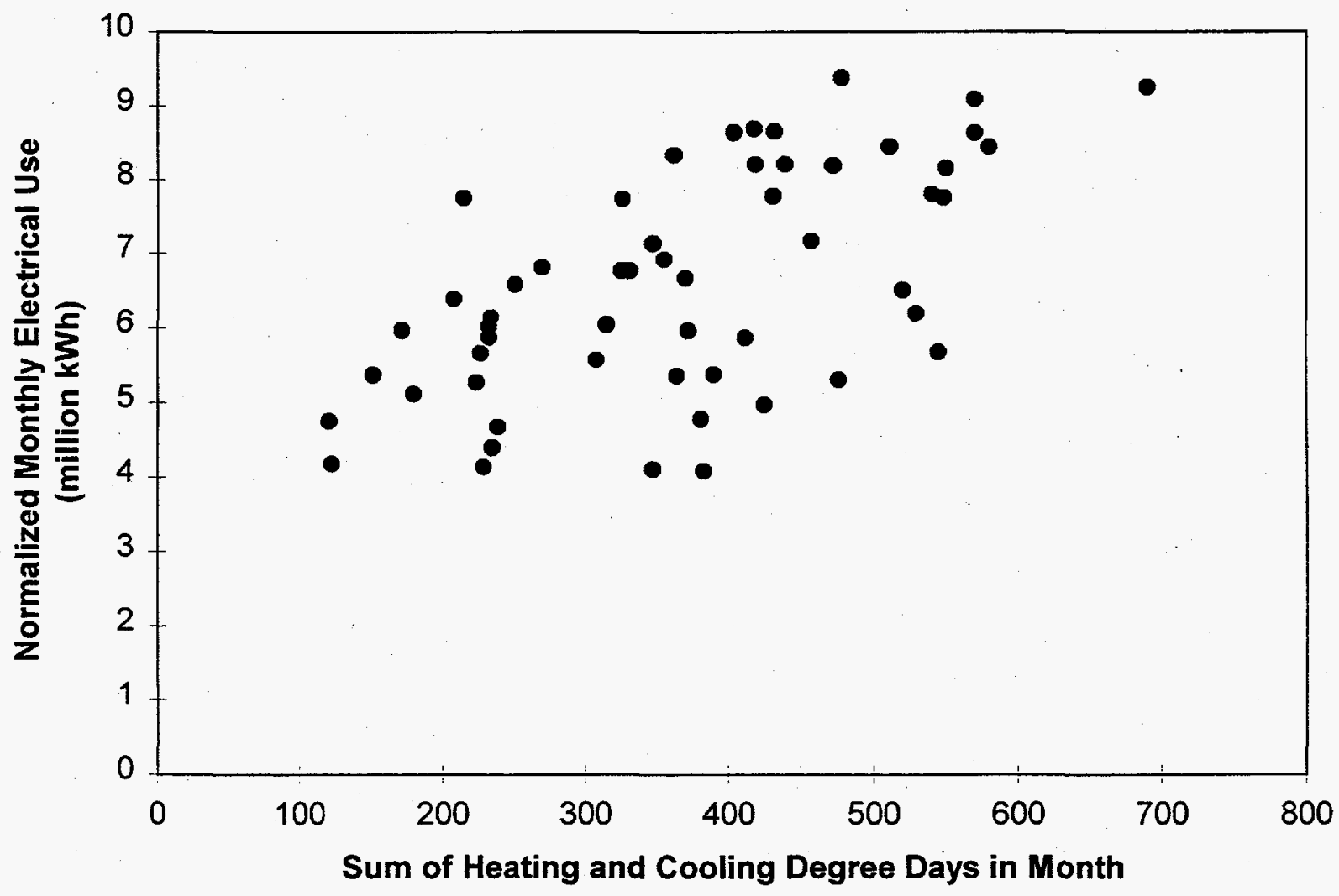

Fig. 7.2. Historical electricity consumption in Fort Polk family housing (normalized to a 30-day month).

Note that Eq. (7.1) is not a true least-squares fit to the entire 55-month data set represented in Fig. 7.2. An actual least-squares quadratic regression of all historical data gives: 


$$
\mathrm{kWh} / \text { month }=(2.7541 \times \mathrm{X} 2+4970.6 \times \mathrm{X}+4,398,939) \times(\mathrm{n} / 30) .
$$

The RMSE of this equation is $1,202,902 \mathrm{kWh}$, which is $17.9 \%$ of the average monthly electrical consumption.

When plotted these quadratic expressions appear almost linear; therefore, a linear regression equation was also developed. A least-squares linear regression of all historical data gives

$$
\mathrm{kWh} / \text { month }=(6900.5 \times \mathrm{X}+4,073,720) \times(\mathrm{n} / 30) .
$$

The RMSE of the linear regression is 1,$203 ; 813 \mathrm{kWh}$, which is $17.9 \%$ of the average monthly consumption. In this case there appears to be no advantage to using a subset of the historical data or using quadratic as opposed to linear regression. If this project were done again, we would recommend developing separate baseline equations for each feeder and using linear regression equations when the RMSE is comparable to the quadratic RMSE.

For projects that lack sufficient historical data for development of baseline equations, we recommend collecting the necessary data during the project development phase. For example, we presented in Sect. 4 the details of baseline equations that predict daily energy use for the housing on each feeder based on average daily temperature. When used to predict total housing electricity consumption for the 55-month baseline period, our model shows an RMSE of $1,072,624$, or $16.1 \%$ of the average monthly consumption. This indicates that in the case of Fort Polk family housing, and most likely for most other facilities, accurate baseline models can be derived from daily data collected over a period of 6 to 12 months. The daily interval enables the collection of sufficient data for development of statistically valid regression equations, even though the calendar period is relatively short. The 6 to 12 months are needed to assure that heating-dominated, cooling-dominated, and intermediate days are represented. Such a baseline equation appears to be as accurate as the baseline equations developed with 4.5 years of historical monthly data.

Table 7.1 shows the actual $\mathrm{kWh}$ usage in family housing (from manually collected meter readings), comparing it with the weather-corrected baseline usage predicted by our model (the "ORNL baseline"developed from 12 months of 15 -minute-interval data) and with the contract baseline. The table also compares the payments the ESCO would receive for $77 \%$ of the $\mathrm{kWh}$ savings based on the two baselines, assuming an electrical energy price of $\$ 0.06$ per $\mathrm{kWh}$. The agreement between the two over the sixmonth period (a difference of less than 1\%) indicates that a baseline developed from 12 months of 15 minute-interval data may be just as accurate as one developed from about 4:5 years of historical data.

All of the baseline equations are able to predict annual consumption for the 1989-1992 period within about 7\%; this is shown in Fig. 7.3. The point here is that the statistical accuracy of a baseline equation is often less important than the fact that both parties to the contract-the customer and the ESCO-agree to use it.

Table 7.1 Comparison of payments to the ESCO: ORNL baseline vs contract baseline

\begin{tabular}{ccrccccc}
\hline & & & & \multicolumn{2}{c}{ ORNL baseline } & \multicolumn{2}{c}{ Contract baseline } \\
\cline { 6 - 8 } Month & Days/month & Metered kWh & TDD & kWh & Payment & kWh & Payment \\
\hline $7 / 96$ & 31 & $5,954,810$ & 607 & $8,041,738$ & $\$ 96,416$ & $8,770,467$ & $\$ 130,083$ \\
$8 / 96$ & 31 & $5,531,792$ & 508 & $7,455,011$ & $\$ 88,853$ & $8,161,637$ & $\$ 121,499$ \\
$9 / 96$ & 30 & $4,245,368$ & 351 & $7,210,381$ & $\$ 136,984$ & $6,706,459$ & $\$ 113,702$ \\
$10 / 96$ & 31 & $4,290,899$ & 194 & $6,115,453$ & $\$ 84,294$ & $5,371,975$ & $\$ 49,946$ \\
$11 / 96$ & 30 & $3,478,709$ & 237 & $5,978,498$ & $\$ 115,490$ & $5,643,052$ & $\$ 99,993$ \\
$12 / 96$ & 31 & $4,733,698$ & 379 & $7,143,831$ & $\$ 111,348$ & $7,173,576$ & $\$ 112,722$ \\
Total & & $28,235,276$ & & & $\$ 633,385$ & & $\$ 627,945$ \\
\hline
\end{tabular}




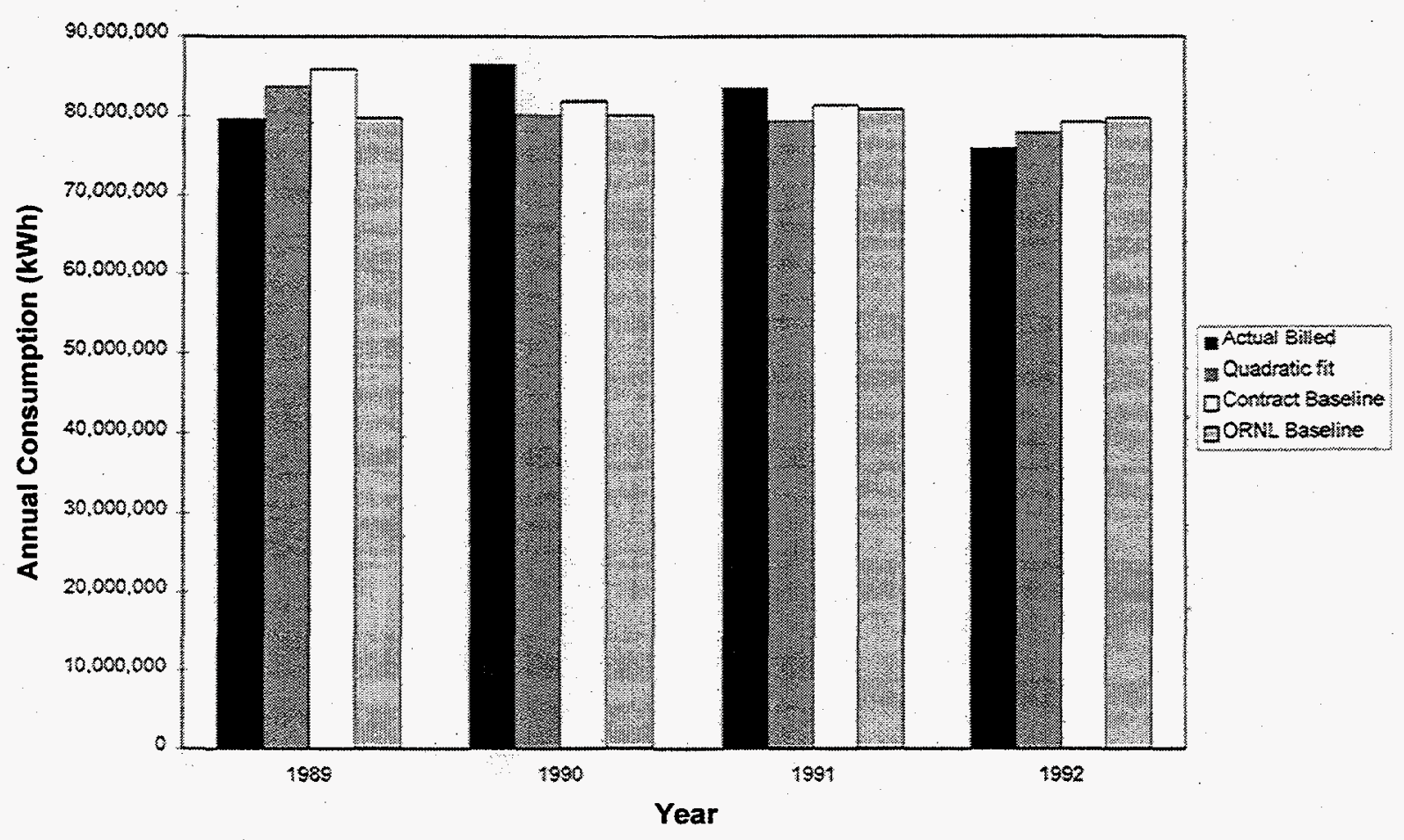

Fig. 7.3. Annual electricity consumption in family housing as billed by the utility provider and as predicted by three methods.

\subsubsection{Sources of Variability}

All four of the above baseline equations automatically adjust the baseline for weather but do not attempt to remove variation from other sources. Aside from weather; occupant behavior is the next largest source of variation. The very large variation seen in apartment- and building-level data is due to occupant behavior, but over larger populations such as all the apartments on a feeder, the average behavior of occupants becomes apparent in the form of less variation. Based on our experience, baseline equations do not need to address occupant behavior explicitly as long as the data are sufficiently aggregated (about 10 or more apartments).

Occupancy rate, which differs from occupant behavior, is also worth mentioning. Military family housing occupancy rates are generally steady because such accommodations are less expensive to service personnel than off-base housing. However, the occupancy rate is generally below full capacity because apartments are held open for transfers and because occupants leave periodically for vacations. Large upward changes in occupancy rate are physically impossible. In times of crisis calling for large troop movements, large numbers of service personnel may be shipped out, leaving only dependents behind. If the baseline equation does not consider occupancy rate, the "apparent" savings during these times will be larger than normal, but the Army would still be making the same fixed monthly payments under the ESPC, not larger ones. M\&V only serves to verify the guarantee at the end of the year, which would easily be met under these circumstances. In fact, as discussed in Sect. 2.4, there is some evidence that low occupancy during 1997 caused an "apparent" energy savings of 2.62 million kWh.

It would be possible to introduce another variable into the baseline regression equation: $Y$, defined as the monthly average population per square foot. If this were done the "apparent" savings would fall 
with occupancy rate and a year-end true-up payment by the ESCO would be required if the contract assigned responsibility for occupancy rate to the ESCO. However, our expectation is that the Army would be assigned responsibility for occupancy rate under the contract. Therefore, moving large numbers of troops out for extended periods would trigger a baseline adjustment, with the net effect of adjusting "apparent" savings upward to a "contracted" value that, all else being equal, would exceed the guaranteed energy cost savings level. We see no reason to complicate the baseline equation only to create the need for additional baseline adjustments so that the same answer-that guaranteed savings were delivered - is obtained at these times.

Although properly developed baseline equations can prevent unnecessary baseline adjustments, our experience indicates that customers and ESCOs should expect that baseline adjustments will be needed whenever Option-C M\&V is used in a long-term ESPC. For example, a particular concern in housing is that the use of electrical energy tends to rise over time because of purchases of new appliances (i.e., by plug-load creep). According to DOE (EIA 1995), electrical energy use in U.S. residences, exclusive of space conditioning and water heating, rose by $22 \%$ between 1980 and 1993 , or by $1.54 \%$ annually as a national average.

To see how this could affect the Fort Polk project, consider that the contracted baseline, based on 1989-1992 data, predicts a pre-retrofit energy use of 79.4 million $\mathrm{kWh}$ per year; our analysis of the postretrofit data predicts an annual consumption of $53.6 \mathrm{million} \mathrm{kWh}$, for an annual "apparent" savings of 25.8 million $\mathrm{kWh}$ in a TMY. Inspection of Fig. 7.2 indicates that baseline water heating/lighting/ appliance use is about 4.1 million $\mathrm{kWh}$ per month or 49.2 million $\mathrm{kWh}$ per year. According to DOE (EIA 1995), 46\% of this, on a national average, is for water heating and lighting, the remainder of 26.6 million $\mathrm{kWh}$ per year being used for appliances.

If appliance use in Fort Polk family housing follows the national trend and rises $1.54 \%$ annually, it is conceivable that by year 20 of the contract, the residences at Fort Polk could be using 63.1 million kWh per year, even when the energy used for lighting, space conditioning, and water heating is held constant. If the baseline consumption is still 79.4 million $\mathrm{kWh}$ per year, the "apparent" savings in the last year of the contract would drop to just 16.3 million $\mathrm{kWh}$ per year, $37 \%$ less than the first-year value. Although this is only a rough estimate, it illustrates the point. Since it is our expectation that the customer will generally be assigned responsibility for plug-load creep under ESPC contracts, periodic baseline adjustments will likely be necessary.

\subsubsection{Baseline Adjustments for "Plug-Load Creep"}

It is important for the customer and ESCO to agree on an approach to periodic baseline adjustments that is practical yet makes the best use of available information. Two parameters must be agreed upon or estimated to support consideration of baseline adjustments for plug-load creep at the annual true-up: the annual baseline appliance load and the annual percentage of growth. As indicated above, a ballpark estimate of baseline water heating/lighting/appliance use can be obtained from Fig. 7.2. A value of 4.1 million $\mathrm{kWh}$ per month is obtained by drawing a horizontal line to determine the $\mathrm{Y}$-intercept of the lowest data points. To understand how months with total degree days ranging from 100 to 400 could have the same $\mathrm{kWh}$ use, consider that a month with outdoor temperature equal to $75^{\circ} \mathrm{F}$ every hour of every day would accrue 10 heating degree days (base $65^{\circ} \mathrm{F}$ ) per day or 300 in a 30-day month, and no electricity use for heating and cooling would be expected. In Louisiana the weather is not that steady and some of the $\mathrm{kWh}$ use in these months may be for heating and cooling. On the other hand, some of these months may have had unusually low occupancy rates.

There are several ways to estimate the baseline water heating/lighting/appliance use. Setting $X$ equal to zero in Eq. (7.2) gives 4,398,939 kWh per month. Setting X equal to zero in Eq. (7.3) gives 4,073,720 $\mathrm{kWh}$ per month. Averaging the data used to plot Fig. 7.2 for the six months of lowest energy use results in $4,317,797 \mathrm{kWh}$ per month (rather than the $4,100,000$ value that can be seen in Fig. 7.2). These values 
include all non-HVAC loads on the feeders, including nonhousing loads such as streetlights. For an estimate which does not include loads outside of the apartments, we analyzed pre-retrofit Level-3 data from 13 all-electric apartments and found that, weighted by apartment size, the average non-HVAC apartment load was $0.0257 \mathrm{kWh} / \mathrm{ft}^{2}$ per day. Multiplying by the total square feet of family housing and by 30.417 days per month gives an estimate of $4,359,332 \mathrm{kWh}$ per month. Given the general agreement among these estimates, the customer and ESCO may agree on a value of 4.3 million $\mathrm{kWh}$ per month at the apartment level, or 51.6 million $\mathrm{kWh}$ per year.

Next an estimate of baseline appliance load isolated from the combined water heating/lighting/ appliance use is needed. Using national averages for energy use in all-electric households, $28 \%$ is for water heating (EIA 1995) and 25\% of the remaining use is for lighting (DOE 1994), leaving (1-0.28)(1 $-0.25)=54 \%$, or 27.9 million $\mathrm{kWh}$ per year as the baseline appliance load. In this case, the Level-3 data could be used for water heating rather than relying on national averages for water heating and lighting (see Sect. 4). This would result in an estimate of 29 million $\mathrm{kWh}$ per year as the baseline appliance load. The customer and ESCO may agree on a value of 29 million $\mathrm{kWh}$ per year.

Next the customer and ESCO must agree on the actual adjustments to the baseline. One approach would be to agree to upward adjustments equal to the actual national average of annual growth in the base year appliance load of 29 million $\mathrm{kWh}$ per year according to some periodically updated official source such as the DOE CORE Data Book (DOE 1994). Under this approach the year-end adjustments to the constant term of the baseline equation [e.g., Eq. (7.3)], assuming $1.54 \%$ load growth in the most recent year, would be 0.4466 million $\mathrm{kWh}$ in year one, 0.4535 million $\mathrm{kWh}$ in year two (if the most recent year load growth continued at $1.54 \%$ ), etc. An alternative approach would be to maintain an ongoing monitoring effort in a sample of apartments to measure lighting/appliance load as described above under Option B, assume lighting remains constant (unless surveys of random samples of apartments indicate that CFLs are being replaced by incandescents), and calculate the annual percentage growth in appliance loads from the data. Other reasonable approaches could also be developed and agreed upon.

\subsubsection{Summary of an Option-C Plan for an ECM Package}

To summarize, a reasonable Option-C M\&V plan for the comprehensive package of ECMs might be described as follows. The pre-ECM task of quantifying baseline energy use is satisfied by gathering the historical monthly feeder-level $\mathrm{kWh}$ readings, inspecting and cleaning up the data, and developing baseline regression equations. The pre-ECM task of verifying baseline conditions is satisfied by a variety of actions necessary to support engineering estimates of energy savings for the package of ECMs. For low-flow shower heads this may include developing engineering calculations to determine energy savings, accepting a handbook value for daily hot water use, and performing spot measurements to verify average hot water supply temperature and makeup water temperature. For lighting this may involve developing engineering calculations to determine energy savings and performing a detailed lighting survey on a random sample of apartments that would include one-time measurements of pre-retrofit fixture watt draw and two weeks of runtime measurements. For attic insulation this may involve developing engineering calculations to determine energy savings, inspecting a random sample of upper apartments representing all construction vintages to establish existing conditions, deciding on typical improvements per vintage, and using construction drawings to estimate the total area. For desuperheaters this may involve developing engineering calculations to determine energy savings, spot measurements to verify average hot water supply temperature and makeup water temperature, collecting two weeks of 15-minute-interval data on hot water tank element $\mathrm{kWh}$ for a random sample of apartments, and inspecting construction drawings to estimate the number of apartments where the proximity of heat pumps and hot water tanks makes desuperheater installation practical without major equipment relocation. For heat pumps this may involve developing engineering calculations to 
determine energy savings when they are converted to geothermal units, inspecting construction drawing equipment schedules to establish the sizes of existing air-source units and the number of each, using construction drawings and the plans for other ECMs as the basis for developing design heating and cooling load calculations for each apartment type in order to size the geothermal units, and installing several BHEx's and taking short-term measurements on them in order to determine the effective average soil properties of the subsurface formation.

The installation and operation of all ECMs is verified during inspections to accept construction by verifying that each apartment has had the ECMs installed and that (attic insulation excluded) the ECMs operate satisfactorily. The resulting annual energy savings estimate for the package of ECMs is translated into dollars, and judgment is used to establish the guaranteed savings level relative to that. An annual payment is established that must be less than the annual guaranteed cost savings. The first-year monthly payments to the ESCO are $1 / 12^{\text {th }}$ of the annual payment.

With Option-C M\&V the first annual true-up for an ESPC may go something like this: The longterm average (or TMY) base $65^{\circ} \mathrm{F}$ monthly heating and cooling degree days for the site are assembled and summed to obtain the long-term average (or TMY) total degree days for each month. These values are fed into baseline equations for the 16 feeders to determine TMY kWh by feeder by month. In this case summing across all values shows consumption of 79.4 million $\mathrm{kWh}$ in a TMY across all family housing. For this example, let us assume that the estimated energy savings for all ECMs was 32 million $\mathrm{kWh}$ in a TMY, or $\$ 1.92$ million at $\$ 0.06$ per $\mathrm{kWh}$. Let us also assume that the ESCO guaranteed energy cost savings of $\$ 1.92$ million in a TMY and agreed to an annual payment equal to $78 \%$ of that, or $\$ 1,497,600$. During the first year the customer paid $1 / 12^{\text {th }}$ of this amount, or $\$ 124,800$, to the ESCO each month.

Next the year-specific base $65^{\circ} \mathrm{F}$ monthly heating and cooling degree days that occurred at the site are assembled and summed to obtain the year-specific total degree days for each month. These values are fed into the 16 feeder baseline equations to determine the year-specific $\mathrm{kWh}$ by feeder by month, and summed to determine the year-specific baseline consumption. If the weather was more severe than typical, the year-specific baseline will be higher than $79.4 \mathrm{million} \mathrm{kWh} / \mathrm{year}$, and if weather was milder it will be lower. The year-specific manual monthly $\mathrm{kWh}$ readings from each of the 16 feeder meters are assembled and summed to obtain the actual $\mathrm{kWh}$ consumption over the year. The savings actually delivered over the year equals the year-specific baseline consumption minus the actual consumption. One would expect actual savings to be higher in years with severe weather and lower in years with mild weather.

A statistically valid verification of whether the guarantee was met may not be possible at the end of the first year because this requires the development of post-retrofit regression equations to determine post-retrofit monthly consumption as a function of total degree days, and only 12 data points (i.e., pairs of monthly $\mathrm{kWh}$ and monthly total degree days) are available after one year. However, the equations can be developed, the RMSE values noted, and estimates of post-retrofit consumption in a TMY made. Apparent energy cost savings in a TMY equal 79.4 million $\mathrm{kWh}$ minus post-retrofit consumption in a TMY, multiplied by $\$ 0.06$ per $\mathrm{kWh}$. If this value exceeds $\$ 1.92$ million the guarantee has been met. If the guarantee does not appear to be met, but RMSE values indicate that the post-retrofit equations are not yet reliable, it may be desirable to delay true-up payments for another year. Data points for 24 months will likely support robust post-retrofit regression equations, and 36 data points most certainly will.

There are several ways to implement true-up payments if an ESCO fails to deliver the guaranteed savings. Within a specified period after the year-end audit, the ESCO could repay the customer in full with a single payment; alternatively, the monthly ESCO payment in the following year could be reduced by $1 / 12^{\text {th }}$ of the true-up amount. The method of guarantee enforcement is stipulated in the contract.

Even with Option-C M\&V it may be a good idea to verify the ongoing potential of all installed ECMs to continue to generate energy savings. This can be done by annually drawing a random sample of apartments and performing inspections to verify that low-flow shower heads and CFLs are in place 
and functional, the hot water tank electric resistance element control is set at the proper temperature, the desuperheater loop pump is properly cycling in response to controls and its flow and temperature rise are in expected ranges, the ground loop pump is properly cycling in response to controls and its flow and temperature rise are in expected ranges, and the heat pump filter is clean and refrigerant charge and power draw and other parameters are within expected ranges. The ESCO should be implementing a preventative maintenance program, and annual inspections can verify that their program is effective.

\subsection{OPTION D}

All ESPC projects require some type of engineering model to estimate savings. The model may be as simple as the Option A plan to predict energy savings due to installation of low-flow shower heads, or as complex as DOE-2, TRNSYS, and BLAST, which can consider interactions between ECMs and permit detailed modeling of building energy use. Option-D M\&V uses this type of detailed building model, calibrated to site-monitored data at the feeder, apartment, building, or end-use level, to determine energy savings.

Section 4 discusses the use of a calibrated model to predict energy savings. We used TRNSYS to model the pre- and post-retrofit electrical energy use for an entire electrical feeder that supplied 200 apartments. If such a model is used for Option-D M\&V, the first requirement is to collect pre-retrofit baseline data on electrical energy use for the feeder. Since energy use in housing is closely correlated to outdoor temperature, it is most useful to collect energy use and weather data during the same period. If new data are being collected during the project development phase, daily data are recommended so that the needed data can be obtained over a modest calendar period. Although data were collected at Fort Polk for about a year prior to the retrofits, we have shown elsewhere that daily energy use falls into three separate regions corresponding to heating, cooling, and mild-weather days. To characterize the behavior of the feeder we recommend collecting daily energy use and daily average temperature data for at least 10 days when the daily average temperature is below $50^{\circ} \mathrm{F}, 10$ days with daily average temperature above $75^{\circ} \mathrm{F}$, and 10 days with daily average temperature between 60 and $70^{\circ} \mathrm{F}$. At Fort Polk, the required number of days can be captured by monitoring continuously for six months beginning on January 1. The minimum monitoring period for other sites would of course depend on the local climate. At Fort Polk the required data could even be obtained with disciplined manual recordings from the existing feeder meters.

The next step is to model the buildings and streetlighting loads connected to the feeder. As-built construction plans are obtained from the site, and the construction details are entered into the model. For this project we used TRNSYS because it was convenient for implementing a BHEx model, but for other projects not involving geothermal heat pumps, software packages such as BLAST or DOE-2 would be adequate.

Our model for Feeder 1 used data on hot water draw and lighting/appliance electrical use from other monitored apartments; however, the profiles obtained from this data were similar to handbook values. Thus, in future projects it would not be necessary to perform detailed end-use monitoring unless there were reason to suspect that some aspect of energy use deviated significantly from the values we obtained or the available handbook information. Our calibrated model also relied on post-retrofit data from a pilot installation of the package of ECMs in one apartment. Specifically, this data was used to calibrate the BHEx model by inversing the effective average soil properties experienced by the BHEx. If accurate soil property data is available, it would not be necessary to collect this data.

To calibrate the model we varied outdoor air infiltration and heating/cooling setpoint temperatures until the modeled and metered feeder annual energy use in a TMY (estimated from five-parameter dualchangepoint models of the modeled and metered daily data) matched, and the changepoints of the fiveparameter models matched. In other projects where outdoor air infiltration will be affected by ECMs installed - for example, weather-stripping and caulking of windows - it would be necessary to use a 
measured value for air infiltration and to calibrate the model by varying some other parameter that affects heating and cooling loads- for example, envelope thermal characteristics.

The results of the calibration for this feeder were presented in Fig. 4.5, which compares the model's prediction with site-monitored data on a daily basis. The daily analysis is useful for calibrating the model and allows acquisition of all the necessary data in as little as six calendar months, but a monthly model is more practical for the purposes of M\&V. Figure 7.4 compares the model's monthly predictions for a TMY with two years of historical energy use data from the feeder. With the exception of two outliers (probably related to low occupancy rate), the model corresponds quite well to the historical data.

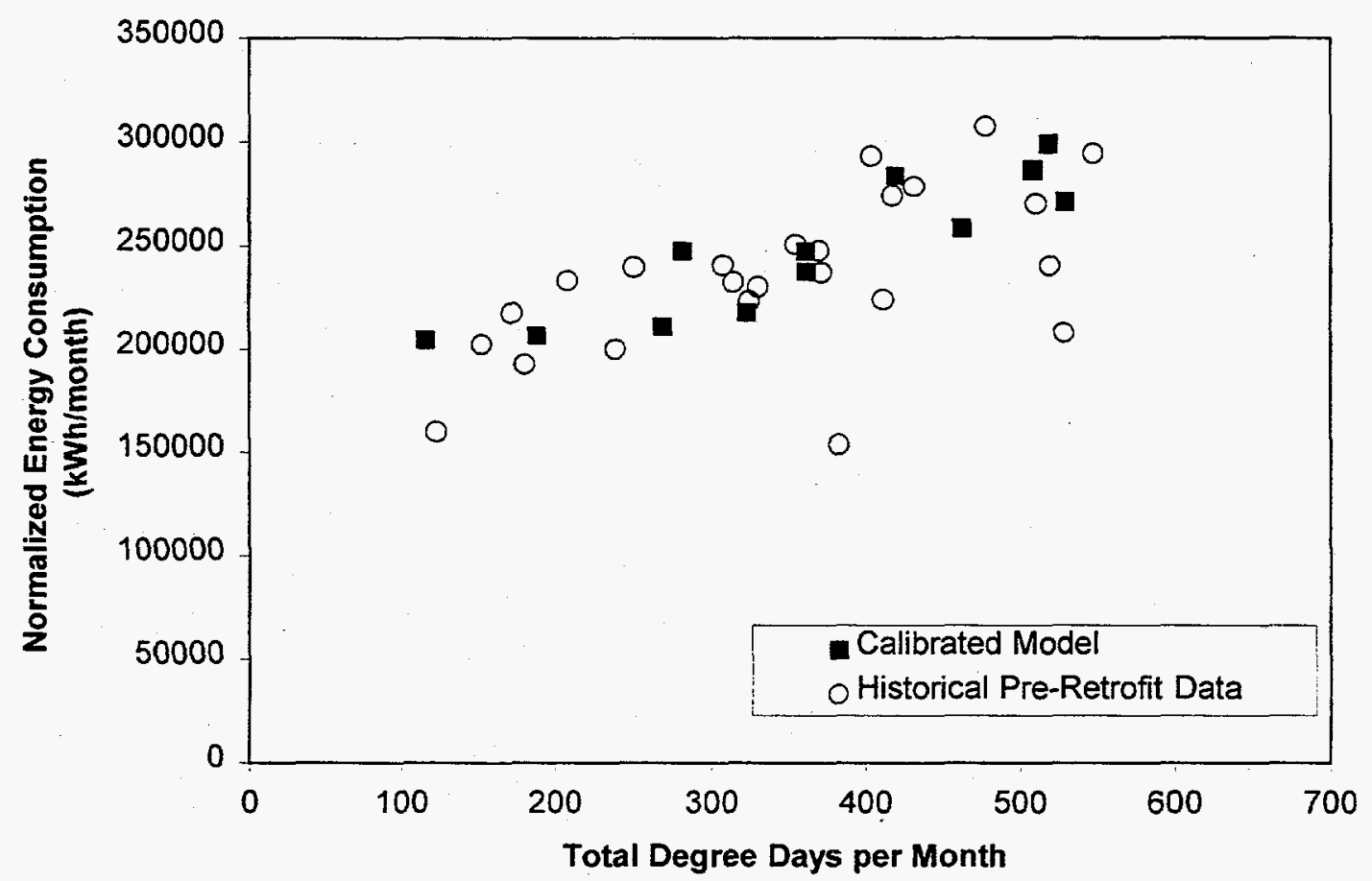

Fig. 7.4. Comparison of the calibrated model's monthly predictions of monthly energy usage for a TMY with two years of historical energy use data from the modeled feeder.

Once the pre-retrofit model is calibrated to the feeder-level data, the package of ECMs is implemented in the software, and the model is run again with all other parameters remaining the same as in the pre-retrofit case. The results were presented in Sect. 4 , and Fig. 4.8 presents a comparison of the model with actual post-retrofit data. Figure 7.5 illustrates the modeled pre-retrofit energy use, postretrofit energy use, and energy savings for a TMY. The calibrated model predicts an annual energy savings of $30.2 \%$. For comparison, the metered data normalized to a TMY indicated an annual energy savings of $30.1 \%$. Also the metered data, when normalized to a TMY, predicts an annual pre-retrofit energy use of $2,874,000 \mathrm{kWh}$, so by applying the estimated savings percentage to the observed preretrofit annual use an estimated annual savings of $868,000 \mathrm{kWh}$ is obtained. The ESCO would likely multiply this by a safety factor, say 0.95 , and guarantee $824,500 \mathrm{kWh}$ of savings for the feeder.

Translating this into dollars at 6 cents per $\mathrm{kWh}$, the guaranteed annual energy cost savings would be $\$ 49,470$. Under an ESPC, the agreed-upon annual ESCO payment would have to be less than or equal to the guaranteed savings, so let us assume it is $\$ 49,470$.

With the engineering model calibrated to pre-retrofit data, an Option-D M\&V plan would operate as follows. In each month during the first year, the facility pays the ESCO an amount corresponding to 


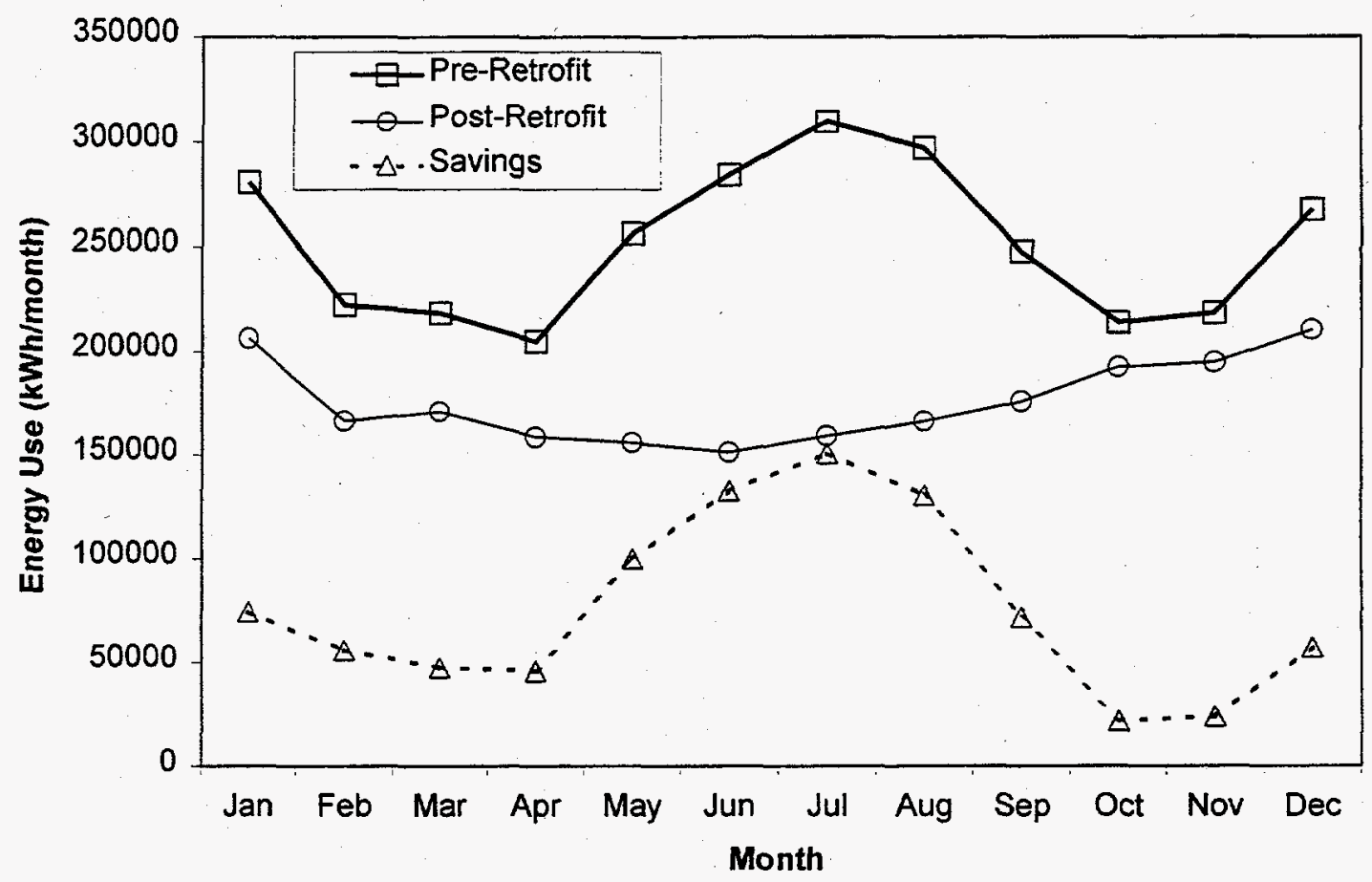

Fig. 7.5. The calibrated model's predictions of pre-retrofit energy use, post-retrofit energy use, and energy savings for a TMY.

$1 / 12^{\text {th }}$ of the annual ESCO payment, which in this case is $\$ 4,122.50$. The baseline equation is determined from a linear regression of the historical pre-retrofit monthly energy use vs total degree days. Baseline energy consumption in a TMY is determined by driving the baseline equation with TMY total degree days for each month, and summing to obtain the annual total. The post-retrofit consumption equation is determined from a linear regression of the post-retrofit monthly energy use vs total degree days. Postretrofit energy consumption in a TMY is determined by driving the post-retrofit consumption equation with TMY total degree days for each month, and summing to obtain the annual total. "Apparent" energy savings in a TMY is calculated as the difference between baseline energy consumption and post-retrofit consumption. If there are no baseline adjustments, "apparent" and "contracted" energy savings are equal; otherwise the adjustments are applied to determine "contracted" energy savings, which are converted to dollars. A verification is made that "contracted" energy cost savings exceeds guaranteed energy cost savings at the end of each year. If contracted savings are less than guaranteed savings for the year, monthly ESCO payments in the following year would be debited by $1 / 12^{\text {th }}$ of the shortfall.

Up to this point, the only difference between our examples of Option-D and Option-C M\&V plans is the greater accuracy of the savings estimate in Option D. However, a major advantage of a calibrated simulation model is its usefulness for developing baseline adjustments. In order to demonstrate the concept, we will use a slightly different data set for Feeder 1 than the one we have been using previously. The reason is that, as is apparent from Fig. 2.6, the post-retrofit daily electrical consumption for Feeder 1 falls into two separate regimes. The phenomenon is most evident in the heating data, where the regression line lies between what appear to be separate "high" and "low" electrical consumption regimes. Examination of the data shows that the transition from high to low consumption occurs on a specific date and lasts for about three months, after which time the feeder resumes "high" consumption. Given this behavior, it is likely that a portion of the load was switched to another feeder during the three-month period. Since the existence of the two regimes made detailed calibration difficult, we decided to 
eliminate the "low" consumption period for the purposes of this analysis. In the following discussion we refer to a reduced data set from which the period of abnormally low consumption is eliminated. The preand post-retrofit data are presented in Fig. 7.6. Based on the reduced data set, the post-retrofit TMY annual consumption (derived from a least-squares regression to a dual-changepoint model) is estimated at $2,125,444 \mathrm{kWh}$. The estimated pre-retrofit TMY consumption remains at 2,873,622 $\mathrm{kWh}$, which represents an annual savings of $748,179 \mathrm{kWh}$, or $26 \%$ of the pre-retrofit total.

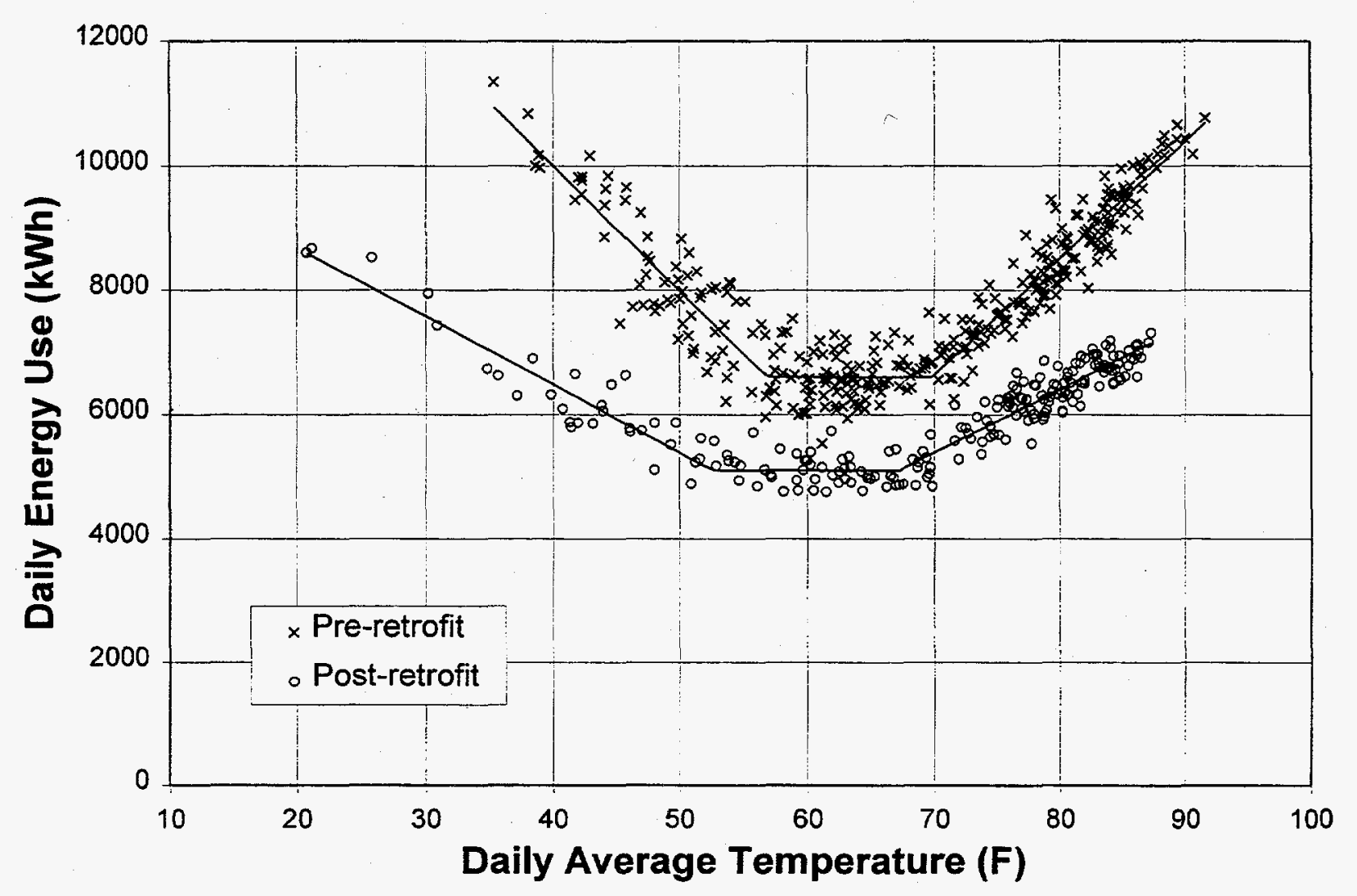

Fig. 7.6. Reduced data set for Feeder 1.

As an example of how a calibrated simulation model can be used to perform baseline adjustments, assume that the contract specifies heating and cooling setpoints of $68^{\circ} \mathrm{F}$ and $78^{\circ} \mathrm{F}$, respectively, and assigns responsibility to the customer for maintaining them. Say the customer and ESCO originally agreed to install heat pump compressor controls that are not adjustable by tenants (control input from bulb-type return air temperature sensors rather than conventional thermostats), but when these provoked complaints from tenants, conventional thermostats were installed. The energy cost savings estimate, guaranteed cost savings level, and agreed-upon annual ESCO payment were all based on $68^{\circ} \mathrm{F} / 78^{\circ} \mathrm{F}$. But now the apartments are being operated at tenant-selected setpoints that cause greater energy use, and "apparent" energy cost savings are less than the guaranteed level. This is clearly a case where a baseline adjustment is reasonable, and the calibrated simulation model provides the means to estimate a reasonable correction.

The engineering model calibrated to pre-retrofit data predicts annual TMY energy consumption of $2,832,698 \mathrm{kWh}$. The heating and cooling setpoints which best matched the data were $73^{\circ} \mathrm{F}$ and $78^{\circ} \mathrm{F}$, respectively. When the retrofits are implemented in the calibrated engineering model with heating and cooling setpoints of $68^{\circ} \mathrm{F}$ and $78^{\circ} \mathrm{F}$, the model predicts a post-retrofit annual TMY consumption of 
$1,923,181 \mathrm{kWh}$; thus, had the setpoints been adhered to, the contractor would have based his savings estimates on a figure of $909,517 \mathrm{kWh}$. But now the tenants are allowed to control their own setpoints. If short-interval data is no longer being collected, the engineering model calibrated to pre-retrofit data can still be used to estimate annual consumption in the post-retrofit period. Since tenants controlled their own thermostats before the retrofit, it is logical to assume that in the post-retrofit period they maintain the living units at the same setpoints. The calibrated model predicts that with heating and cooling setpoints of $73^{\circ} \mathrm{F}$ and $78^{\circ} \mathrm{F}$, this feeder would consume $2,007,277 \mathrm{kWh}$ in a typical year. Thus, the apparent effect of the setpoint change is to reduce the electrical savings by $84,096 \mathrm{kWh}$ annually on this feeder. When scaled up to the entire population of 4003 housing units at Fort Polk, the change in setpoints reduces annual savings by 2.03 million $\mathrm{kWh}$. This value provides a reasonable starting point for negotiating a baseline adjustment.

A take-back effect has been observed in some past projects when tenants choose greater comfort after more efficient systems are installed, and this could be the basis for an even larger baseline adjustment. In this case we also have the necessary post-retrofit data to calibrate the model and determine the best-match post-retrofit setpoints. The result of this effort is best-match setpoints of $71^{\circ} \mathrm{F} / 74^{\circ} \mathrm{F}$, indicating that there was a small take-back effect. With these setpoints, the model predicts an annual TMY energy consumption of $2,109,577 \mathrm{kWh}$ for the feeder. Had the setpoints remained the same as in the pre-retrofit, annual energy consumption would have been only $2,007,277 \mathrm{kWh}$. The difference, $103,300 \mathrm{kWh}$, when added to the $84,096 \mathrm{kWh}$ derived from the analysis above, indicates that the total effect of allowing tenants to control their own thermostats was to increase annual energy consumption by $187,396 \mathrm{kWh}$ per year. Housing-wide, this represents an annual loss of 4.53 million $\mathrm{kWh}$ in electrical savings because setpoints of $68^{\circ} \mathrm{F} / 78^{\circ} \mathrm{F}$ were not adhered to in the post-retrofit period. This exercise could be repeated on several feeders if the parties could not agree that the 200 apartments on Feeder 1 were sufficiently representative of the population. 


\section{CONCLUSIONS}

Our conclusions from our evaluation of the Fort Polk ESPC project are presented below in subsections that correspond to topics covered in Sects. 2 through 7 of this report, with the exception of our conclusions about the economic outcome of the project, which are given in Sect. 8.3, just after discussions of the energy, demand, and maintenance savings.

\subsection{ENERGY AND DEMAND SAVINGS}

Our findings indicate that the GHP-centered retrofit project will save 25.8 million $\mathrm{kWh}$ in a typical meteorological year (TMY), or $32.5 \%$ of the pre-retrofit whole-community electrical consumption, and $100 \%$ of the whole-community natural gas use for space and water heating (260,000 therms), in Fort Polk family housing. These savings result in a reduction in $\mathrm{CO}_{2}$ emissions of an estimated 22,400 tons per year. Summer peak electrical demand has been reduced by $7.55 \mathrm{MW}$, which is $43.5 \%$ of the pre-retrofit peak demand. These energy and demand savings correspond to an improvement in the whole-community electric load factor from about 0:52 to 0.62 . At the end-use level, the GHPs were found to save about $42 \%$ of the pre-retrofit electrical consumption for heating, cooling, and water heating in housing units that were all-electric in the pre-retrofit period.

These values are the energy and demand savings that are "apparent" from analyzing the monitored data. The "apparent" savings may differ from the "contracted" savings. Determining "contracted" savings may require adjustments to the baseline (see Sect. 7) for factors that are beyond the ESCO's control and responsibility under the ESPC contract. Baseline adjustments are negotiated, may be supported by engineering estimates (see Sect. 7), and in this project may result in "contracted" savings of 30 million $\mathrm{kWh}$ or more. The Army pays the ESCO $77 \%$ of the "contracted" energy cost savings under this 20 -year shared-energy-savings contract.

\subsection{MAINTENANCE SAVINGS}

Historically Fort Polk maintained the HVAC equipment in family housing using private service contractors. Averaged over the 20 years, our estimate of the baseline maintenance cost was $\$ 369.05$ per apartment per year, or 26 cents/ $\mathrm{ft}^{2}$ per year for the approximately $5,600,000 \mathrm{ft}^{2}$ of family housing. For comparison, the baseline maintenance costs appearing in the contract and agreed upon by the Army and ESCO are 24.1 cents $/ \mathrm{ft}^{2}$ per year. These baseline maintenance costs may be somewhat low, depending on the assumption for existing HVAC equipment service life. For example, if the handbook value (ASHRAE $1995 \mathrm{a}$ ) of 15 years is used rather than the value derived from the actuarial approach (Sect. 3), the 26 cents $/ \mathrm{ft}^{2}$ per year becomes 32.8 cents/ $\mathrm{ft}^{2}$ per year.

From the Army's point of view, 100\% of the baseline maintenance cost will be saved each year, since the ESCO assumes responsibility for HVAC maintenance in family housing for the 20 -year contract period. However, under the contract the Army pays the ESCO a $77 \%$ share of these savings, or about 18.1 cents/ $\mathrm{ft}^{2}$ per year. 


\subsection{ECONOMIC OUTCOME}

\subsubsection{The Fort Polk Perspective}

The Army's annual cash flow for energy and energy-related maintenance for Fort Polk family housing is presented in Fig. 8.1 for three periods-before, during, and after the 20-year contract. Before the retrofit project the Army was consuming 79.4 million $\mathrm{kWh}$ of electricity in family housing, and spending $\$ 4,764,000$ at $\$ 0.06$ per $\mathrm{kWh}$ in a TMY. The Army was also consuming 260,000 therms of natural gas for space and water heating in family housing, which cost $\$ 130,000$ at $\$ 0.50$ per therm in a TMY. In addition the Army was going to spend, on average over the next 20 years, 26 cents $/ \mathrm{ft}^{2}$ or $\$ 1,456,000$ annually for HVAC maintenance in family housing. The sum of the pre-retrofit costs is $\$ 6,350,000$ per year.

The "apparent" savings of the project are 25.8 million $\mathrm{kWh}(\$ 1,548,000)$ in electricity in a TMY, 260,000 therms $(\$ 130,000)$ in natural gas in a TMY, and 26 cents/ $\mathrm{ft}^{2}(\$ 1,456,000)$ annually for HVAC maintenance. The sum of the apparent savings is $\$ 3,134,000$ in a TMY. Figure 8.1 assumes that the payment to the ESCO is $77 \%$ of the "apparent" savings, or $\$ 2,413,180$ in a TMY. The Army must also pay for the remaining electricity consumption of 53.6 million $\mathrm{kWh}(\$ 3,216,000)$ in a TMY. The sum of the costs in a TMY during the project is $\$ 5,629,180$, or about $\$ 720,820$ less than the "before" baseline.

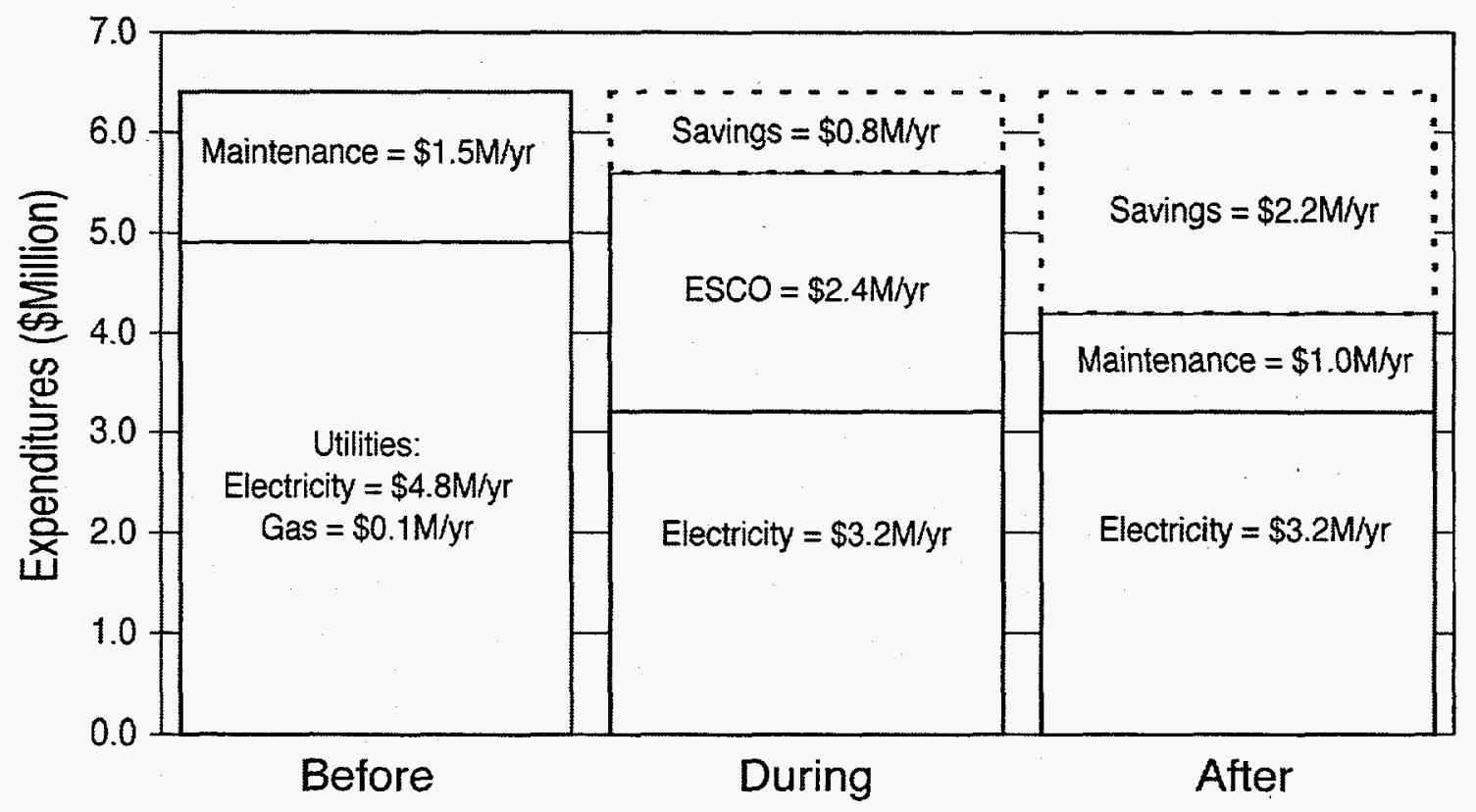

Fig. 8.1. The Army's annual cash flow for energy and energy-related maintenance for Fort Polk family housing before, during, and after the ESPC contract period.

After the 20-year contract term the ESCO payment goes away, but the Army will then need to hire a private services contractor (perhaps the ESCO) to maintain the HVAC equipment. Figure 8.1 assumes that this extended maintenance could be obtained for 18.1 cents $/ \mathrm{ft}^{2}$ per year or $\$ 1,013,600$, the 20-yearaverage price the Army is paying the ESCO during the project. Figure 8.1 also assumes that the electricity consumption and payment would remain at $\$ 3,216,000$. The sum of the costs in a TMY after the ESPC contract expires would be $\$ 4,229,600$, over $\$ 2$ million less than before the project. 
Using a standard 7\% annual discount rate over the 20-year life of the contract (BLCC 1998) the net present value of the shared energy savings contract to Fort Polk is $\$ 8.2$ million. This figure does not include the salvage value of the improvements at the end of the contract period, nor the continuing savings of over $\$ 2$ million annually for as long as the systems remain operable. The water-source heat pumps may be near the end of their service lives after 20 years (ASHRAE 1995a indicates a 19-year life for commercial water-to-air heat pumps), but the vertical borehole ground heat exchangers will likely outlive several more heat pumps. This will reduce the Army's cost to renew the space conditioning and water heating systems, should it desire to do so.

The values in Fig. 8.1 are based on "apparent" energy savings. Several adjustments to the baseline for factors that are beyond the ESCO's control and responsibility under the contract may be required. For example, Sect. 7.4.4 discusses periodic baseline adjustments for plug-load creep. About 29 million $\mathrm{kWh}$ of the 79.4 million $\mathrm{kWh}$ baseline consumption in a TMY is appliance loads, which historically have grown about $1.54 \%$ annually in residences on a national average. If the parties agree to annual baseline adjustments according to the most recent CORE Data Book trends (DOE 1994), and if appliance loads actually grow by that amount while energy use for lighting, space conditioning, and water heating is held constant in a TMY by continued performance of the ECMs installed and maintained by the ESCO, then the net effect of the annual baseline adjustments is to keep the annual ESCO payment constant even though family housing electricity use and cost in a TMY rises. The rationale is that the appliance load growth is the responsibility of Fort Polk, and would have happened with or without the project.

Another example of a potential baseline adjustment would be for deviation from contracted comfort setpoints, as described in Sect. 7.5. Before the project the residents of family housing were enjoying their desired comfort levels of about $73^{\circ} \mathrm{F}$ for heating and $78^{\circ} \mathrm{F}$ for cooling. But consider the effect if Fort Polk tries to use the opportunity of the retrofit project to impose the comfort levels prescribed by law (at the time) of $68^{\circ} \mathrm{F}$ and $78^{\circ} \mathrm{F}$ on residents, but changes course during the early stages of construction when occupants complain. The ESCO has agreed to accept $77 \%$ of the savings over a 20 -year period on the basis of savings estimates based on the $73^{\circ} \mathrm{F} / 78^{\circ} \mathrm{F}$ setpoints before the retrofits and $68^{\circ} \mathrm{F} / 78^{\circ} \mathrm{F}$ after. Had the savings estimates been based on $73^{\circ} \mathrm{F} / 78^{\circ} \mathrm{F}$ before and $71^{\circ} \mathrm{F} / 74^{\circ} \mathrm{F}$ after, the ESCO never would have agreed to $77 \%$ of the savings over 20 years. The ESCO would have required a larger share of the savings over 20 years, or a longer contract term. In this case the purpose of the baseline adjustment of 4.53 million $\mathrm{kWh}$ or $\$ 271,800$ in a TMY is to effectively raise the ESCO's share of the savings from $77 \%$ to $86 \%$ over the 20 years, to correspond to what the original agreement would have been had the contract specified "resident-desired comfort levels" before and after the retrofit and if the "take-back" effect had been anticipated and factored into the savings guarantee. Under this scenario the "apparent" savings of 25.8 million $\mathrm{kWh}$ per year is consistent with a "contracted" savings of 30.3 million $\mathrm{kWh}$ per year.

If the comfort level baseline adjustment is implemented it would result in a one-time increase in the ESCO payment in a TMY from $\$ 2,413,180$ to $\$ 2,685,000$, effective at time of Fort Polk's acceptance of the retrofit construction. Only the comfort level baseline adjustment affects Fort Polk's retained savings during the contract, shown in Fig. 8.1 as $\$ 720,820$, which decrease to $\$ 449,020$. The baseline adjustments for plug-load creep account for load growth that was not considered in Fig. 8.1, and would have happened with or without the project. In effect, these adjustments would offset declines in "apparent" energy savings due to plug-load growth, which is not the responsibility of the ESCO.

\subsubsection{The ESCO Perspective}

From the standpoint of the ESCO the financial picture is somewhat different. The ESCO secured $\$ 18.9$ million in capital to finance the construction of the project. As retrofitted buildings were accepted by the government, the ESCO would draw down funds that covered direct costs as well as a margin to allow recovery of indirect project development costs and profit, until all construction was completed and 
accepted and all funds drawn. During the 20-year performance period the ESCO's primary liability, aside from costs to maintain HVAC equipment, is debt service on the $\$ 18.9$ million borrowed to purchase and install the ECMs, recover the working capital required to develop the project, and earn a profit on these implementation-period tasks. At $9 \%$ interest compounded monthly, this would be about $\$ 2.025$ million per year. If payments from the Army are on the basis of "apparent" savings, the payment in a TMY would be $\$ 2.413$ million, leaving $\$ 388,000$, or about 6.9 cents $/ \mathrm{ft}^{2}$ for maintaining the equipment installed in the 4003 housing units. Even considering the Consumer Price Index escalator on the maintenance payment built into the contract, it would be very difficult for the ESCO to provide acceptable maintenance over the 20 years under these conditions.

However, assuming the comfort level baseline correction is implemented, the ESCO payment in a TMY would rise to $\$ 2.685$ million, leaving $\$ 660,000$, or about 12 cents $/ \mathrm{ft}^{2}$, for maintenance. Since the most recent published figures for maintenance costs of GHP equipment (Cane et al. 1998) are in the range of 7 to 11 cents $/ \mathrm{ft}^{2}$ per year, ESCO delivery on their 20 -year maintenance commitment appears financially feasible. The ESCO also has a variety of good business practices at its disposal to improve its financial return on the project, including refinancing their debt at a more favorable interest rate (at $8 \%$ the annual debt service drops to $\$ 1.884$ million) and implementing a preventive maintenance program to minimize maintenance costs over the 20 -year period.

Implementing annual plug-load creep baseline adjustments would not change the ESCO payment in a TMY, but would prevent the erosion of the ESCO payment over time due to load growth that is the Army's responsibility under the contract.

In general, ESPCs are long-term partnerships between customers and ESCOs, and each party has an obligation to be reasonable and negotiate contract issues in good faith. In the case of this project, there may be some basis for consideration of additional baseline adjustments to account for an overly conservative maintenance cost baseline, occupant installation of numerous ceiling fans with attached lights (given out to occupants by the family housing self-help program), and other factors. Additional baseline adjustments could increase "contracted" savings above 30.3 million $\mathrm{kWh}$ per year and improve the ESCO's financial outlook on this project. That said, customers and ESCOs on future projects may also benefit from a stronger technical basis for proposed baseline adjustments, so that trust is maintained throughout the negotiation process, and negotiations can be concluded on a more timely basis.

\subsection{USE OF CALIBRATED ENGINEERING MODELS TO PREDICT ENERGY SAVINGS}

Accurate predictions of the energy savings to be expected from ESPCs can reduce risk, decrease financing costs, and help avoid post-construction disputes over performance contract baseline adjustments. Use of calibrated engineering models to predict energy savings was determined to be an accurate and effective approach. The method relies on engineering models calibrated to field data-specifically, preretrofit feeder energy consumption and post-retrofit data from one pilot test site (see Sect. 8.5).

As described in Sect. 4, an engineering model of pre-retrofit electricity use was developed for all housing and nonhousing loads on an entire feeder (Feeder 1) serving 46 buildings containing 200 allelectric apartments. This model was calibrated to the pre-retrofit feeder data normalized to a TMY by varying one parameter, the infiltration rate. The retrofits were then implemented in the model and the model used to estimate the post-retrofit electricity consumption of the feeder in a TMY. Comparison of the pre- and post-retrofit modeled results indicated an estimated electricity savings in a TMY of $30.2 \%$. Comparison of the pre- and post-retrofit data indicated an electricity savings in a TMY of $30.3 \%$. Applying the modeled savings of $30.2 \%$ to the pre-retrofit baseline consumption in a TMY derived from data would have resulted in an estimate of electricity savings within $0.1 \%$ of the observed value.

This methodology was also applied to a feeder that served gas/electric apartments before the retrofit project. In this case an engineering model of pre-retrofit electricity use was developed for all housing and 
nonhousing loads on Feeder 12, which served 48 buildings containing 142 gas/electric apartments. This model was calibrated to the pre-retrofit feeder data normalized to a TMY, again by varying the infiltration rate. The retrofits were then implemented in the model and the model used to estimate the post-retrofit electricity consumption of the feeder in a TMY. Comparison of the pre- and post-retrofit modeled results indicated an estimated electricity savings in a TMY of 9.5\%. Comparison of the pre- and post-retrofit data indicated an electricity savings in a TMY of $16.2 \%$. This prediction is also reasonably good, considering the lack of data on pre-retrofit natural gas consumption for use in calibration and the uncertainty as to whether attic insulation improvements were implemented in this vintage- 1975 housing as part of the ESPC.

\subsection{GEOTHERMAL HEAT PUMP SYSTEM MODELS CALIBRATED TO DATA}

The apartment-level engineering model is the building block for the feeder-level model used for predicting energy savings. The pre-retrofit apartment-level model represents the housing unit (heating, cooling, water heating, and lighting/appliance loads), conventional space conditioning and water heating equipment, and controls. Conventional models of this sort are widely available. However, to represent the post-retrofit case, the apartment-level model must be able to implement all of the ECMs of the project, including the GHP system, and for greatest accuracy the ECM representations should be calibrated in some way.

In this project the model of the post-retrofit apartment served by the GHP system was calibrated against "energy-balance" data, or data needed to fully or partially verify energy balances around each component of the system. The data were recorded at one apartment after the full GHP-centered retrofit package was installed. Each component model was calibrated to post-retrofit data. The calibrated component models were then interconnected to form the system model. The system model was then found to compare well with apartment-level data.

To illustrate the level of agreement achieved, the maximum predicted heat pump entering water temperature (from the BHEx) was $85.9^{\circ} \mathrm{F}$, compared to a measured value of $85.1^{\circ} \mathrm{F}$. Over the nine-month calibration period the predicted heat pump electricity consumption was within $0.2 \%$ of the measured data.

Perhaps the most important model inputs determined during the calibration exercise were the effective average soil thermal properties required by the BHEx component model. Inverse heat transfer techniques were used to determine values near handbook values listed for heavy saturated soil (thermal conductivity of $1.41 \mathrm{Btu} / \mathrm{h} \cdot \mathrm{ft} \cdot{ }^{\circ} \mathrm{F}$, and thermal diffusivity of $0.04 \mathrm{ft} / \mathrm{h}$ ). Short-term tests at the site during the project development phase had suggested values corresponding to heavy damp soil. If effective average soil thermal properties can be more accurately determined during project development by using improved short-term tests, or by better analysis of test data, pilot test sites may not be necessary, because all GHP system components except the BHEx are conventional and well understood.

\subsection{COMPARISON OF PRACTICAL BHEx DESIGN METHODS TO A FORT POLK DATA/MODEL BENCHMARK}

The calibration of an apartment-level post-retrofit (i.e., GHP) engineering model against energybalance data produced a useful data/model benchmark for practical BHEx design methods. Five practical methods were compared with the data/model benchmark and with one another in order to establish the degree of consistency among the methods available in 1994 when the Fort Polk project was designed.

Great variation was observed in the recommended BHEx sizes from the tested methods, as described in Sect. 6. Differences on the order of a factor of 1.8 are observed between the detailed calibrated model and some of the practical BHEx design methods. This occurred even though inputs to all methods were kept as consistent as possible. 
When the Fort Polk project was engineered, BHEx design was largely experience-based. A small cadre of experienced designers could develop effective BHEx designs by adjusting the outputs of the practical BHEx design methods they used based on experience. Except for the experienced few, designers are not in a position to adjust BHEx design method results to arrive at effective designs. We conclude that further well-documented calibration/comparison exercises are needed to give the developers of BHEx design methods an opportunity to improve and release next-generation BHEx design methods with the experience built in, so that the pool of designers that can develop effective designs can be expanded more rapidly than would otherwise be possible.

\subsection{MEASUREMENT AND VERIFICATION OF ENERGY SAVINGS}

$\mathrm{M} \& \mathrm{~V}$ of energy savings is a fundamental component of energy savings performance contracting and has become more prominent since the Fort Polk project was initiated. The type of contract implemented at Fort Polk-the "shared-energy-savings" contract, wherein M\&V is used to determine the amount of monthly payments to the ESCO_- has since been supplanted by a contract form wherein M\&V is used to verify that guaranteed savings are achieved annually (see the Federal Regulation at Title 10 CFR Part 436).

As discussed in Sect. 7, several major protocols for M\&V now exist, which describe four basic options for determining energy savings:

Option A: Performance is estimated based on engineering calculations, sometimes supplemented with short-term measurements.

Option B: $\quad$ Uses ongoing field measurements on individual ECM retrofits or a sample of individual ECM retrofits.

Option C: $\quad$ Uses ongoing field measurements at the site, building, or apartment level (i.e., data from utility or customer/ESCO meters).

Option D: Uses an engineering model calibrated to energy-use data at the site, building, apartment, or end-use level.

We conclude that there is no best approach to $\mathrm{M} \& \mathrm{~V}$, and that all options or even combinations of options may be appropriate for future GHP-centered ESPC projects. Customers and ESCOs need to balance cost and precision as they evaluate and agree on methods for their projects. M\&V implementation is another project cost that must be covered by the savings generated by the project. Overly zealous $M \& V$ may mean fewer ECMs can be implemented as part of the project than would otherwise be the case, or that the contract term must be longer than would otherwise be the case. 


\section{RECOMMENDATIONS}

\subsection{FUTURE ESPC PROJECTS}

We recommend that federal agencies and any other entity responsible for buildings seriously consider GHP-centered comprehensive energy efficiency and renewable energy retrofit projects as a tool for achieving their facility management objectives. A nearly universal facility management objective is to minimize the capital investment and annual energy and maintenance operating expenses necessary to keep buildings, and the energy-consuming systems within them, renewed and delivering the environments that enable successful activities within. Added to this universal objective is the mandate by the National Energy Policy Act of 1992 and Executive Order 12902 for federal agency sites to reduce their energy consumption by $30 \%$ relative to a 1985 baseline by 2005 . Results at Fort Polk demonstrate that comprehensive projects centered on GHPs are able to support both the universal and unique federal objectives.

As of this writing, Fort Polk is the largest ESPC already constructed and generating savings in the federal sector. It is also the largest installation of geothermal heat pumps in the world. Based in part on the objective technical evaluation of the project documented in this report, Fort Polk, the Army Corp of Engineers, and the ESCO (Co-Energy Group) were recently awarded Vice President Gore's Hammer Award. The Hammer Award recognizes work being done to make government "work better and cost less" and symbolizes efforts to "hammer away" at unnecessary bureaucracy and costly inefficiency. We applaud these efforts under the old "shared-energy-savings" federal statutory authority, which have created momentum for use of the updated ESPC statutory authority.

Geothermal heat pump projects can potentially provide significant savings of energy and taxpayer dollars; however, we encourage sites to develop realistic expectations about the GHP-centered projects they are considering, especially if the projects are to be implemented as ESPCs. For example, at Fort Polk the investment required by the ESCO to develop the project, design it, build it, and gain government acceptance of it was $\$ 18.9$ million, or about $\$ 4700$ per apartment (with an area of about $1400 \mathrm{ft}^{2}$ per apartment on average). The "apparent" energy savings at $\$ 0.06$ per $\mathrm{kWh}$ and $\$ 0.50$ per therm are $\$ 1,678,000$ annually, or about $\$ 419$ per apartment. Our estimate of maintenance savings, which includes "replace on failure" equipment renewal, equals the 20 -year average baseline maintenance cost estimate because the ESCO assumes full maintenance responsibility under the contract. The maintenance savings estimate is 26 cents $/ \mathrm{ft}^{2}$ or $\$ 1,456,000$ annually, or about $\$ 364$ per apartment. The total "apparent" project savings is $\$ 3,134,000$ or $\$ 783$ per apartment, $53.5 \%$ due to energy savings and $46.5 \%$ due to maintenance and equipment renewal savings. This is the cash flow savings created by the project and available for payment to the ESCO or to be retained by the agency site.

The federal statutory authority for energy savings performance contracting allows projects like the one at Fort Polk so long as the savings to the annually appropriated operating budget for energy and energy-related maintenance exceed the ESCO payment, which must come from this operating budget (see the Federal Regulation at Title 10 CFR Part 436). The only appropriation needed to enter into an ESPC is the current year's operating budget, although Congress must be notified if the sum of ESCO payments over the ESPC term exceeds $\$ 750,000$. (This will almost always be the case; at Fort Polk the sum of ESCO payments over 20 years is on the order of $\$ 50$ million.)

\subsubsection{Opportunities Through Super-ESPC Procurements for GHPs}

While ESPC authority is an improvement over "shared-energy-savings" authority, we recommend some measures that will make the implementation of GHP-centered ESPC projects in the federal sector more practical. First, we recommend that a national GHP-technology-specific "Super-ESPC" 
procurement be implemented. Under Super-ESPC procurements, a small cadre of the best qualified ESCOs receive indefinite-delivery, indefinite-quantity (IDIQ) contracts covering any federal facility in a specified geographic area. Federal agency sites can then implement their ESPC projects as delivery orders (or task orders) against the IDIQ contracts, which is a far less onerous process than implementing a site-specific ESPC procurement from scratch. For example, Fort Polk took over 3 years from concept to start of construction, whereas it is hoped that delivery orders can be done in 4 to 6 months. The SuperESPC concept is now in common use, as DOE, the Army, and the Air Force are in various stages of blanketing the country with IDIQ contracts with ESCOs (Energy Services \& Telecom Report 1997). However, these are all "general-purpose" IDIQ awards, where the scope of allowable energy-cost-saving measures (ECSMs) is a list of about 15 mainstream energy efficiency and renewable energy technology categories.

A national GHP-technology-specific Super-ESPC procurement could overcome several abstacles to realizing energy and cost savings through GHP-centered ESPCs. As demonstrated at Fort Polk, GHPcentered projects offer an extremely comprehensive " $30 \%$-plus deep savings" option, but the GHP energy and maintenance savings will not be found unless the ESCO is specifically looking for them, and having an IDIQ contract that requires any delivery orders to be GHP-centered provides the necessary motivation. In addition, having the GHP-centered ESPC IDIQs available as an option will help overcome the well-founded concerns of federal agency sites about the competence of typical architecture/engineering contractors with GHP technology, given that it is relatively new and not yet in the mainstream.

The recommended scope of the GHP Super-ESPC is national, so that after only one procurement all federal agency sites will have GHP-centered ESPC IDIQs available as an option. The recommended scope of ECSM technology categories would include the mainstream ECSM categories that are in the "general-purpose" Super-ESPCs that apply to buildings that are candidates for GHPs. This will enable the same sort of comprehensive " $30 \%$-plus deep savings" delivery order projects as the one implemented at Fort Polk.

The scope of the GHP Super-ESPC should also include an ECSM category for energy cost reduction through rebates and rate reduction. Utility demand-side management rebates are becoming increasingly rare, but where they are available they should be brought into projects to effectively lower the financed amount. The ESCO should also be empowered, at agency option, (1) to advise federal agency sites to change to more favorable rate schedules or otherwise negotiate lower rates with their current energy suppliers; and (2) where the law allows, to advise and arrange for federal agency sites to secure lowercost supplies of energy where available. The Fort Polk project raised the annual electric load factor across all family housing from 0.52 to 0.62 . If the post-retrofit consumption of 53.6 million $\mathrm{kWh}$ in a TMY could be secured for $\$ 0.01$ per $\mathrm{kWh}$ less as a result of this load factor improvement (possible where choice of electricity supplier is allowed by law or by negotiation with the current supplier), that would be an additional savings of $\$ 536,000$ per year. Applying $77 \%$ of this to the ESCO payment as with the other savings would have shortened the term of the ESPC at Fort Polk from 20 years to 15.

\subsubsection{Improving ESPC Statutory Authority}

We also recommend that federal legislative action be taken to improve ESPC statutory authority to make its implementation more practical. The current ESPC authority and implementing rules and regulations do allow a simpler ESCO payment scheme than with shared savings (flat payments with annual verification of guaranteed savings, rather than onerous calculations to determine varying monthly payments). Current rules also allow the contract term to be as long as 25 years, and improved M\&V protocols have clarified determination of energy cost savings. In other ways, however, the current authority (or interpretation of authority) is still quite restrictive. 


\section{Qualified Maintenance Savings}

ESPC rules require that any maintenance savings claimed must be real savings, i.e., they must be cuts in amounts of money that the government is currently either spending or planning to spend. If not, the money will not be available in the government's appropriated operating budget for ESCO payments. Since many federal facilities are currently operating in a mode where maintenance is done in-house, staff reductions have already occurred, and the activities of remaining staff are crisis-driven; ESPC projects in many federal facilities will not be able to generate real maintenance savings as defined above, but only alleviate crises by partially unloading in-house maintenance staff. In cases where the maintenance is currently subcontracted it is relatively easy to capture maintenance savings in an ESPC. The item is currently in the government's operating budget, the ESCO assumes the task under the ESPC, and hence real savings are generated. Another case where it is relatively easy to capture the maintenance savings is when the government chooses to lay off maintenance personnel because the ESCO assumes the task.

The dilemma for GHP-centered ESPC projects is that, because of the nature of the technology, energy and maintenance savings are about equal in magnitude. The Fort Polk project could not have been done on the basis of energy cost savings alone. Although the ESCO did assume the responsibilities of previous maintenance subcontractors and generated real savings, the payments to the previous subcontractors were inadequate for the task as evidenced by their financial failure. The Army exercised flexibility to recognize this, and agreed to a higher 20-year average baseline maintenance cost than they had been spending with poor result. Our analysis indicates that even this higher maintenance cost baseline is probably low.

Since the ESPC rules regarding treatment of maintenance savings are unlikely to change in the short term, we anticipate that customers and ESCOs pursuing GHP-centered projects will have to work very hard on a case-by-case basis to justify their maintenance cost baselines and demonstrate that the spending is real. They will have to work equally hard to defend the assertion that the real life-cycle maintenance costs of GHP systems are substantially lower than for conventional HVAC systems. We recommend that acceptable approaches to maintenance cost baseline development be documented. We also recommend that GHP stakeholders accelerate efforts to use the installed base of systems to develop service life and maintenance cost estimates that are statistically valid and acceptable at ASHRAE.

\section{Flexibility in Financing}

Narrow interpretation of current ESPC rules is also effectively restricting the government's ability to follow basic principles of good business practice. After having entered into an ESPC, a federal agency site's options are limited to continuing as originally planned until the end of the contract term, or terminating the contract and paying the cancellation price with an appropriation. The government should be able to aggregate ESPCs signed during periods of high interest rates, seek and obtain an appropriation, and pay off the debt portion of the contracts, but retain the performance-based services of the ESCOs for the duration of the original contract term. This could save millions at Fort Polk, where the government is servicing an $\$ 18.9$ million debt at $9 \%$ as part of its monthly ESCO payment over a 20 -year term. Currently the U.S. Treasury Department can borrow like-term money for about $6.5 \%$. Assume the prepayment penalty is $0.5 \%$ on the principal balance $(\$ 94,500)$. With no buyout, the government will pay $\$ 168,782$ per month for 240 months, or $\$ 40.5$ million, as part of the ESCO payment stream. With buyout, the government would pay $\$ 94,500$ to the ESCO plus $\$ 140,154$ per month for 240 months to whomever bought the treasury bonds, or $\$ 33.7$ million in total. If the government had the flexibility to buy out the ESPC debt, it could pay $\$ 7$ million less over the next 20 years on this project for the same level of guaranteed savings. Interest rates rise and fall, and the government should be able to act in a businesslike manner and refinance at opportune times. 
We recommend the adoption of new statutory language to clarify that federal agencies can buy out the debt service portion of an ESPC, just as they routinely use end-of-year funds to buy out the debt service portion of energy service contracts under their basic ordering agreements with serving utilities. This will remove any risk from agency lawyers and contracting officers who interpret "payments cannot exceed savings in any year," a passage in the current ESPC rule, to mean that agencies cannot buy out debt at opportune times.

\section{Required Payback Periods and ESPC Terms}

As if the ESPC rules were not restrictive enough, some federal agencies have developed even more restrictive requirements for energy savings performance contracting because of an apparent confusion between a project's simple payback period and the necessary term of an ESPC. The simple payback of a project is calculated from the building owner's viewpoint assuming the owner is making the investment, maintaining the facilities, and retaining all of the savings. In the case of Fort Polk, the investment is $\$ 18.9$ million and the "apparent" energy savings are $\$ 1,678,000$ annually. The maintenance savings equals the 20 -year average baseline ( 26 cents/ $\mathrm{ft}^{2}$ or $\$ 1,456,000$ annually) less the 20 -year average estimated cost to maintain the new systems (let us assume this is the amount for which the ESCO agreed to do it, 18.1 cents/ $/ \mathrm{ft}^{2}$ or $\$ 1,013,600$ annually), or $\$ 442,400$ annually. The simple payback period is then the investment divided by the savings per year, or about 10 years.

Although the simple payback of the project is 10 years, the term of the shared-savings ESPC needed to be 20 years because Fort Polk is retaining about $23 \%$ of the annual savings during the project, and the $77 \%$ ESCO share must cover debt service on the $\$ 18.9$ million investment as well as maintenance. The term of an ESPC is generally longer than the simple payback period by a factor of 2 or more.

Our recommendation is that individual federal agencies avoid establishing maximum ESPC terms of less than 25 years without good justification. Consider the example of a 10 -year maximum ESPC term. As a consequence of the 10-year term limit, the maximum aggregate simple payback of the comprehensive package of ECMs within a project is limited to 5 years or less. Since the National Energy Policy Act of 1992 and Executive Order 12902 direct federal agencies to implement energy projects with 10-year simple paybacks or less, a 10-year term limit effectively eliminates energy savings performance contracting as a tool for fully implementing these mandates. Agency policies limiting ESPC terms are particularly detrimental to GHP-centered projects which must, by definition, replace the conventional HVAC systems. HVAC replacement is always a long-payback action, even when conventional new systems are installed.

\section{Applying Savings from Avoided Capital Projects}

Some agency lawyers and contracting officers are reluctant to allow use of appropriated capital dollars in ESPC projects that avoid the need for the originally planned project. The ability to apply savings from avoided capital projects is particularly important for GHP-centered ESPCs, because all GHP-centered ESPCs must replace conventional HVAC systems. A logical time for the replacement is when the conventional HVAC is near the end of its service life, when agencies may have budgeted and programmed appropriations earmarked for renewing the conventional equipment. By allowing the ESCO to draw down appropriated funds as phases of construction are completed until such funds are depleted, and then finishing construction with private financing, the government can effectively lower the "financed amount" of the ESPC. This means the ESPC can have a shorter term, lowering overall debt service costs, and allowing the government to retain all of the savings sooner. We recommend adoption of new statutory language to remove this risk from agency lawyers and contracting officers, allowing such savings to be realized. 


\subsection{MEASUREMENT AND VERIFICATION OF ENERGY SAVINGS}

In Sect. 8.7 we conclude that customers and ESCOs need to balance cost and precision as they evaluate and agree on $M \& V$ methods for their projects. M\&V implementation is another project cost that must be paid for out of the savings generated by the project. That said, we do have some specific recommendations for future projects similar to Fort Polk.

We recommend Option-D M\&V, which involves the use of engineering models calibrated to energy-use data. The major benefit of Option $D$, a benefit shared with Option $C$ (see Sect. 7), is its low implementation cost. Data collection at Fort Polk is accomplished by driving around to 16 electric feeder meters on a monthly basis and manually recording meter readings. At year end, the monthly heating and cooling degree days can be pulled in over the internet, and the necessary calculations can be made on a spreadsheet to verify whether guaranteed savings were delivered over the year.

Concerning development of baselines and adjustments for plug-load creep, which would apply to either Option $\mathrm{C}$ or $\mathrm{D}$, we recommend: (1) developing separate baseline regression equations for each feeder meter serving a large number of apartments (more than 10); (2) combining feeders serving a small number of apartments ( 10 or fewer) with an adjacent feeder serving apartments with the same type of space conditioning equipment; (3) that the functional form of the baseline regression equations be as simple as possible (linear, if the RMSE is comparable to quadratic, with one independent variable-the total degree days); (4) collecting daily baseline data over a period of 6 to 12 months during project development if historical data is not available, and developing monthly baseline regression equations from that data; and (5) agreeing to automatic annual baseline adjustments for plug-load creep indexed to the most recent national average increase for buildings of similar use.

Option-D M\&V has two major advantages over any other M\&V option: better capability to estimate energy savings prior to construction and the availability of a calibrated engineering model to address technical issues and resolve disputes. Accurate predictions of energy savings are important because they reduce risk, decrease financing costs, and help avoid post-construction surprises and disputes. Disputes that do arise are more easily resolved by using the calibrated model to bring additional information into the negotiation process.

\subsection{VERTICAL BOREHOLE GROUND HEAT EXCHANGER DESIGN}

As described in Sect. 6, even with inputs kept as consistent as possible, five practical BHEx design methods calculated very different required borehole lengths when compared to each other and to a detailed Fort Polk model/data benchmark. We recommend that further well-documented calibration/comparison exercises be performed to give the developers of practical BHEx design methods an opportunity to improve and release next-generation BHEx design methods. These next-generation methods can have the experience built in, so that the pool of designers that can develop effective designs can be expanded more rapidly than would otherwise be possible.

The most important inputs to any BHEx design method are the effective average thermal properties of the soil/rock formation into which the BHEx is installed. In Sect. 5 we noted that the effective average thermal properties determined by applying inverse heat transfer techniques to time-interval data collected from an operating heat pump system at Fort Polk were quite different from the values obtained from analyzing short-term data from several BHEx's at Fort Polk installed solely for the purpose of property testing during the project development phase. We recommend that further well-documented calibration/comparison exercises be performed to give developers of methods to determine thermal properties an opportunity to improve their data collection protocols and data analysis methods so that reliable and cost-effective inputs to BHEx design methods are available for future projects. 


\section{REFERENCES}

Aldridge, D. 1995. Developing a Shared Savings Energy Contract. Heating/Piping/Air Conditioning, pp. 61-63, September.

ASHRAE (American Society of Heating, Refrigeration, and Air Conditioning Professionals). 1977, 1981, 1985, 1989, 1993. ASHRAE Handbook of Fundamentals.

ASHRAE. 1991. ASHRAE Handbook of HVAC Applications.

ASHRAE. 1995. ASHRAE Applications Handbook.

ASHRAE. 1995a. ASHRAE Applications Handbook, Chapter 33: Owning and Operating Costs.

ASHRAE. 1995b. ASHRAE Applications Handbook, Chapter 45: Service Water Heating.

Barnes, P. R., J. W. Van Dyke, B. W. McConnell, and S. Das. 1996. Determination Analysis of Energy Conservation Standards for Distribution Transformers. ORNL-6847.

BLCC (Building Life Cycle Cost) Software version BLCC 4.8-1998. Available from the DOE Federal Energy Management Program (FEMP), at 1-800-363-3732.

BOMA (Building Owners and Managers Association International). 1995. 1995 BOMA Experience Exchange Report.

Bucher, M.E., et al. 1990. Heat Pump Life and Compressor Longevity in Diverse Climates. ASHRAE Transactions, vol. 90-29, no. 3, pp. 1567-1570.

Butler, C. 1996. Archer Heating and Refrigeration, Knoxville, Tennessee. Personal communication to J. Shonder.

Cane, D., A. Morrison, B. Clemes, and C. Ireland. 1997. Survey and Analysis of Maintenance and Service Costs in Commercial Building Geothermal Systems: Final Report. Geothermal Heat Pump Consortium, Inc., RP-024.

Cane, D., et al. 1998. Maintenance and Service Costs of Commercial Building Ground-Source Heat Pump Systems. To be published in ASHRAE Transactions.

Caneta Research, Inc. 1995. GS2000 ${ }^{\mathrm{TM}}$ Version 1.0 User's Manual. Caneta Research, Inc., Missisauga, Ontario, Canada. August.

DOE (U.S. Department of Energy). 1994. CORE Data Book. U.S. DOE Office of Building Technologies. June.

DOE. 1996a. Measurement and Verification Guideline for Federal Energy Projects. U.S. DOE Office of Federal Energy Management Programs. February.

DOE. 1996b. North American Energy Measurement and Verification Protocol Version 1.0. March.

EIA (Energy Information Administration). 1995. Household Energy Consumption and Expenditures, 
1993. DOE/EIA-0321(93).

Energy Services \& Telecom Report. 1997. "Air Force Seeks Performance Pacts for up to $\$ 400$ Million; Taking Bids." McGraw-Hill. July 31.

EPRI (Electric Power Research Institute). 1990. Pilot Study of Commercial Water Loop Heat Pump Compressor Life, EPRI Report No. CU-6739, Project 2480-6.

Ewbank and Associates. 1995. Thermal Test Results, Fort Polk, Louisiana, October.

Fels, M. F., and K. M. Keating. 1993. Measurement of Energy Savings from Demand-Side Management Programs in U.S. Electric Utilities. Annu. Rev. Energy Environ., vol. 18, pp. 57-88.

Geothermal Heat Pump Consortium, Inc. 1996. Maintenance Cost Data for Commercial Buildings. Earth Comfort Update, vol. 3, no. 1, December.

Gordon, R. 1997. Applied Energy Management Techniques. Personal communication to J. Shonder, January.

Hellstrom, G. 1983. Heat Storage Subroutines in MINSUN. Duct Storage Systems. Department of Mathematical Physics, University of Lund, Sweden.

Hellstrom, G. 1989. Duct Ground Heat Storage Model, Manual for Computer Code. Department of Mathematical Physics, University of Lund, Sweden.

Hellstrom, G., L. Mazzarella, and D. Pahud. 1996. Duct Ground Heat Storage Model. Lund-DST. TRNSYS 13.1, Version January 1996. Department of Mathematical Physics, University of Lund, Sweden.

Huang, Y. J, R. Ritschard, J. Bull, S. Byrne, I. Turiel, D. Wilson, C. Hsui, and D. Foley. 1987. Methodology and Assumptions for Evaluating Heating and Cooling Energy Requirements in New Single-Family Residential Buildings (Technical Support Document for the PEAR Microcomputer Program). Lawrence Berkeley Laboratory Report LBL-19128.

Hughes, P. 1980. Improved Heat Pump Model for TRNSYS. In: Proceedings of the American Section of the International Solar Energy Society.

Hughes, P., J. Shonder, R. Gordon, and T. Giffin. 1997. Geothermal Heat Pump Energy Savings Performance Contract at Fort Polk, Louisiana: Lessons Learned. ASHRAE Transactions.

Hughes, P. J., and J. A. Shonder. 1996. Geothermal Heat Pumps at Ft. Polk: Early Results. In: Proceedings of the 1996 ACEEE Summer Study on Energy Efficiency in Buildings, vol. 1, pp. 142-146, American Council for an Energy-Efficient Economy, August.

Kavanaugh, Steve. User's Guide for Ground Source Heat Pump Design Software-GchpCalc Commercial Building Version 2.1. Energy Information Services, Tuscaloosa, Alabama.

Kim, G. 1982. Con Edison Hourly Electric Load Model. In: Approaches to Load Forecasting: Proceedings of the Third EPRI Load Forecasting Symposium, pp. 144-167, Electric Power Research Institute, July. 
Klein, S. A., et al. 1996. A Transient Simulation Program (TRNSYS Manual), Version 14.2 for Windows. Solar Energy Laboratory, University of Wisconsin. September.

Koomey, J. G., C. Dunham, and J. D. Lutz. 1994. The Effect of Efficiency Standards on Water Use and Water Heating Energy Use in the U. S.: A Detailed End-Use Treatment. Lawrence Berkeley Laboratory, LBL-35475.

Kusuda, T., and P. R. Archenbach. 1965. Earth Temperature and Thermal Diffusivity at Selected Stations in the United States. ASHRAE Transactions, vol. 71, part 1, Lausanne, Switzerland.

L'Ecuyer, M., K. Zoi, and J. S. Hoffman. 1993. Space Conditioning: The Next Frontier. Environmental Protection Agency.

Lovvorn, N. C., and C. C. Hiller. 1985. A Survey of Heat Pump Life. Electric Power Research Institute Report No. EM-4163, July.

Mancini, R., H. W. Heiss, and J. B. Singh. 1996. Operating and Maintenance Experience with Commercial/Institutional Ground Source Heat Pump Systems. ASHRAE Transactions, accepted for publication.

Marshall, C. L., and J. D. Spitler. GLHEPRO: The Professional Ground Loop Heat Exchanger Design Software-User's Guide. International Ground Source Heat Pump Association.

Mazzarella, L. 1991. MINSUN 6.0-NEWMIN 2.0. A Revised IEA Computer Program for Performance Simulation of Energy Systems with Seasonal Thermal Energy Storage. In: Proceedings Thermastock 91 , pp. 3.5-1-3.5-7, Scheveningen, the Netherlands.

Mazzarella, L. 1993. Duct Thermal Storage Model. Lund-DST. TRNSYS 13.1 Version 1993. ITW, Universitat Stuttgart, Germany, and Dipartimento di Energetica, Politechnico di Milano, Italy.

Nelson, W. 1982. Applied Life Data Analysis, 1st ed., pp. 150-154. New York: Wiley.

Pahud, D., A. Fromentin, and J.-C. Hadorn. 1996. The Duct Ground Heat Storage Model (DST) for TRNSYS Used for the Simulation of Energy Piles. User manual for the December 1996 version. Internal report. Laboratory of Energy Systems (LASEN), Swiss Federal Institute of Technology (EPFL).

Pahud D., and G. Hellstrom. 1996. The New Duct Ground Heat Model for TRNSYS. Eurotherm Seminar $N^{*} 49$, Eindhoven, the Netherlands, pp. 127-136.

Pientka, K. A. 1987. Heat Pump Service Life and Compressor Longevity in a Northern Climate. ASHRAE Transactions, vol. 87-09, no. 1, pp. 1087-1090.

Press, W. H., B. P. Flannery, S. A. Teukolsky, and W. T. Vetterling. 1986. Numerical Recipes: The Art of Scientific Computing. Cambridge University Press.

R. S. Means, Inc. 1992. Means Mechanical Cost Data, 15th Annual Edition.

Ruch, D., and D. E. Claridge. 1992. A Four-Parameter Changepoint Model for Predicting Energy Consumption in Commercial Buildings. Journal of Solar Energy Engineering, 114, pp. 77-82.

Sand, J. R., S. K. Fischer, and V. D. Baxter. 1997. Energy and Global Warming Impacts of HFC 
Refrigerants and Emerging Technologies. Oak Ridge National Laboratory.

Shonder, J. A., and P. J. Hughes. 1997a. Electrical Energy and Demand Savings from a Geothermal Heat Pump ESPC at Fort Polk, Louisiana. ASHRAE Transactions.

Shonder, J. A., and P. J. Hughes. 1997b. Estimated Maintenance Cost Savings From a Geothermal Heat Pump Energy Savings Performance Contract at Fort Polk, Louisiana. ASHRAE Transactions.

Thornton, J. W., T. P. McDowell, and J. A. Shonder. 1997a. Comparison of Five Practical Vertical Ground Heat Exchanger Sizing Methods to a Fort Polk, La., Data/Model Benchmark. ASHRAE Transactions.

Thornton, J. W. , T. P. McDowell, J. A. Shonder, P. J. Hughes, D. Pahud, and G. Hellstrom. 1997b. Residential Vertical Geothermal Heat Pump System Models: Calibration To Data. ASHRAE Transactions.

Typical Meteorological Year User's Manual, TD-9734. 1981. National Climatic Center. Asheville, North Carolina.

U.S. Department of Commerce. 1982. Life-Cycle Cost Manual for the Federal Energy Management Program. NBS Handbook-135(Rev.) (DE82017356).

Wright Associates, Inc. 1992. RIGHT-Loop User's Manual Version 1.00. Lexington, Massachusetts. September. 


\section{ACKNOWLEDGMENTS}

The authors would like to acknowledge that the opportunity to evaluate the ESPC at Fort Polk Joint Readiness Training Center was created by the efforts of several organizations. Personnel at Fort Polk championed the ESPC and continue to administer the contract. The Huntsville Division of the Army Corps of Engineers contributed to efforts to determine the feasibility of the ESPC, develop the request for proposal, and award the contract. The energy services company selected to carry out the contract, Co-Energy Group, was responsible for designing, financing, and building the energy conservation retrofits in return for a share of the energy savings and is responsible for maintaining the installed equipment for the duration of the 20-year contract. Applied Energy Management Techniques, under subcontract to Co-Energy Group, surveyed the family housing, developed the energy consumption baseline from historical data, and developed the retrofit designs and estimates of costs and savings. ORNL carried out an independent evaluation of the ESPC with sponsorship from the U.S. Department of Defense Strategic Environmental Research and Development Program (DoD-SERDP), the DOE Office of Energy Efficiency and Renewable Energy, Geothermal Division (DOE-EERE/GD), and Climate Master, Inc. Under subcontract to ORNL, Science Applications International Corporation provided field data collection and Thermal Energy Systems Specialists provided TRNSYS modeling. 


\section{DISTRIBUTION}

Internal

1. R. N. Baugh

2. V. D. Baxter

3. M. A. Brown

4. J. M. Campbell

5. J. E. Christian

6. G. E. Courville

7. P. D. Fairchild

8. S. K. Fischer

9. P. J. Hughes

10. J. Mike MacDonald
11. M. G. Madgett

12. M. M. Martin

13. H. A. McLain

14. T. R. Sharp

15. J. A. Shonder

16. J. J. Tomlinson

17. Laboratory Records-RC

18. Central Research Library

19. Laboratory Records - OSTI

\section{External}

20. Office of Scientific and Technical Information, P.O. Box 62, Oak Ridge, TN 37831

21. Conn Abnee, East Kentucky Power Coop., P.O. Box 707, Winchester, KY 40392-0707

22. James Adams, President, Energy Systems Group, 101 Plaza East Blvd., Ste. 320, Evansville, IN $47715-2804$

23. D.K. Adams, Vice President, Mor-Lite of North America, Inc., 7207-A 114th Avenue North, Largo, FL 33773-5121

24. Michael Albertson, ClimateMaster, 4508 Blackberry Run, Oklahoma City, OK 73112

25. Phil Albertson, WaterFurnace International, Inc., 7998 Georgetown Rd \#500, Indianapolis, IN 46268

26. Phil Albertson, Charles Machine Works/Ditch Witch, PO Box 735, Perry, OK 73077

27. Howard Alderson, Alderson Engineering, Inc., 1588 Heather Road, Huntingdon Valley, PA 19006

28. Jay Althof, The Trane Company, 4831 White Bear Parkway, St. Paul, MN 55110

29. Falah Alugaily, ICRC Energy Inc., 10461 White Granite Dr \#225, Oakton, VA 22124

30. David Ames, Jr., Vice President, Virginia Energy Services, 3200 West Moore Street, Richmond, VA 23230

31. John Archibald, Acting Director, Office of Federal Energy Management Programs, U.S. Department of Energy, EE 090, Room 6B-088, 1000 Independence Avenue, SW, Washington, DC 20585

32. Marilyn Arnold, Equitable Resources, $3333 \mathrm{~K}$ Street NW, Washington, DC 20007

33. David Austin, SRS Corp., 5625 Dillard Drive \#101, Cary, NC 27511

34. Charles Aycock, Duke Engineering and Services Inc., P.O. Box 1004, Charlotte, NC 28201-1004

35. John Bailey, Jr., ClimateMaster, 8709 Rail Fence Road, Fort Wayne, IN 46835

36. David Balle, President, UCONS, L.L.C., 3055 112th Ave., N.E., Suite 225, Bellevue, WA 98004-2067

37. Tom Balster, Interstate Power Company Inc., P. O. Box 769, 1000 Main, Dubuque, IA 52004-0769

38. Dan Banard, President, Comprehensive Energy Management, Inc., 230 Lille Lane, Suite 318, Newport Beach, CA 92663

39. Mark Barber, Vice President, Commercial Engineering Corporation, 2890 Dundee Rd., Northbrook, IL 60062-2502

40. John Barlean, Northwest Rural Public Power District, P.O. Box 249, Hay Springs, NE 69347

41. Chip Barnaby, Wright Associates, Inc., 394 Lowell Street, Suite 12, Lexington, MA 02173

42. Marcia A. Barnard, Naval Facilities Engineering Command Contracts Office, Code 27, Bldg. 41, Port Hueneme, CA 93043

43. Kevin Barrett, P.O. Box 270983, Oklahoma City, OK 73137-0983

44. Eddie Barron, Vice President and COO, Utility Engineering Corporation, 5601 I-40 West, Amarillo, TX 79106-4605

45. Monika Bay, Federal Project Manager, Baltimore Gas \& Electric Company, 7225 Windsor Boulevard, Baltimore, MD 21244

46. Freddie Beason, HQ AFCESA/CESE, 139 Barnes Drive, Suite 1, Tyndall AFB, FL32403-5319

47. Michael Beccaria, Director, Government Performance Contracts, ERI Services, 350 Fairfield Ave., Bridgeport, CT 06604 
48. Ned Belt, Jr., Chairman/CEO, Systems Engineering and Management Corporation, 1820 Midpark Rd., Suite C, Knoxville, TN 37921-5950

49. Jeannette Bennion, General Manager, e.three, P O Box 30069, Reno, NV 89520-3069

50. Mark Berman, Director of Business Development, Davis Energy Group, Inc., 123 C Street, Davis, CA 95616

51. Paul Bilbrey, President, Natural Lighting Company, Inc., 7021 W. Augusta \#106, Glendale, AZ 85303

52. Douglas Billiet, ECONAR Energy Systems Corp., 19230 Evans St., Ste. 201, Elk River, MN 55371

53. George Bivens, Delmarva Power, 252 Chapman Rd., P.O. Box 9239, Newark, DE 19714-9239

54. Kenneth Black, Entergy Systems \& Services, 2410 Shrewbury Run, Collierville, TN 38017

55. Stephen Black, Vice President, CONECO Corporation, 280 Summer Street, Boston, MA 02210

56. John Bleem, P.E.Platte River Power Authority, 2000 E. Horsetooth Rd., Fort Collins, CO 80525-5721

57. John Boehme, Manager Technical Sales, Nicor Solutions, 1844 Ferry Road, Naperville, II 60563

58. Roger Bohon, ENCAP Systems Inc., 1202 Franklin Road, Roanoke, VA 24016

59. Suzette Bollinger, Fall River Rural Electric, 714 Main Street, P.O. Box 830, Ashton, ID 83420

60. James Bose, Oklahoma State University, Engineering Technology, 294 Cordell South, Stillwater, OK 74078

61. Ralph S. Bosek, Executive Vice President, Bosek, Gibson \& Associates, Inc., 508 West Fletcher Avenue, Suite 102, Tampa, FL 33612

62. Jos Bouma, IEA Heat Pump Centre, Swentiboldstraat 1, Box 17, 6137 AE Sittard, Netherlands

63. Sandra Bourdeau, Manager, Government Services, Xenergy, Inc., Three Burlington Woods, Burlington, MA 01803-4543

64. Van Bourne, ClimateMaster, 7300 SW 44th Street, P.O. Box 25788, Oklahoma City, OK 73179

65. Robert Boyer, Pennsylvania Power \& Light Co., 1801 Brookwood St., P.O. Box 1461, Harrisburg, PA $17105-1461$

66. Jerry Brandom, UtiliCorp United Inc., 20 West 9th Street MS 7-280, Kansas City, MO 64105

67. Benjamin Brant, President, Planetec Utility Services Company, Inc., 1153 Evergreen Pkwy., Ste. M471, Evergreen, CO 80439

68. Harry Braud, 13519 Bluff Road, Geismar, LA 70734

69. Robert J. Braun, KeySpan Energy Management, Inc., 30 Jericho Executive Plaza, Suite 200C, Jericho, NY 11753-1025

70. Richard Bremer, EnerShop Inc., 1616 Woodall Rogers Freeway, Dallas, TX 75202

71. Wayne N. Brown, CEO, Planergy, Inc., Barton Oaks Plaza Two, Suite 495, 901 MoPac Expressway South, Austin, TX 78746

72. $\quad$ Robert Brown, ClimateMaster, 4060 N. 100 West, Markle, IN 46770

73. Wyatt Brown, AEP Energy Services, One Riverside Plaza, Columbus, OH 43215-2355

74. Tim Burke, HydroDelta Corporation, 10205 Gravois, St. Louis, MO 63123

75. Jeff Bush, Vice President, Pacific Enterprises Energy, Services Company, 633 W. Fifth Street, Los Angeles, CA $90071-2006$

76. Juan Cabrera, President, Lord \& Company, Inc., 8811 Sudley Rd., Manassas, VA 20110-4728

77. Ralph Cadwallader, Loop Tech International, 607 Highway 19, Huntsvile, TX 77340

78. Douglas Cane, Caneta Research, Inc., Suite 102, Bldg. 2, 7145 W. Credit Avenue, Mississauga, ON L5N 6J7 Canada

79. George Caraghiani, FPL Energy Services, 1982 N. State Rd. 7, Margate, FL 33063

80. Steven Carlson, CDH Energy Corp., PO Box 641, Cazenovia, NY 13035

81. Millard E. Carr, President, Energy Management Solutions, Inc., 9213 Hidden Creek Drive, Great Falls, VA 22066

82. George Cashman, Vice President Financial Products \& Services, Energis Resources, 499 Thornall, Edison, NJ 08837

83. Frank Cassidy, Energis Resources Inc., 499 Thornall Street, Edison, NJ 08837

84. Jim Caughran, ProSolutions, 3101 Carlisle Street, Columbia, SC 29205

85. Harold Chappell, CEO, IllumElex Corporation, 2925 Huntleigh Dr., Ste. 104, P.O. Box 10461, Raleigh, NC 27604

86. Tom Cirello, Government Market Manager, Johnson Controls, Inc., Government Systems Group, 9550 Ridgehaven Court, San Diego, CA 92123-1681

87. Tim Clemons, Executive Vice President of Business Development, Custom Energy, L.L.C., 9217 Cody, Overland Park, KS 66214 
88. Peyton Collie, NRECA, 1800 Mass. Ave., NW, Washington, DC 20036-1883

89. Christopher Condy, Senior Operating Executive, Proven Alternatives, Inc., 1740 Army St., San Francisco, CA 94124

90. Craig Conner, Marketing Manager, Landis \& Staefa, Inc., 1000 Deerfield Pkwy., Buffalo Grove, II 600894513

91. Frank Costanza, President, EnTrust Energy Solutions, 20 W. 9th Street, Kansas City, MO 64105

92. Arthur R. Coughlin, PSCRC9 Campus Drive, Parsipany, NJ 07059

93. Steven Cowell, President, Conservation Services Group, 441 Stuart St., Sth Floor, Boston, MA 02116

94. Bernie Cowsert, Vice President, Conserve-A-Watt Lighting, Inc., 720 Vallejo, Denver, CO 80204

95. Don Creyts, Advanced Geothermal Technologies, P.O. Box 511, Reading, PA 19607

96. Gary Crooks, Avista Advantage Inc., P.O. Box 3727, Spokane, WA 99220

97. James Crossman, President, Financial Energy Management, Inc., 1625 Downing Street, Denver, CO 80218

98. Brian Curran, President/CEO, Energy Conservation Management, Inc., 518 North Charles St., Baltimore, MD 21201

99. Michael Dandrea, AYP Capital, 800 Cabin Hill Dr., Greensburg, PA 15601

100. Charles Davidson, Vice President, Comprehensive Services, Limbach Company, 1005 Alderman Dr., Suite 108, Alpharetta, GA 30005

101. Timothy Davis, Vice President, Services, L.P., dba ServiceMaster Management, 9000 East Nichols Ave., Ste. 150, Englewood, CO 80112-4165

102. Bill Dean, WaterFurnace International, Inc., 9000 Conservation Way, Fort Wayne, IN 46809

103. Diana L. Dean, P.E., Colorado Springs Utilities, 6 North Tejon Street MC 146, P.O. Box 1103, Colorado Springs, CO 80947-1546

104. Rebecca DeLamotte, Vice President, Energy Investment, Inc., One Winthrop Square, 2nd Floor, Boston, MA 02110-1209

105. Sam Dellario, Government Projects Director, Viron Corporation, 216 NW Platte Valley Dr., Riverside, MO 64150

106. Karen Den Braven, University of Idaho, Mechanical Engineering Dept., Moscow, ID 83844-0902

107. Jim DePorche, Manager, Energy Project Services, Syska \& Hennessy/CEM, Inc., 11500 West Olympic Blvd., Los Angeles, CA 90064

108. Alan F. Destribats, Xenergy Inc., 3 Burlington Woods, Burlington, MA 01803-4543

109. Leonard DeVanna, COM/Energy Enterprises Inc., One Main Street, Cambridge, MA 02142

110. Joseph J. DeVirgilio, Jr., Central Hudson Gas \& Electric, 284 South Avenue, Poughkeepsie, NY 12601

111. Jack Dienna, Member Services Manager, Geothermal Heat Pump Consortium, Inc., 701 Pennsylvania Avenue, NW, Washington, DC 20004-2696

112. John Dilliplane, Preferred Products Group, 214 W State St., Trenton, NJ 08608-1002

113. David Dinse, Tennessee Valley Authority, Tech Adv., 1101 Market Street, Chattanooga, TN 37402-2801

114. Thomas Dinwoodie, President, PowerLight Corporation, 2954 San Pablo Ave., Berkeley, CA 94710

115. Shawn Dion, Rose Technology Group, Inc., Suite 300 Bldg. 5, Foster Plaza, 651 Holiday Dr., Pittsburgh, PA $15220-2740$

116. Bob Dixon, Director Performance Contracting, Landis \& Staefa, Inc., 1000 Deerfield Parkway, Buffalo Grove, II $60089-4513$

117. Bob Dombroski, Wisconsin Power \& Light, 222 West Washington Ave., Madison, WI 53703

118. Floyd Dooris, Central Hudson Enterprises Corp., 110 Main Street, Poughkeepsie, NY 12601

119. William Douglas, Vice President and General Manager, Industrial Energy Applications, Inc., P.O. Box 351, Cedar Rapids, IA 53406

120. Roger Dower, Director, Federal and Special Projects, SYCOM Enterprises, 1010 Wisconsin Ave., N.W., Ste. 340, Washington, DC 20007

121. Patrick Doyle, Vice President, IllumElex Corporation, Suite 104, 2925 Huntleigh Dr., Raleigh, NC 27604

122. Thomas K. Dressen, CEO, Energy Performance Services, Inc., 2003 Renaissance Blvd., King of Prussia, PA 19406

123. M. Michelle Duffy, CPABGE Energy Projects \& Services Inc., 7225 Windsor Blvd., Baltimore, MD 21207

124. Bob Dupuis, Strategic Resource Solutions, 1099 Gum Branch Road, Jacksonville, NC 28540

125. Tom Eckhart, Chief Executive Officer, UCONS, L.L.C., Suite 225, 3055 112th Avenue, NE, Bellevue, WA 98004 
126. Robert F. Edwards, Director, Project Development, Energy Pacific, P. O. Box 502228, San Diego, CA 921502228

127. Bernard Egan, Geo Thermal Plus, Inc., 205 Haven Ct., Lexington, KY 40509-1490

128. Ray Ehmer, HL\&P Energy Services Inc., P.O. Box 4300, Houston, TX 77210-4300

129. Frank Ehrhardt, Director of Alliance Management, Illinova Energy Partners Inc., Suite 305, 1420 Kensington Road, Oak Brook, IL 60521

130. Larry Eitelman, FHP Manufacturing, 565 S. Hudson Ave., Tulsa, OK 74112

131. Dan Ellis, ClimateMaster, 7300 SW 44th Street, P.O. Box 25788, Oklahoma City, OK 73125

132. William Ely, Mammoth, Inc., 341 E. 7th St., Holland, MI 49423

133. Susan Engeleiter, Vice President Government Markets, Honeywell, Inc., Honeywell Plaza, P.O. Box 524, Minneapolis, MN 55440-0524

134. Stephen R. Etsler, NIPSCO Energy Services Inc., 5265 Holman Avenue, Hammond, IN 46320

135. Jeffrey Evans, Vice President, Rieck Mechanical Services, Inc., 5245 Wadsworth Rd., Dayton, OH 45414

136. Garen Ewbank, Geothermal Design and Engineering, Inc., 704 N. Villa, Ste. 100, Oklahoma City, OK 73101

137. Steven Farinha, President, Farinha, Inc., dba Paragon Construction, 12405 Locksley Lane, Auburn, CA 95602

138. Luis Fernandez, Executive Vice President, Imperial Construction \& Electric, Inc., 359 Long Ave., Hillside, NJ 07205-2016

139. Peter M. Feroli, Eastern Utilities Associates, 750 West Center Street, West Bridgewater, MA 02379

140. Philip Fine, P.E., Vice President, Savage-Alert, Inc., 707 Bloomfield Ave., P.O. Box 707, Bloomfield, CT 06002

141. Craig Fischbach, Mammoth, Inc., 101 West 82nd Street, Chaska, MN 55318

142. William S. Fleming, Jacwill Services, Inc., 4571 East Lake Road, Cazenovia, NY 13035

143. Robert Fleming, Director of Utility Partnerships, Energy Masters Corporation, 9101 West 110th St., Ste. 200, Overland Park, KS 66210

144. Frederick G. Florian, BGE Energy Projects \& Services Inc., 7225 Windsor Blvd., Baltimore, MD 21244

145. Michaele Fossum, President, Sun Trapper Solar Systems, Mfg., 12118 Radium St., San Antonio, TX 78216

146. Gustav Foster, Jr., 1240 S. Spring Rd., Vineland, NJ 08361

147. Trevor M. Foster, Executive Vice President, EMCOR Facilities Services Inc., 7th Floor, 101 Merritt 7, Norwalk, CT 06851

148. J. Phillip Frazier, Plum Street Enterprises Inc., 507 Plum Street, Syracuse, NY 13204

149. Morris Friedlander, New York Energy Savers Group, Inc., P.O. Box 154, Brooklyn, NY 11219

150. William Gang, Director, Business Development, The Bentley Company, 1777 Botelho Drive, Suite 350, Walnut Creek, CA 94596-5041

151. James Gardner, President, Gardner Engineering, Inc., 270 Parr Boulevard, Reno, NV 89512

152. William Gary, Executive Vice President, Onsite Energy, 701 Palomer Airport Rd., Ste. 200, Carlsbad, CA 92009

153. Scott W. Gebhardt, PG\&E Energy Services, 353 Sacramento Street \#1900, San Fransisco, CA 94111

154. Randy Gee, President, Industrial Solar Technology Corporation, 4420 Mclyntyre St., Golden, CO 80403

155. Denny George, Sales Manager, FPL Energy Services, Inc., 11770 U.S. Highway One, Golden Bear Plaza, Suite \#500, North Palm Beach, FL 33408-3013

156. Mark Gilbert, President, Energy Solutions, Inc., 618 East Douglas, Wichita, KS 67202

157. David C. Gill, Director of Sales, Siebe Environmental Controls, 1354 Clifford Ave., Loves Park, II 61111

158. Donald Gilligan, President, CONECO Corporation, 280 Summer St., Boston, MA 02210

159. Richard Gordon, Gordon Associates, $508 \mathrm{SW}$ Jefferson, Corvallis, OR 97333

160. David Graves, Eau Claire Electric Cooperative, 8214 Highway 12, P.O. Box 368, Fall Creek, WI 54742-0368

161. William Greelis, Cinergy Solutions Inc., 139 East Fourth Street, Cincinnati, OH 45202

162. Peter Greenberg, President, Energy-Wise Lighting, Inc., P.O. Box 15443, Washington, DC 20003

163. R. Kirk Gregg, Product Manager, Kansas City Power \& Light Co., P. O. Box 418679, Kansas City, MO 64141-9679

164. Henry Gross, GEI Technologies Ltd., 62 Plant Farm Blvd., Brantford, ON N3T-5T7

165. Dan Grover, GPU Advanced Resources Inc., 2675 Morgantown Road Suite GH2-3300, Reading, PA 19607

166. Andy Guarriello, Energy One, 911 Main Street, Kansas City, MO 64105

167. Joseph Gustin, Mid-America Energy Resources Inc., One Monument Circle, Indianapolis, IN 46206-6161 
168. Stephen Guthrie, President, D-Base Communications, Inc., dba, Energy Controls and Concepts, 1758 Orange Tree Lane, Redlands, CA 92374

169. Shane Gydesen, McQuay International, PO Box 1551, Minneapolis, MN 55401

170. Richard Hackner, Energy Center of Wisconsin, 595 Science Drive, Madison, WI 53711-1060

171. Brian Haggart, The Environmental Group, 7300 Southwest $44^{\text {th }}$ Street, Oklahoma City, OK 73125

172. B. James Halpern, Measuring \& Monitoring Services, Inc., 620 Shrewsbury Avenue, Tinton Falls, New Jersey 07701

173. Don Hamilton, Carolina Power \& Light Co., 1099 Gum Branch Road, Jacksonville, NC 28540

174. Jeff Hammond, WaterFurnace International, Inc., 9000 Conservation Way, Ft. Wayne, IN 46809

175. John Haney, General Manager, FPL Energy Services, Inc., Golden Bear Plaza, Suite 500, 11770 US Highway One, North Palm Beach, FL 33408-3013

176. Darr Hashempour, P.E., Energy Services Program Manager, CH2M HILL, 3 Hutton Centre Drive, Suite 200, Santa Ana, CA 92707

177. Michelle Hayden, President, Energy Applications, Inc., 1565 Hotel Circle South, Suite 360, San Diego, CA 92108

178. Timothy Hayes, General Manager, Aircon Energy, Inc., 4234 North Freeway Blvd., Ste. 100, Sacramento, CA 95834

179. William Heil, All Energy Marketing Company, LLC95 Sawyer Road, Waltham, MA 02154

180. Harold Heiss, 6860 Kilt Ct., Worthington, OH 43085-2129

181. John K. Helbling, IES Utilities Inc, 200 First St. S.E., P.O. Box 351, Cedar Rapids, IA 52401

182. Goran Hellstrom, Dept. Mathematical Physics, Lund University, Box 118, 5-221 00 Lund, Sweden

183. Hugh Henderson, Jr., CDH Energy Corp., P.O. Box 641, Cazeovia, NY 13035-0641

184. Ronald Herbst, Manager of Energy Systems, KDC, Inc. dba KDC Systems, 7700 Pioneer Way, Ste. 103, Gig Harbor, WA 98335

185. Rob Hile, Federal Sales Manager, Control Systems International, Inc. (CSI), 1625 W. Crosby Road, Suite 100, Carrollton, TX 75006

186. Carl Hiller, Manager, Geothermal Heat Pumps and Water Heating, EPRI, 3412 Hillview Ave., P.O. 10412, Palo Alto, CA 94303

187. Stephen Hincks, Vice President, TeleCommunication Systems, 275 West Street, Suite 400, Annapolis, MD 21401

188. Sidney W. Hinton, Southern Development and Investment Group, 64 Perimeter Center, East Atlanta, GA 30346

189. Ernest C. Hoelzer, PE, Navy Public Works Center, Code 332 Energy Management Branch, 9742 Maryland Ave., Norfolk, VA 23511-3095

190. John Hollick, President, Conserval Systems Inc., 4242 Ridge Lea Rd. \#1, Buffalo, NY 14226-1051

191. Thomas Holmes, Chairman/CEO, USA Planergy, Inc., 23679 Calabasas Road, Suite 527, Calabasas, CA 91302

192. Walter Hood, GPU Energy, 2800 Pottsville Pike, P.O. Box 16001, Reading, PA 19640-0001

193. Michiel Hoogstede, Puget Sound Energy Services, 26317 Ansell Rd NW, Poulsbo, WA 98370

194. Charles Hopkins, National Sales Manager, Performance Contracting, United Technologies Carrier, Building Systems and Services, 3206 Canterbury Lane, Montgomery, TX 77356

195. John Hopper, President, Valley Air Conditioning \& Repair, Inc., 1350 F Street, Fresno, CA 93706

196. Robert E. Hough P.E., Syracuse Energy, 159 Dwight Park Drive, Syracuse, NY 13209

197. ' Richard Housh, President, Control Solutions, 1770 Mason Morrow Rd., Lebanon, OH 45036-9298

198. Rodney W. Houston, KU Solutions Corporation, One Quality Street, Lexington, KY 40507

199. Kent Hudson, Knowledge Builders Inc., 111 East Main Street, Coats, NC 27521

200. P. E. Hudson, Vice President, Radian Corporation, P.O. Box 201088, Austin, TX 78720-1088

201. Roger Hurst, Chief Financial Officer, Global EPS LC, 8582 Katy Freeway, Ste. 150, Houston, TX 77024

202. Darcy Immerman, Vice President of Business Development, EUA Cogenex Corporation, Boott Mills South, 100 Foot of John Street, Lowell, MA 01852

203. Ric Johnson, Empire Energy Services, P.O. Box 127, Joplin, MO 64802

204. Scott Jones, Econar Energy Systems Corp., 19230 Evans St. \#201, Elk River, MN 55303

205. John Judge, CONECO Corporation, 280 Summer Street, Boston, MA 02210

206. Phil Kairis, Dakota Energy Altenatives, 4300 220th Street W, Farmmington, MN 55024-9583 
207. Larry Kaufman, Detroit Edison Co., 2000 2nd Ave. 318 WCB, Detroit, MI 48226-1279

208. Steve Kavanaugh, University of Alabama, Box 870276, 290 Hardaway Hall, Tuscaloosa, AL 35487-0276

209. William Kelly Jr., President, FMS Lighting Management Systems, Inc., 323 Commerce Park Dr., P.O. Box 10162, Jackson, MS 39286-0162

210. George Kennedy, President, United Resource Group, Inc., 30311 Clemens Road, Suite 260, Westlake, OH 44145-1023

211. Naresh Khosla, President, EMR, 1901 North Fort Myer Drive, Suite 500, Arlington, VA 22209

212. John Kierzkowski, Spectrum Energy Services Corp., Two North Ninth St., Allentown, PA 18101

213. Jerry Kilby, Kentucky Utilities Company, One Quality Street, Lexington, KY 40507

214. Robert Koschka, WaterFurnace International, Inc., 126 East $48^{\text {th }}$, Indianapolis, IN 46205

215. James P. Kovalcik, PNM Energy Partners, Alvarado Square-BA52, Albuquerque, NM 87158

216. Kathi Kraft, Oglethorpe Power Corporation, 2100 East Exchange Place, P.O. Box 1349, Tucker, GA 30085-1349

217. David Kramka, Johnson Controls Inc., 2400 Kilgust Road, Madison, WI 53713

218. Rich Landy, Entergy Integrated Solutions Inc., 4740 Shelby Drive \#105, Memphis, TN 38118

219. Brett Lawrie, Copeland Corporation, 1675 W. Campbell Road, Sidney, OH 45365-0669

220. Franco Lenarduzzi, Ontario Hydro, 800 Kipling Avenue, KR312, Toronto, ON M8Z 5S4 Canada

221. Robert P. Lewis, II, Director, Major Energy Projects, BGE Energy Project \& Services, Inc., 7225 Windsor Boulevard, Baltimore, MD 21244

222. . Tom Lewis, Centerprise Inc., One Main Street \#600, Minneapolis, MN 55414

223. Paul Liepe, Geothermal Heat Pump Consortium, Inc., 701 Pennsylvania Ave., NW, Washington, DC 200042696

224. Marilyn Linette, McQuay International, 13600 Industrial Park Blvd., P.O. Box 1551, Minneapolis, MN 55440

225. Edward T. Liston, President, EUA Cogenex Corporation, Boott Mills South, 100 Foot of John Street, Lowell, MA 01852

226. Thomas Londos, Asst. Vice President, Science Applications International Corporation, 4161 Campus Point Court, San Diego, CA 92121

227. Lee Loomis, Rochester Gas and Electric Corp., 89 East Evenue, Rochester, NY 14649-0001

228. Morris Lovett, Group Vice President/Director, Geothermal Design and Engineering, Inc., 704 N. Villa, Suite 100, Oklahoma City, OK 73107

229. Nance Lovvorn, Alabama Power / Southern Company, 600 N. 18th St., P.O. Box 2641, Birmingham, AL 35291

230. Andrew Lowenstein, 18 Cameron Ct., Princteon, NJ 08540-3924

231. Alfred Lutz, P.E., Energy Services Group, Atlantic Energy, Inc., 6801 Black Horse Pike, Egg Harbor Township, NJ 08234-4130

232. James Lynn, Director, Business Development, Trigen Development Corporation, One North Charles Street, Baltimore, MD 21201

233. Rudy Lyon, Ingersoll-Rand Co., 7500 Shadwell Drive, Roanoke, VA 24019

234. Guy Lyons, Special Projects Manager, Destec Energy, Inc., 1000 Louisiana, Suite 5800, Houston, TX $77002-$ 5050

235. John Mahoney, President, Viron Energy Services, 216 NW Platte Valley Drive, Riverside, MO 64150

236. E. John Majkowski, Precision Power Inc., 165 Skiff Street, Hamden, CT 06517

237. Robert Mancini, Mancini, Saldan Associates Ltd., 5468 Dundas St. West, Etobicoke, Ontario M9B 6E3 Canada

238. John Manning, P.E., Water Source Supply Co., P.O. Box 3, Skaneateles, NY 13152

239. Robert Marshall, Plumas-Sierra Rural Electric Coop, 73233 Highway 70, P.O. Box 2000, Portola, CA 96122

240. John U. Martin, TU Electric, 1601 Bryan St., P.O. Box 660268, Dallas, TX 75201

241. David E. Matasek, Manager, Utility Services, Johnson Controls, Inc. Controls Group, 507 E. Michigan Street, P. O. Box 423, Milwaukee, WI 53201-0423

242. Michael F. McGowan, Planergy, U.S. 1 \& 202, Brandywine Two \#300, Chadds Ford, PA 19317

243. Richard A. Michelfelder, Atlantic Energy, 6801 Black Horse Pike, Egg Harbor Township, NJ 08234-4130

244. Frank A. Migneco, GPU Energy, 300 Madison Avenue, PO Box 1911, Morristown, NJ 07962-1911

245. Phillip M. Mikulsky, WPS Energy Services Inc., 677 Baeten Road, Green Bay, WI 54304 
246. Patricia Mishic, Hudson Extrusions, Inc., P.O. Box 255, Hudson, OH 44236

247. Charles Mitchell, Vice President, North American Lighting, Inc., 25057 Anza Drive, Suite B, Valencia, CA 91355

248. John Mitchell, Con Edison Solutions, 701 Westchester Avenue, Suite 210W, White Plains, NY 10604

249. Thomas W. Mitchell, President, Co-Energy Group, Suite N136, 1050 E. Flamingo Road, Las Vegas, NV 89119

250. Michael Montgomery, Managing Director, EnerShop Inc., 1616 Woodall Rodgers Freeway, Dallas, TX 75202

251. Alex Moore, Princeton Economic Research, inc., 1700 Rockville Pike, Suite 550, Rockville, MD 20852

252. Duncan Morrison, Combined Energies Inc., 41 Anthony Avenue, Augusta, ME 04330

253. Randy Mortensen, Vice President Sales, Energy Masters International, 1385 Mendota Heights Rd., St. Paul, MN 55120

254. Earl Muir, Copeland Corporation, 1675 W. Campbell Road, Sidney, OH $45365-0669$

255. Joseph Mulloney, Jr., P.E., CEM, Senior Engineer, EA Engineering, Science, and Technology, Inc., 11019 McCormick Rd., Hunt Valley, MD 21031

256. David Munn, Southwest HEC, 1232 E. Broadway Road, Tempe, AZ 85282-1509

257. Jay Murphy, K \& M Shillingford, Inc., 5004 E. Archer, Tulsa, OK 74115

258. William Murphy, University of Kentucky/Ag Engr. Dept., 128 Ag Engr. Building, Lexington, KY 405460276

259. Patrick J. Murray, Mich Con, 500 Griswold, Detroit, MI 48038

260. Gordon Nelson, Addison Products Company, 7050 Overland Road, Orlando, FL 32810

261. Richard Niess, Gilbert \& Associates, Gloucester Pt Office Plaza, Suite D, 1811 G. Washington Mem Hwy, Gloucester Point, VA 23062

262. Robert Noonen, Energy Services Manager, Siebe Environmental Controls, Division of Barber-Colman Company, 1354 Clifford Ave., Loves Park, IL 61111

263. Joe Norton, St. Joseph Light \& Power Co., 520 Francis St., P.O. Box 998, St. Joseph, MO 64502-0998

264. Jim Nuemberger, Senior Contract Administrator, Illinova Energy Partners, 500 South 27th Street, P.O. Box 511, Decatur, Il 62525-1805

265. Thomas O'Day, Today Assoc., Inc., 500 S. Salina St., Syracuse, NY 13202

266. Richard O'Neil, Niagara Mohawk Power Corporation, 507 Plum Street, P.O. Box 5001, Syracuse, NY 132505001

267. Paul Ogle, Knowledge Builders Inc., 111 East Main Street, Coats, NC 27521

268. Paul Ogle, Strategic Resource Solutions, Suite 101, 5625 Dillard Dr., Cary, NC 27511

269. Arthur N. Olson, American Electric Power, One Riverside Plaza 27th Floor, Columbus, OH 43215

270. Carl Orio, Water \& Energy Systems Corp. - ClimateMaster, 100 Maple Ave., Atkinson, NH 03811

271. Greg Orman, Custom Energy LLC, 6409 City West Parkway, Eden Prairie, MN 55344

272. Ken Ormsbee, Director, Federal and Defense Markets, Energy Masters International, Inc., 1385 Mendota Heights Road, St. Paul, MN 55120-1128

273. Thomas Ott, Palisades Energy Services Inc., One Blue Hill Plaza, Pearl River, NJ 10965

274. Timothy Otto, Director of Strategic Alliances, Edison Source/Edison International, 13191 Crossroads Parkway North \#405, City of Industry, CA 91746

275. G. Ronald Owens, Mid America Drilling Equipment, Inc., 5802 SW 6th Place, Ocala, FL 34474

276. Fred Paepke, Bard Manufacturing Co., 1914 Randolph Dr., P.O. Box 607, Bryan, OH 43506

277. Greg Page, Vice President, Abacus Engineered Systems, Inc., 401 Second Avenue South \#201, Seattle, WA 98104

278. Steve Paiewonsky, HydroDelta Corporation, 5 Pocono Heights, E. Stroudsburg, PA 18301

279. Daniel W. Parke, President, Parke Industries, Inc., 2246 Lindsay Way, Glendora, CA 91740

280. Thomas Paterno, Vice President of Energy Services, Southland Industries, 1661 E. 32nd Street, Long Beach, CA 90807

281. Robert Payne, Director, Federal Energy Services, DukeSolutions, Inc., 230 South Tryon St., Suite 400, Charlotte, NC 28202

282. Stephen Pazian, Edison Source, 13191 Crossroads Parkway N \#405, City of Industry, CA 91746

283. George Penn, Global Energy Options, 4634 Bonner Lane, Madison, WI 53704-1327

284. Barry Peterson, Phillips Driscopipe, Inc., 2929 N. Central Expy., Ste. 300, Richarsdon, TX 75083

285. Gary Phetteplace, U.S. Army Cold Regions Lab, 72 Lyme Road, Hanover, NH 03755-1290 
286. Thomas W. Philbin, President, HEC Energy Corporation, 24 Prime Parkway, Natick, MA 01760

287. David Phillips, Proposal Development Manager, Combined Energies, 41 Anthony Avenue, Augusta, ME 04330

288. R. A. (Tony) Pierce, Southern California Edison, 300 North Lone Hill Ave., San Dimas, CA 91773

289. Alan Pong, President, Ferreira Service, Inc., 2566 Barrington Court, Hayward, CA 94545

290. Ted Pope', Pacific Gas \& Electric, 123 Mission St Rm 2284, P.O. Box 770000 MC H28L, San Francisco, CA 94177

291. Lew Pratsch, U.S. Department of Energy, 1000 Independence Ave., S.W., Code 342, Washington, DC 20585

292. Pete Prydybasz, HydroDelta Corporation, 2352A Wentzel Rd, RD 2, Mohnton, PA 19540

293. James Quigley, Public Service of New Mexico, Alvarado Square-MS BA52, Albuquerque, NM 87158

294. Michael J. Quigley, E Prime, 1331 17th Street \#201, Denver, CO 80202

295. Kevin Rafferty, GEO Heat Center, Oregon Institute of Technology, 3201 Campus Drive, Klamath Falls, OR 97601

296. John Ramill, Bosek Gibson and Associates, 508 West Fletcher Avenue, Tampa, FL 33612

297. Curtis Ranger, President, Biomass Energy Systems, Inc., P.O. Box 8641, 425 S. Main Street, Suite 201, Ann Arbor, MI 48107

298. Scott Rankert, Entech Sales \& Service, Inc., 3404 Garden Brook Dr., Dallas, TX 75234

299. Phil Rawlings, The Rawlings Company, 2308 Watchill Dr., Greenville, TX 75402-6444

300. Philips Reese, Conectiv Service, P.O. Box 6066, Newark, DE 19714-6066

301. Francis Reilly Jr., President, Harris Energy Systems, 66 Long Wharf, Boston, MA 02110

302. Charles Remund, South Dakota State University, 210B CEH, ME Dept., Brookings, SD 57007

303. Manfred Reuss, Technische Universität München, Bayer. Landesanstalt für Landtechnik, Vöttinger Strasse 36, Freising, Germany D-85354

304. Michael J. Richards, Chotawhatchee Electric Coop. Inc., 1350 W. Baldwin Ave., P.O. Box 512, DeFuniak Springs, FL 32433

305. Randy Richgruber, Minnesota Power Company, 30 W Superior St., Duluth, MN 55802

306. Russell Riley, ESPC Manager, Mason \& Hanger-Silas Mason Co., Inc., First National Bank Building, Suite 420, 701 South Taylor Street, Amarillo, TX 79101

307. Richard Rinck, Atlantic Electric, 6801 Black Horse Pike, Egg Harbor Township, NJ 08234-4130

308. John Rinehart, President, Industrial Electric Corporation, P.O. Box 1188, Beaver, WV 25813

309. John Rizzo, PE, Vice President, Northeast Energy Services Company (Noresco), Point West Place, 111 Speen St., Ste. 500, Framingham, MA 01701

310. David Robb, Rose Technology Group, Inc., 651 Holiday Drive, Suite \#300, Pittsburgh, PA 15220-2740

311. Ronald A. Robertson, Energy Performance Services Inc., 2003 Renaissance Blvd., King of Prussia, PA 19406

312. Wayne Robertson, PE, CEM, Director of Energy Consulting, Heery International, Inc., 999 Peachtree St., NE, Atlanta, GA 30367-5401

313. Scott H. Rollings, T. C. Technologies, 6757 Paljay Court, Las Vegas, NV 80117

314. Blake W. Ross, Director, Business Development, Governmental \& Industrial EnergyUSA, P. O. Box 1200, Brattleboro, VT 05302

315. David Ross, Policy Research Assoc., Inc., 11260 Roger Bacon Drive, Ste. 206, Reston, VA 22090-5203

316. Samuel Roth, President, Roth Bros., Inc., 3847 Crum Rd., P.O. Box 4209, Youngtown, OH 44515

317. Frank Rotondi, MP Energy Services Company, 40 East Broadway, Butte, MT 59701

318. Arlo Rude, City of Thief River Falls, P.O. Box 528, Thief River Falls, MN 56701

319. Harvey Sachs, Geothermal Heat Pump Consortium, 701 Pennsylvania Ave, $3^{\text {rd }}$ Floor, Washington, DC 200042696

320. Tanya Sadler, Office of Federal Energy Management Programs, U.S. Department of Energy, EE 090, 1000 Independence Avenue, SW, Washington, DC 20585

321. Stephen P. Sain, PE CE, Sain Engineering Assoc., Inc., 2820 Columbiana Rd., Ste. 100, Birmingham, Al 35216

322. George P. Sakellaris, President \& CEO, NORESCO, Point West Place, 111 Speen Street, Framingham, MA 01701

323. Chris Salzmann, Manager, Performance Contracting, Westar Business Services, 818 Kansas Avenue, Topeka, KS 66612

324. James Samis, President, Thermonetics, Inc., 101 E. Park Blvd., Suite 543, Plano, TX 75074 
325. Burkhard Sanner, Geothermal Association, Gartenstrasse 36, Geeste, Germany D-49744

326. B. Y. Sarandah, Vice President and Manager, Bechtel National, Inc., 45 Fremont Street, P.O. Box 193965, San Francisco, CA 94119-3965

327. Sanjiv Saste, President, Energy Conservation Specialists, Inc., 5425 Theresa Road, Suite G., Tampa, FL 33615-3813

328. Ken Schedin, Vice President, Sylvania Lighting Services Corp., 100 Endicott Street, Danvers, MA 01923

329. Nancy Schibonski, Northern States Power - MN414, Nicollet Mall RS-55, Minneapolis, MN 55401

330. Perry Schmidt, President, Energy Services Group, L.L.C., 2335 Nevada Ave. North, Minneapolis, MN 55427

331. Phil Schoen, Geo Enterprises, 308B W. Red Bird, Broken Arrow, OK 74012

332. Richard E. Schonbachler, Baltimore Gas \& Electric Co., 7130 Rutherford Road, Baltimore, MD 21244

333. David Schrier, President, Management \& Business Associates, Inc., 6595 NW 36th Street, Suite C 309, Miami, FL 33166

334. Dean Schultzbank, P.E., Federal Accounts Manager, Wisconsin Electric Company, 231 West Michigan Avenue, Milwaukee, WI 53201

335. Robert Schultz, Illinova Energy Partners, 1420 Kensington Road \#305, Oak Brook, IL 60521

336. Joe Schwartzenberger, Manager of Operations, The Montana Power Trading and Marketing Company, 16 East Granite-Street, Butte, MT 59701-9326

337. Bill Scribner, OG\&E, 101 N. Robinson, Oklahoma City, OK 73102

338. Vicki Severson, Otter Tail Power Co., 215 South Cascade, P.O. Box 496, Fergus Falls, MN 56537

339. Christopher S. Sharpe P.E., Duke Power Company, 526 S. Church St EC12F, P.O. Box 1006, Charlotte, NC 28201-1006

340. Rita Sharpe, Westar Energy, 818 Kansas Avenue, Topeka, KS 66612

341. Craig Shephard, QST Energy Inc., 300 Hamilton Blvd. \#300, Peoria, IL 61602

342. Michael S. Sherber, P.E.Sherber Associates Inc., 20 Woodmont Rd., Avon, CT 06001

343. William Shivly, CMS Marketing Services and Trading, One Jackson Square Suite 1060, Jackson, MI 49201

344. Duane Shover, Enertech Inc., 220 West Main, Louisville, KY 40202

345. A. Gienn Simpson, PEPCO Services Inc., 2000 K Street N.W. \#750, Washington, DC 20006

346. Andy Sinclair, Carrier Corporation, P.O. Box 70, Indianapolis, IN 46206

347. Jitendra Singh, 14 Kory Drive, Kendall Park, NJ 08824-1608

348. Steve Siverson, Business Unit Manager, J. B. Rodgers Performance Contracting, 706 East Bell Rd., Ste. 206, Phoenix, AZ 85022

349. Daniel P. Skaar, General Manager, NI Energy Services Company, 802 Canonie Dr., Porter, IN 46304

350. Allan Skouby, GeoPro, Inc., 1444 Rogers Ct., Allen, TX 75013

351. Carmen Smargiassi, PECO Energy, 2301 Market Street S7-4, P.O. Box 8699, Philadelphia, PA 19101

352. Chris Smith, FHP Manufacturing, 601 N.W. 65th Court, Ft. Lauderdale, FL 33309

353. Cristy S. Smith, FirstEnergy, 76 S. Main Street, Akron, OH 44308

354. Donald O. Smith, Energy Masters Corp., 9101 W. 110th St \#200, Overland Park, KS 66210

355. Marvin Smith, Oklahoma State University, GHP Research, 499 Cordell South, Stillwater, OK 74078

356. Robert Smith, Commonwealth Edison, 1919 Swift Road, Oak Brook, IL 60521

357. Janey Sorensen, Delta-Montrose Electric Association, 121 E 12th St., P.O. Box 59, Delta, CO 81416

358. Scott D. Souza, Noresco, 111 Speen Street, Framingham, MA 01701

359. Richard T. Sperberg, President, Onsite Energy Corporation, Suite 200, 701 Palomar Airport Road, Carlsbad, CA 92009

360. Judy Spinner, Kansas City Power \& Light Co., 1201 Walnut 20th Fl., Kansas City, MO 64106

361. Jeffrey Spitler, Oklahoma State University, School of Mechanical \& Aerospace Engineering, Engineering North 218, Stillwater, OK 74078

362. Russell Spitz, Ph.D., Senior Vice President, Vision Impact Corporation (VIC), 3733 Crown Point Road, Jacksonville, FL 32257

363. Lisa Staggs, Butler REC Inc., 3888 Stillwell-Beckett Road, Oxford, OH 45056

364. Bobby Starling, CEHNC-PM-CR, Huntsville Division, U. S. Army Corps of Engineers, P.O. Box 1600, Huntsville, AL 35807-4301

365. Ray Starling, HEI Power Corporation, P.O. Box 3160, Honolulu, HI 96802

366. Pam Bard Steel, Bard Manufacturing Co., 1914 Randolph Dr., P.O. Box 607, Bryan, OH 43506

367. Charles B. Steen, Director, Entergy Retail Services, Inc., P. O. Box 1640, Jackson, MS 39215-1640 
368. Lynn Stiles, Richard Stockton College of New Jersey, NAMS/Stockton College; P.O. Box 195, Pomona, NJ 08240-0195

369. Donna Stoughton, Charter Plastics, Inc., P.O. Box 770, Titusville, PA 16354

370. James Sugden, Lehr Associates, 20 Park Plaza \#467, Boston, MA 02116

371. William Sullivan, 324 Hermosa Dr. SE, Albuquerque, NM 87108-2614

372. John Summers, Government Marketing Manager, Entergy Integrated Solutions, Inc., 3838 N. Causeway Blvd. Suite 3400, Metairie, LA 70002

373. Stephen Sunderhauf, Potomac Electric Power Co., 1900 Pennsylvania Ave NW, Room 842, Washington, DC 20068

374. S. Lynn Sutcliffe, President and CEO, SYCOM Enterprises, First Floor, 27 Worlds Fair Dr., Somerset, NJ 08873

375. Kenneth Swan, General Manager, Performance Contracting, Building Controls \& Services, Inc., 4 Peuquet Parkway, Tonawanda, NY 14150

376. Sam Tadros, President, Super Systems, Inc., 17561 Teachers Ave., Bldg. A, Irvine, CA 92614

377. Vance Tang, National Manager-PACT, The Trane Company, a Division of American Standard, Inc., Asset Management Services, 4831 White Bear Parkway, St. Paul, MN 55110

378. Daniel Tarkington, P.E., President, Four Seasons Environmental, 849 Cannes Court, Loveland, OH $45140-$ 9497

379. Jay Taylor, Manager, Government Services, LighTec, Inc., 25 Depot St., Merrimack, NH 03054

380. Greg Tech, Cresline Plastic Pipe Co., Inc., 2100 S 35th Street, Council Bluffs, IA 51501

381. Woodman Teele, Engineering Manager, General Electric Company, Motors and Industrial Systems, 2101 Executive Dr., \#60, Hampton, VA. 23666

382. Scott Terrell, Truckee Donner PUD, P.O. Box 309, Truckee, CA 96160

383. Tom Thomas, Dixie Escalante REA, 145 W. Bringham Road, St. George, UT 84790

384. Jeff Thornton, Thermal Energy System Specialists, 5610 Medical Circle, Suite 31, Madison, WI 53719

385. Steven Tillman, Manager, Morrison Construction Services, Inc., 1990 Saint Street, Richland, WA 99352

386. John Tipton, Manager, Commercial Services, HL\&P Energy Services Company, P.O. Box 4300, Houston, TX 77120-4300

387. Ellen Trick, Trane Company, P.O. Box 7916, Waco, TX 76714-7916

388. B. N. Tripathi P.E., CES/Way International Inc., 5308 Ashbrook, Houston, TX 77081

389. Jerry Troyer, President, American Illuminetics, Inc., 5940 Darwin Court, Carlsbad, CA $92008-7372$

390. Darryl Tveitbakk, Northern Municipal Power Agency, 123 North Main Avenue, P.O. Box 528, Thief River Falls, MN 56701-0528

391. Mutch Usera, Black Hills Power \& Light Co., P.O. Box 1400, Rapid City, SD 57709

392. Gary Valli, Allegheny Power, 800 Cabin Hill Dr., Greensburg, PA 15601

393. Len van Essen, Lennox Industries, Inc., 1600 Metrocrest, P.O. Box 110877, Carrollton, TX 75011-0877

394. David Van Hersett, Vice President, Northwest Energy Services, Inc., 9 South Washington, Suite 500, Spokane, WA 99201

395. Gary VonFischer, Director of Government Entities, Enron Energy Services Operations, Inc., 400 Metro Place North, Dublin, OH 43017-3375

396. Joel Wagner, Southwest Energy Solutions Inc., P.O. Box 711, Tucson, AZ 85702

397. Fred Wajcs, Northeast Utilities, P.O. Box 270, Hartford, CT 06141-0270

398. Bernard Walker, York International Corp., 2675 Eisenhower Ave., Norristown, PA 19403-2398

399. John Walker, Mobile Drill Co., 3807 Madison Ave., Indianapolis, IN 46227

400. Mike Wallace, Maine Public Service Company, P.O. Box 120910, Parkhurst Siding Rd., Presque Isle, ME 04769-1209

401. John Welch, Secure Energy Inc., One Northshore Center, Pittsburgh, PA 15212

402. Prof. M. W. Wildin, University of New Mexico, Department of Mechanical Engineering, Albuquerque, NM 87131

403. Barry Wilhelm, Virginia Power, 701 E. Cary Street 8th Floor, P.O. Box 26666, Richmond, VA 23261

404. Bob Williamson, Addison Products Company, 7050 Overland Road, Orlando, FL 32810

405. Dennis Wilson, President, Enersave, Inc., 355 Lexington Ave., 19th Floor, New York, NY 10017

406. Kerry R. Wilson CEM CLEP, Evantage, One James River Plaza 7th Fl., 701 E. Cary St., Richmond, VA 23219 
407. Kerry Wilson, Product Manager, Evantage, a Division of Virginia Power, 5000 Dominion Blvd., 3 SE, Glen Allen, VA 23060

408. Buddy Winslow, Winslow Pump and Well, Inc., P.O. Box 521, Hollywood, MD 20636

409. Brian Wolka, Jackson County REMC, 274 E. Base Rd., P.O. Box K, Brownstown, IN 47220-0311

410. Bernie Woller, Buckeye Power, Inc., P.O. Box 26036, Columbus, OH 43226-0036

411. Richard Wright, American Thru Wall Manufacturing Corp., 59-BC Remington Boulevard, Ronkonkoma NY 01179

412. Margaret Wyers, Crispaire Geothermal Heat Pumps, 3285 Saturn Ct. NW, Norcross, GA 30092

413. Raymond Zawadzki, CPCM, Contracts Manager, Strategic Resource Solutions Corp., 5625 Dillard Rd., Suite 101, Cary, NC 27511

414. Jon Zellhoefer, Principal Engineer, FMCS Energy Services, 30601 Avenue Seven, Madera, CA 93637 